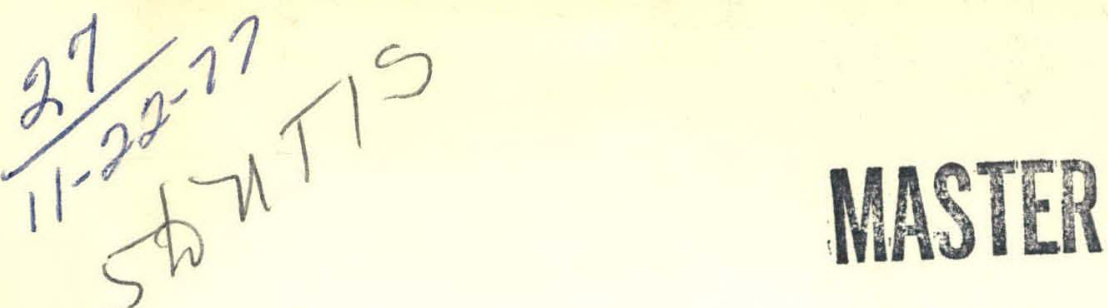

\title{
POSTTEST RELAP4 ANALYSIS OF LOFT EXPERIMENT L1-3A
}

JAMES R. WHITE HEIKKI L. O. HOLMSTROM

BORTIONS OF THTS REPORT ARE ILLEGTBLE. It

has begn reprosuc arom the best available

copy to permit the broadestpossible avalle

gebsaty.

October 1977

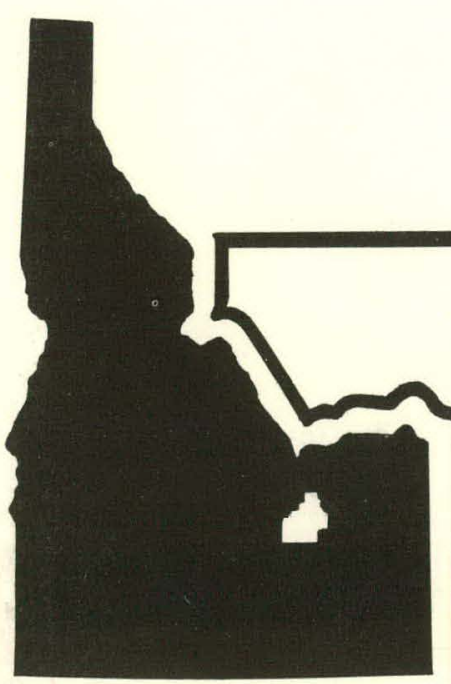

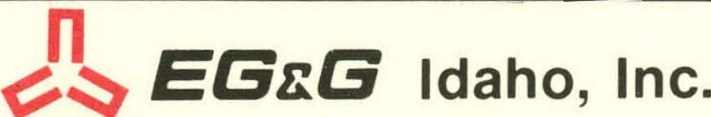

IDAHO NATIONAL ENGINEERING LABORATORY

\section{ENERGY RESEARCH AND DEVELOPMENT ADMINISTRATION}




\section{DISCLAIMER}

This report was prepared as an account of work sponsored by an agency of the United States Government. Neither the United States Government nor any agency Thereof, nor any of their employees, makes any warranty, express or implied, or assumes any legal liability or responsibility for the accuracy, completeness, or usefulness of any information, apparatus, product, or process disclosed, or represents that its use would not infringe privately owned rights. Reference herein to any specific commercial product, process, or service by trade name, trademark, manufacturer, or otherwise does not necessarily constitute or imply its endorsement, recommendation, or favoring by the United States Government or any agency thereof. The views and opinions of authors expressed herein do not necessarily state or reflect those of the United States Government or any agency thereof. 


\section{DISCLAIMER}

Portions of this document may be illegible in electronic image products. Images are produced from the best available original document. 
Printed in the United States of America Available from

National Technical Information Service

U.S. Department of Commerce 5285 Port Royal Road

Springfield, Virginia 22161

Price: Printed Copy $\$ 9.25$; Microfiche $\$ 3.00$

"The NRC will make available data tapes and operational computer codes on research programs dealing with postulated loss-of-coolant accidents in light water reactors. Persons requesting this information must reimburse the NRC contractors for their expenses in preparing copies of the data tapes and the operational computer codes. Requests should be submitted to the Research Applications Branch, Office of Nuclear Regulatory Research, Nuclear Regulatory Commission, Washington, D.C. 20555."

This report was prepared as an account of work sponsored by the United States Government. Neither the United States nor the Energy Research and Development Administration, nor the Nuclear Regulatory Commission, nor any of their employees, nor any of their contractors, subcontractors, or their employees, makes any warranty, express or implied, or assumes any legal liability or responsibility for the accuracy, completeness or usefulness of any information, apparatus, product or process disclosed, or represents that its use would not infringe privately owned rights. 


\section{POSTTEST RELAP4 ANALYSIS OF LOFT EXPERIMENT LI-3A}

$\vdots$

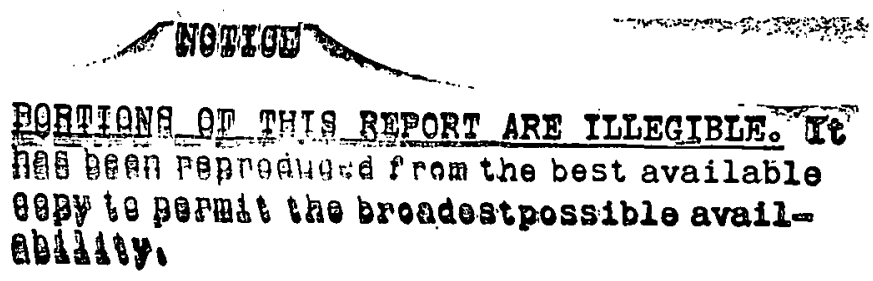

Approved:
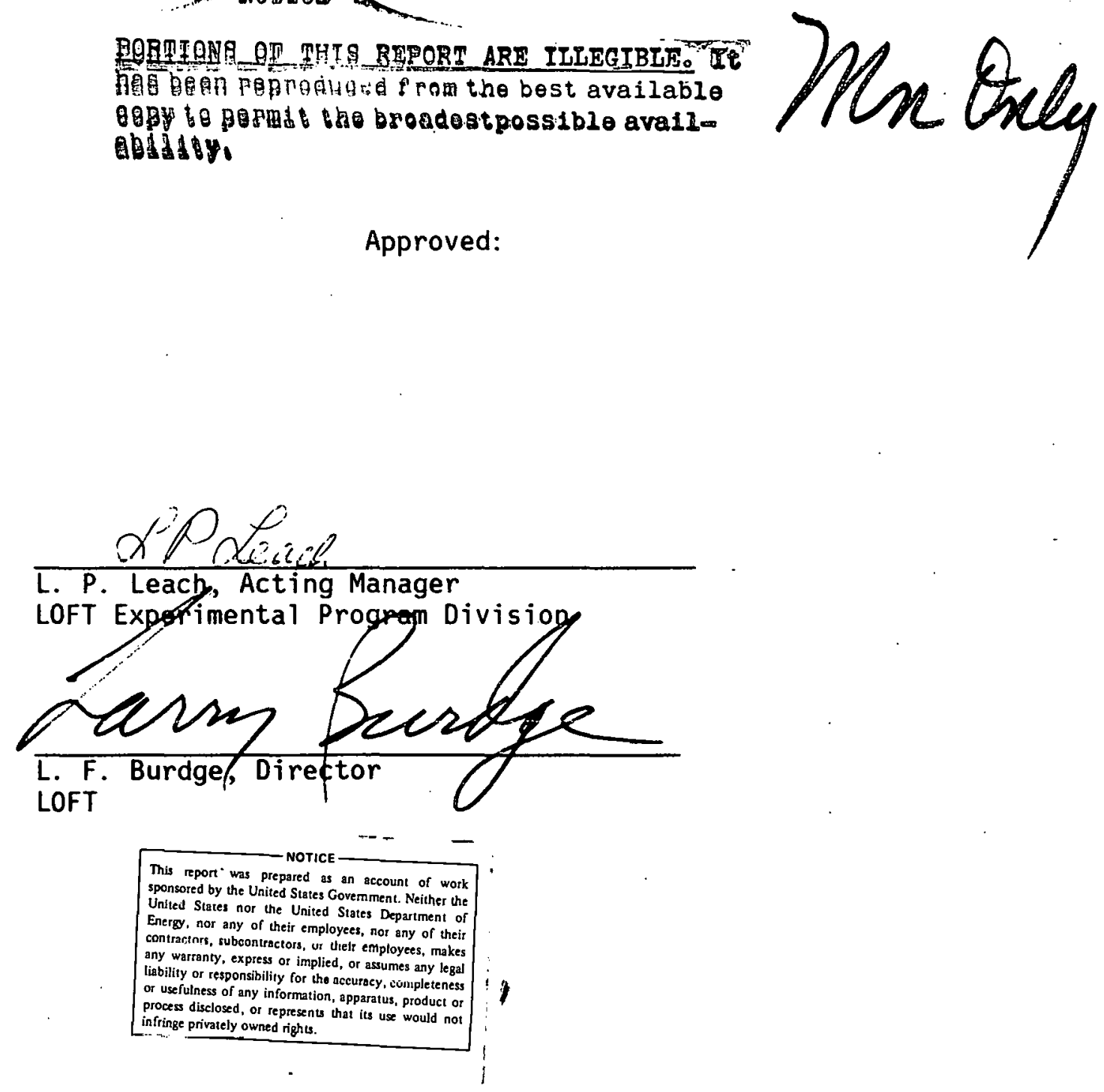
TREE-NUREG-1137

Distributed Under Category: NRC -2 Water Reactor Safety Research Sys tems Engineering

\title{
POSTTEST RELAP4 ANALYSIS OF LOFT EXPERIMENT L1-3A
}

\author{
by \\ James R. White \\ and
}

Heikki L. 0. Holmstrom

EG\&G I daho, Inc.

October 1977

\author{
PREPARED FOR THE \\ U. S. NUCLEAR REGULATORY COMMISSION AND \\ DEPARTMENT OF ENERGY \\ IDAHO OPERATIONS OFFICE \\ UNDER CONTRACT NO. EY-76-C-07-1570
}


Appreciation is expressed to $H$. C. Robinson for his help in checking the RELAP4 dimensional data and to the members of the Data Systems Branch in preparing the plots in a timely manner. C. G. Branson, J. V. Hurley, and J. R. Pittman all made significant contributions for the analytical effort for which the authors are in deep appreciation. Special appreciation is also expressed to G. Hammer; G. W. Johnsen, T. K. Larson, L. P. Leach, S. A. Naff, and T. K. Samuels for their,invaluable comments on the draft of this report and for their help in preparing the final document. 


\section{ABSTRACT}

This report presents selected results of posttest RELAP4 modeling of LOFT loss-of-coolant experiment LI-3A, a double-ended isothermal cold leg break with lower plenum emergency core coolant injection. Comparisons are presented between the pretest prediction, the posttest analysis, and the experimental data. It is concluded that pressurizer modeling is important for accurately predicting system behavior during the initial portion of saturated blowdown. Using measured initial conditions rather than nominal specified initial conditions did not influence the system model results significantly. Using finer nodalization in the reactor vessel improved the prediction of the system pressure history by minimizing steam condensation effects. Unequal steam condensation between the downcomer and core volumes appear to cause the manometer oscillations observed in both the pretest and posttest RELAP4 analysis. 


\section{ACRONYMS}

$\begin{array}{ll}\text { ECC } & \text { Emergency Core Coolant } \\ \text { ECCS } & \text { Emergency Core Cooling System } \\ \text { EOS } & \text { Experiment Operating Specification } \\ \text { ESF } & \text { Engineered Safety Features } \\ \text { HPIS } & \text { High-Pressure Injection System } \\ \text { LOCA } & \text { Loss-of-Coolant Accident } \\ \text { LOCE } & \text { Loss-of-Coolant Experiment } \\ \text { LOFT } & \text { Loss of Fluid Test } \\ \text { LPIS } & \text { Low-Pressure Injection System } \\ \text { LPWR } & \text { Large Pressurized Water Reactor }\end{array}$




\section{CONTENTS}

ACKNOWLEDGMENTS. . . . . . . . . . . . . . . . . . . . . .

ABSTRACT . . . . . . . . . . . . . . . . . . . . . . . $\mathrm{i}$. .

ACRONYMS .......................... . . . iv

1.0 INTRODUCTION. . . . . . . . . . . . . . . . . . . . 1

2.0 POSTTEST MODELING OF LOFT EXPERIMENT L1-3A WITH RELAP4/MOD5 . . 11

2. 1 Modeling the LOFT Pressurizer and the Effects of Pressurizer Modeling on Early Blowdown Behavior. . . . . . . . 11

2.2 Overall Modeling Changes and Justification . . . . . . . 30

2.2.1 Improved Pressurizer Modeling . . . . . . . . . . . 30

2.2.2 Using Measured Experiment L1-3A Initial
Conditions. . ................ 31

2.2.3 RELAP4 Nodalization............... . 31

2.2.4 ECC Modeling. . . . . . . . . . . . . . . . 34

2.2.5 Code Changes. . . . . . . . . . . . . . . 35

2.3 Data Comparisons . . . . . . . . . . . . . . . 35

2.3.1 Early Blowdown System Behavior. . . . . . . . 35

2.3.2 System Behavior After ECC Injection... . . . . . . 44

2.3.3. Overall System Behavior. . . . . . . . . . . . 54

3.0 CONCLUSIONS . . . . . . . . . . . . . . . . 74

4.0 REFERENCES. . . . . . . . . . . . . . . . . . . . . 75

APPENDIX A -- INPUT AND TIME $=0.0$ LISTING FOR THE NEW PRESSURIZER MODEL RELAP4 RUN (RELAP4 RUN L135-A23) . . . . . . 77

APPENDIX B - INPUT AND TIME $=0.0$ LISTING FOR THE POSTTEST ANALYSIS RUN (RELAP4 RUN L135-A22) . . . . . . . . . 137

\section{FIGURES}

1. LOFT major components . . . . . . . . . . . . . . . 6

2. LOFT thermo-fluid measurements instrumentation. . . . . . . . 8

3. LOFT piping and instrument diagram. . . . . . . . . . . . . . . 9

4. LOFT reactor vessel instrumentation . . . . . . . . . . . 10 
5. Comparison of RELAP4 predicted and experimentally measured pressure in pressurizer.................. . 14

6. Comparison of RELAP4 predicted and experimentally measured liquid level in pressurizer. . . . . . . . . . . . . . 14

7. Comparison of RELAP4 predicted and experimentally measured pressure in intact loop . . . . . ... . . . . . . . 15

8. Comparison of RELAP4 predicted and experimentally measured density in intact loop cold leg. . . . . . . . . . . . . . 16

9. Comparison of RELAP4 predicted and experimentally measured density in intact loop hot leg. . . . . . . . . . . . . . 17

10. Comparison of RELAP4 predicted and experimentally measured density in intact loop between steam generator outlet and pump inlet. . . . . . . . . . . . . . . . . . . 17

11. Comparison of RELAP4 predicted and experimentally measured density in broken loop cold leg . . . . . . . . . . . . . . 19

12. Comparison of RELAP4 predicted and experimentally measured density in broken loop hot leg. . . . . . . . . . . . . 19

13. RELAP4 model schematic for LOFT cold leg break configuration at $t=0.2$ second . . . . . . . . . . . . . . . . 21

14. RELAP4 model schematic for LOFT cold leg break configuration at $\mathrm{t}=0.4$ second . . . . . . . . . . . . . . . . 23

15. RELAP4 model schematic for LOFT cold leg break configuration at $\mathrm{t}=1.6$ seconds. . . . . . . . . . ...... . 25

16. RELAP4 model schematic for LOFT cold leg break configuration at $\mathrm{t}=3$ seconds. . . . . . . . . . . . . . . . . 27

17. RELAP4 model schematic for.LOFT cold leg break configuration at $\mathrm{t}=5$ seconds. . . . . . . . . . . . . . . . . . . 29

18. RELAP4 model schematic for the pretest prediction of LOFT Experiment LI-3A. . . . . . . . . . . . . . . . . . . 32

19. RELAP4 model schematic for the posttest analys is of LOFT Experiment LI-3A. . . . . . . . . . . . . . . . . . 33

20. Comparison of RELAP4 calculated and experimentally measured fluid temperature in intact loop cold leg . . . . . . . . 36

21. Comparison of RELAP4 calculated and experimentally measured fluid temperature in intact loop hot leg. . . . . . . . . 36 
22. Comparison of RELAP4 calculated and experimentally measured fluid temperature in broken loop cold leg.......... 37

23. Comparison of RELAP4 calculated and experimentally measured fluid temperature in broken loop hot leg. . . . . . . . . . . 37

24. Comparison of RELAP4 calculated and experimentally measured pressure in intact loop cold leg. . . . . . . . . . . . . . . 39

25. Comparison of RELAP4 calculated and experimentaliy measured pressure in broken loop hot leg. . . . . . . . . . . . . . 39

26. Comparison of RELAP4 calculated and experimentally measured density in intact loop hot leg.

27. Comparison of RELAP4 calculated and experimentally measured density in broken loop cold leg . . . . . . . . . . . . . . . .

28. Comparison of RELAP4 calculated and experimentally measured differential pressure across primary coolant pump . . . . . . . 43

29. Comparison of RELAP4 calculated and experimentally measured differential pressure across steam generator. . . . . . . . . . 43

30. Comparison of RELAP4 calculated and experimentally measured volumetric flow rate from accumulator. . . . . . . . . . . .

31. Comparison of RELAP4 calculated and experimentally measured

32. Comparison of RELAP4 calculated and experimentally measured pressure in ECC injection line. . . . . . . . . . . . . . .

33. Comparison of RELAP4 calculated and experimentally measured pressure in core simulator.

34. Comparison of RELAP4 calculated and experimentally measured pressure in core simulator.

35. Comparison of RELAP4 calculated and experimentally measured fluid temperature in lower plenum at 0.54 meters above reactor vessel bottom ....................

36. Comparison of RELAP4 calculated and experimentally measured fluid temperaure in downcomer at 0.74 meters above reactor vessel bottom . . . . . . . . . . . . . . . . . . .

37. Comparison of RELAP4 calculated and experimentally measured fluid temperature in downcomer inlet annulus at 4.81 meters above reactor vessel bottom . . . . . . . . . . . . 50

38. Comparison of RELAP4 calculated and experimentally measured fluid temperature in core simulator. 
39. Comparison of RELAP4 calculated and experimentally measured momentum flux in downcomer. . . . . . . . . . . . . . 52

40. Volume weighted average void fraction in lower plenum from posttest analysis run . . . . . . . . . . . . . . . 52

41. Volume weighted average void fraction in downcomer from posttest analysis run . . . . . . . . . . . . . . . 53

42. Volume weighted liquid fraction in lower plenum, downcomer, and inlet annulus from posttest analysis run. . . . . . . . . 53

4.3. Comparison of RELAP4 calculated and experimentally measured density in broken loop cold leg. . . . . . . . . . . . . 55

44. Comparison of RELAP4 calculated and experimentally measured density in broken loop hot leg. . . . . . . . . . . . . . . 55

45. Comparison of RELAP4 calculated and experimentally measured density in intact loop cold leg.............. 56

46. Comparison of RELAP4 calculated and experimentally measured density in intact loop hot leg. . . . . . . . . . . . . . 56

47. Comparison of RELAP4 calculated and experimentally measured density in intact loop between steam generator outlet and pump inlet. . . . . . . . . . . . . . . . . . . 57

48. Comparison of RELAP4 calculated and experimentally measured liquid level in pressurizer. . . . . . . . . . . . . . 58

49. Comparison of RELAP4 calculated and experimentally measured pressure in prossurizer... . . . . . . . . . . . . . . . 59

50. Comparison of RELAP4 calculated and experimentally measured pressure in primary system. . . . . . . . . . . . . . . 59

51. Comparison of RELAP4 calculated and experimentaliy measured pressure in steam generator secondary side. . . . . . . . . . 61

52. Comparison of RELAP4 calculated and experimentally measured temperature in downcomer in steam generator secondary side.

53. Comparison of RELAP4 calculated and experimentally measured fluid temperature in broken loop cold leg........... 6

54. Comparison of RELAP4 calculated and experimentally measured fluid temperature in intact loop between steam generator outlet and pump inlet.................. . 63

55. Comparison of RELAP4 calculated and experimentaliy measured fluid temperature in intact loop cold leg........... 63 
56. Comparison of RELAP4 calculated and experimentally measured speed of primary coolant pump l........... 65

57. Comparison of RELAP4 calculated and experimentally measured differential pressure across primary coolant pumps. . . . . . 65

58. Comparison of RELAP4 calculated and experimentally measured fluid velocity in intact loop cold leg. . . . . . . . . . 67

59. Comparison of RELAP4 calculated and experimentally measured momentum flux in intact loop cold leg . . . . . . . . . . 67

60. Comparison of RELAP4 calculated and experimentally measured fluid velocity in intact loop between steam generator outlet and pump inlet................ 68

61. Comparison of RELAP4 calculated and experimentally measured fluid velocity in reactor vessel downcomer. . . . . . . 68

62. Comparison of RELAP4 calculated and experimentally measured fluid velocity in broken loop cold leg. . . . . . . . . . 70

63. Comparison of RELAP4 calculated and experimentally measured mass flow rate per system volume in broken loop cold leg. . . . 70

64. Comparison of RELAP4 calculated and experimentally measured differential pressure across broken loop cold leg...... . 71

65. Comparison of RELAP4 calculated and experimentally measured differential pressure across broken loop cold leg break plane . 71

66. Comparison of RELAP4 calculated and experimentally measured mass flow rate per system volume in broken loop hot leg . . . 72

67. Comparison of RELAP4 calculated and experimentally measured differential pressure across broken loop steam generator simulator. . . . . . . . . . . . . . . . 73

68. Comparison of RELAP4 calculated and experimentally measured differential pressure across broken loop pump simulator. . . . 73

TABLES

I. Nomenclature for LOFT Instrumentation. . . . . . . . . . . 7 


\subsection{INTRODUCTION}

The purpose of this report is to document some of the posttest RELAP4 analyses performed for nonnuclear Experiment L1-3A which was conducted in the Loss-of-Fluid Test (LOFT) facility. The various improvements made in modeling the LOFT system and how these improvements have increased the agreement between the calculations and the LOFT experimental data are discussed in this report.

Section 2.0 discusses the changes in RELAP4 calculated results for LOFT Experiment LI-3A due to the following changes in modeling:

(1) Effects of pressurizer modeling

(2) Effects of using measured instead of specified initial conditions on early blowdown behavior

(3) Effects of new reactor vessel nodalization during the emergency core coolant (ECC) injection phase

(4) Effects of changed ECC modeling

(5) Effects of code changes

(6) Overall effects of modeling changes in calculated transient response.

Section 2.0 also contains a description and justification of the modeling changes in the RELAP4 analysis of Experiment L1-3A. 
Section 3.0 presents conclusions drawn from the information presented and discusses the need for further modeling improvements.

The appendices contain supplemental information about the RELAP4 analysis presented in this report.

LOFT Experiment $L 1-3 A$ was a repeat of Experiment $L 1-3$, which was the third in a series of five nonnuclear isothermal blowdown tests conducted by the LOFT Program. For these tests the LOFT system was configured to simulate a loss-of-coolant accident (LOCA) in a large pressurized water reactor (LPWR) resulting trom a $>00 \%$ duulile ended shear break in a cold leg of the primary coolant system. As outlined in Volume 2 of the experiment operating specification (EOS) $[1,2]$, the specific objectives of Experiment LI-3A include, in addition to facility checkout, operator training, and procedure checkout:

(1) Comparison of break flow data with predictions

(2) Measurement of pump resistance and coastdown characteristics

(3) Determination of system performance with ECC injection into the lower plenum

(4) Determination of two-phase flow resistance for various system components

(5) Evaluation of scaling effects for various primary system components

(6) Evaluation of effects of intact loop resistance by cumparison with corresponding results from Experiment $L 1-2$.

The objectives of the LOFT̄ Experimental Proyram are:

(1) To provide data required to evaluate the adequacy and improve the analytical methods currently used to predict the LOCA 
response of LPWRs. The performance of engineered safety features (ESF) with particular emphasis on emergency core cooling systems (ECCS) and the quantitative margins of safety inherent in the performance of the ESF are of primary interest.

(2). To identify and investigate any unexpected event(s) or threshold(s) in the response of either the plant or the ESF and develop analytical techniques that adequately describe and account for such unexpected behavior.

Several series of experiments have been planned to meet the program objectives. The first series of experiments consists of five nonnuclear tests designated $L 1-1$ through $L 1-5$. For Tests $L 1-1$ through $L 1-4$, a core simulator is installed in the reactor vessel to provide a pressure drop representative of the LOFT nuclear core. The nuclear core will be installed for Test L1-5, but it will not be active during the test.

The major purposes of the nonnuclear test series are ${ }^{[4]}$ :

(1) To determine that the equipment/systems function properly

(2) To demonstrate that the entire test facility can withstand the structural loads of blowdown

(3) To determine that the blowdown test procedures are adequate

(4) To provide experience to operators prior to nuclear tests

(5) To obtain ișothermai loss-of-coolant experiment (LOCE) data for comparison with similar data from other experimental programs and to experimentally verify thermal-hydraulic system behavior prior to nuclear blowdown.

Prior to each LOFT experiment, the experiment is modeled and run on the computer using the RELAP4 computer code. This provides a prediction 
of LOFT system responses during a LOCE. Some of the more important reasons for doing an experiment prediction are to:

(1) Determine whether a test will meet its stated objectives

(2) Evaluate parameters that affect the safety of the facility during the intended test

(3) Provide input to the operating procedure for event times

(4) Provide information or possible instrument range adjustments

(5) Provide information to evaluate the capability of the modeling techniques employed in experinent prediction analysis.

From the data acquired from the experiment prediction analysis, an experiment prediction document is prepared. This document is issued approximately 1 month prior to the experiment, and it provides:

(1) Comprehensive pretest predictions for those test parameters which are related to the specific objectives of the particular LOCE, and which are illustrative of how these objectives are accomp 1 ished

(2) Detailed pretest predićtions for each measurement transducer to be recorded during the LOCE with the exception of strain gages and accelernmeters

(3) A description of the calculational techniques used in performing the pretest predictions.

After an experiment is performed, the data are compared with the predicted data in a quick-look report. The experimental data are then presented fully in an experiment data report. The experimental data are compared extensively to the predicted data, and parametric studies are undertaken to improve the modeling techniques. This is done not in the 
sense that code "tuning" is done but to better understand and model the actual physical processes that are observed in the experimental data. The posttest analysis reports document the more important analys is which is done after the test is performed.

A detailed description of the LOFT system can be found in Reference 3. The major components of the LOFT system are shown on Figure 1. Nomenclature for the LOFT instruments is listed in Table I, and locations of the experimental transducers are shown on Figures 2 through 4. 
$a$

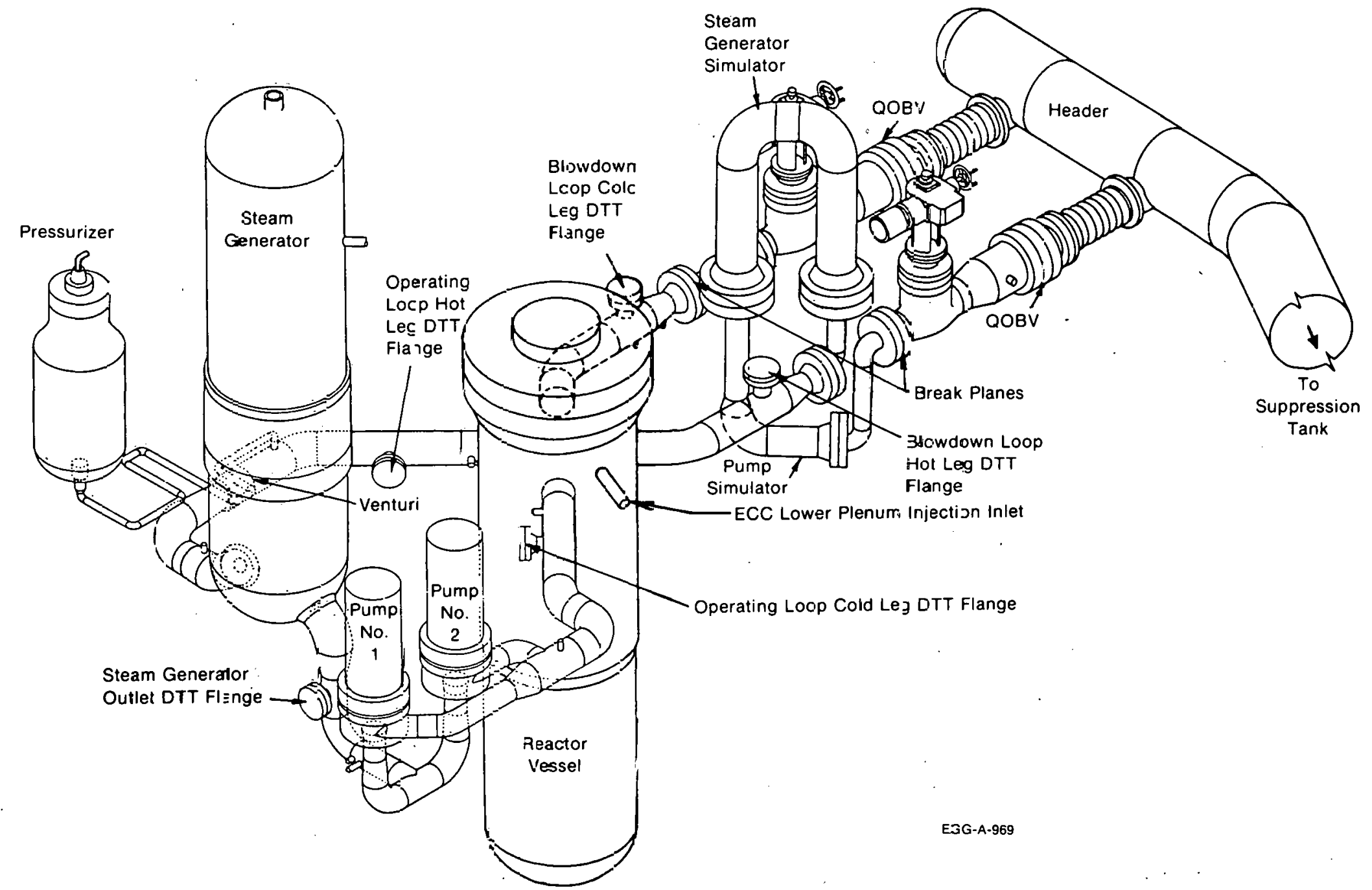

Fig. 1 LDFT major components. 


\section{TABLE I}

NOMENCLATURE FOR LOFT INSTRUMENTATION

The designations for the different types of transducers are as follows:

1. TE - Temperature element

2. TT - Temperature transmitter

3. PE - Pressure transducer

4. PT - Pressure transmitter

5. PdE - Differential pressure element

6. PdT - Differential pressure transducer

7. LE - Coolant level transducer

8. LT - Level transmitter

9. FE - Coolant flow transducer

10. FT - Flow transmitter

11. $\mathrm{AE}$ - Accelerometer

12. DiE - Displacement transducer

13. ME - Momentum flux transducer

14.. SE - Strain gage

15. RpE - Pump speed transducer

16. DE - Densitometer

17. LIT - Level indicating transmitter

18. CV - Control valve

The designations for the different systems, except for the core, are as follows:

1. $P C$ - Primary coolant intact loop

2. BL - Blowdown loop

3. SG - Steam generator

4. RV - Reactor vessel

5. MTA - Test assembly

6. SV - Suppression tank

7. CS - Core simulator

8. UP - Upper plenum

9. LP - Lower plenum

10. ST - Downcomer stalk 


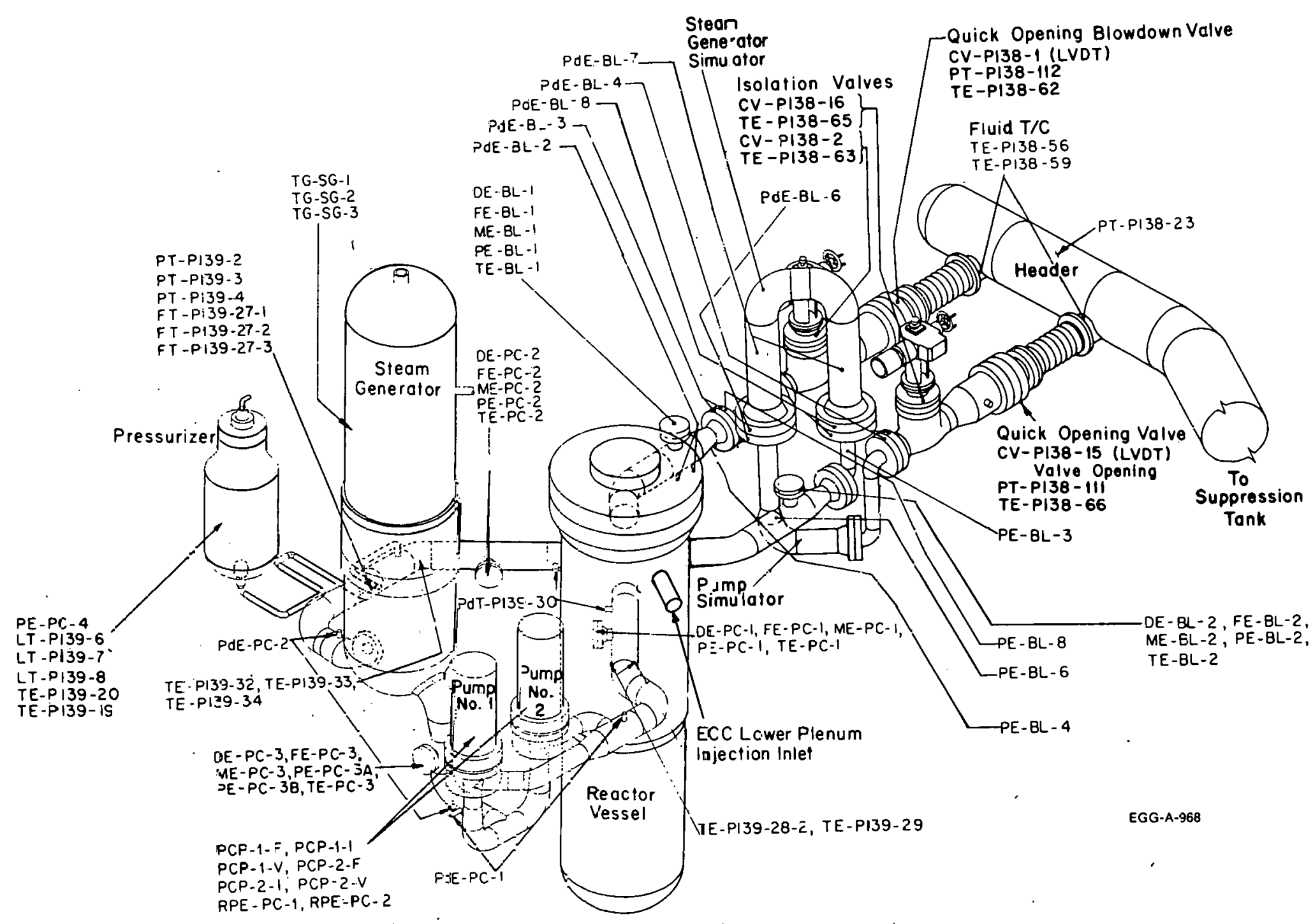

Fig. 2 LCFT trermc-fluid measurements instrumentation. 


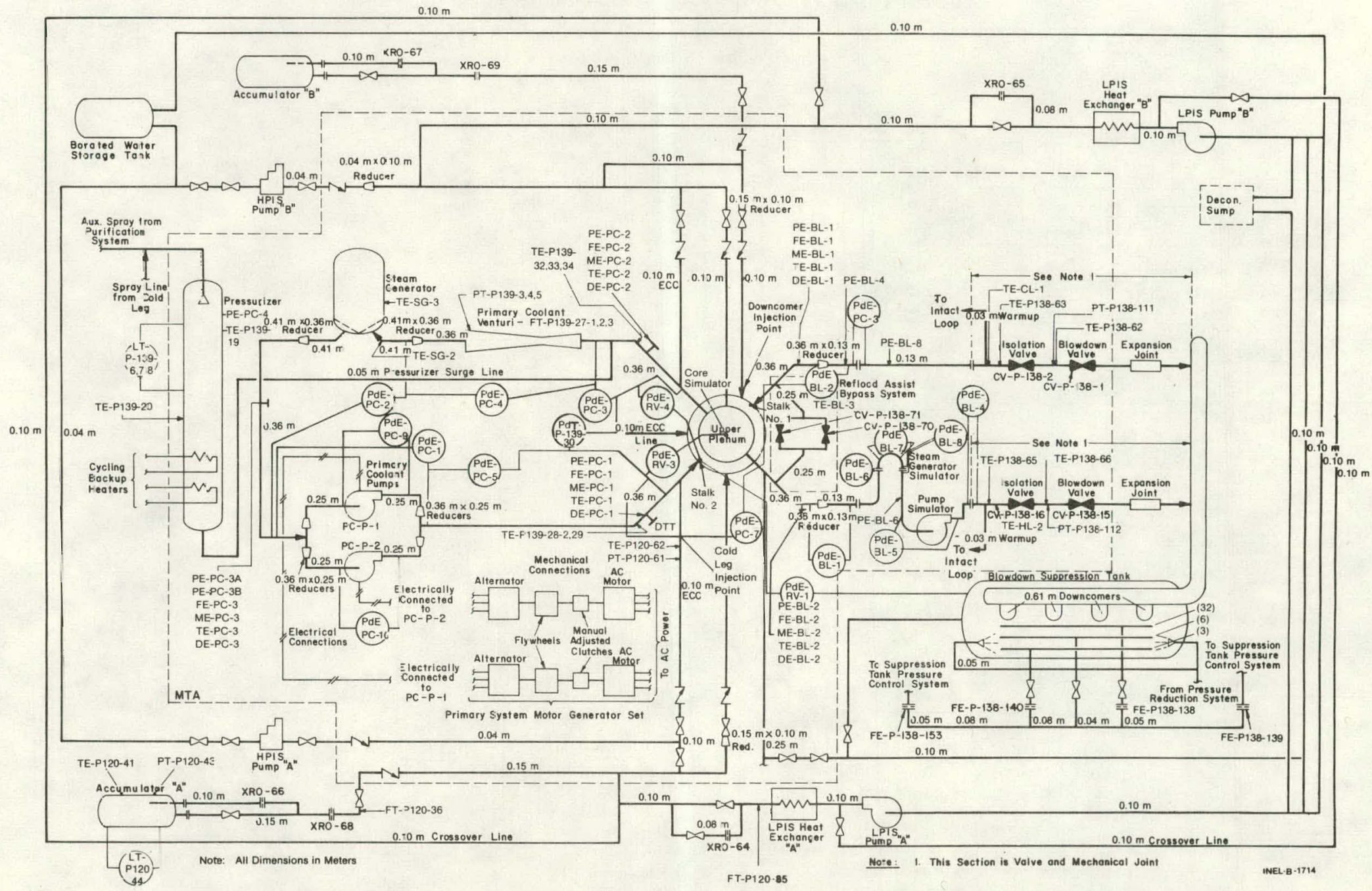

Fig. 3 LOFT piping and instrument diagram. 


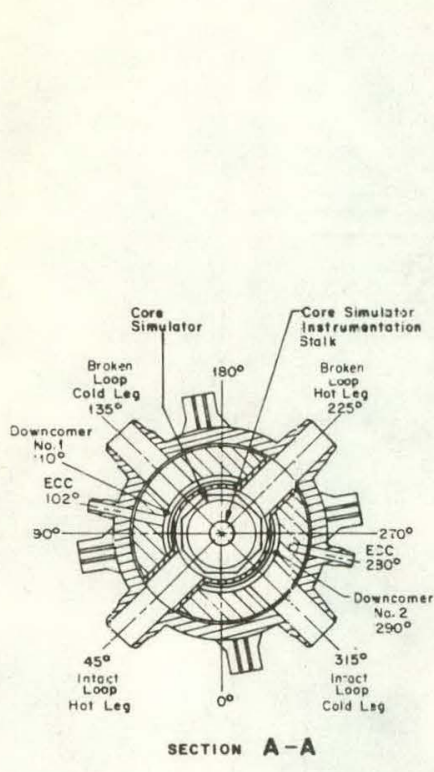

$\overrightarrow{0}$
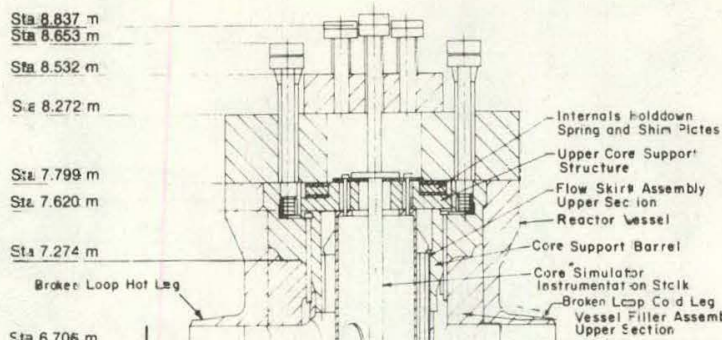

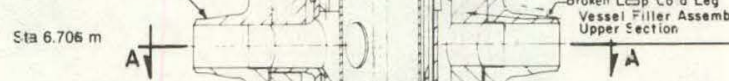

SE $6.180 \mathrm{~m}$ Orsticem plite

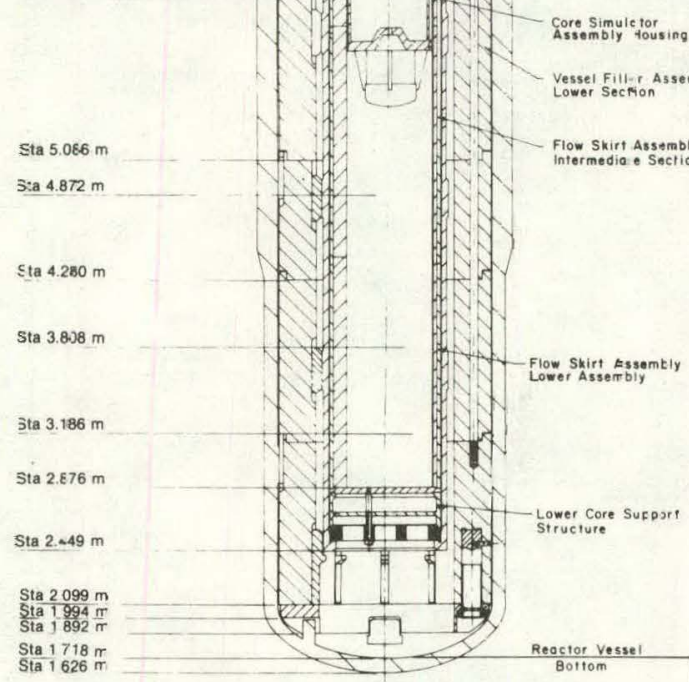

Sta $1718 \mathrm{~m}$

\section{LEGENC}

- Theormocouples (TE's) Presure (DE's a PAE'D) Dros Diecs (MES)

Turbinometor (FE',

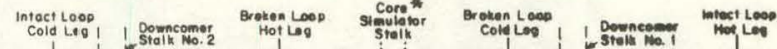

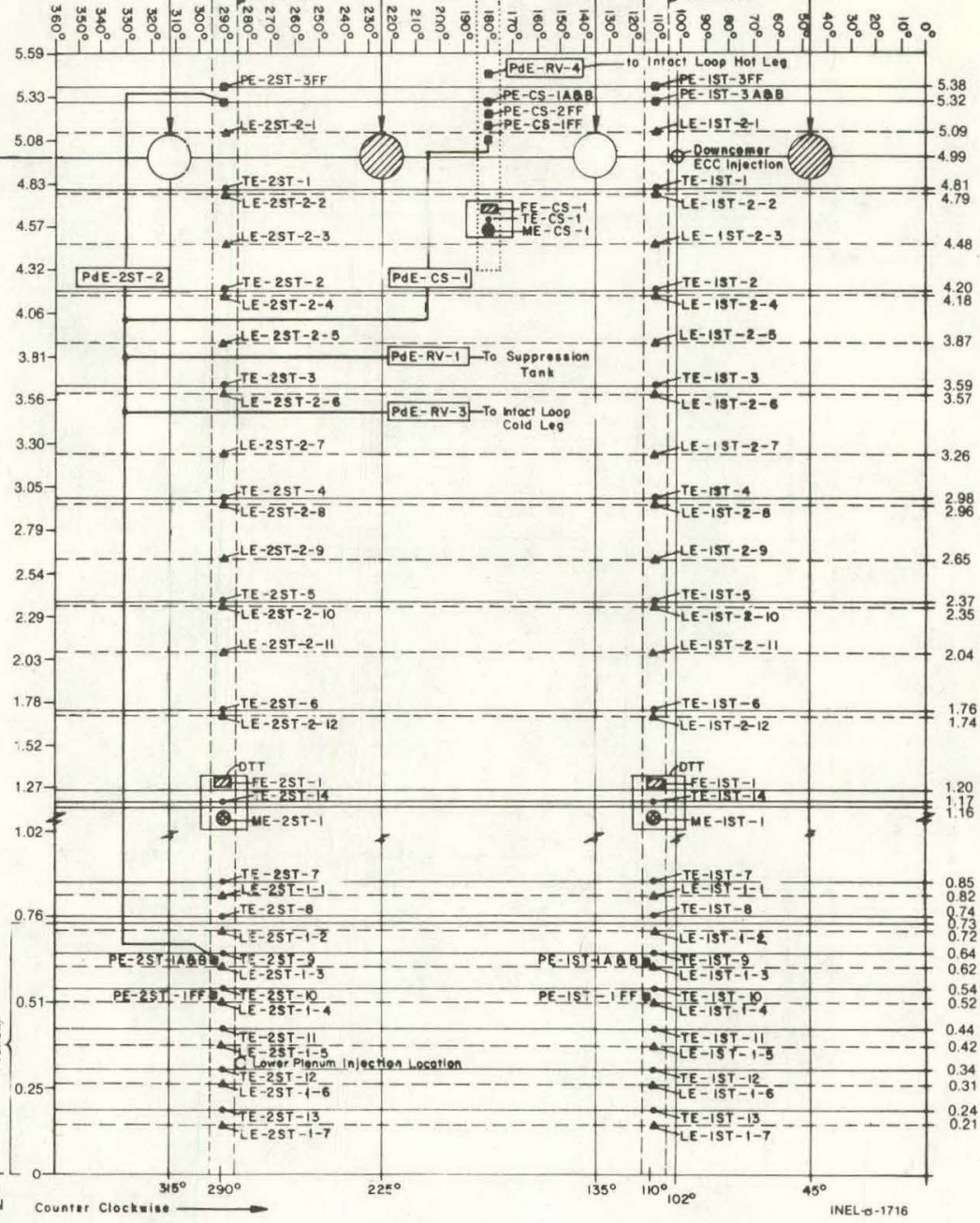

Fig. 4 LOFT reactor vessel instrumentation. 


\subsection{POSTTEST MODELING OF LOFT EXPERIMENT LI-3A \\ WITH RELAP4/MOD5}

\subsection{Modeling the LOFT Pressurizer and the Effects of Pressurizer Modeling on Early Blowdown Behavior}

This section of the report describes modeling of the LOFT pressurizer using the RELAP4 computer code ${ }^{[5]}$, and how the system transient is affected by changed pressurizer modeling.

After reviewing the results of LOFT Experiment $L 1-3 A^{[6]}$, it was apparent that the pressurizer in the RELAP4 pretest prediction run tended to empty too fast [7]. This was evidenced by comparisons between the RELAP4 predicted and experimentally measured pressurizer pressure and liquid level in the pressurizer: As stated in Reference 6 , the pressurizer and surge line are modeled as two volumes, with a single junction connecting the pressurizer to the surge line, and a single junction connecting the surge line to the intact loop hot leg piping.

After checking the inputs to the RELAP4 code, it was apparent that no serious input error was made in the geometric description of the pressurizer and the pressurizer surge line. Various parametric studies were run in which the pressurizer surge line was divided into two and three volumes with the total resistance of the junctions being correspondingly divided. It was found that modeling the surge line with more than one control volume had only a slight effect on the pressurizer outlet flow rate, and the computer running time increased considerably.

Investigation was then made on the effect of Fanning and singlephase form-loss coefficients on calculated pressurizer discharge flow rates. Since a choked flow condition was predicted to exist at the pressurizer surge line to intact loop piping junction, the effect of the critical flow contraction coefficient was also investigated. The result of these investigations led to a new RELAP4 pressurizer model. This new RELAP4 mode 1 had the following changes: 
(1) A slight increase in single-phase form losses was made due to losses in the surge line nozzle, including the effects due to turning losses, losses in the surge line nozzle inlet screen, and losses due to expansions and contractions in the surge line nozzle.

(2) An increase in the form loss was made due to the pipe bends in the pressurizer surge line.

(3) An increase in the form loss was made due to the difference in Fanning losses between smooth piping and rough piping. RELAP4 uses the Karman-Nikuradase equation for calculating the Fanning friction factor for turbulent flow ${ }^{[5]}$. This relation is strictly applicable to smooth pipes and for long runs of small diameter pipe which leads to an understatement of Fanning losses.

(4) Separate two-phase multipliers were applied to the Fanning and form loss increases discussed above t.o account. for two-phase effects ${ }^{[8]}$.

(5) A contraction coofficient of 0.75 was applied to the pressurizer surge line outlet junction to account for the effect of the final bend on the critical flow rate. Reference 9 discusses critical compressible flow in elbows. Subsequent modeling studies have shown that applying the 0.75 contraction coefficient reduces the flow by only a few percent, not by $25 \%$ as was initially expected. Applying the contraction coefficient tends to increase the upstream pressure in such a way as to offset the contraction coefficient change.

(6) A $30 \%$ reduction in the bubble velocity in the bubble rise model in the pressurizer was implemented to account for the lower buoyancy effect due to the higher pressures in the pressurizer. 
(7) A slight increase was made in the elevation of the junction between the pressurizer and the pressurizer surge line. This was done to establish the elevation of the pressurizer surge line nozzle above the bottom of the pressurizer.

After the new pressurizer model was developed and incorporated into the RELAP4 model of the LOFT system, a run was made (designated as L135-A23). This run was identical to the pretest prediction run (designated as L135-B5) "except for the pressurizer model and the pressurizer initial liquid volume. An input listing and time zero output listing of this run are included in Appendix $A$. The input to the pretest prediction RELAP4 run may be found in Reference 7.

Figures 5 and 6 show comparisons between the RELAP4 predicted and the measured pressurizer pressure and pressurizer liquid levels. As can be seen from these figures, the pressurizer emptying rate in the new. model is much closer, but slightly under the experimental data. The effect of changing the junction elevation of the pressurizer outlet junction can be seen in Figure 6 , which shows a discontinuity in the pressurizer level versus time curve at approximately 0.1 metre. 


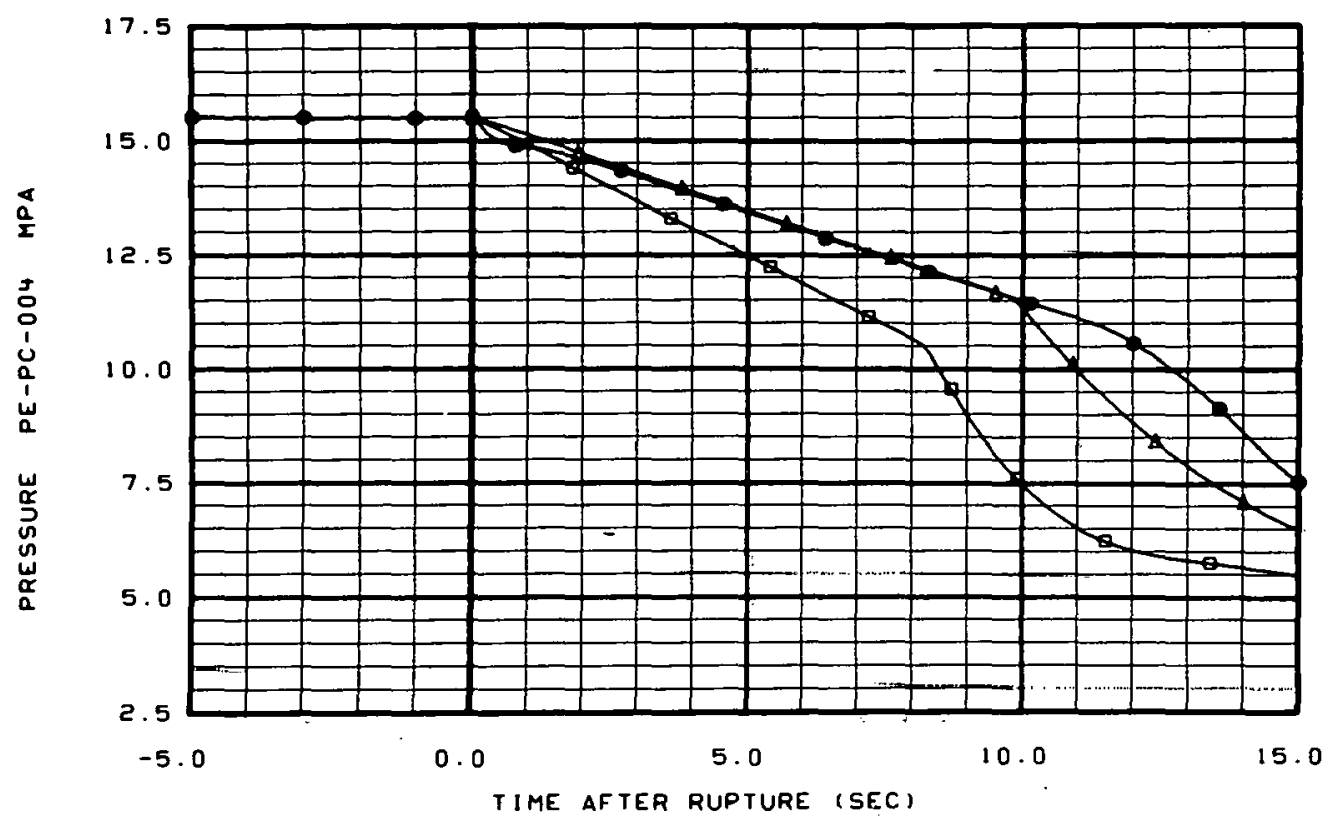

DOT =L I-3A DATA. SQUARE=PRETEST RELAP4, TRIANGLE=L 135-A23 RELAP4

Fig. 5 Comparison of RELAP4 predicted and experimentally measured pressure in pressurizer.

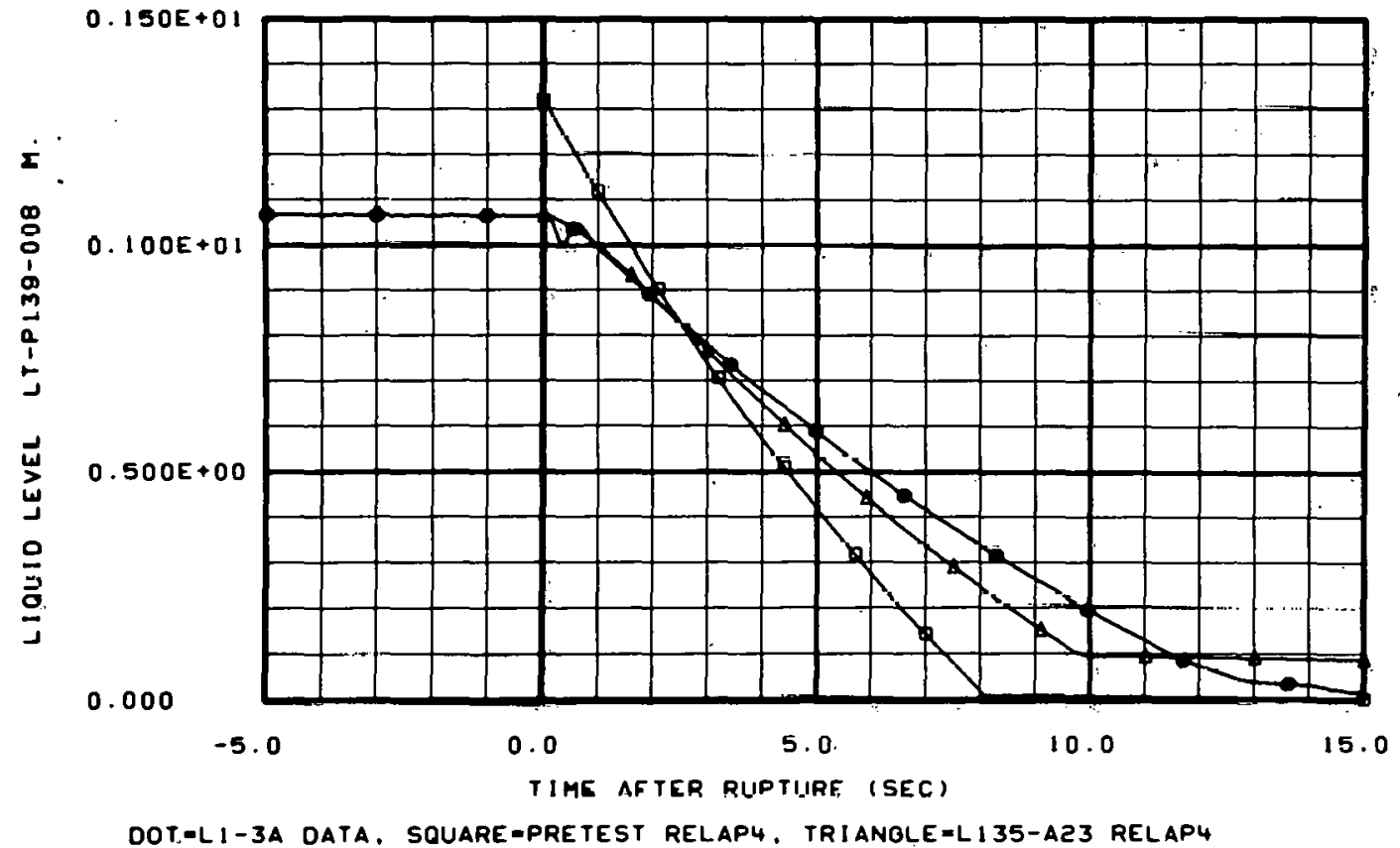

Fig. 6 Comparison of RELAP4 predicted and experimentally measured liquid level in pressurizer. 
- Figure 7 shows a comparison of the calculated and measured pressures in the intact loop. The differences in primary system pressures in the RELAP4 runs were an unexpected result. Careful analysis of the RELAP4 outputs revealed that the primary system pressures after the end of subcooled blowdown $(\sim 0.2 \mathrm{~s})$ tend to be controlled by the saturation pressure of the control volume in the primary system which has the highest temperature. In the two RELAP4 runs, this proved to be the volumes in the intact loop hot leg. By reducing the pressurizer discharge flow of high enthalpy fluid, the energy input into the intact loop was decreased and the temperature in the intact loop was lowered.

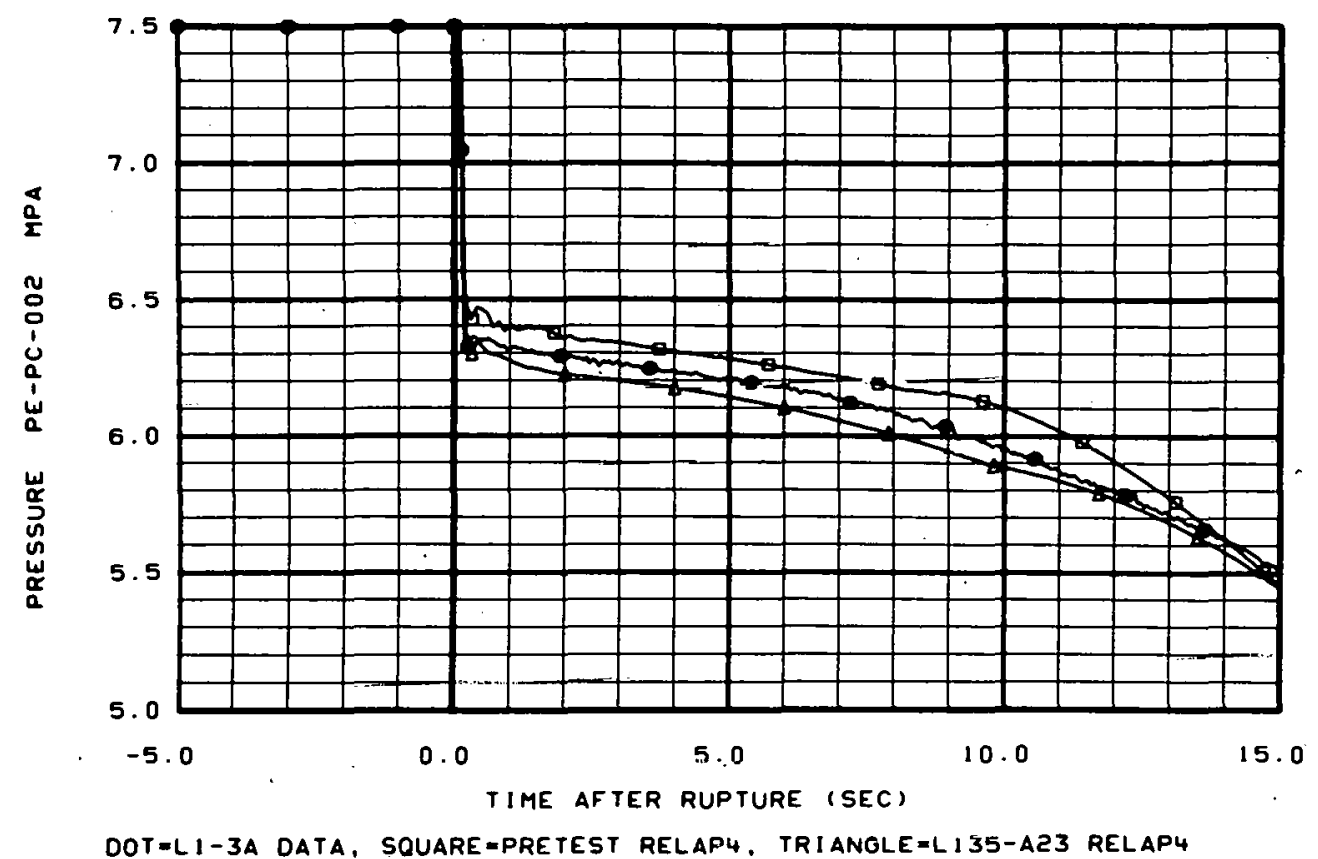

Fig. 7 Comparison of RELAP4 predicted and experimentally measured pressure in intact loop. 
Figures 8, 9, and 10 show comparisons between calculated and measured densities in the intact loop. In essentially every case, changing the pressurizer model has allowed the fluid to begin to flash earlier. This allows for better comparisons between RELAP4 and the experimental data for the first 5 seconds of blowdown. In Figure 9, the agreement between RELAP4 and the experimental data has been markedly improved for the first 4 seconds of blowdown. Analysis of the RELAP4 output shows that a flow reversal takes place in the hot leg at approximately 4.5 seconds after rupture in the RELAP4 run with the new prcssurizor model. When this occurs, the density of the rluid moving past the junction at which the density is computed takes a sudden chanye to a lower value. The experiment behaved in a similar fashion, except the density drop takes place at approximately 6 seconds after rupture.

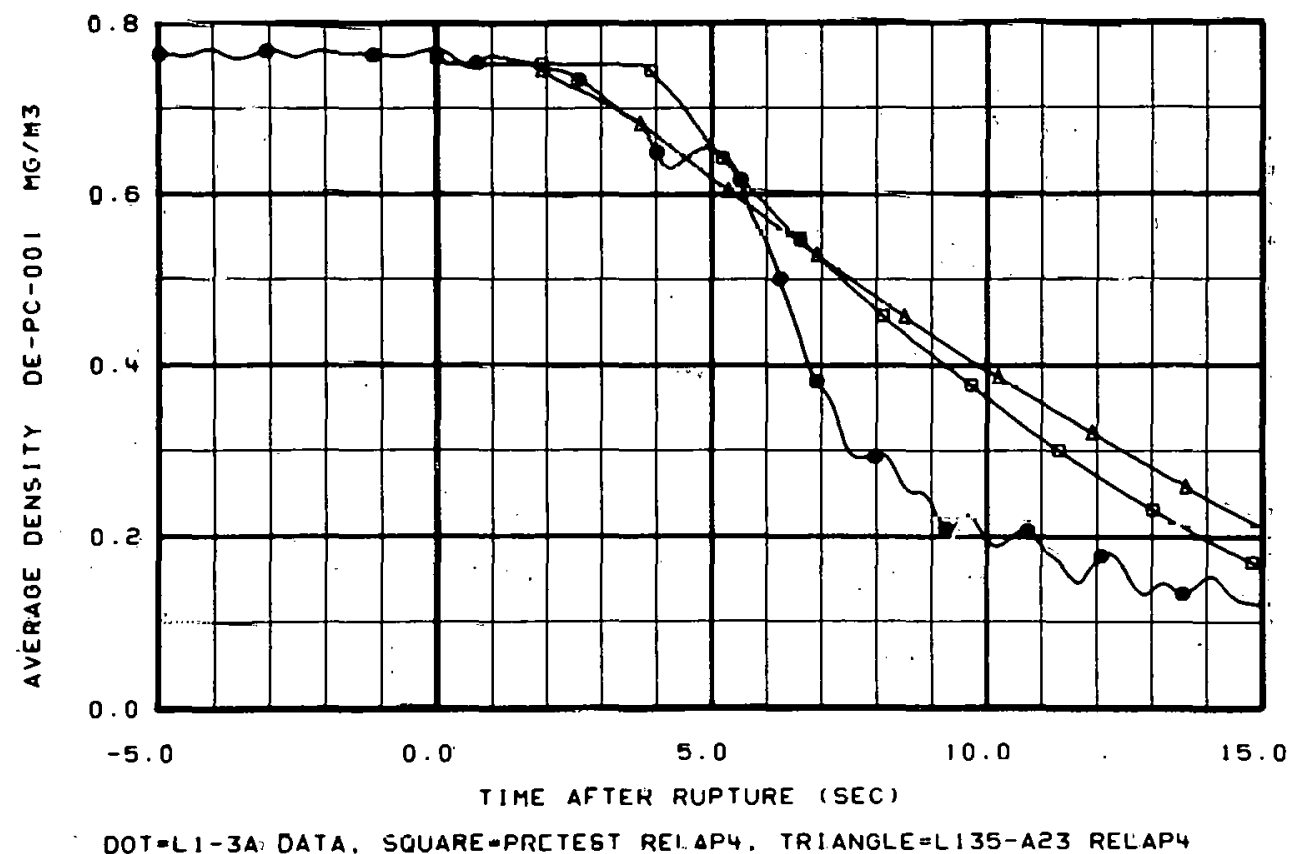

Fig. 8 Comparison of RELAP4 predicted and experimentally measured. density in intact loop cold leg. 


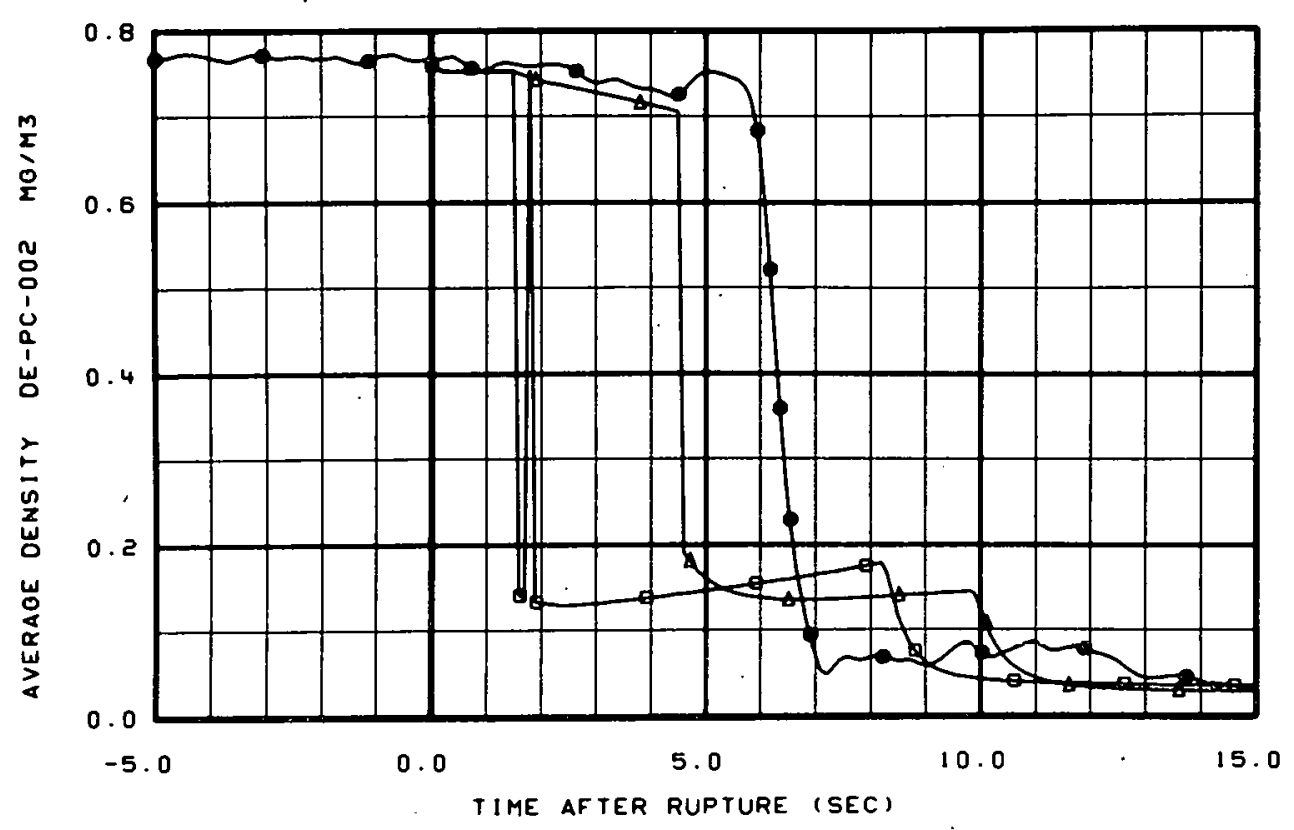

DOT=LI-3A DATA, SQUARE=PRETEST RELAP4, TRIANGLE =LI35-AZ3 RELAP4

Fig. 9 Comparison of RELAP4 predicted and experimentally measured density in intact loop hot leg.

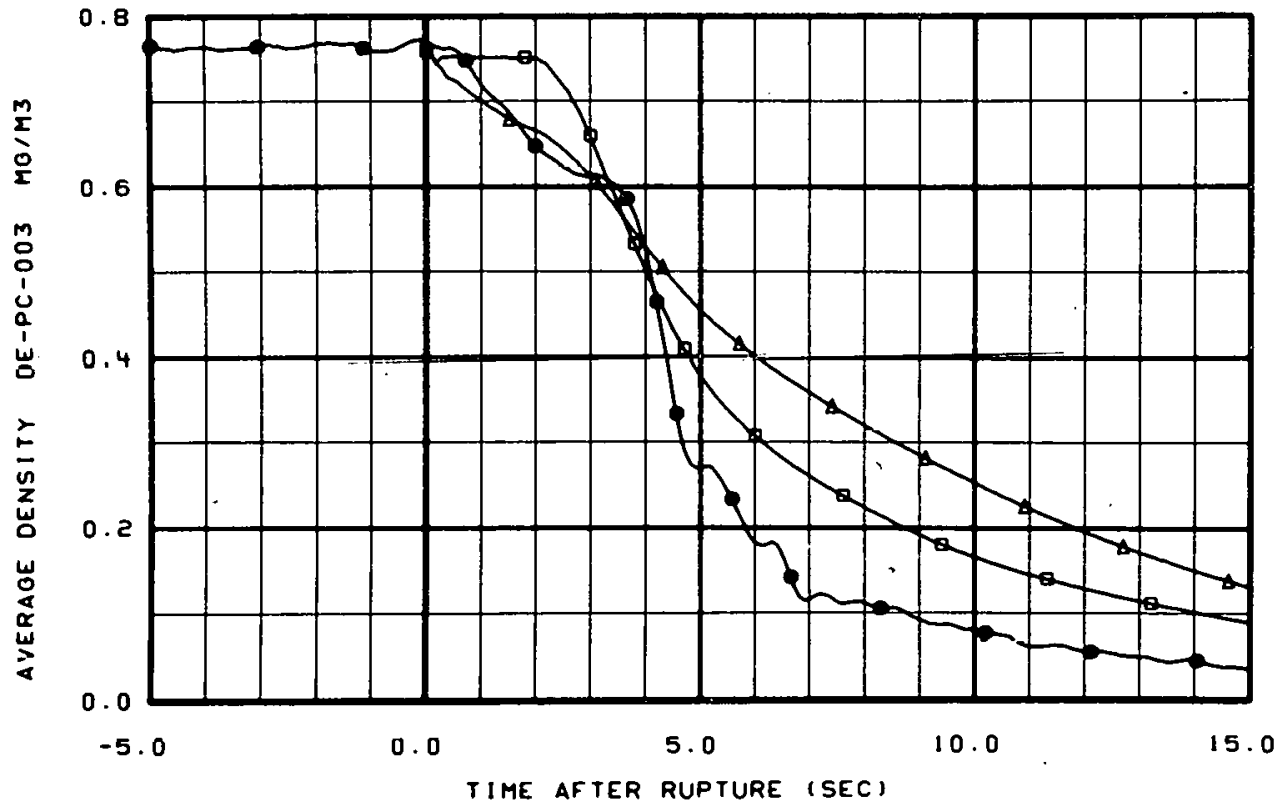

DOT-LI-3A DATA, SQUARE =PRETEST RELAP4, TRIANGLE $=L 135-A 23$ RELAP4

Fig. 10 Comparison of RELAP4 predicted and experimentally measured density in intact loop between steam generator outlet and pump inlet. 
Figures 11 and 12 show comparisons of calculated and measured densities in the broken loop. Here again, an earlier flashing of fluid is shown in the RELAP4 run with the new pressurizer model. 


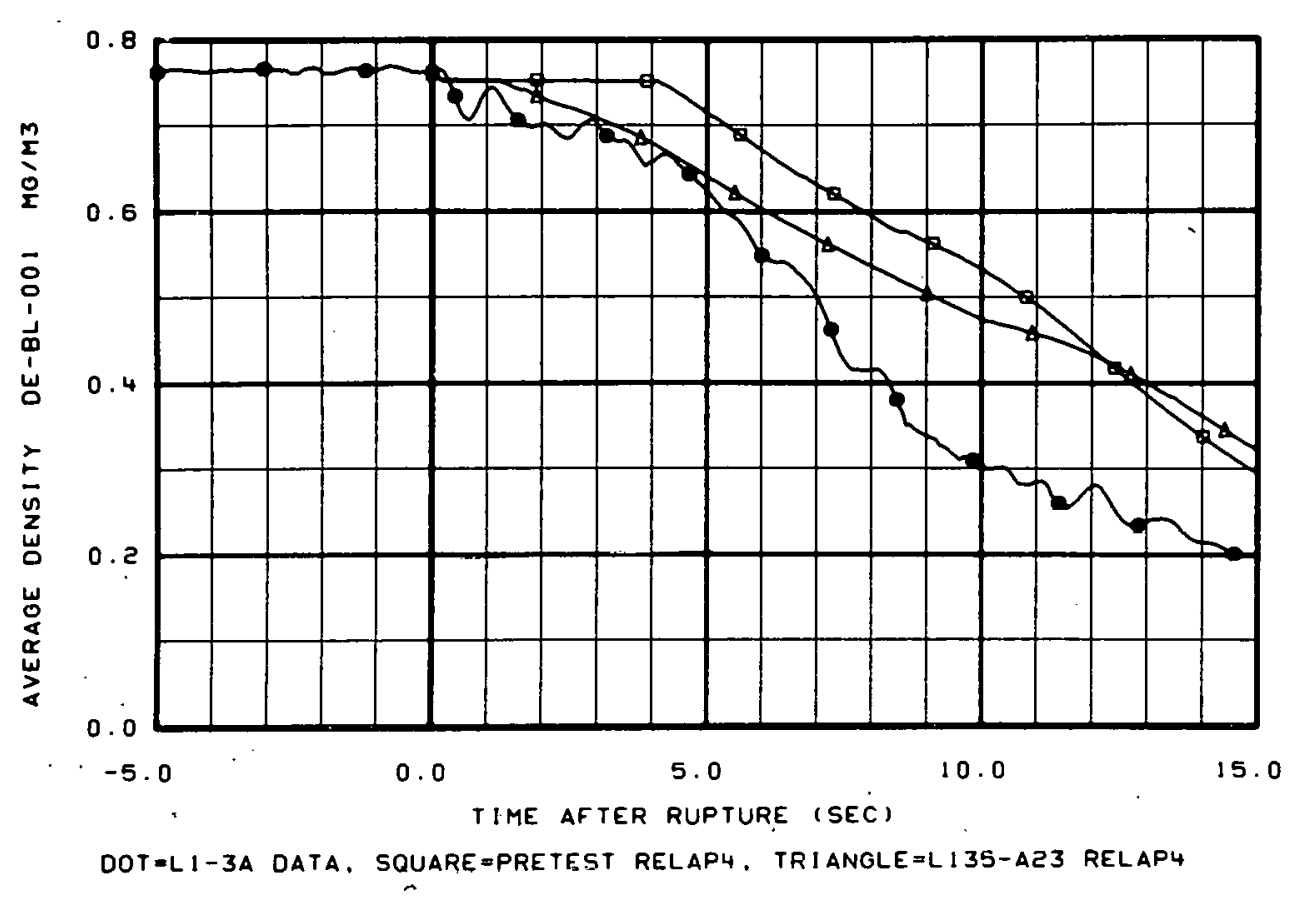

Fig. 11 Comparison of RELAP4 predicted and experimentally measured density in broken loop cold leg.

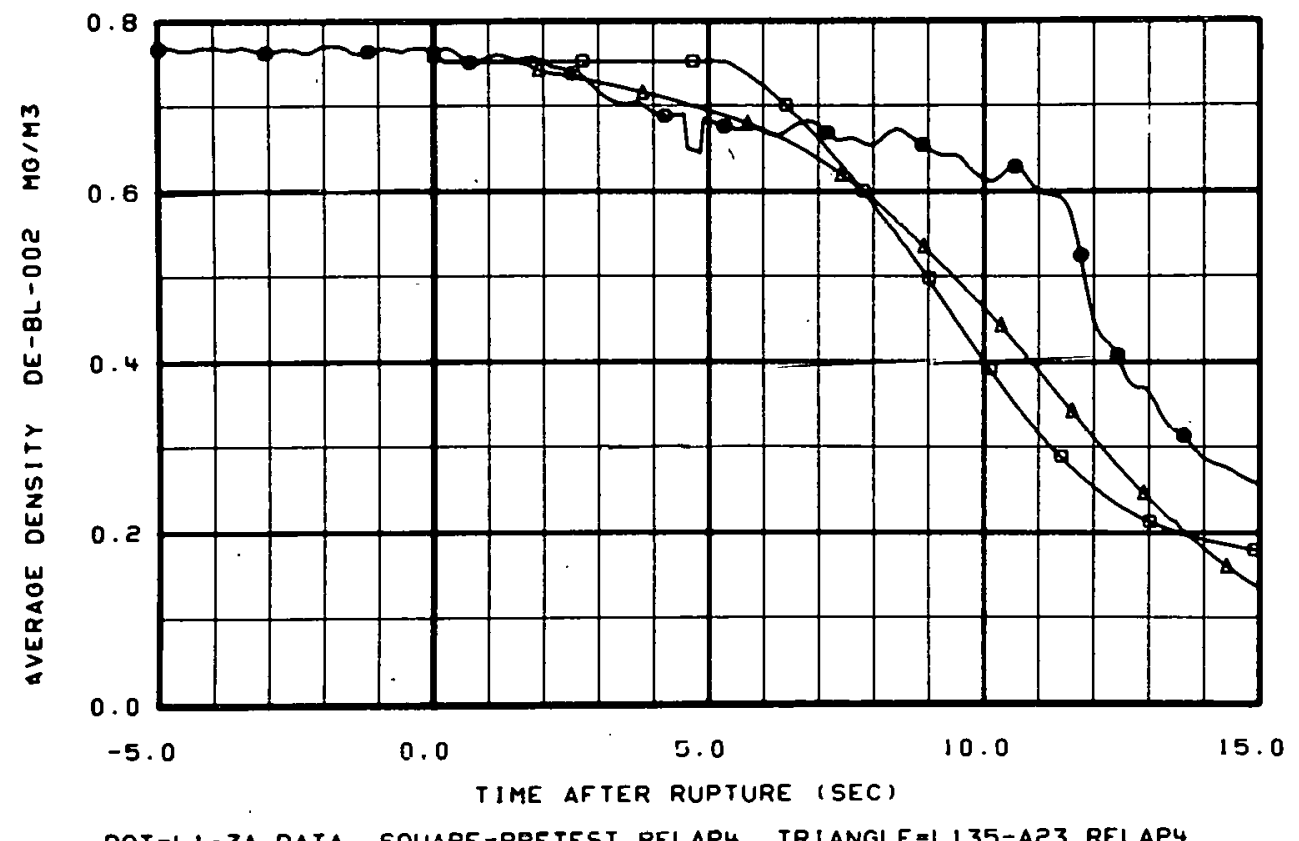

DOT-L1-3A DATA, SOUARE =PRETEST RELAP4, TRI ANGLE =L 135-A23 RELAP4

Fig. 12 Comparison of RELAP4 predicted and experimentally measured density in broken loop hot leg. 
The behavior in space and time of the RELAP4 calculated density behavior can best be seen in Figures 13 through 17 . In this series of figures, the RELAP4 model schematic for both the pretest RELAP4 run and the posttest RELAP4 run with the new pressurizer model (run L135-A23) has been shaded to indicate a range of densities which are calculated to exist in different RELAP4 control volumes. Arrows are used to indicate flow direction from one control volume to another.

Figure 13 shows the density distribution comparisons at $t .=0.2$ seconds after the break begins to open. Flashing has begun in the intact lonp where the pressurizer curgo line enters the hot leg; at the pump inlet, which is the lowest pressure point in the primary system; and in the control volumes just upstream of the break planes. All flow directions are stili in the normal direction. 


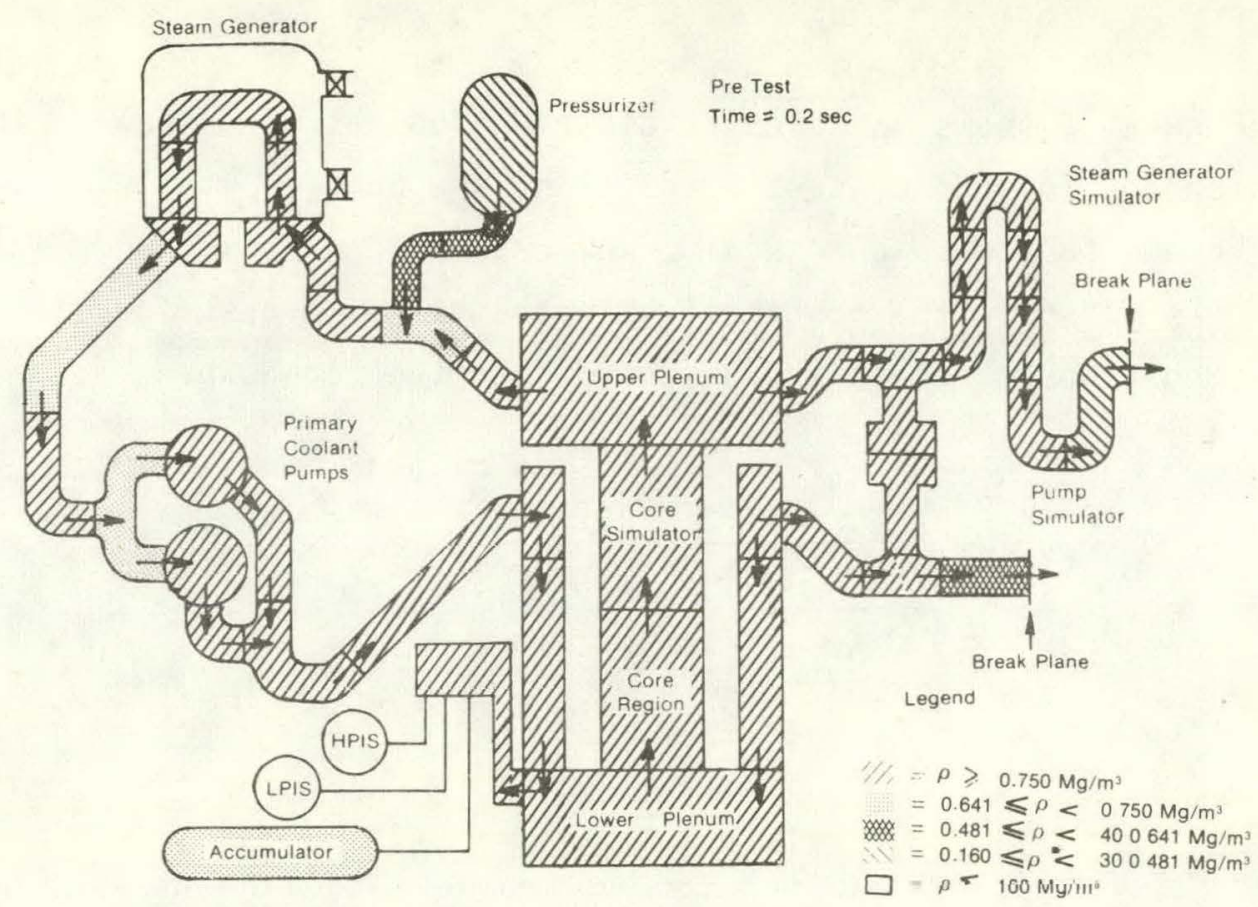

Note: Arrows Indicate Flow Direction

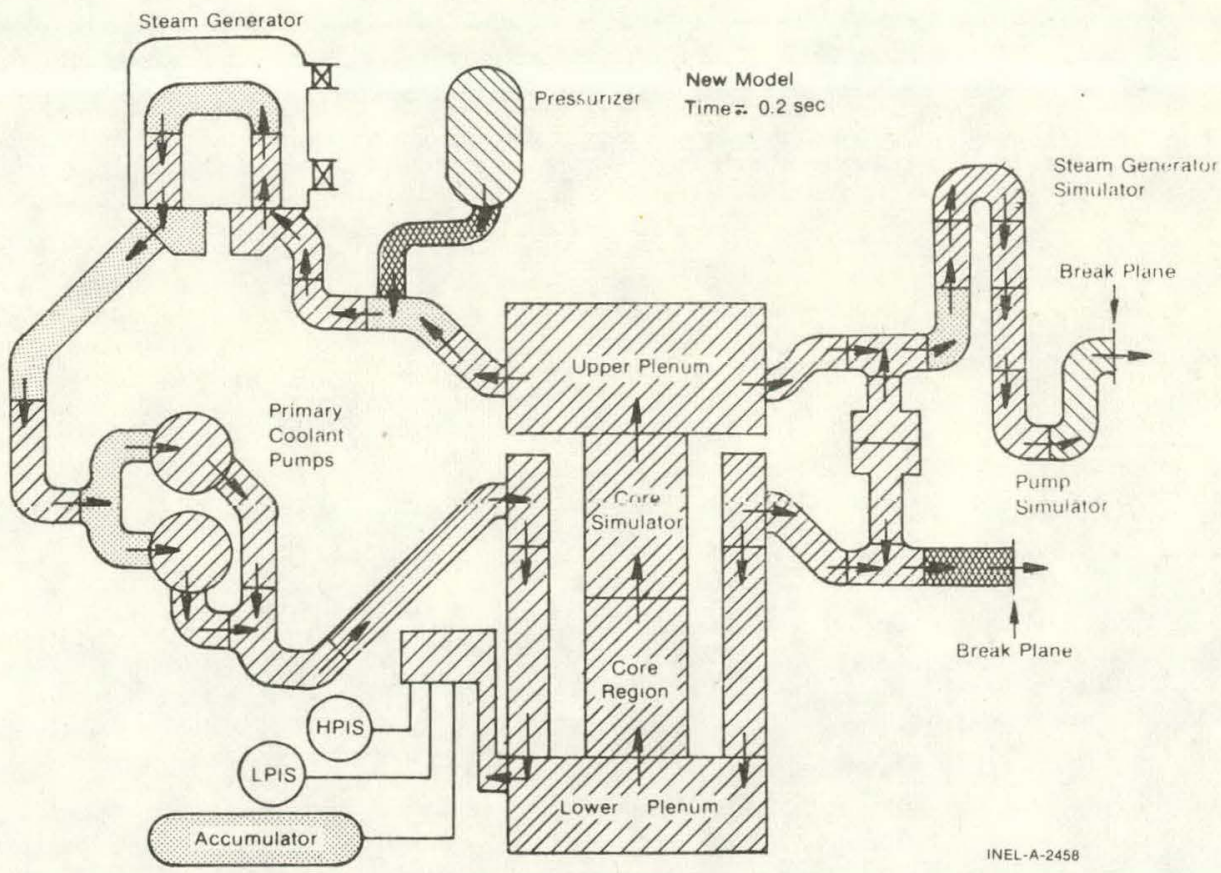

Fig. 13 RELAP4 model schematic for LOFT cold leg break configuration at $t=0.2$ second. 
Figure 14 shows the density distribution at 0.4 second into the transient. In the pretest prediction, the pump inlet fluid conditions have become subcooled once again, while the fluid at the pump inlet has begun to flash in the posttest run with the new pressurizer model. The same conditions exist past 0.8 second into the blowdown. 


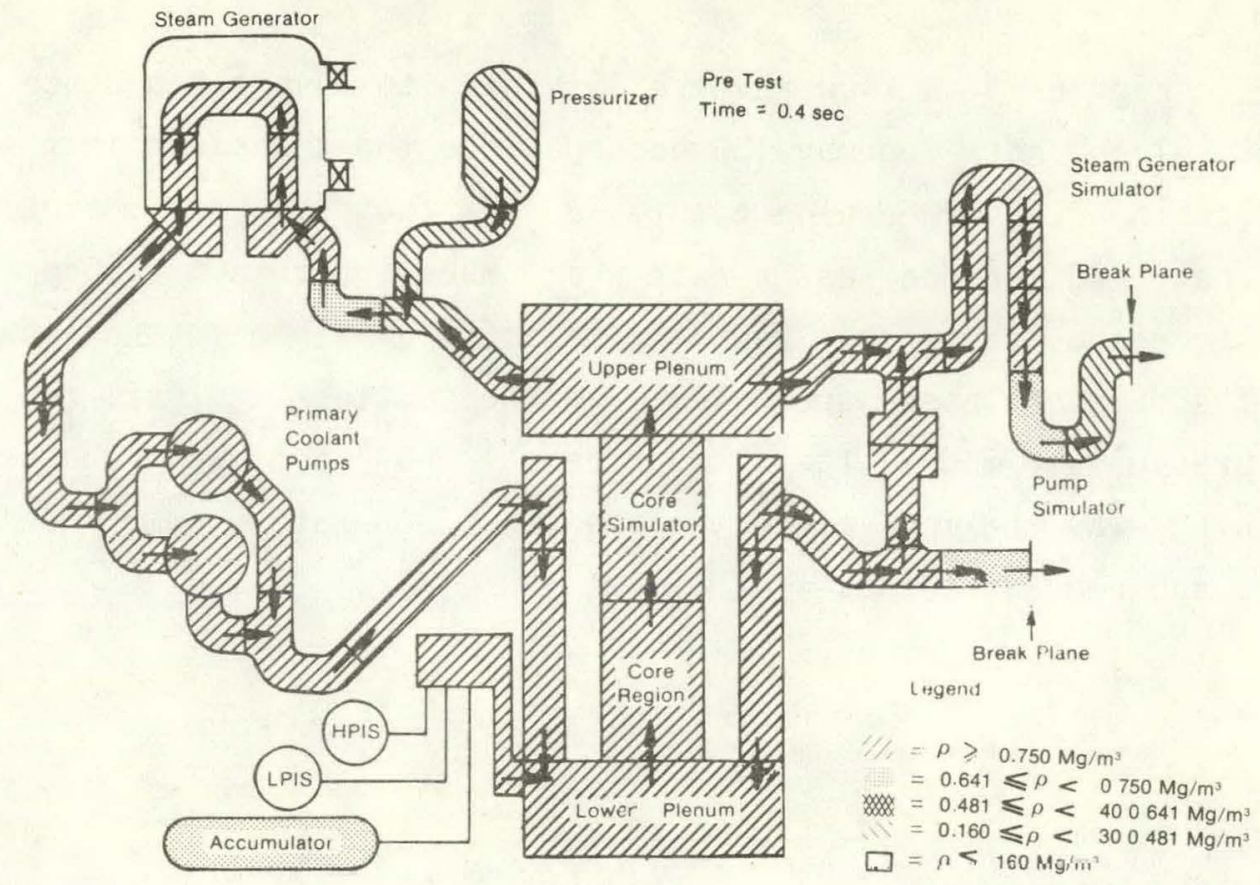

Note. Arrows Indicate Flow Direction

INEL-A-2448

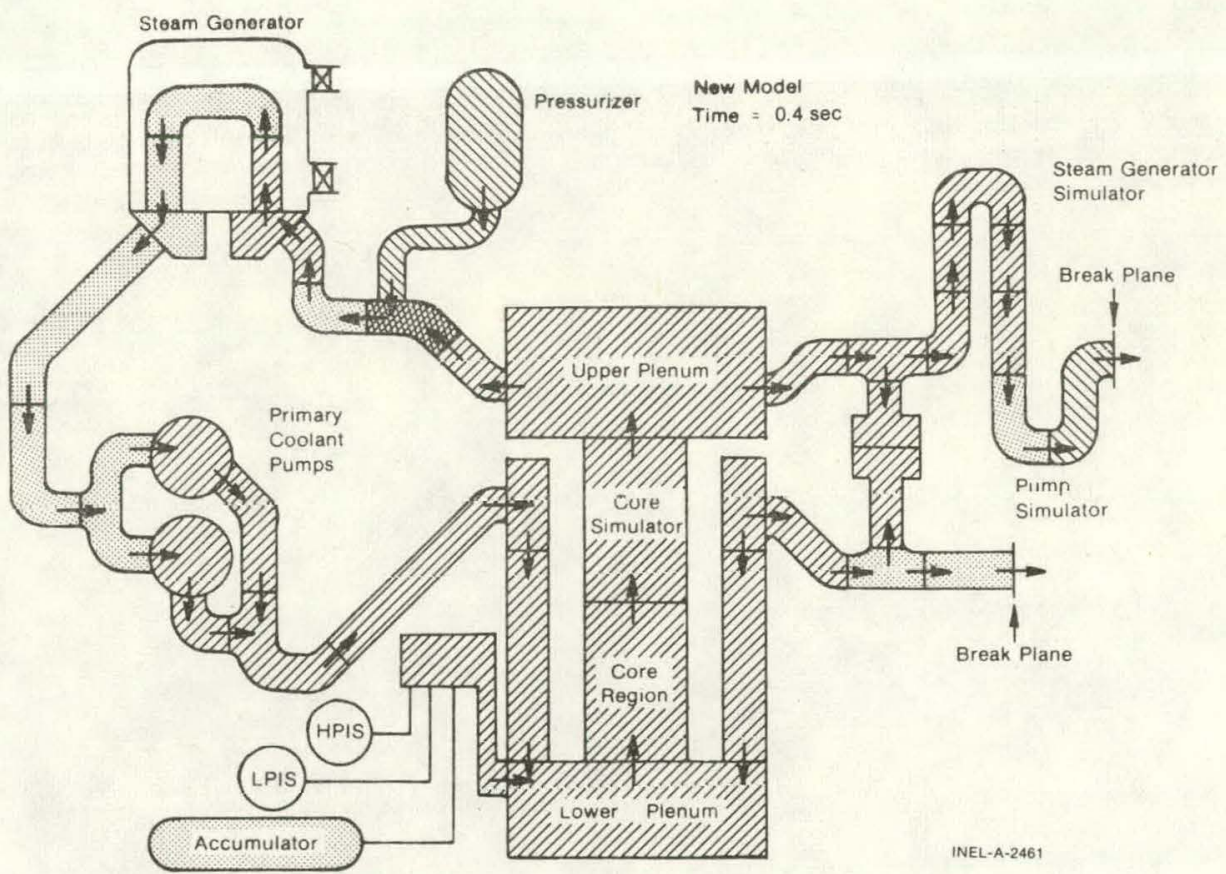

Fig. 14 RELAP4 model schematic for LOFT cold leg break configuration at $t=0.4$ second. 
In Figure 15, a flow reversal is shown to have taken place in the intact loop hot leg by 1.6 seconds into the transient in the pretest prediction RELAP4 run. The hot fluid from the pressurizer emptied into the hot leg at too fast a rate which made the intact loop hot leg act like a pressurizer. This kept the majority of fluid in the intact loop and the reactor vessel subcooled. In the posttest analysis run with the new pressurizer model, the flow reversal has not yet occurred, and flashing was taking place in the steam generator, pump inlet, broken loop, and reactor vessel. 


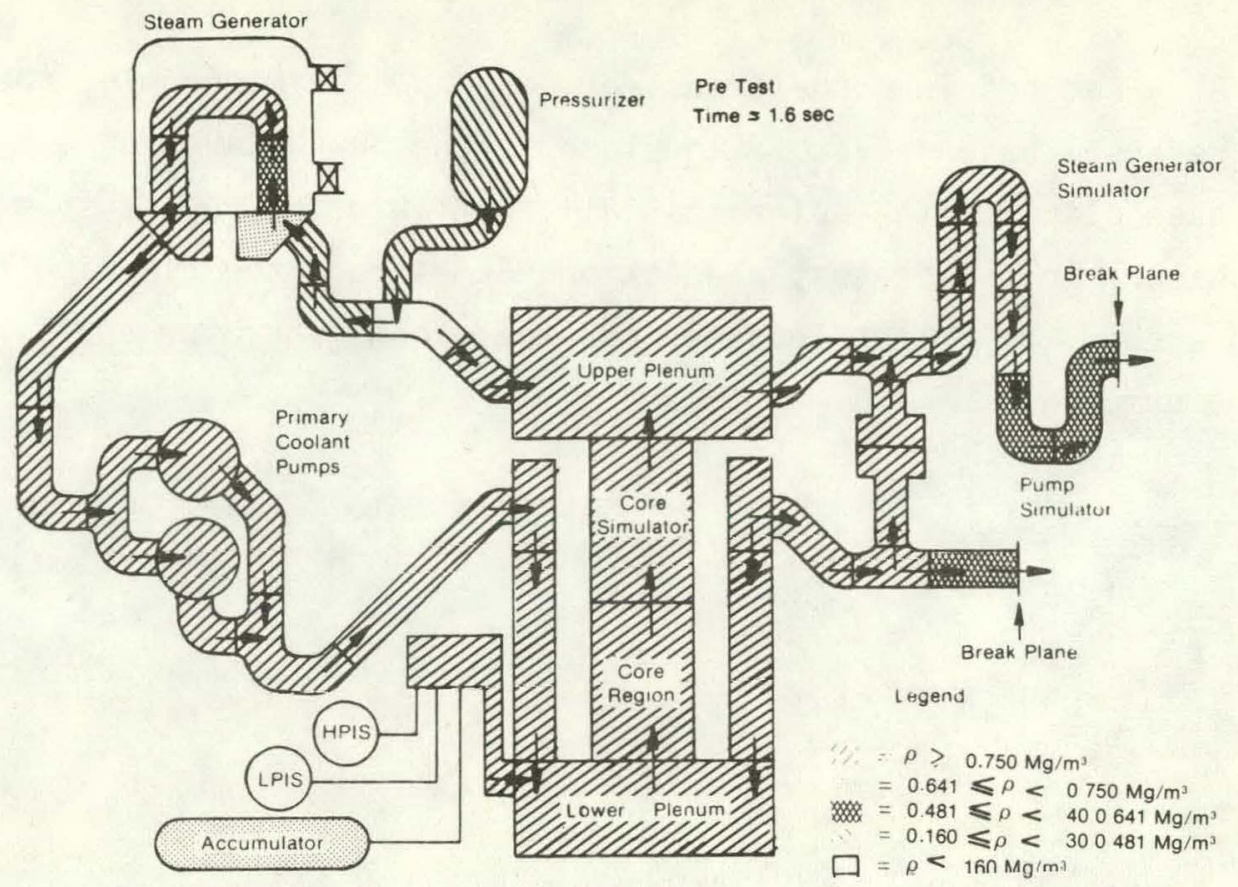

Note: Arrows Indicate Flow Direction

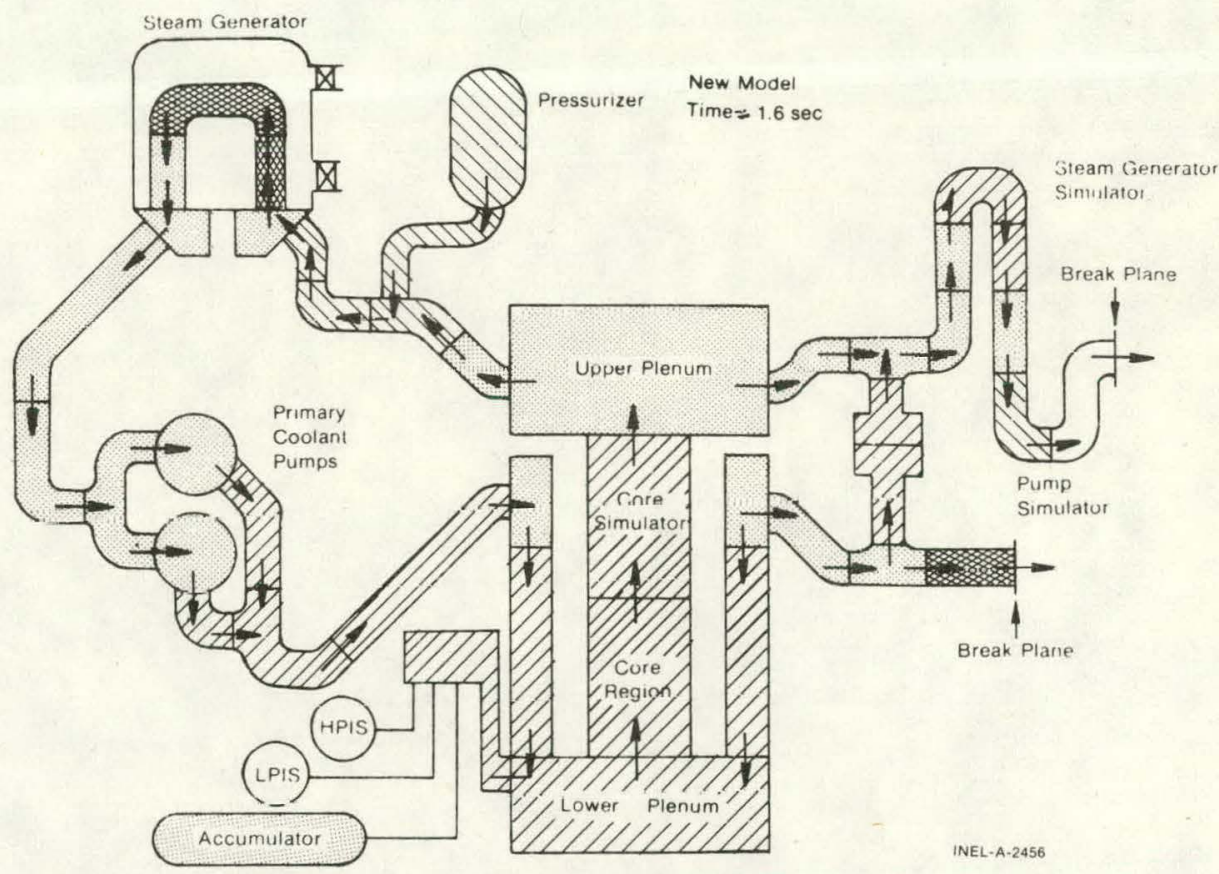

Fig. 15 RELAP4 model schematic for LOFT cold leg break configuration at $t=1.6$ seconds. 
At 3 seconds into the transient, as shown on Figure 16, the hot leg flow reversal has not yet taken place in the new RELAP4 run and flashing has taken place to the point that all the fluid in the system is now two-phase. In the pretest prediction RELAP4 run, the flashing front has moved around the intact loop through the steam generator and is now up to the pump inlet. 


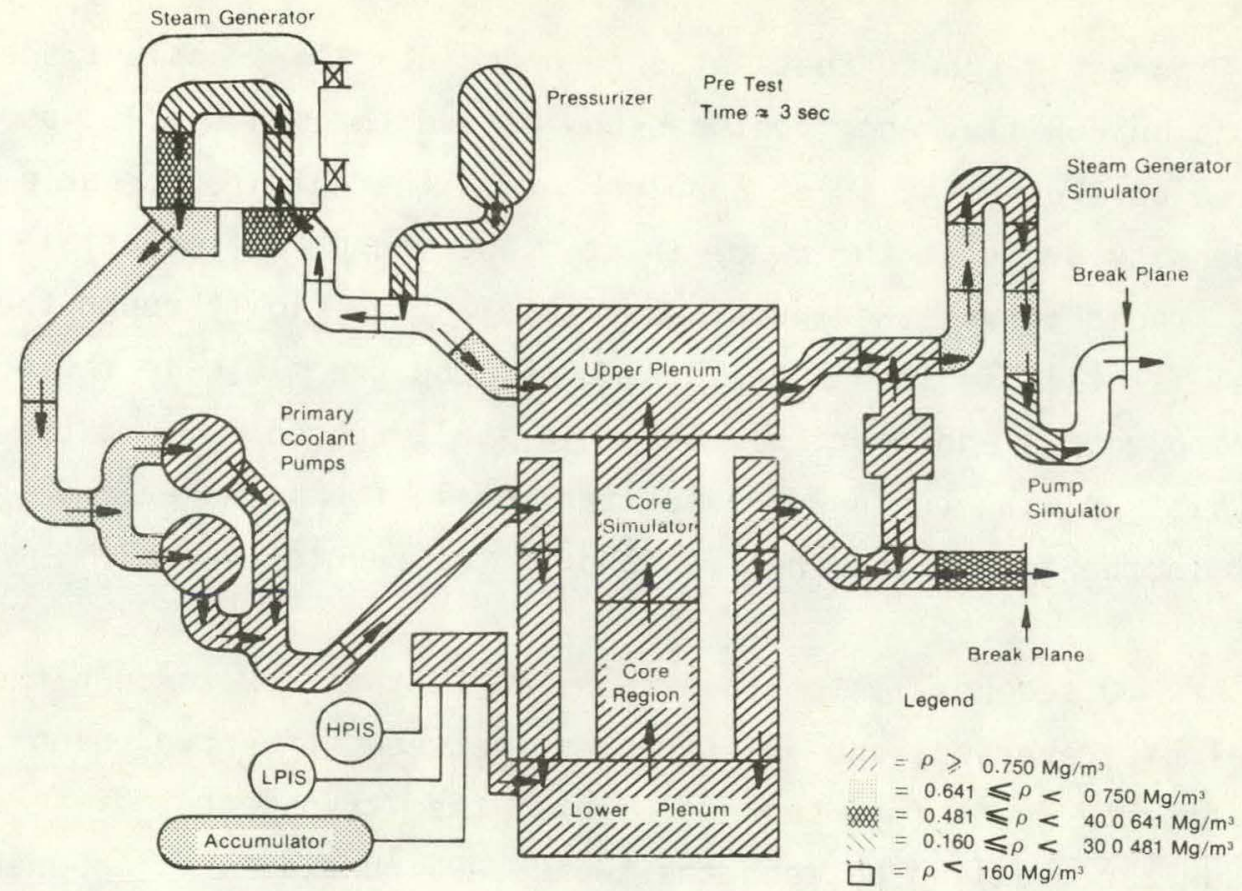

Note: Arrows Indicate Flow Direction

INEL-A-2450

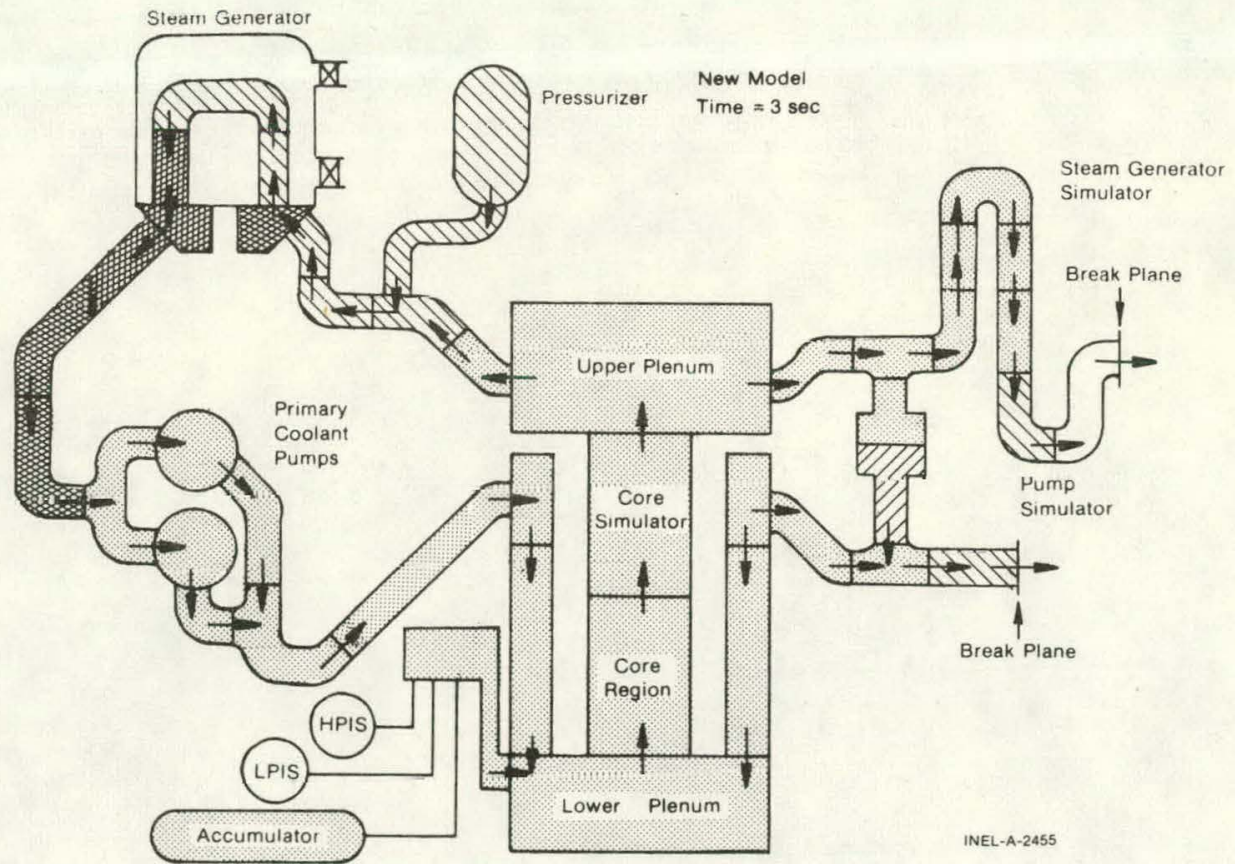

Fig. 16 RELAP4 model schematic for LOFT cold leg break configuration at $t=3$ seconds. 
Figure 17 shows that at 5 seconds into the transient the pretest prediction run flashing front has now passed through the pumps and is proceeding around the inlet annulus toward the cold leg break plane. As the density drops at the pump inlet, the pump differential pressure drops rapidly as the pumps cavitate. The flow through the reactor vessel is still in the normal direction, and the fluid in the downcomer, lower plenum, and core simulator is still subcooled. In the posttest analysis run with the new pressurizer model, the flow reversal has taken place in the intact loop hot leg and in the reactor vessel.

At IO secunds into the tranaient, Llie flow through the reactor vessel has reversed, and differences between the two runs are not significant. At 10 seconds into the transient, differences in pressurizer modeling between the two RELAP4 runs do not appear to be significantly controlling the transient. 


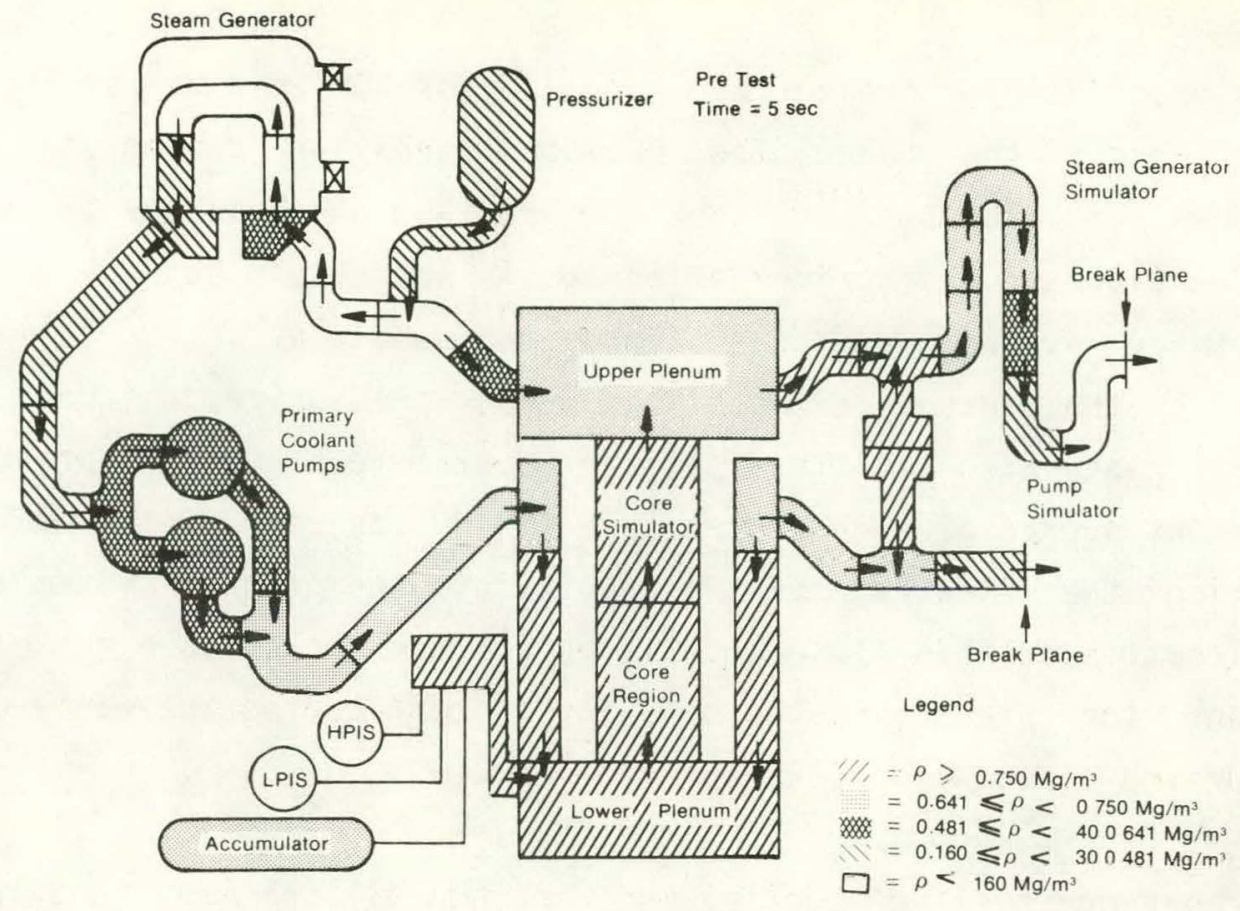

Note: Arrows Indicate Flow Direction

INEL-A-2453

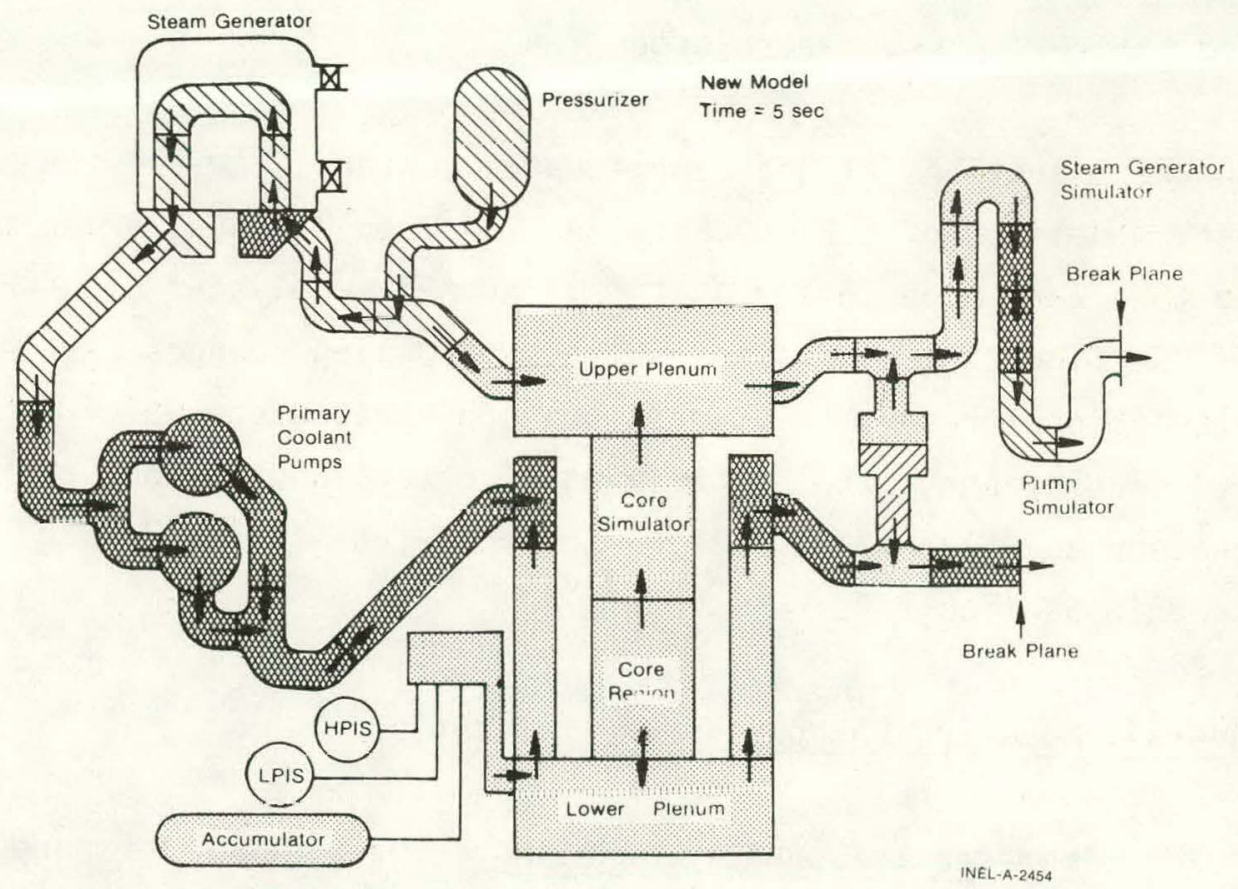

Fig. 17 RELAP4 model schematic for LOFT cold leg break configuration at $t=5$ seconds. 
In conclusion, pressurizer modeling of LOFT nonnuclear LOCEs was shown to affect the calculated blowdown behavior during the first 10 seconds of blowdown in subtle ways. Not only was the pressurizer discharge flow and pressurizer affected, as suspected, but in addition, the primary system pressures, flows, and densities were also markedly affected by the pressurizer modeling. The pressurizer liquid, being initially saturated at the primary system pressure, represents a significant source of high-temperature fluid for an isothermal LOCE. Predicting the flow rate of this fluid into the primary system and the flow direction of this fluid once it enters the intact loop hot leg is important for predicting the behavior of LOFT during the early portion of saturated blowdown for an isothermal LOCE.

Proper pressurizer modeling must include dil the important pressure loss phenomenon in the pressurizer surge line. Two-phase multipliers, rough tubing Fanning losses, and modeling of the form losses in the bends in the pressurizer surge line are important considerations in modeling the LOFT pressurizer surge line.

The next sections of the report are cuncerned with the overall pusttest modeling of LOFT LOCE LI-3A. Section 2.2 deals with modeling changes that were made in the posttest RELAP4 analysis of LOFT LOCE L1-3A. Section 2.3 discusses how these modeling changes have affected the calculational results. Comparisons are presented which show the pretest predictions, the experimental data, and a new RELAP4 run (designated as L135-A22), which incorporates the modeling changes discussed in Section 2.2.

\subsection{Overall Modeling Changes and Justification}

2.2.1 Improved Pressurizer Modeling. The pressurizer mode1, which is discussed in Section 2.1 of this report, was incorporated into the RELAP4 model of the LOFT system and run on the computer for the posttest analysis of LOCE L1-3A. This run, which also incorporates other modeling changes discussed in the following sections of this report, is referred to as the posttest analysis run (L135-A22). 
2.2.2 Using Measured Experiment Ll-3A Initial Conditions. In the posttest analysis run for LOCE L1-3A, the measured initial pressures, temperatures, flow rates, and liquid level in the pressurizer were used as the initial conditions of the RELAP4 posttest analysis run. This was done to eliminate the uncertainty in how the initial conditions affect the comparisons of calculated and measured blowdown behavior.

2.2.3 RELAP4 Nodalization. The RELAP4 nodalization scheme was changed between the pretest and posttest analysis. Figure 18 shows the RELAP4 schematic of the pretest prediction (Run L135-B5), while Figure 19 shows the schematic of the posttest analysis run (Run L135-A22). Comparison between the two figures reveals that the system model has been renodalized in three areas: the reactor vessel, the broken loop just downstream of the reflood assist bypass piping, and the accumulator.

The accumulator was treated as a fill junction in the posttest analysis run, hence the accumulator has no volume number. ECC modeling is discussed in Section 2.2.4.

A volume was added in the 28.4-cm ID piping (14-inch Schedule 160) in the broken loop hot and cold legs. This was done so that junctions would exist in the broken loop at the location of the drag disc. turbine and densitometer instrument locations. Subsequent analys is revealed that this was unnecessary since the fluid conditions just downstream of these added junctions are êssentially identical and are just as useful for data comparisons.

The significant difference between the pretest and posttest RELAP4 nodalization is due to the changes in reactor vessel nodalization. Analysis of the output of the pretest prediction run revealed that when ECC injection began, the lower plenum was only approximately haif full. Futhermore, the pressure in the lower plenum tended to follow the saturation pressure of the temperature of the fluid in the lower plenum, until the lower plenum herame liquid full. This caused the RELAP4 calculated primary system pressure to follow the lower plenum saturation 


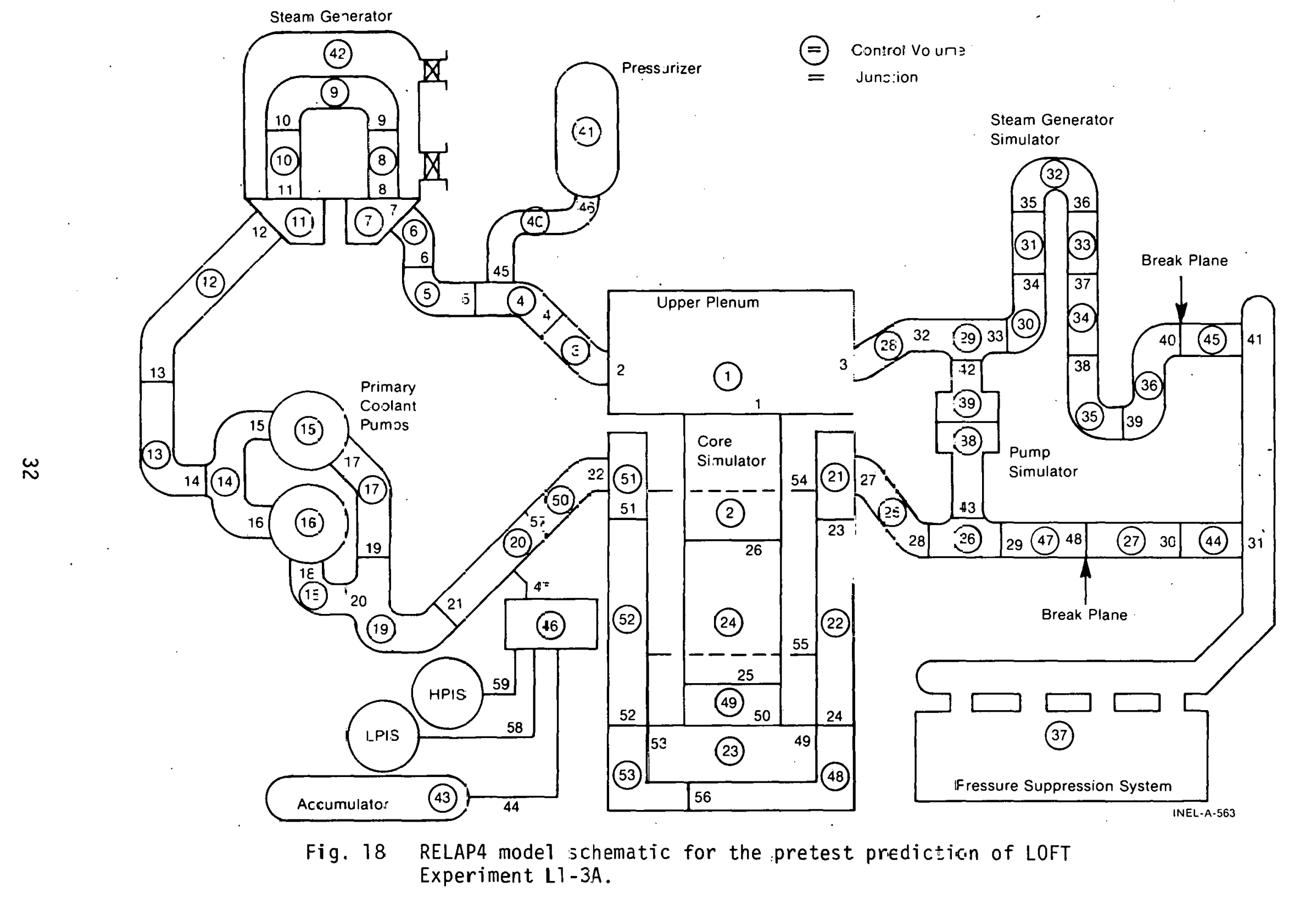




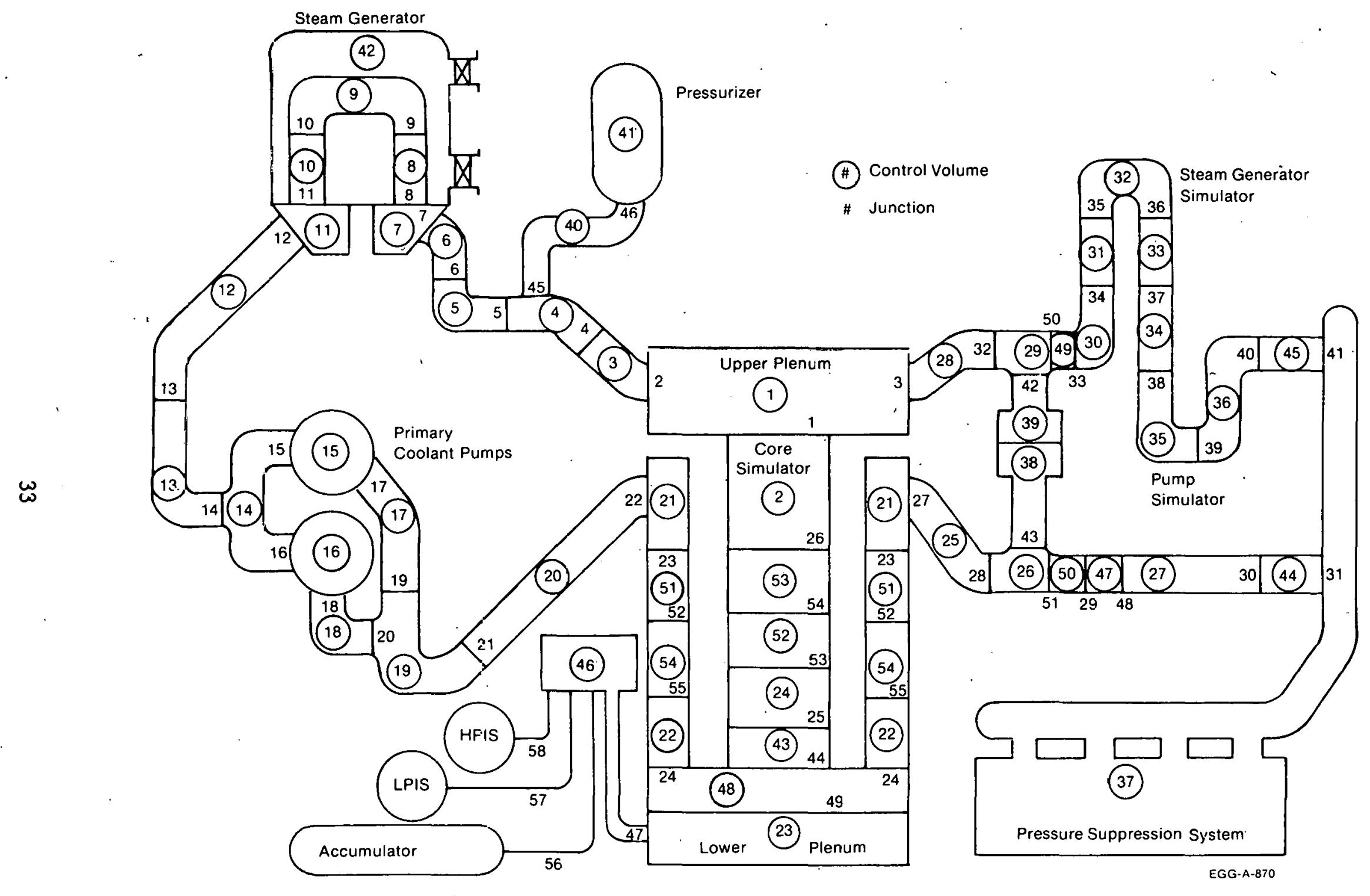

Fig. 19' RELAP4 model schematic for the posttest analys is of LOFT Experiment LI-3A. 
pressure, which was below the experimental data for the ECC filling period. It was felt that by reducing the volume of the control volume in which ECC flow was being directed, the time period in, which this phenomenon occured would be reduced. Therefore, the lower plenum was divided into more volumes, which allow quicker subcooling in the volume in the lower plenum in which ECC was directed.

As soon as the volumes in the lower plenum become liquid full, the fluid conditions in those volumes become subronied. Thus the fluid conditions at the junctions between the lower plenum and the downcomer and the lower plenum and core volumes become subcooled when the lower plenum becomes liquid full. By dividing the downcomer and core volumes into three volumes each, it was again attempted to minimize the volumes in which steam condensation was occurring and thereby minimize the effect of steam condensation on the depressurization.

Dividing the downcomer and lower plenum into several verticaliy stacked volumes also provides a better means of (a) tracking temperatures measured at the lower plenum and downcomer temperature probes and (b) damping the large manometer-type oscillations that were observed in the calculated behavior of the downcomer - lower plenum core regions.

2.2.4 ECC Modeling. In the RELAP4 posttest analysis, the measured ECC flows from the experimental data were input in the RELAP4 run as a function of time. This was done to eliminate the uncertainty of how overpredicting ECC flow rates affects system behavior during the refill and reflood portion of the transient.

Accurate calculation of accumulator flow depends strongly on calculating the pressure difference across the accumulator injection line. RELAP4 tended to overpredict (a) accumulator pressure as a function of accumulator liquid volume and (b) depressurization which occurs in the primary system when the subcooled ECC fluid begins to flow. Subsequent modeling activities revealed that RELAP4 tended to expand the accumulator nitrogen as if it were a constant temperature 
process. The experimental data suggested that the accumulator nitrogen expansion is more nearly an isentropic process. This led to the development of a polytropic nitrogen expansion model, which was used in the prediction analysis for LOFT Experiment L1-4 ${ }^{[10]}$. This model was not available in time for the posttest analysis of LOFT LOCE LT-3A.

2.2.5 Code Changes. The posttest RELAP4 analysis was run on a special version of RELAP4/MOD5 (Update 2) which was identical to RELAP4/MOD5 (Update 2) except a steam generator secondary heat transfer model was added which accounts for natural convection heat transfer in the steam generator secondary side.

Detailed input and time zero output listings of the posttest analysis run may be found in Appendix $B$.

\section{3 Data Comparisons}

This section of the report discusses comparisons of the posttest analysis run with the experimental data and the pretest prediction for various time periods during the LOCE $L T-3 A$ blowdown.

2.3.1 Early Blowdown System Behavior. The effects of pressurizer modeling and initial condition differences on early blowdown behavior are discussed with this first series of graphs. Figures 20 through 23 show comparisions between calculated and measured fluid temperatures during early blowdown. In these short-term plots, it should be kept in mind that the uncertainty in the temperature measurements is approximately $2.5^{\circ} \mathrm{C}$. The RELAP4 data, both pretest and posttest, are within the uncertainty of the measurement. The posttest initial conditions were found by taking an arithmetic average of different temperatures around the intact loop. The posttest analysis, in general, is in better agreement with the shape of the temperature curves, but tends to differ in magnitude slightly from transducer to transducer. 


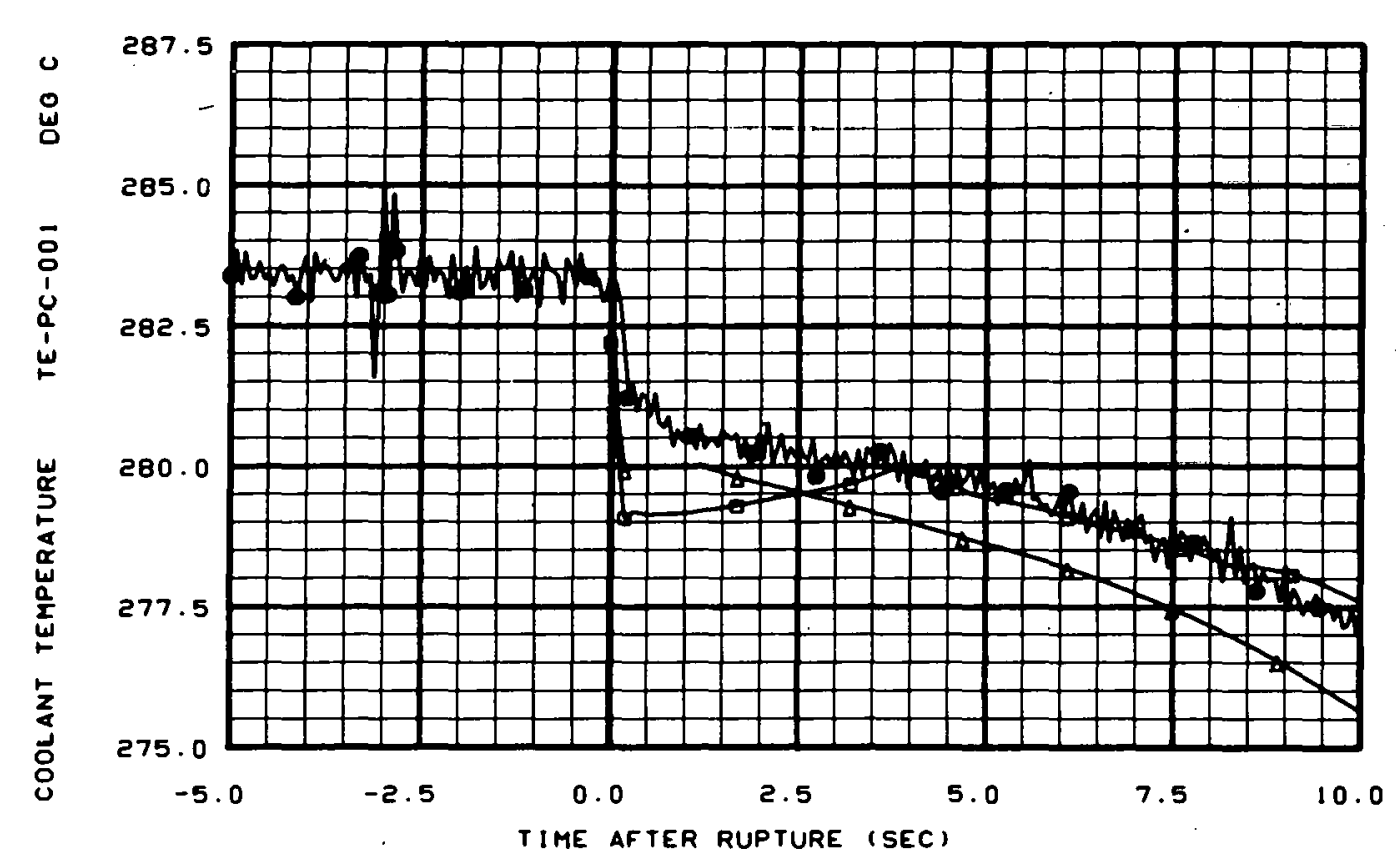

DOT=LI-3A DATA, SQUARE=PRETEST RELAP4. TRIANOLE=L135-A22 RELAPU

Fig. 20 Comparison of RELAP4 calculated and experimentally measured fluid temperature in intact loop cold leg.

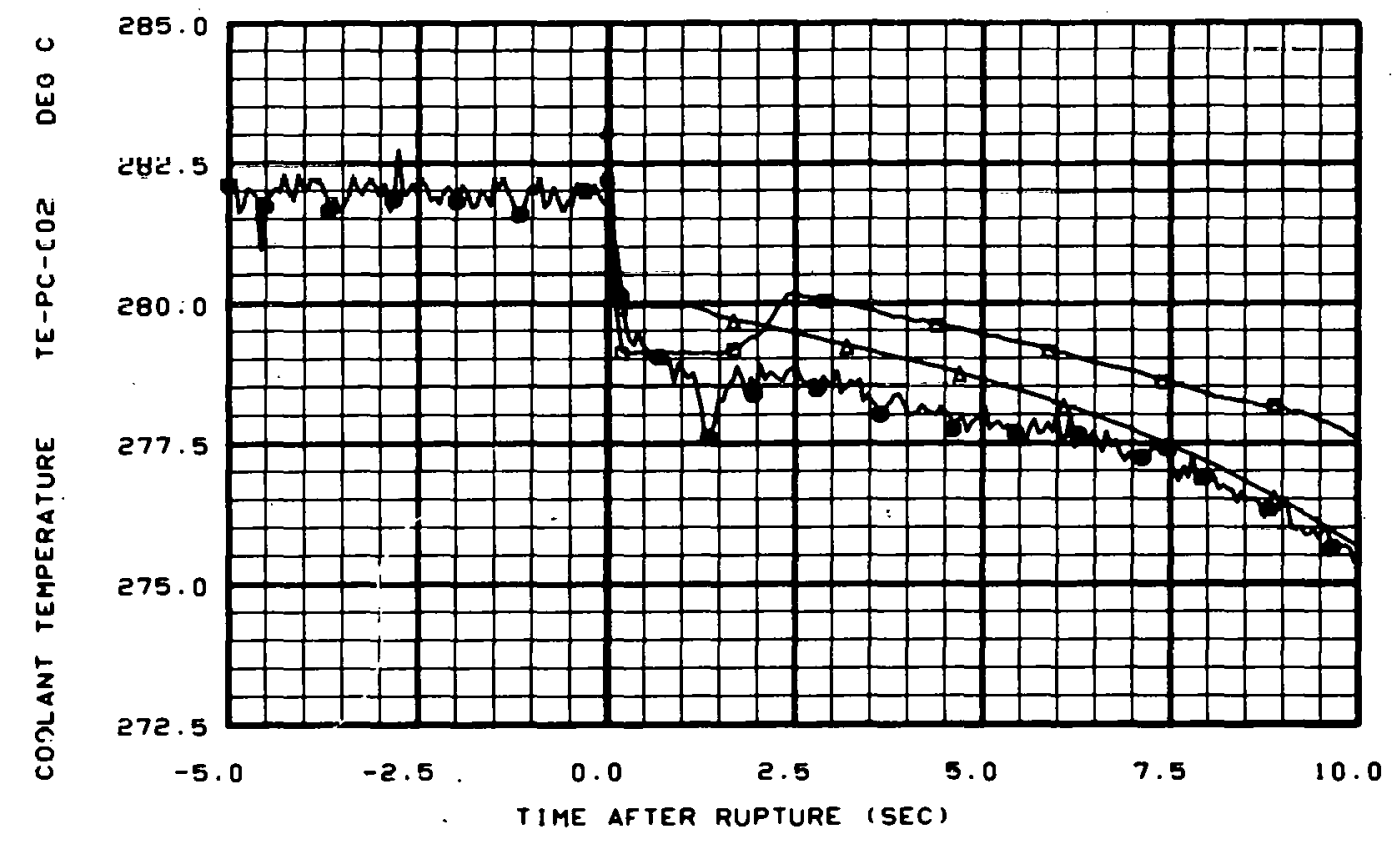

DOT $=$ LI-3A DATA, SQUARE=PRETEST RELAP4, TRIANOLE=L I35-AZ2 RELAP4

Fig. 21 Comparison of RELAP4 calculated and experimentally measured fluid temperature in intact loop hot leg. 


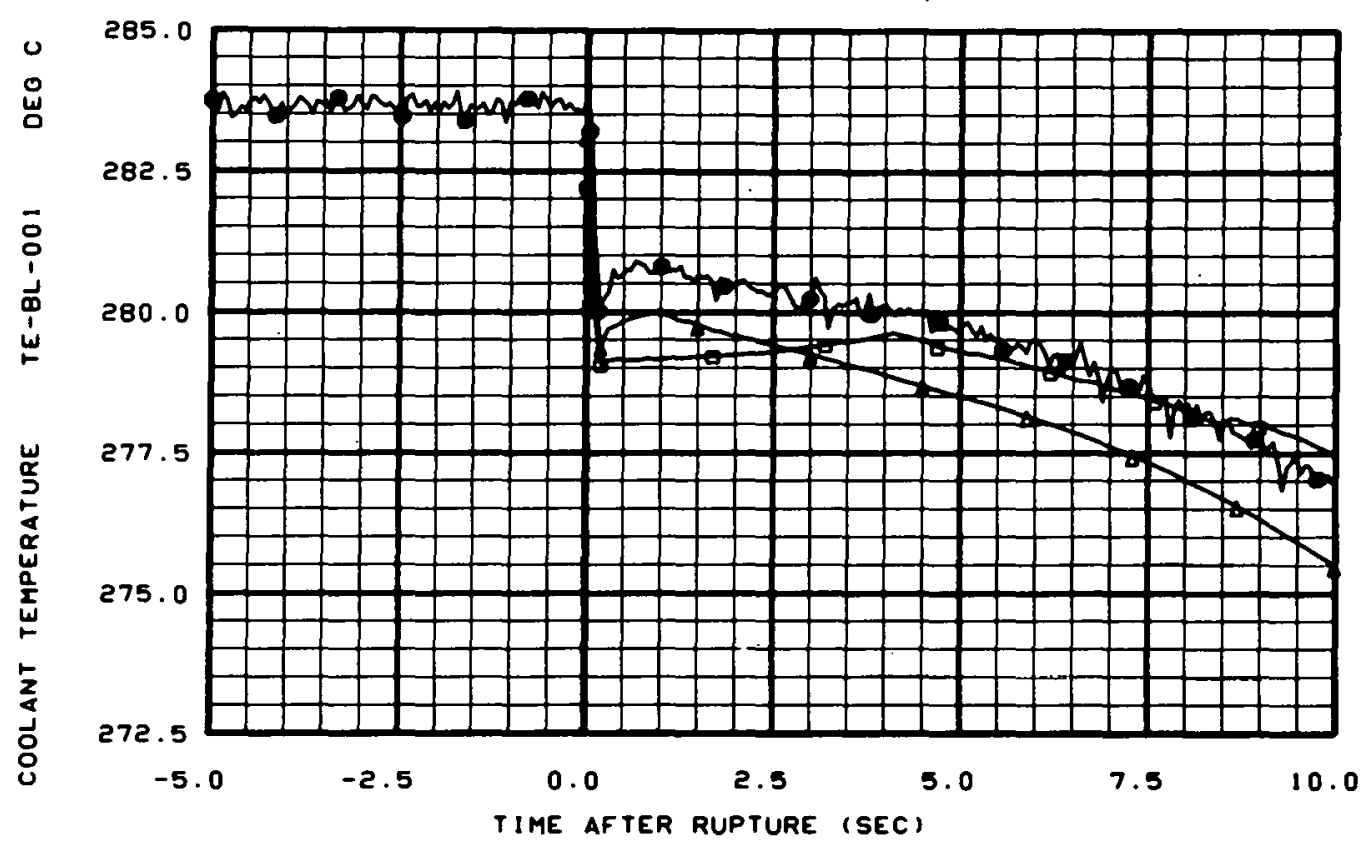

OOT=LI-3A DATA: SQUARE=PRETEST RELAP4, TRIANOLE-LI35-ARE RELAPU

Fig. 22 Comparison of RELAP4 calculated and experimentally measured fluid temperature in broken loop cold leg.

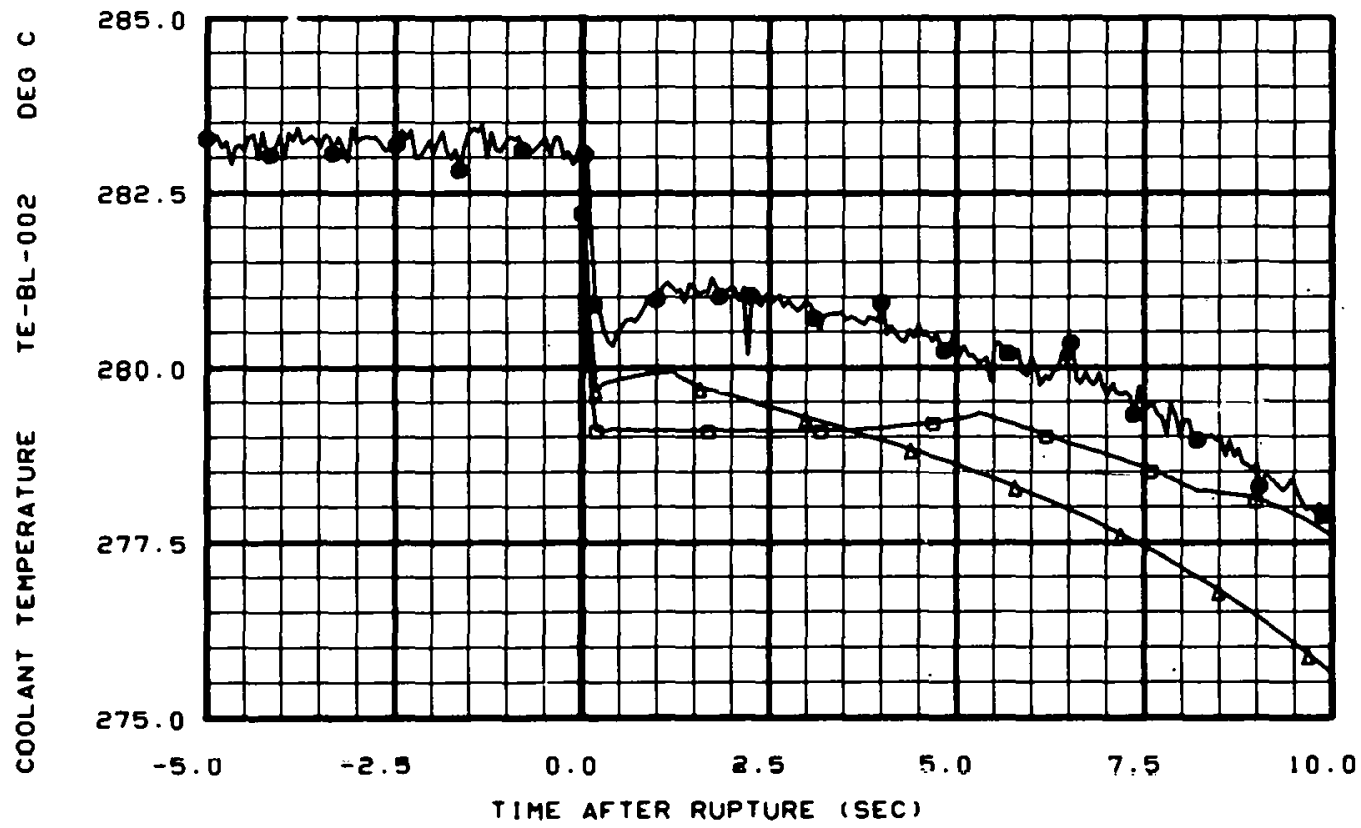

DOT=L1-3A DATA. SQUARE-PRETEST RELAP4, TRIANOLE=L I35-AZ2 RELAPU

Fig. 23 Comparison of RELAP4 calculated and experimentally measured, fluid temperature in broken loop hot ley. 
The pressures in the intact and broken loops can be seen in Figures 24 and 25. The uncertainty in the measured pressure is approximately $0.26 \mathrm{MPa}$, and again the pretest and posttest RELAP4 runs are within the uncertainty of the measurements. The primary system pressure is slightly lower for the posttest analysis run primarily due to the effects of the pressurizer modeling. This makes for an overall better agreement with the data. 


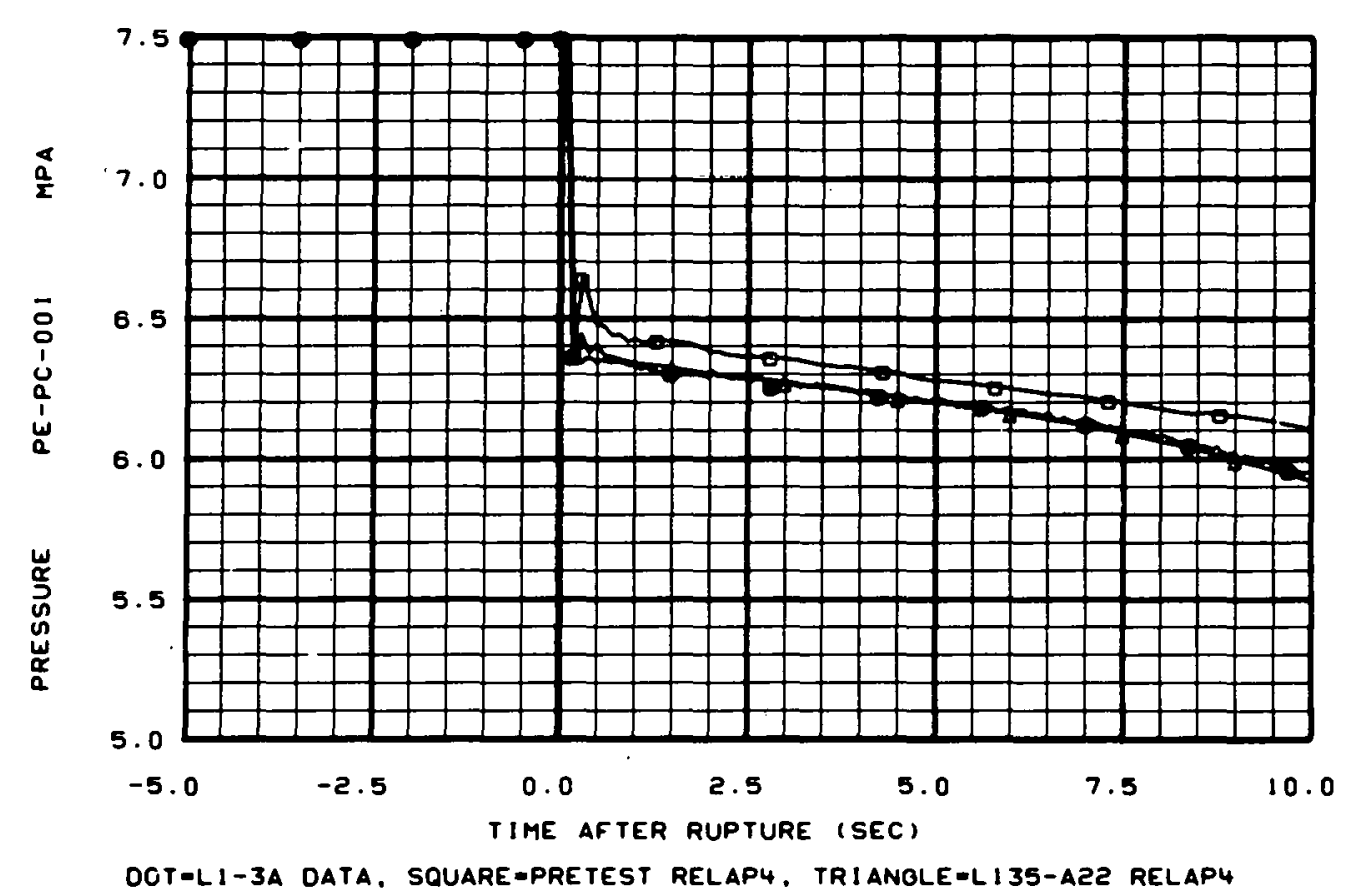

Fig. 24 Comparison of RELAP4 calculated and experimentally measured pressure in intact loop cold leg.

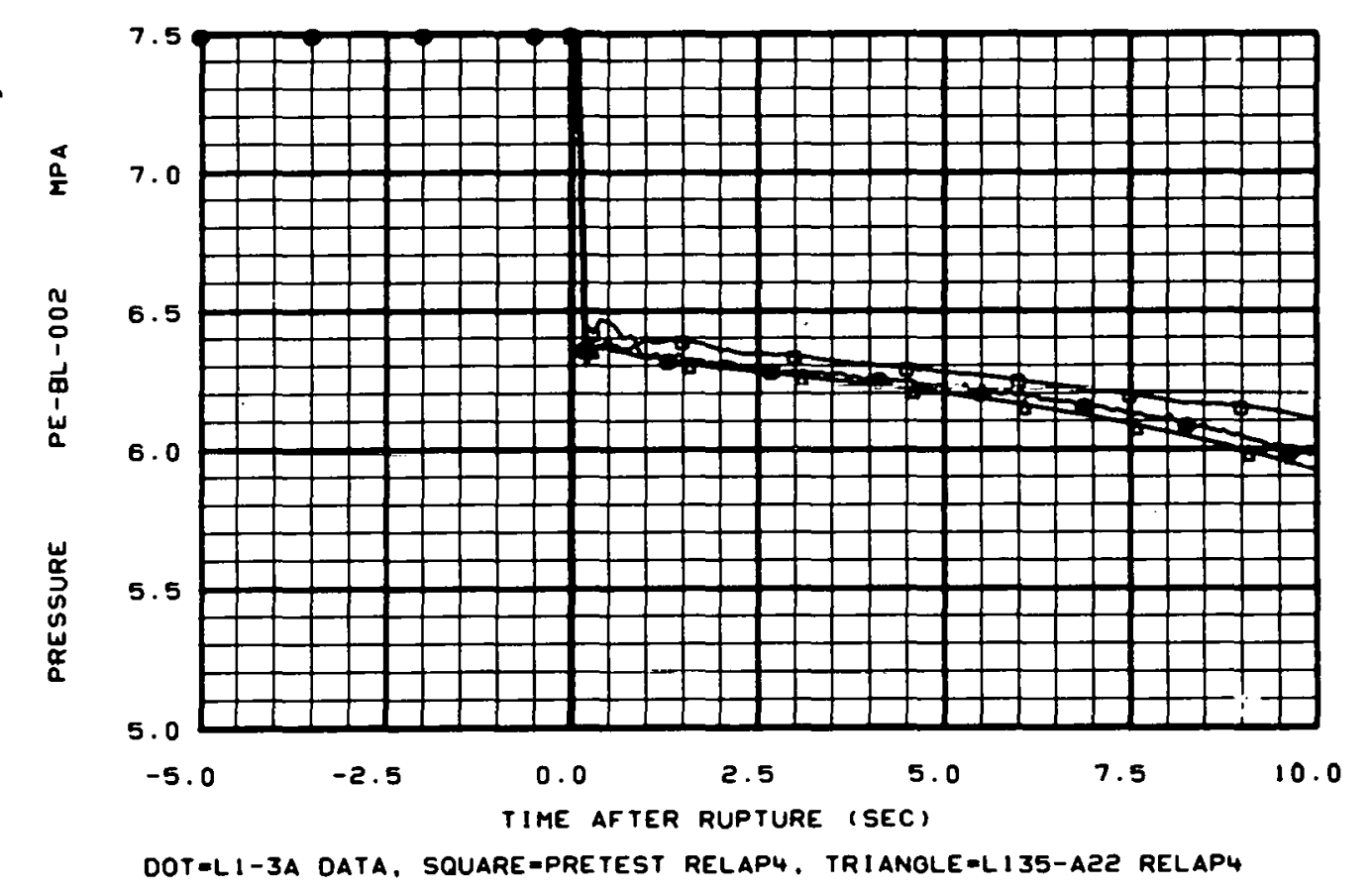

Fig. 25 Comparison of RELAP4 calculated and experimentally measured pressure in broken loop hot leg. 
Figures 26 and 27 show the density behavior in the intact and broken loops during early blowdown. As discussed in Section 2.1, the early blowdown density behavior is improved with the new pressurizer model. In general, the fluid begins flashing sooner in the posttest anaiysis. In Figure 27, the time that the flow reversal takes place in the intact loop hot leg is better predicted in the posttest analysis run. 


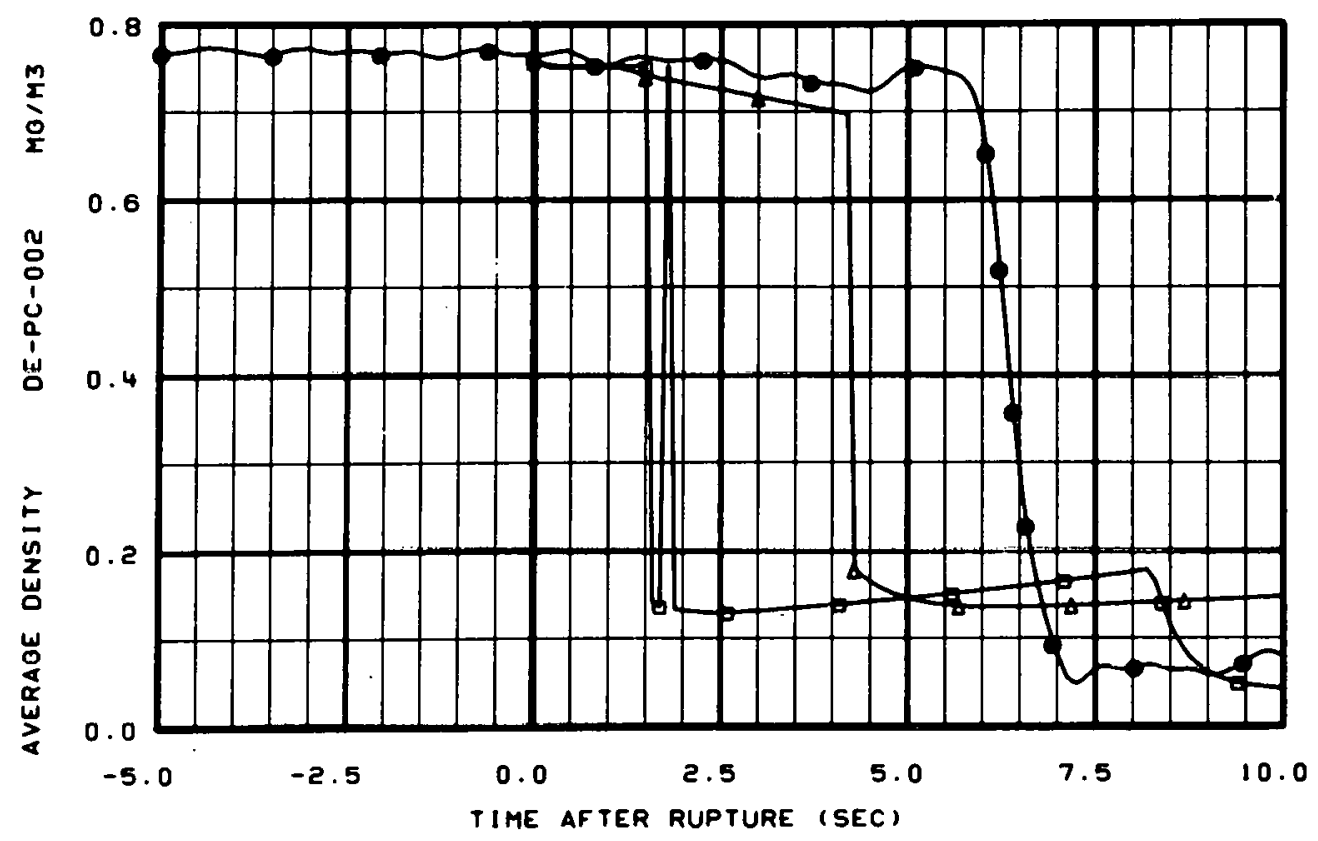

DOT-LI-3A DATA, SQUARE-PRETEST RELAPY, TRIANOLE=L135-AZ2 RELAPY

Fig. 26 Comparison of RELAP4 calculated and experimentally measured density in intact loop hot leg.

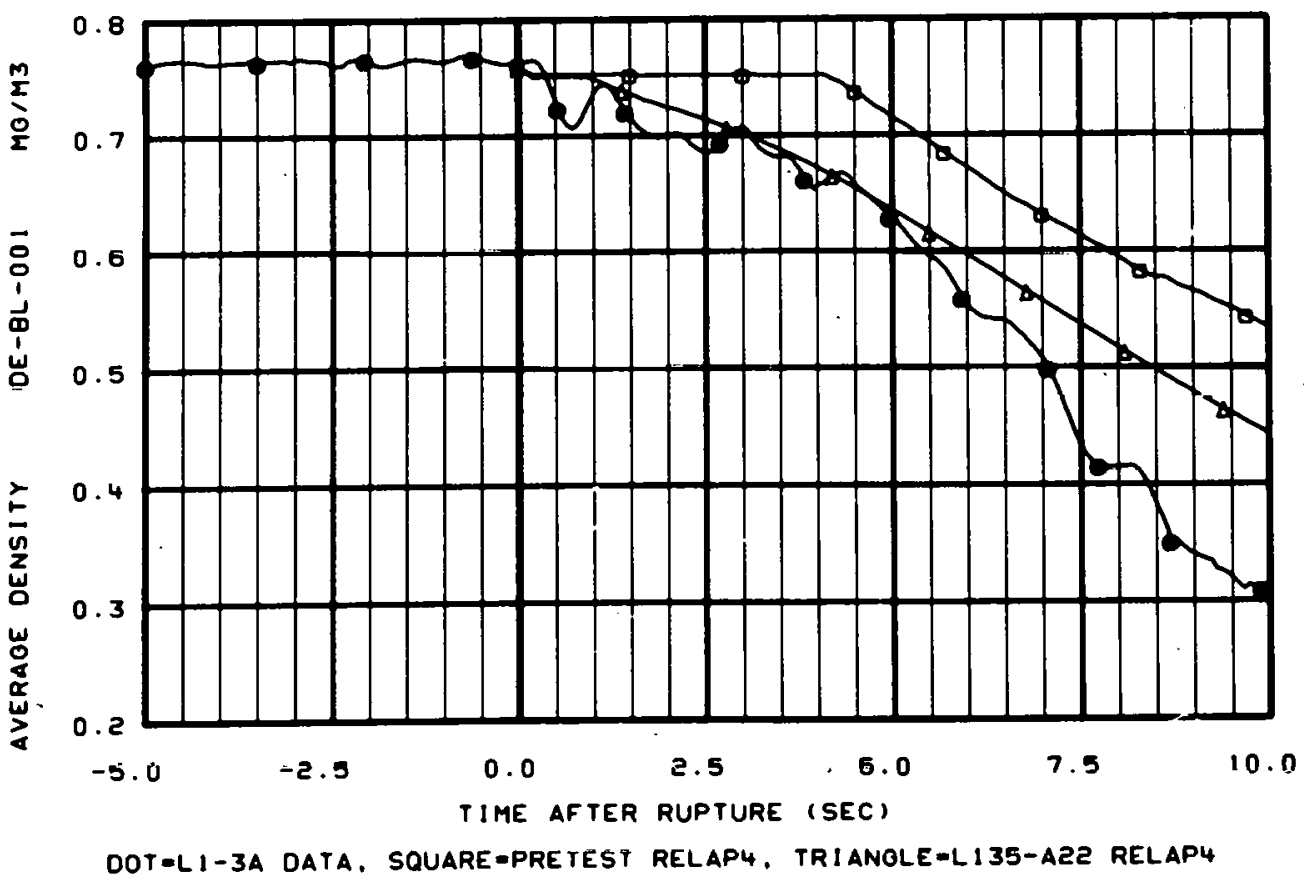

Fig. 27 Comparison of RELAP4 calculated and experimentally measured density in broken loop cold leg. 
The next two figures (Figures 28 and 29) show comparisons between calculated and measured differential pressures around the intact loop. In Figure 28 the pump is shown to degrade faster in the posttest analysis run: This can be largely attributed to the faster flashing in the pump inlet, due primarily to the differences in the pressurizer modeling: The pressure across the steam generator is less in the posttest analysis run, while the differential pressure across the reactor vessel is largely unaffected. 


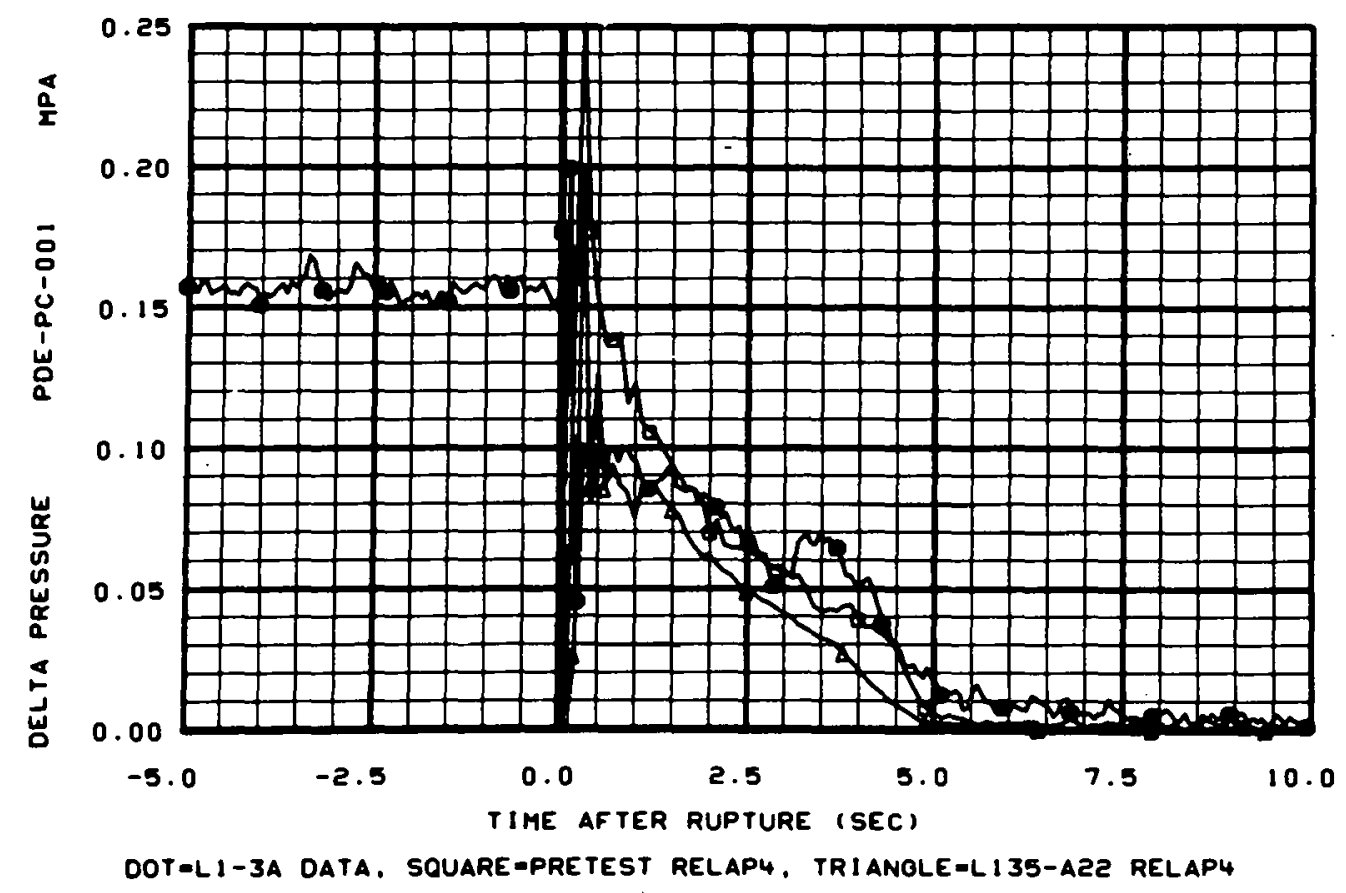

Fig. 28 Comparison of RELAP4 calculated and experimentally measured differential pressure across primary coolant purnp.

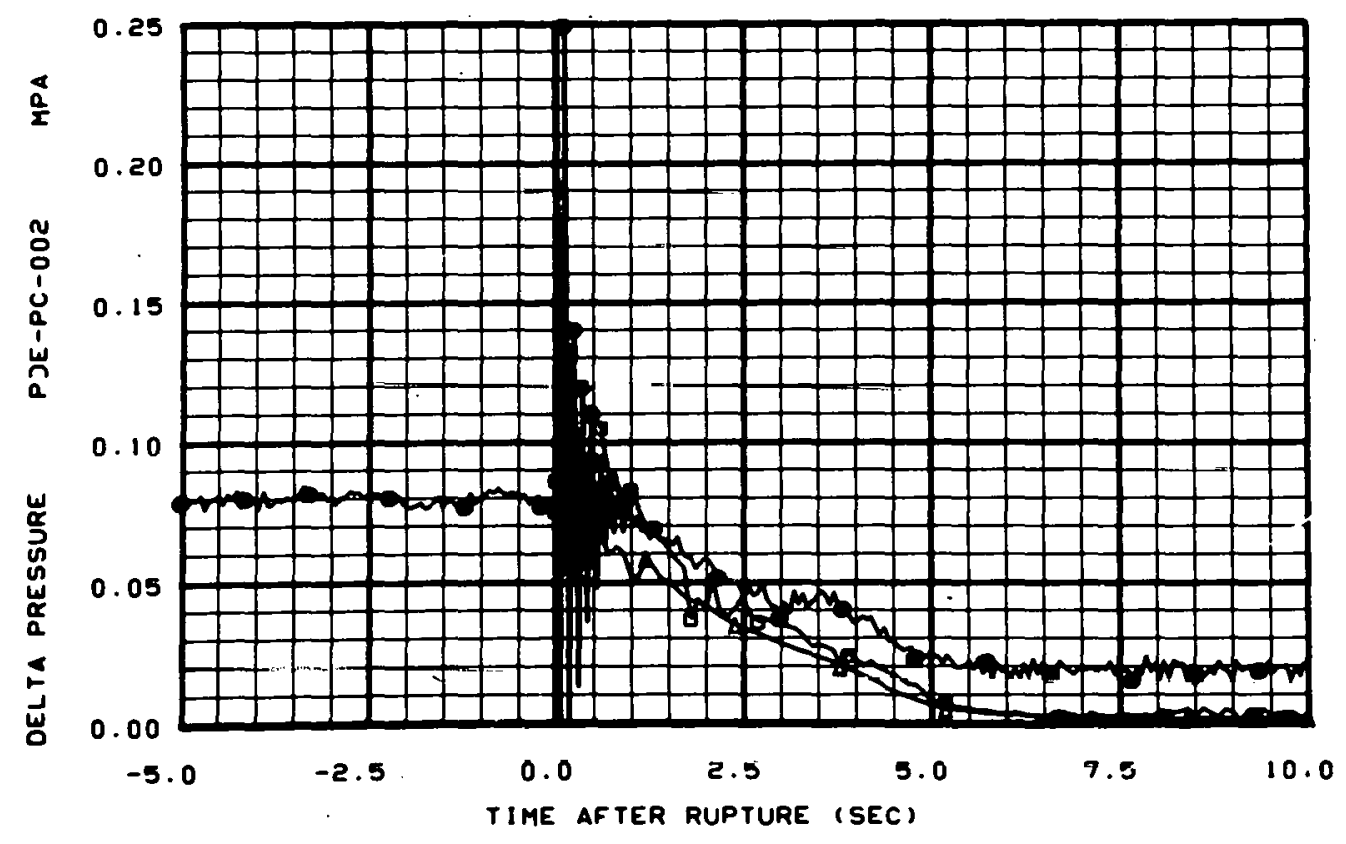

DOT-L1-3A OATA. SQUARE-PRETEST RELAPU, TRIANOLE=L135-AZ2 RELAP4

Fig. 29 Comparison of RELAP4 calculated and experimentally measured differential pressure across steam generator. 
2.3.2 System Behavior After ECC Injection. In this next series of plots, the differences between the two RELAP4 runs and the experimental data are examined for the time period from just before ECC injection begins to the end of blowdown.

Figures 30 and 31 show the. RELAP4 calculated and experimentaliy: measured accumulator and low-pressure injection system (LPIS) flows. The posttest analysis is in good agreement since the ECC flows were input as a function of time and taken from the experimental data. The high-pressure injection system (HPIS) flow, which is not shown, is also in good agreement, both in the pretest and posttest. RELAP4 runs. The overprediction of accumulator flow in the pretest prediction is due to the following factors:

(1) The primary system pressure is underpredicted, especially after ECC injection begins, due primarily to the excessive steam condensation predicted by RELAP4.

(2) The accumulator pressure is overpredicted as a function of accumulator nitrogen volume, due to the isothermal accumulator nitrogen expansion model in RELAP4/MOD5.

(3) The line resistance of the accumulator injection. line was too low in the pretest RELAP4/M005 calculations. This was confirmed by accumulator blowdown tests done atter the $\mathrm{LI}-3$ pretest prediction was run:

The LPIS flow is overpredicted in the pretest prediction primarity due to the underprediction of: primary system pressure. 


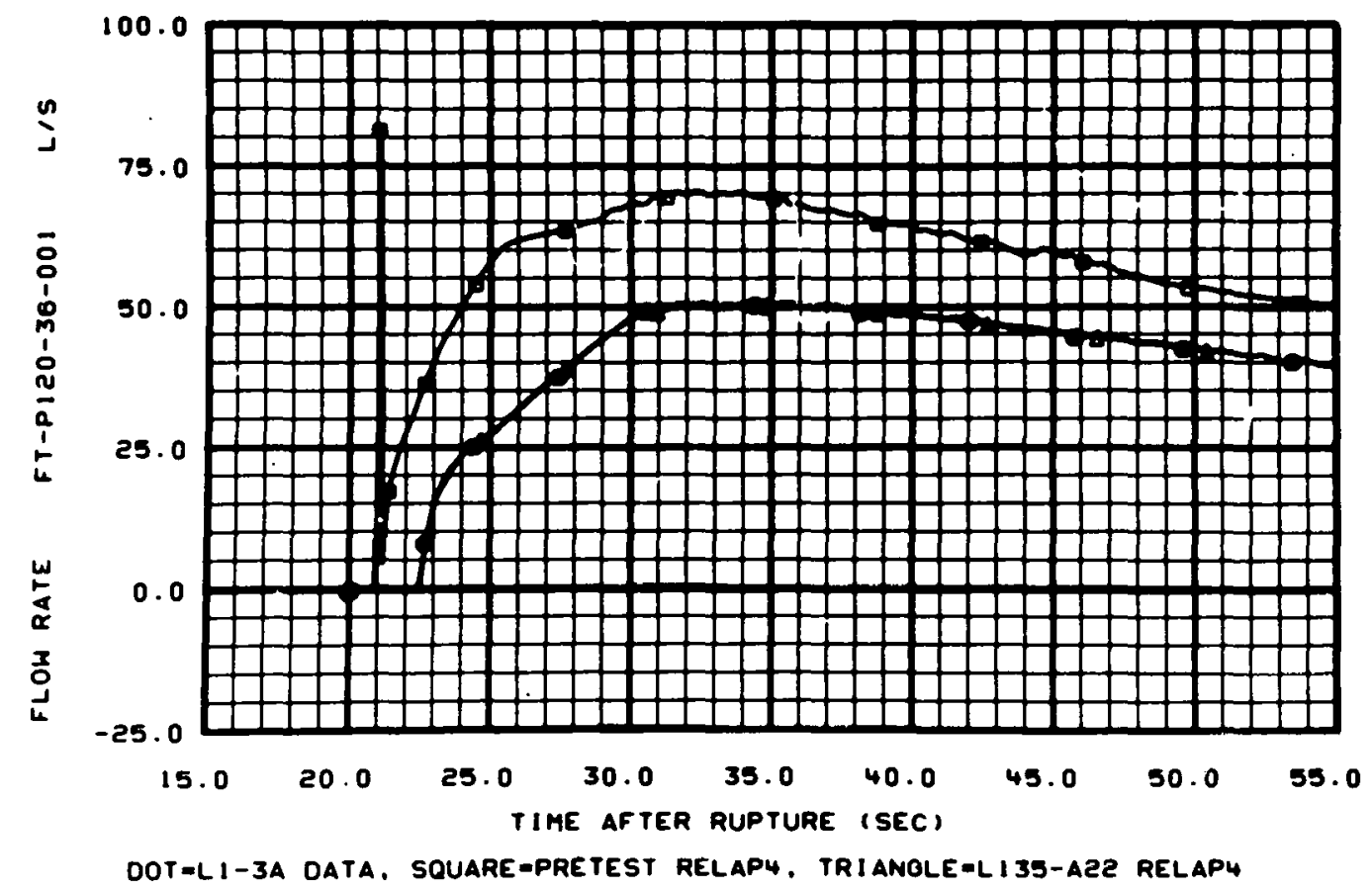

Fig. 30 Comparison of RELAP4 calculated and experimentally measured volumetric flow rate from accumulator.

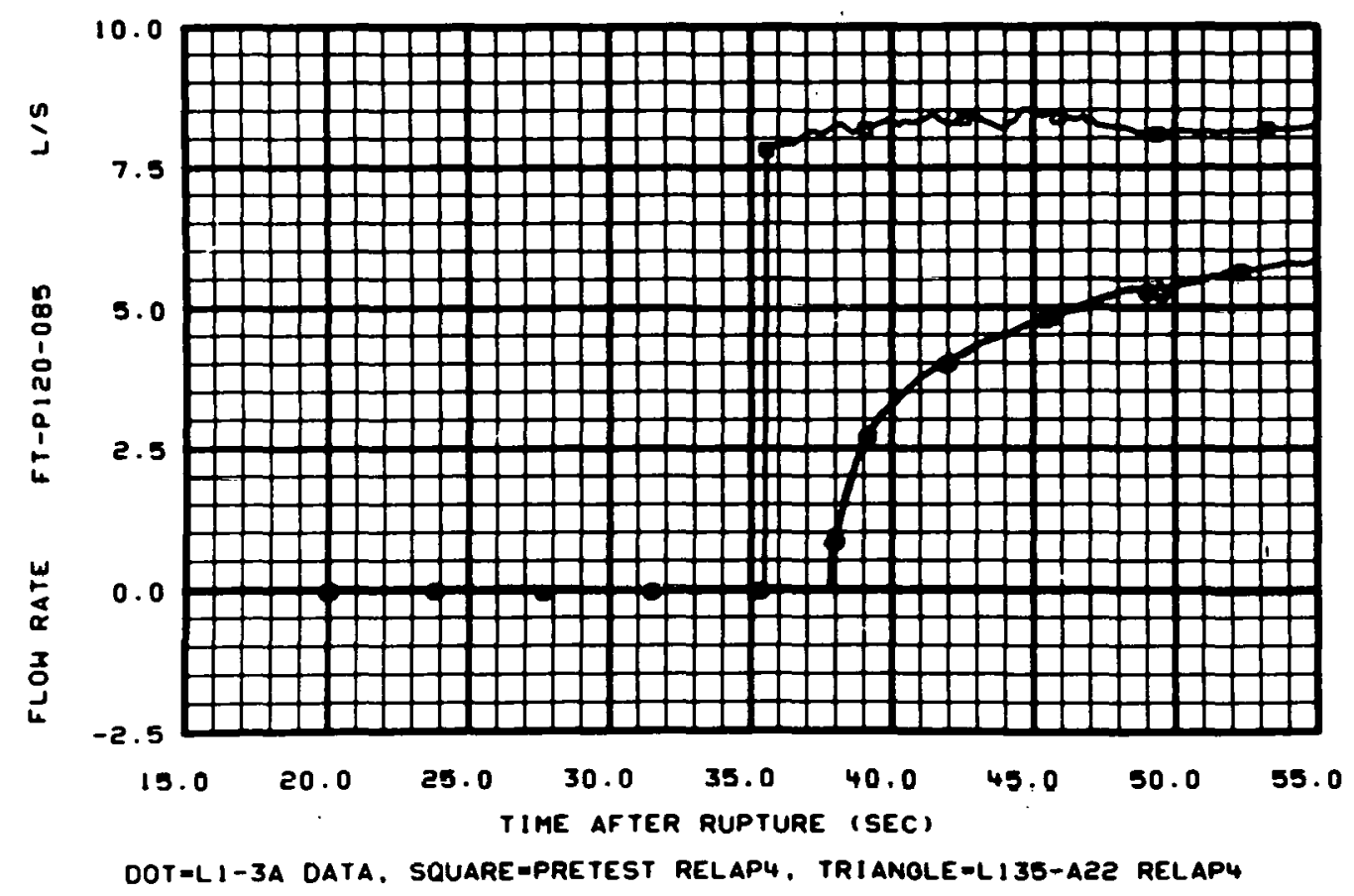

Fig. 31 Comparison of RELAP4 calculated and experimentally measured volumetric flow rate frum LPIS. 
Figures 32 through 34 show the calculated and measured pressures in the ECC injection line and in the reactor vessel core simulator. The spike in Figure 32 in the pretest prediction data is due to ECC condensation in the ECC injection line. This pressure spike causes the spike in the calculated accumulator flow seen in figure 30 . The pressure in the reactor vessel is shown in both Figures 33 and 34, with the data in Figure 33 coming from a high-range pressure transducer, and the data in Figure 34 coming from a more sensitive low-range pressure transducer.

Both RELAP4 calculations underpredict system pressure primarily due to the excessive steam condensation predicted by RELAP4 for lower plenum ECC injection experiments. The posttest analysis run is closer to the data than the pretest prediction run for two main reasons: (a) the finer nodalization in the reactor vessel tended to allow fluid in some of the control volumes in the reactor vessel to fill up, hence reducing the steam condensation in these volumes and (b) the ECC flow rates were in agreement with the data, instead of being overpredicted as in the pretest prediction run.

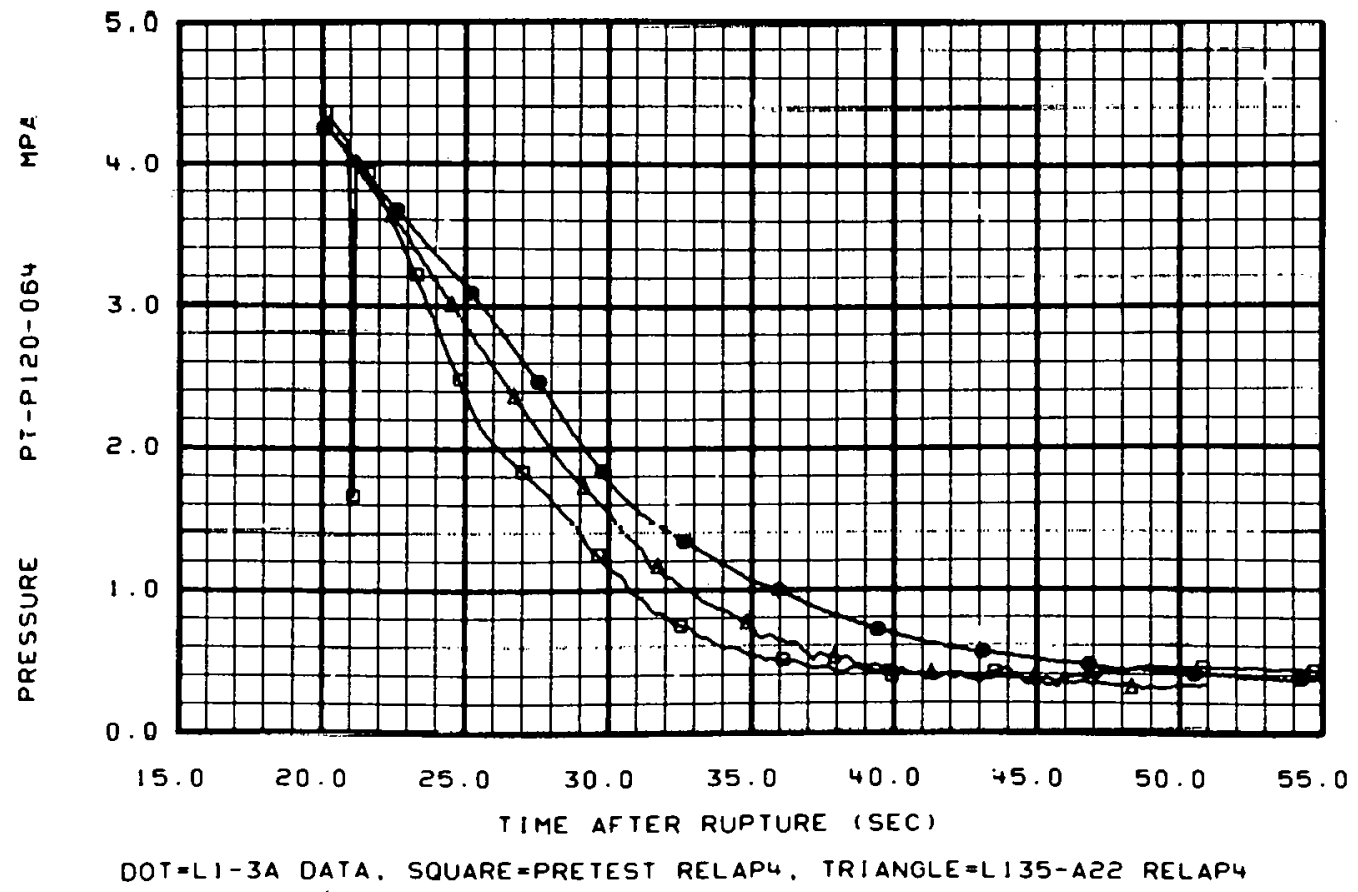

Fig. 32 Comparison of RELAP4 calculated and experimentally measured pressure in ECC injection line. 


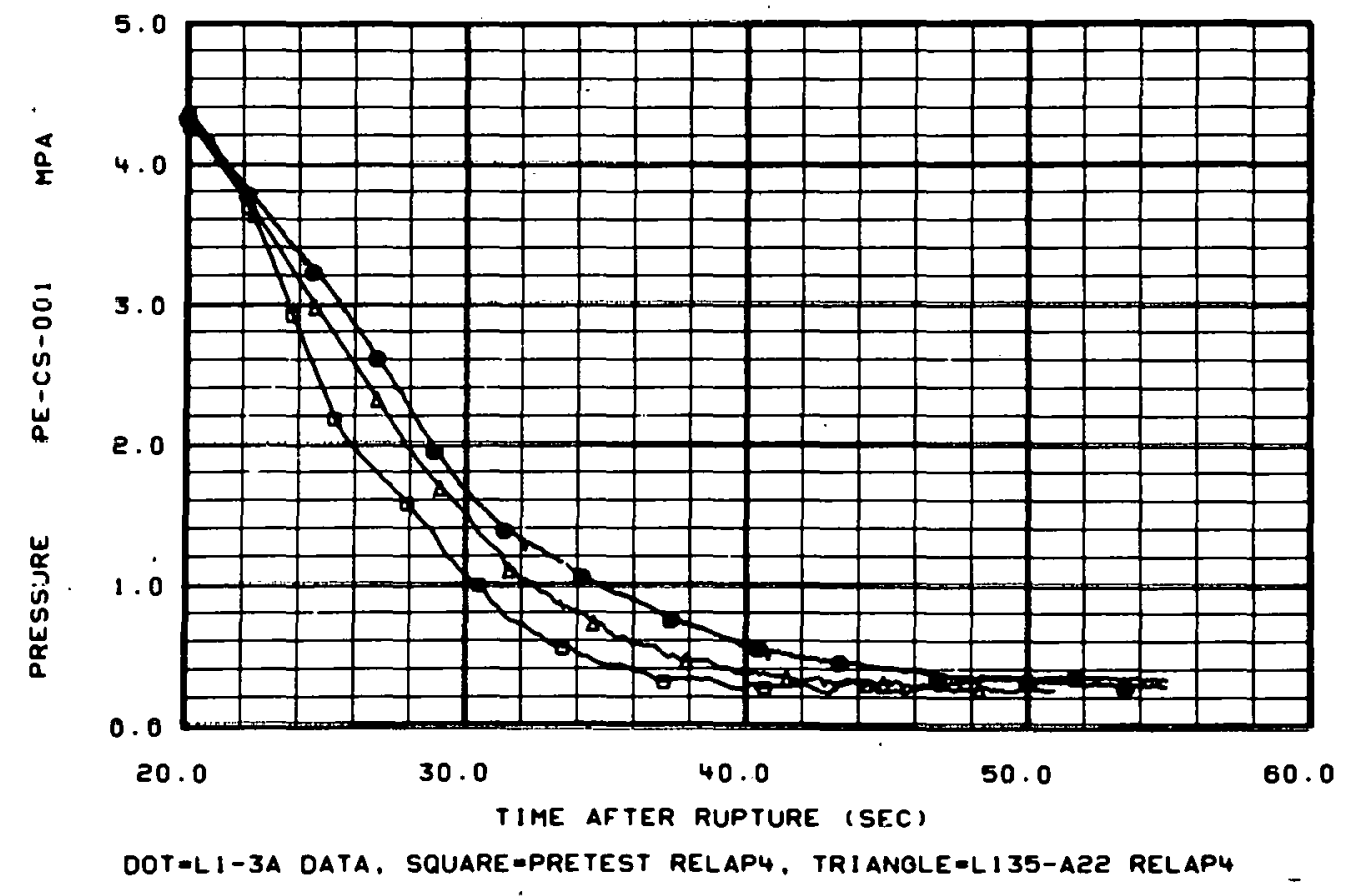

Fig. 33 Comparison of RELAP4 calculated and experimentally measured pressure in core simulator.

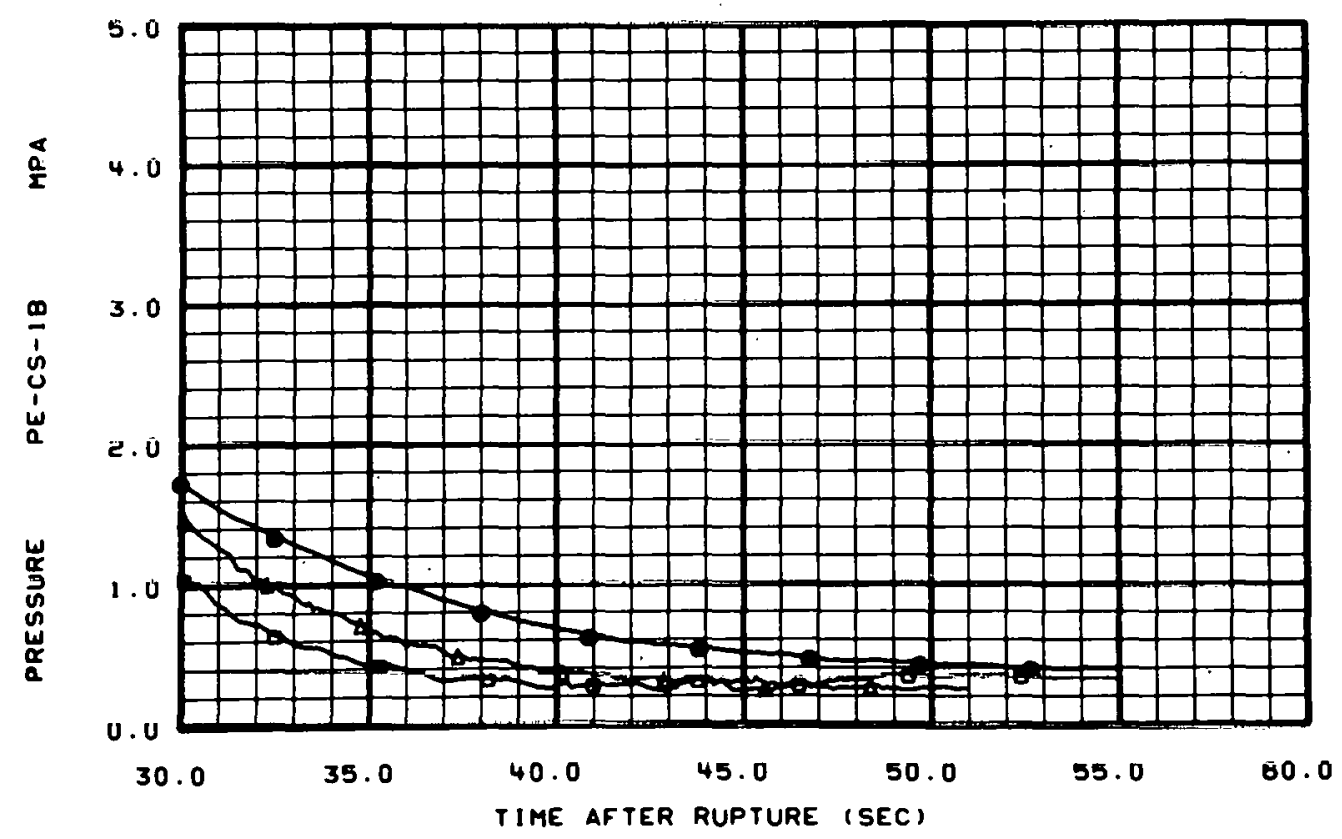

DOT=LI-3A DATA, SQUARE=PRETEST RELAP4, TRIANOLE=L135-A22 RELAP4

Fig. 34 Comparison of RELAP4 calculated and experimentally measured pressure in core simulator. 
Figures 35 through 37 show the comparisons of calculated and measured fluid temperatures in the lower plenum, downcomer, and downcomer inlet annulus during the time period following ECC injection. Except for the lowest portion of the lower plenum, the posttest analysis tracks the fluid temperatures in the lower plenum better than the pretest prediction run. This can be attributed to the finer nodalization and the better prediction of primary system pressure response which allows for a better prediction of saturation temperature as a function of time. The data in Figure 38 show the core simulator fluid temperatures, and all the curves closely follow the saturation teniperatures. 


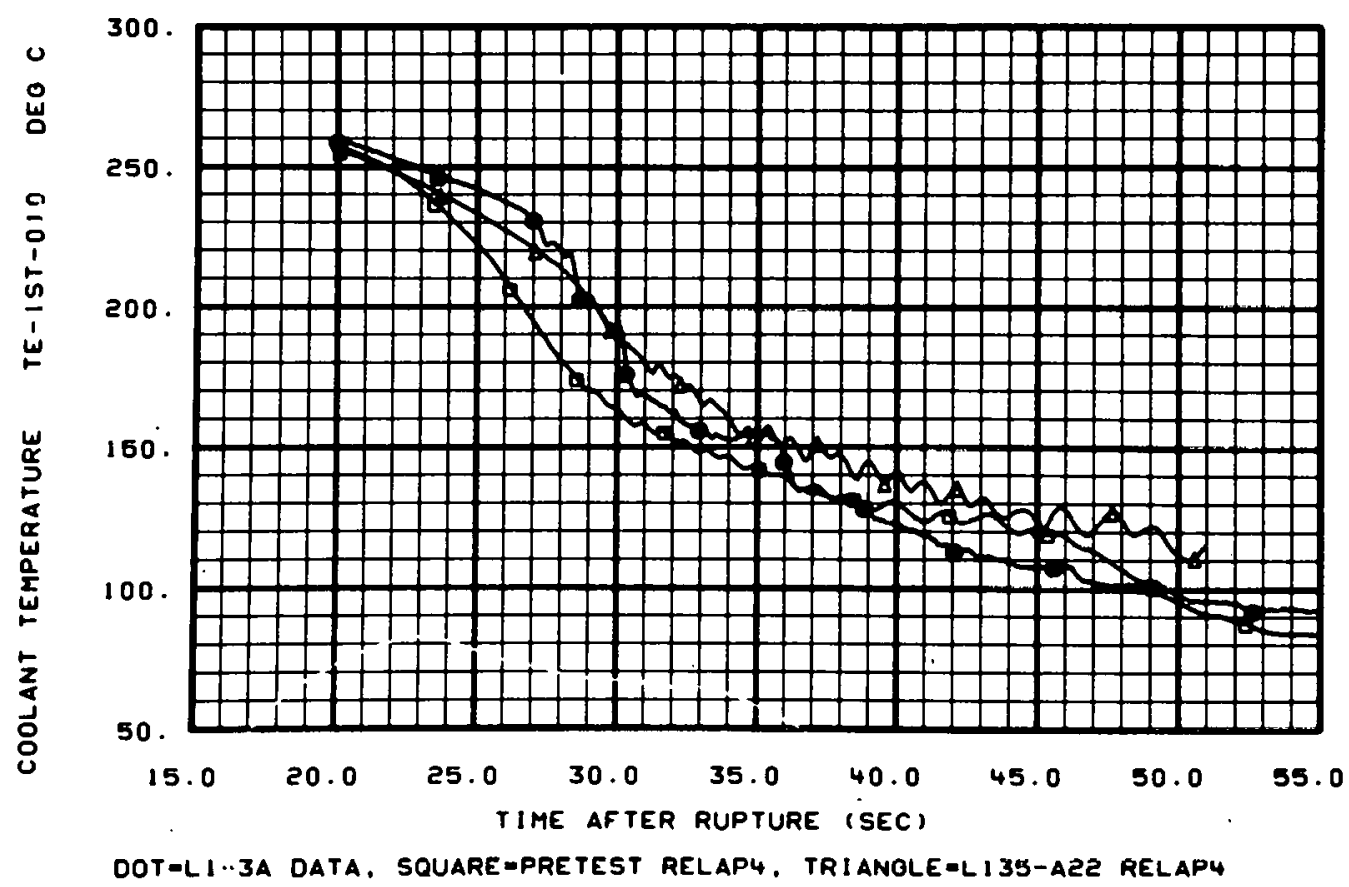

Fig. 35 Comparison of RELAP4 calculated and experimentally measured fluid temperature in lower plenum at 0.54 meters above reactor vessel bottom.

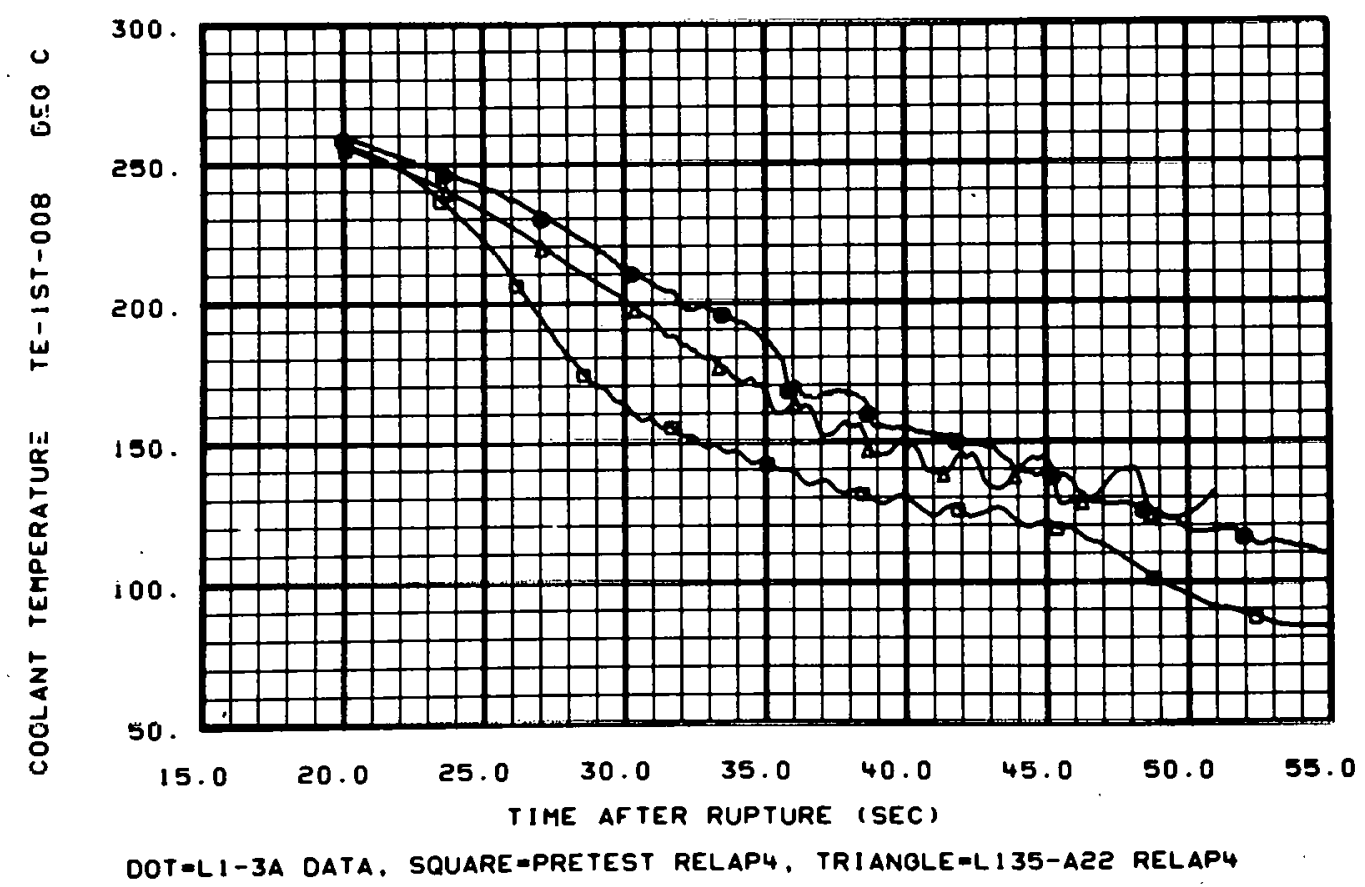

Fig. 36 Comparison of RELAP4 calculated and experimentally measured fluid temperaure in downcomer at 0.74 meters above reactor vessel bottom. 


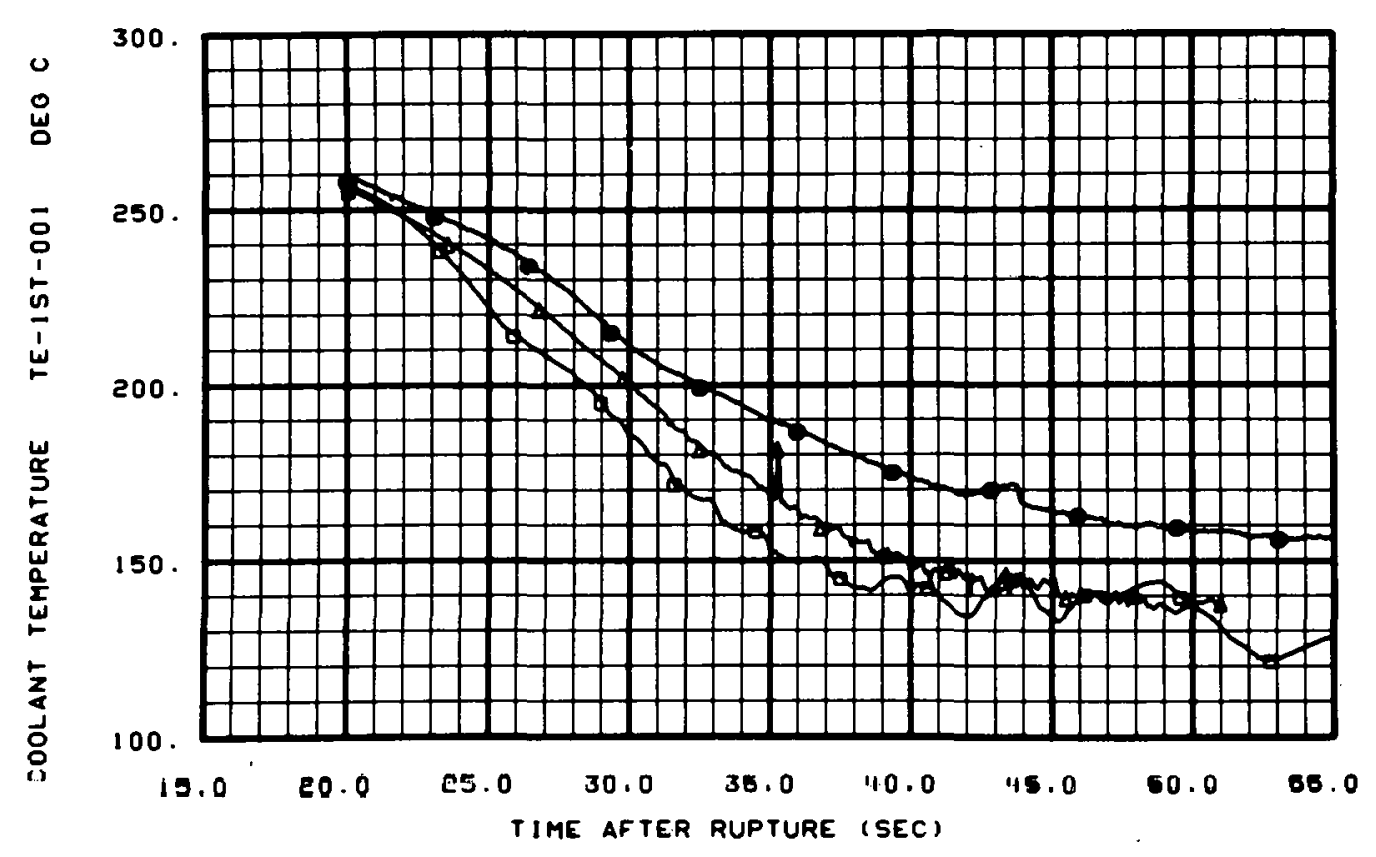

DOT=LI-3A DATA, SOUARE=PRETEST RELAP4. TRIANOLE-L135-A22 RELAPL

Fig. 37 Comparison of RELAP4 calculated and experimentally measured fluid temperature in downcomer inlet annulus at 4.81 meters above reactor vessel bottom.

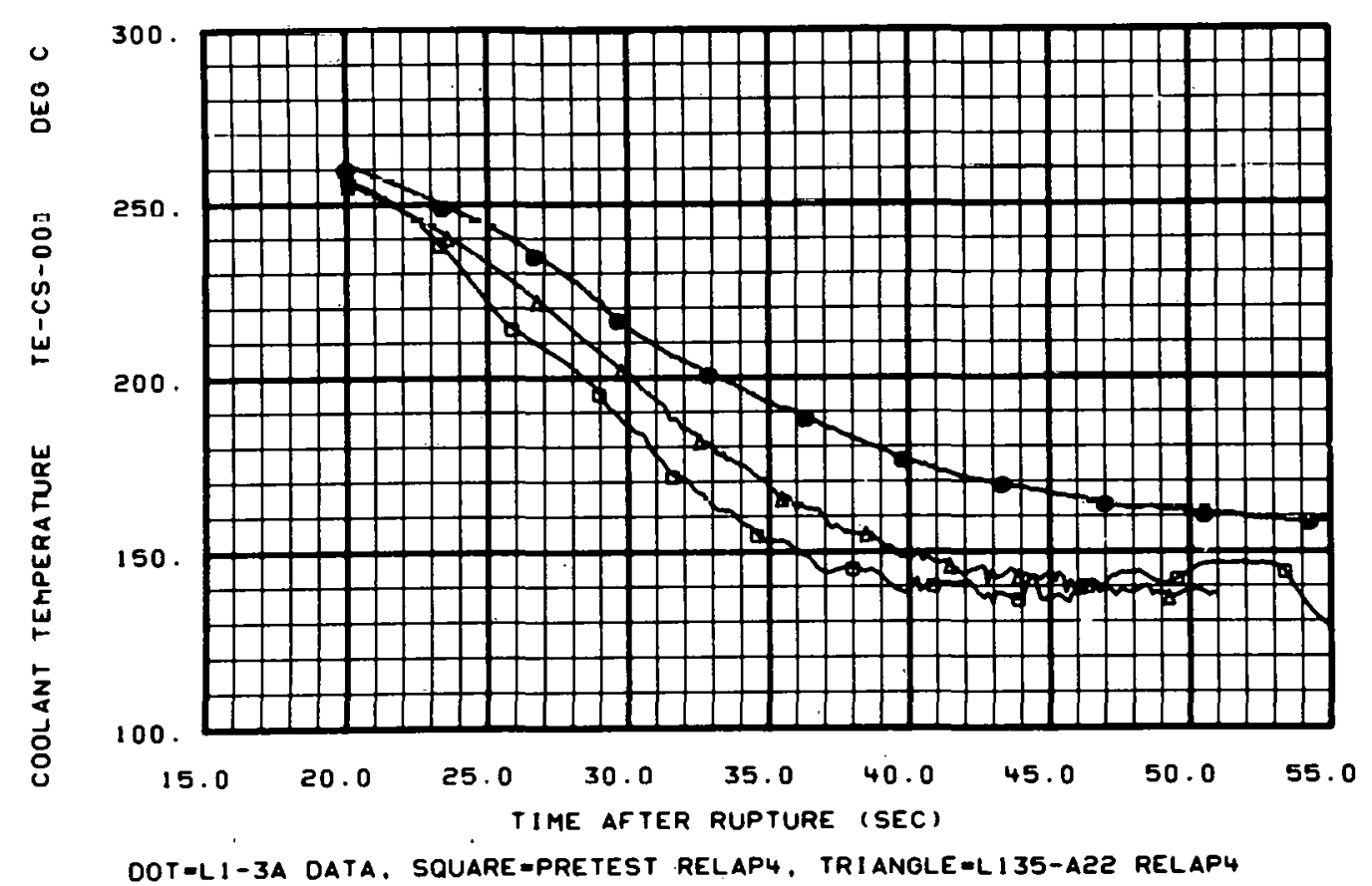

Fig. 38 Comparison of RELAP4 calculated and experimentally measured fluid temperature in core simulator. 
Figure 39 shows comparisons between the calculated and measured momentum fluxes in the downcomer. Both the pretest and posttest analyses runs show large manometer-type oscillations beginning after the lower plenum fills which are not observed in the data.

To understand the nature of these oscillations, consider figures 40 through 42. Figure 40 shows the average lower plenum void fraction from the posttest analysis run, while Figure 41 shows the average downcomer void fraction. Figure 42 shows the average liquid fraction (1-average void fraction) in the lower plenum, downcomer, and inlet annulus. As these graphs show, the oscillations tend to be diverging. 'Plots of void fraction in the core area tend to have the same oscillation frequency, but are out of phase with the oscillations in the downcomer, indicating a manometer-type oscillation.

The oscillations appear to be driven by unequal steam condensation, which is predicted to occur in the reactor vessel. When the lower plenum fills, the fluid conditions go from saturated to subcooled. Subcooled water thus begins to flow into the downcomer and lower core volumes after the lower plenum fills. Because of the larger flow area and lesser resistance, the flow rate into the core area is higher than the flow rate into the downcomer. Thus more steam is condensed in the core than is condensed in the downcomer. This causes even greater flow into the core region due to the faster depressurization in this volume. When the elevation head in the core area becomes great enough, the flow reverses, which causes subcooled water to flow into the downcomer. Because of the large flow of subcooled liquid in the downcomer, steam condensation begins over again in the downcomer instead of the core region. Thus unequal steam condensation is the mechanism which causes the undamped manometer-type oscillations which are observed in the RELAP4 calculations.

To test this hypothesis, an additional RELAP4 run was made in which the temperature of the ECC fluid was set at nearly saturation conditions during this period of the blowdown $\left(226^{\circ} \mathrm{C}\right)$. The oscillations were no longer observed, and the reactor vessel pressure was substantially 


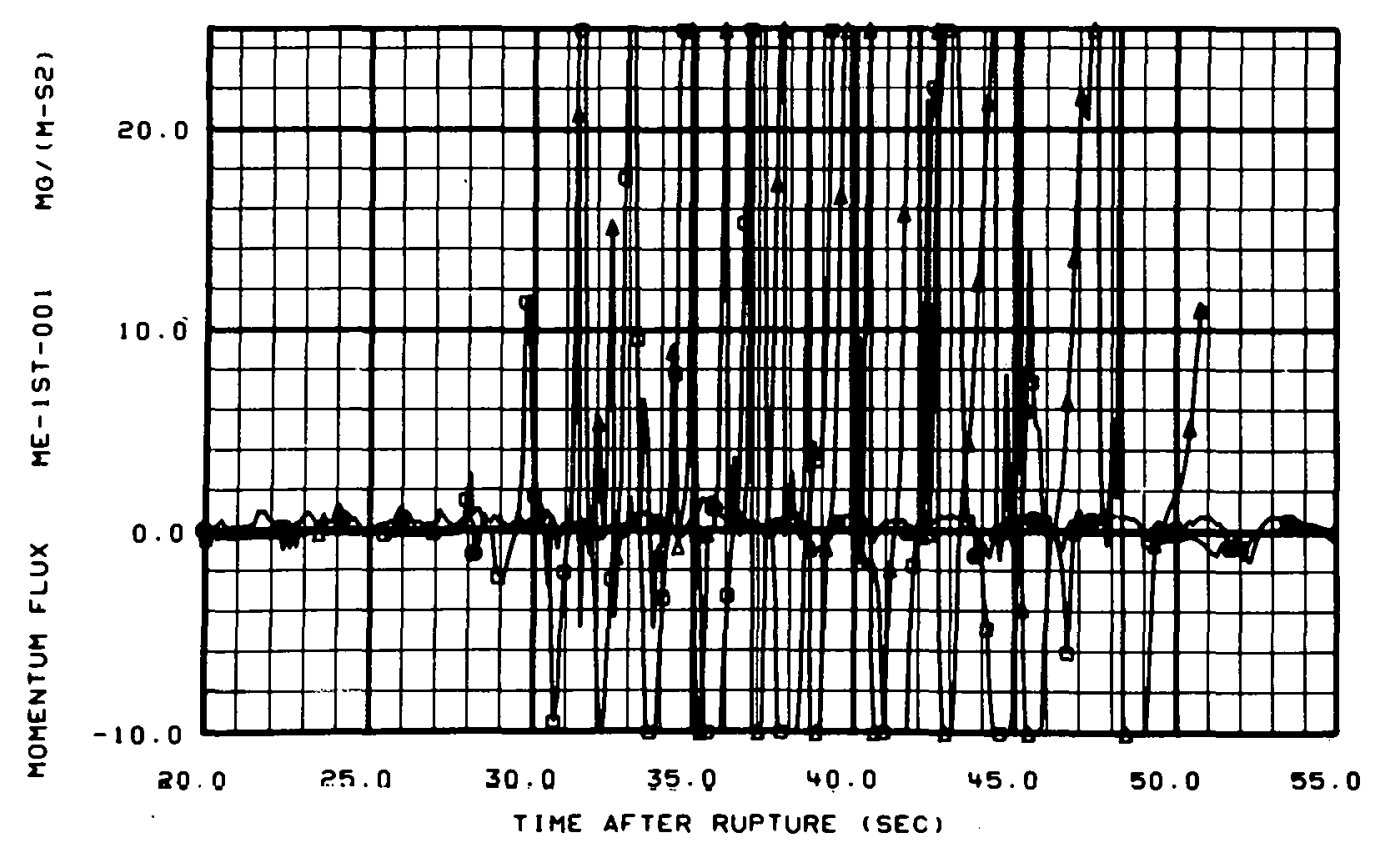

DOT=L1-3A DATA, SQUARE=PRETEST RELAP4, TRIANOLE-L135-A22 RELAP4

Fig. 39 Comparison of RELAP4 calculated and experimentally measured momentum flux in downcomer.

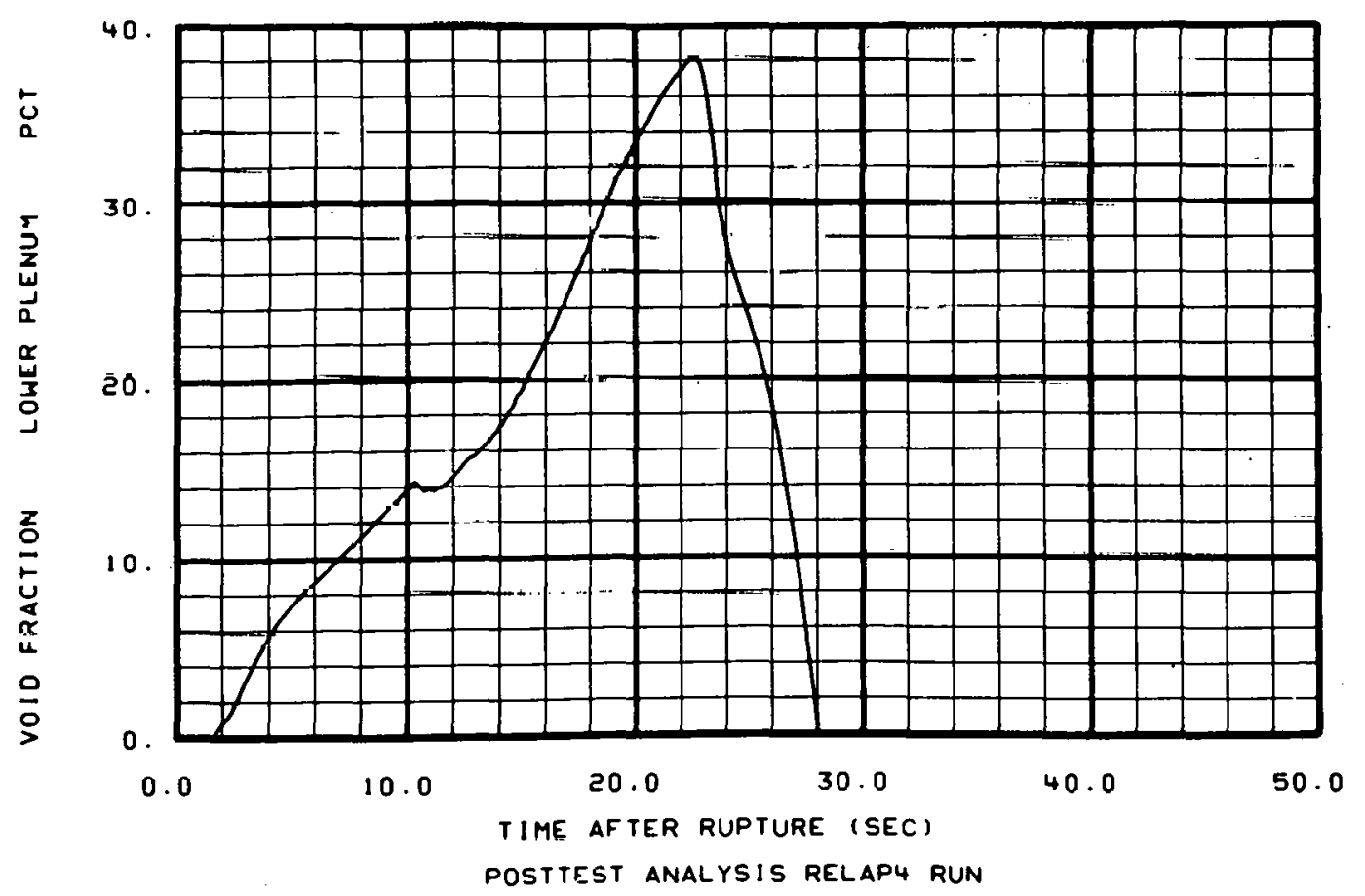

Fig. 40 Volume weighted average void fraction in lower plenum from posttest analysis run. 


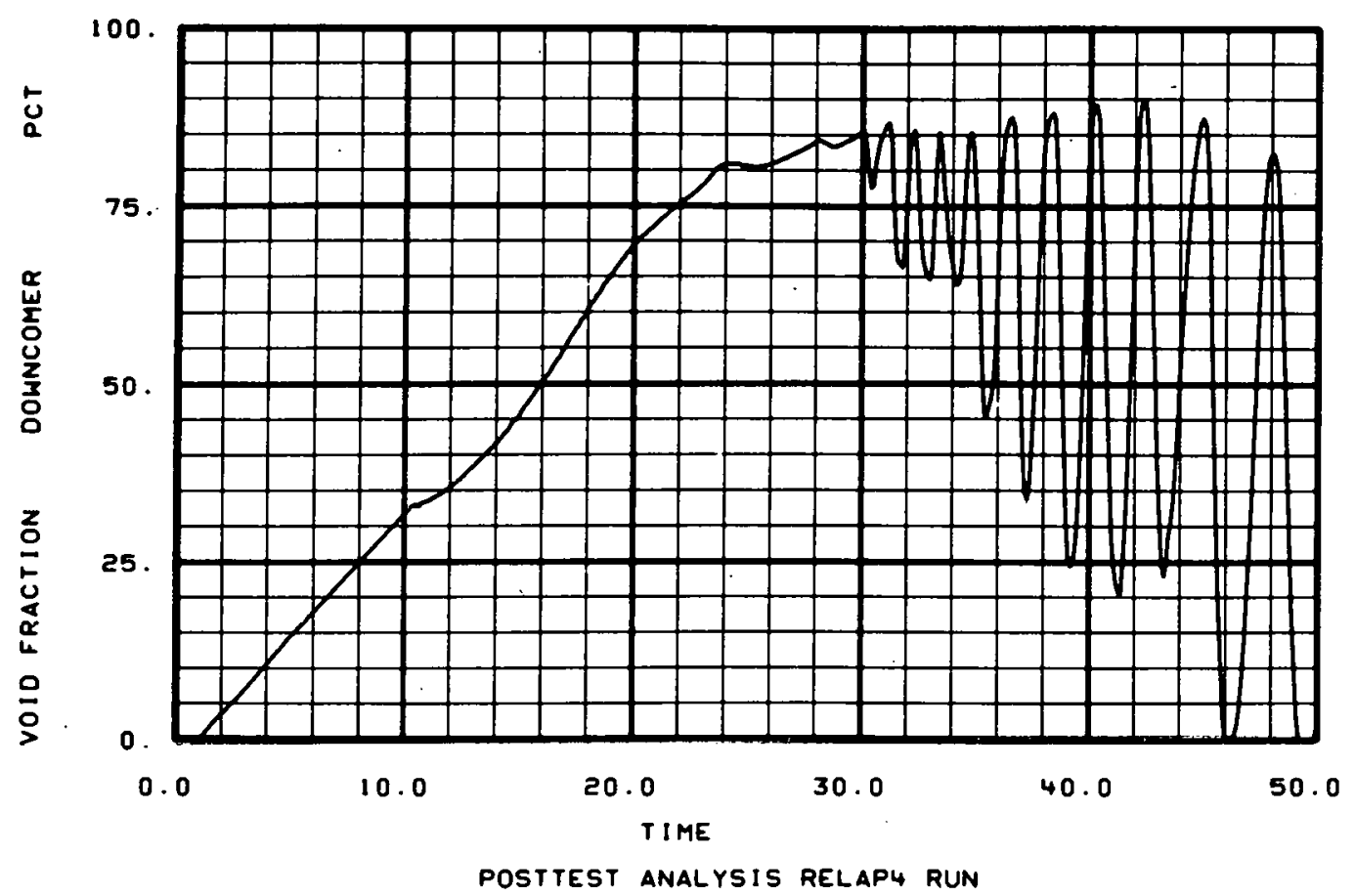

Fig. 41 Volume weighted average void fraction in downcomer from posttest analysis run.

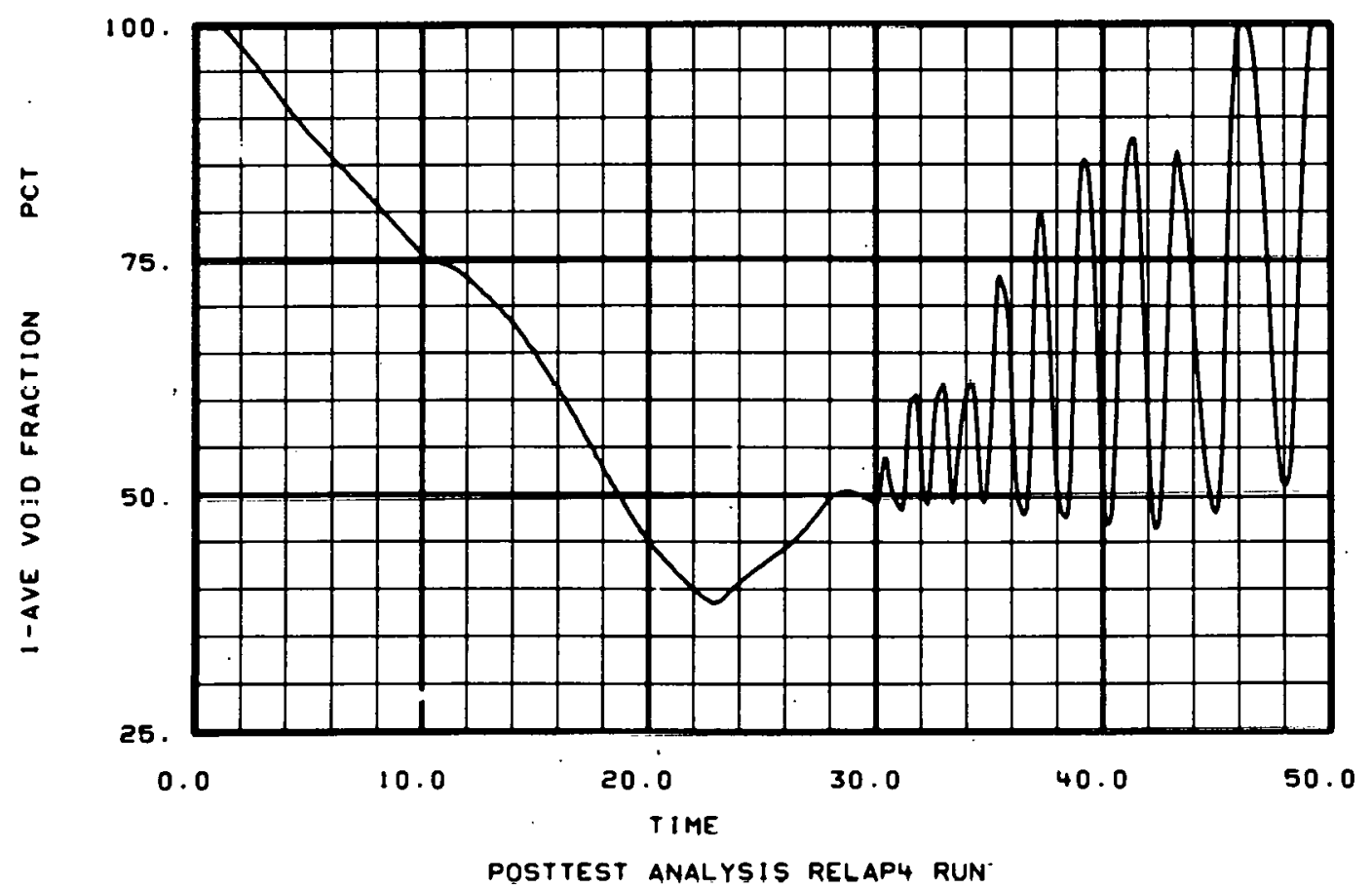

Fig. 42 Volume weighted liquid fraction in lower plenum, downcomer, and inlet annulus from posttest analysis run. 
higher after ECC injection began. Because of the large oscillations observed in the posttest analysis run, it is believed that the finer reactor vessel nodalization was not fully effective in minimizing excessive steam condensation of the ECC fluid due to the homogenizing effect these oscillations had on the fluid conditions in the reactor vessel.

2.3.3 Overall System Behavior. In this section, curves which are representative of the overall system response are discussed in relation t. the differences between the pretest and posttest RELAP4 runs.

Figures 43 through 47 show the calculated and measured densities in the intact and broken loops. The erratic density predictions in the cold legs (Figures 43 and 45) are attributable to the reactor vesse 1 oscillations. The underprediction of density in the broken loop hot leg may be an indication of overprediction of hot leg break flow. Overpredicting broken loop cold leg density may be an indication of underpredicting cold leg break or not fully accounting for phase separation or slip effects in the downcomer.

The hump in the calculated density in the broken loop hul leg is attributable to fluid which collects in the inlet plenum of the steam generator and which later flows from the steam generator inlet plenum, through the intact loop hot leg, through the upper plenum, and out the broken loop hot leg. The experimental data suggest that RELAP4 is correctiy predicting this subtle phenomenon. 


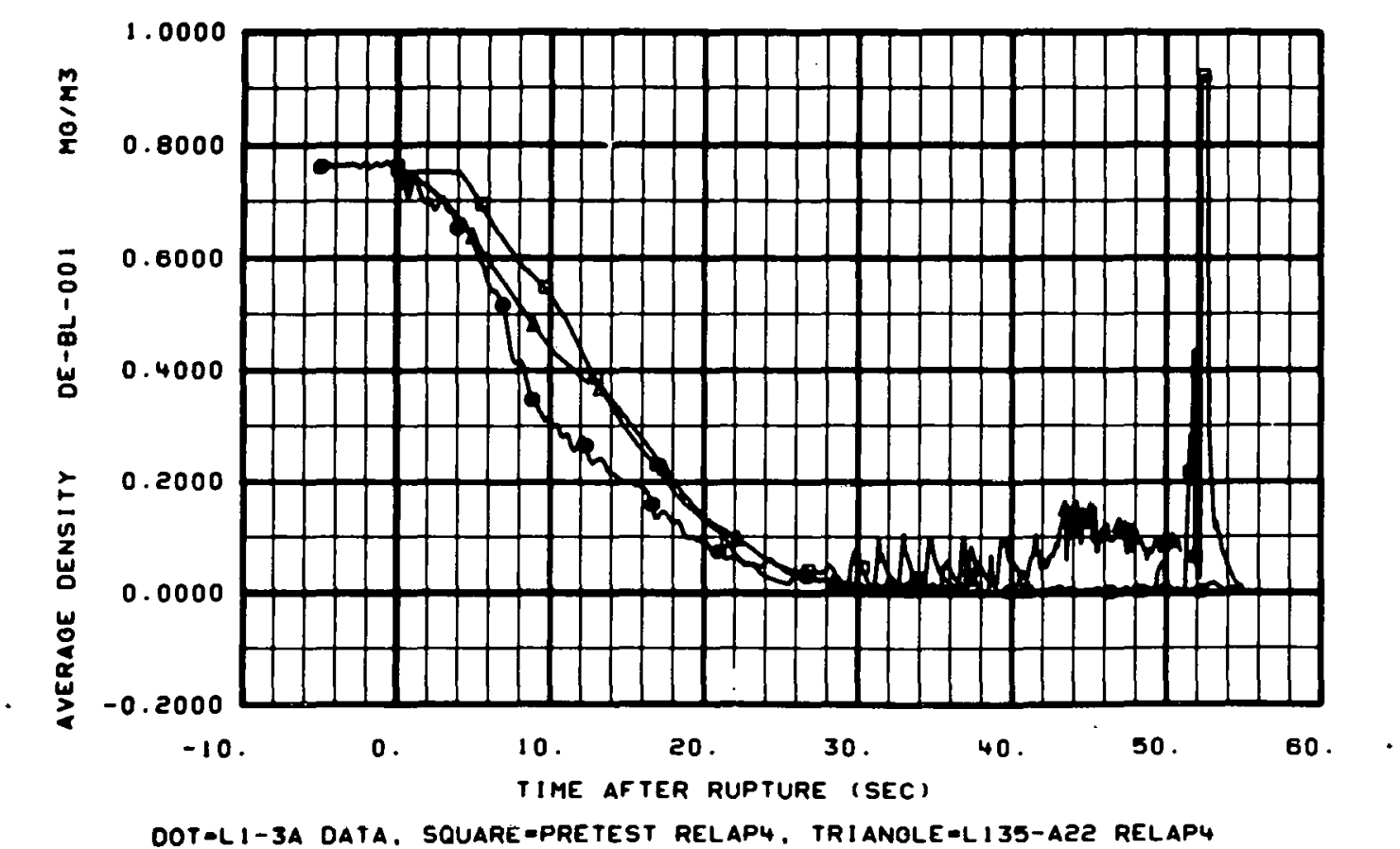

Fig. 43 Comparison of RELAP4 calculated and experimentaliy measured density in broken loop cold leg.

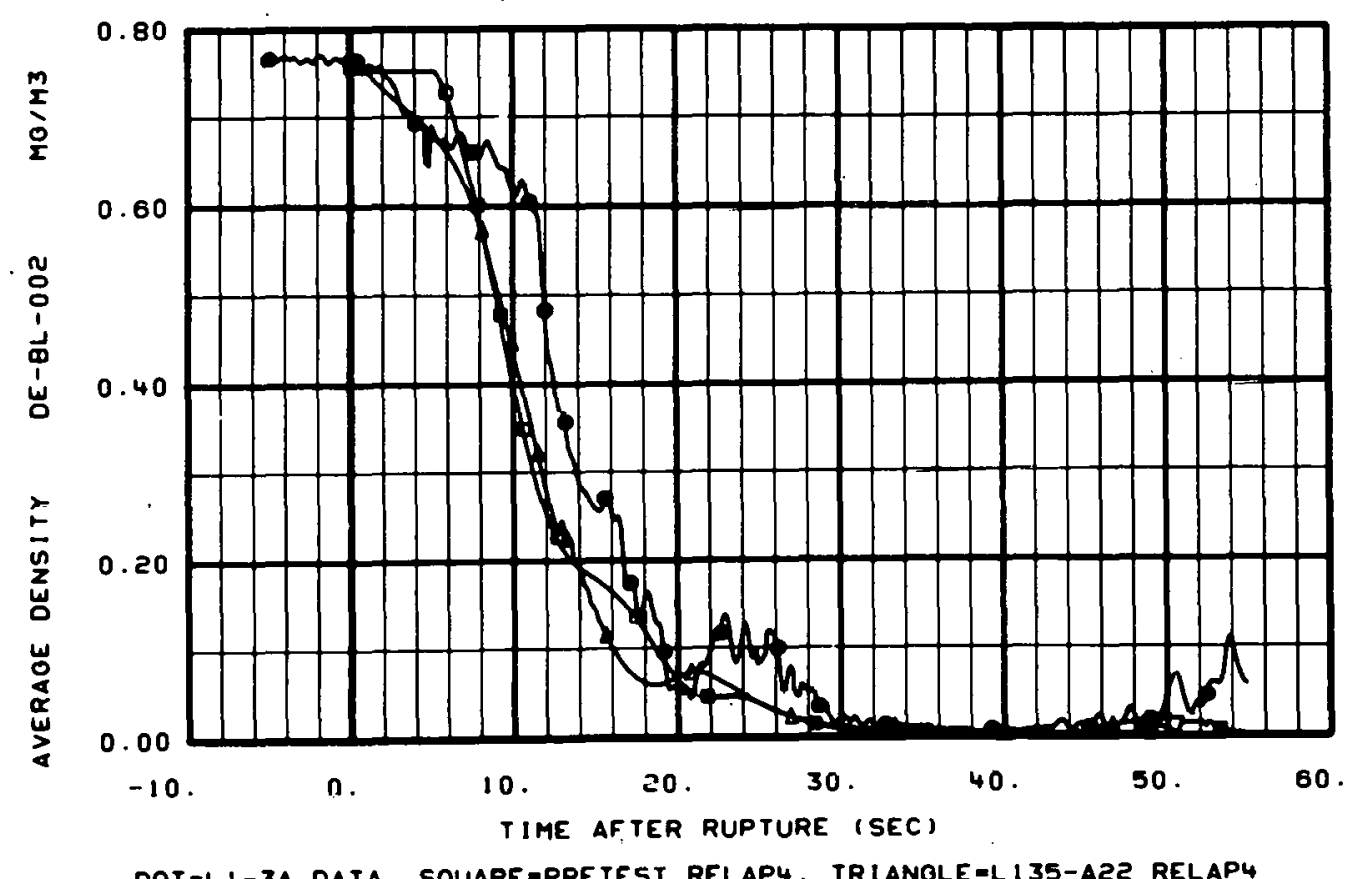

Fig. 44 Comparison of RELAP4 calculated and experimentally measured density in broken loop hot leg. 


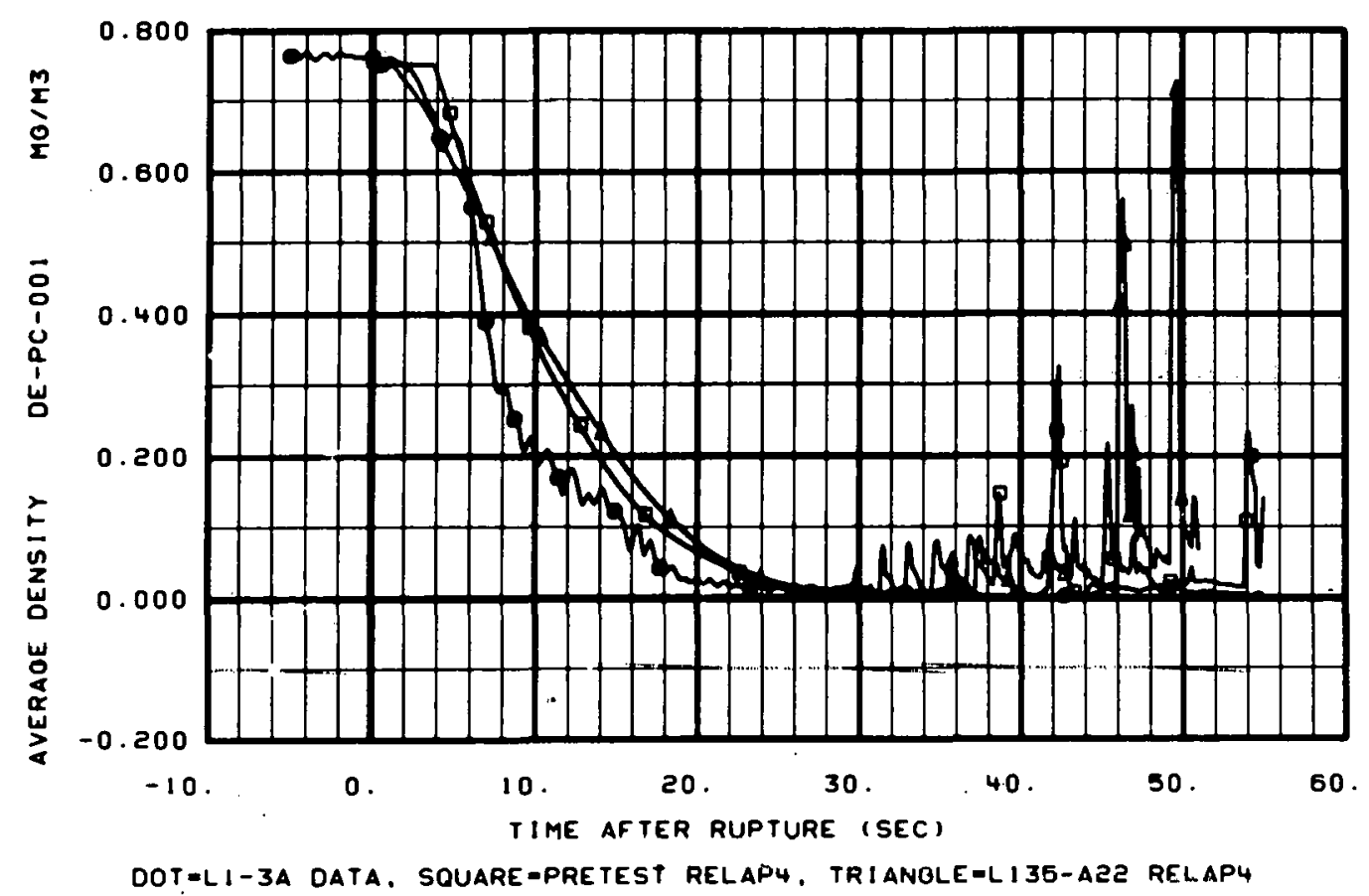

Fig. 45 Comparison of RELAP4 calculated and experimentally measured density in intact loop cold leg.

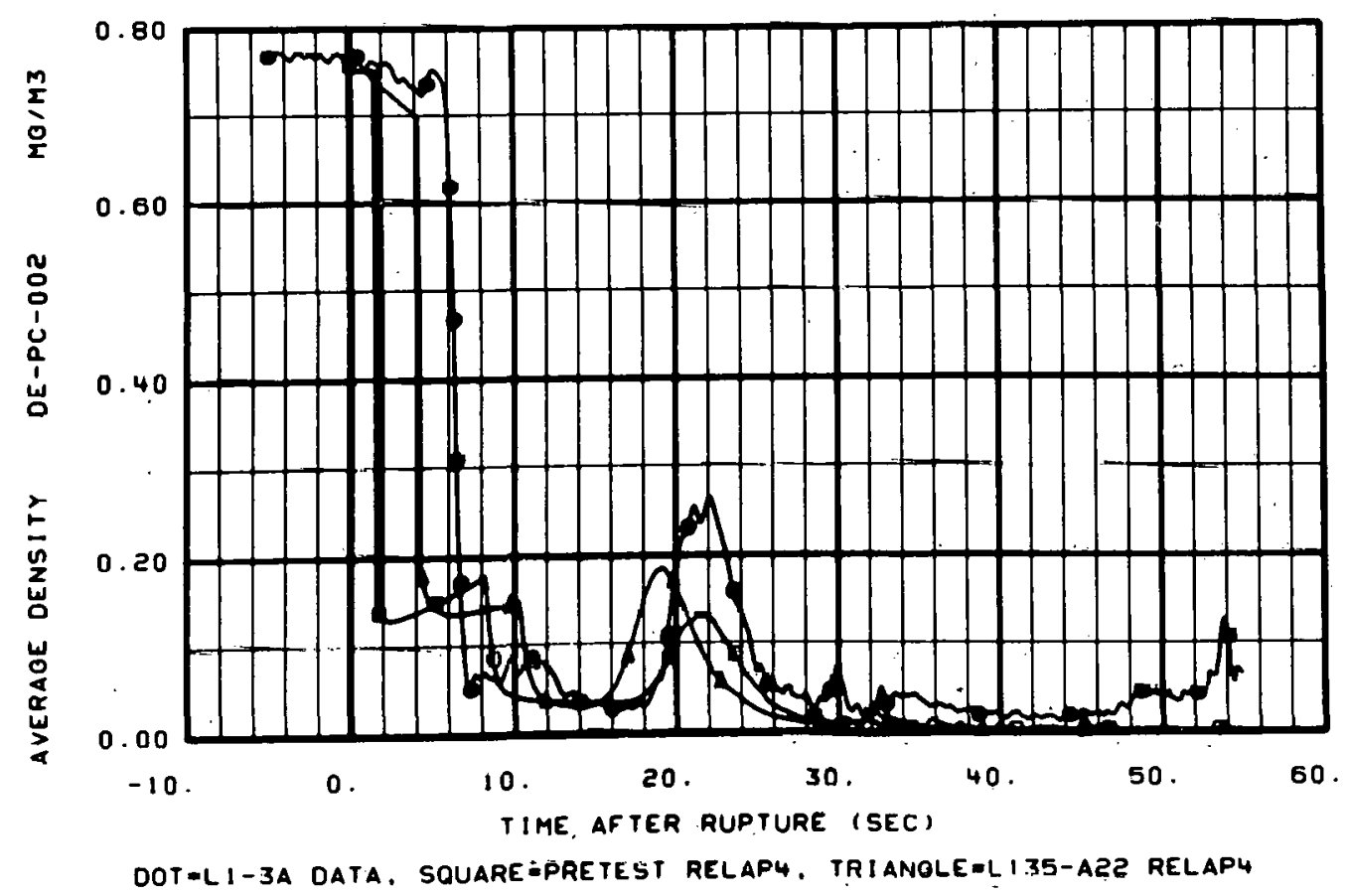

Fig. 46 Comparison of RELAP4.calculated.and experimentally measured density in intact loop hot leg. 


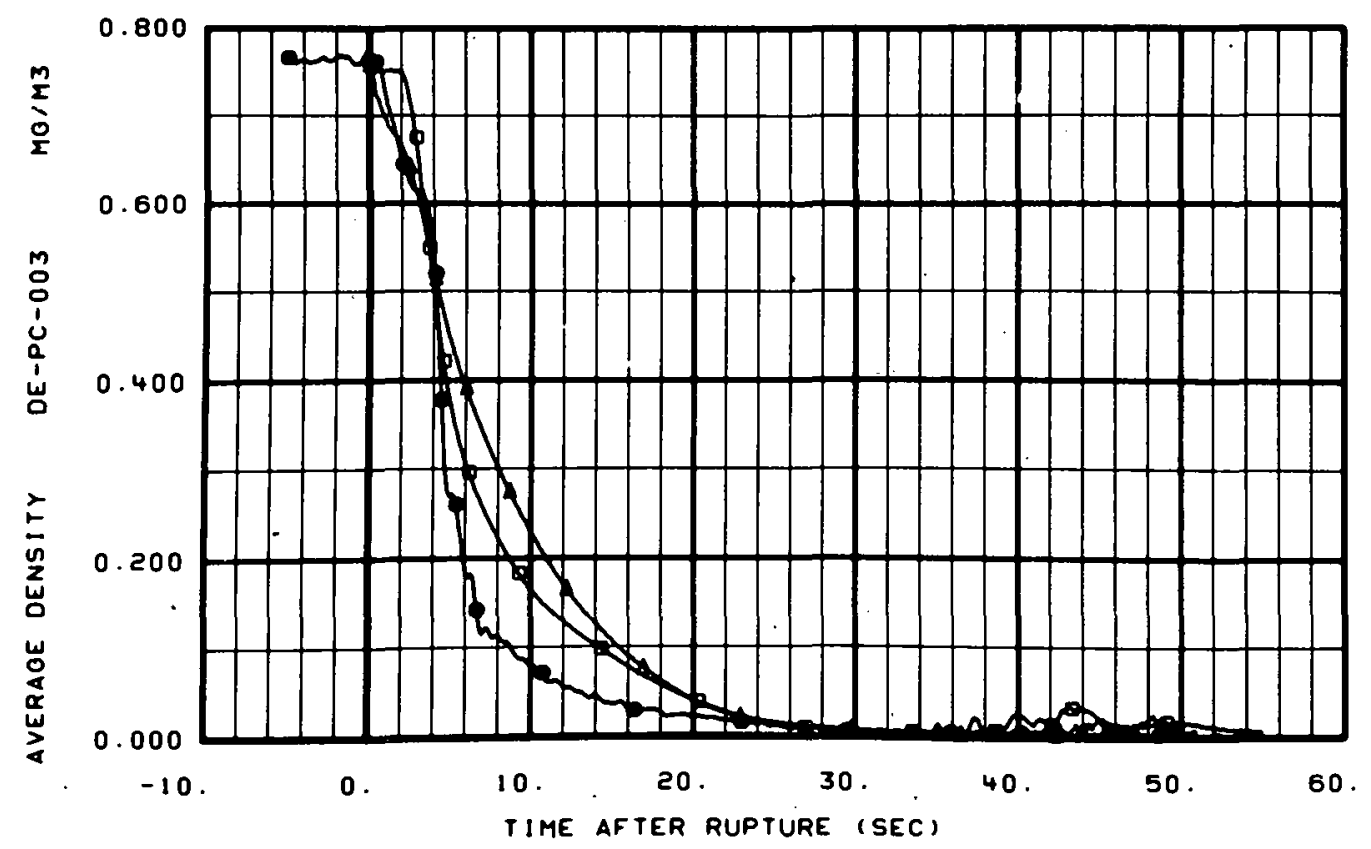

DOT=L I-3A OATA. SQUARE=PRETEST RELAP4, TRIANOLE=L I 35-AZ2 RELAP4

Fig. 47 Comparison of RELAP4 calculated and experimentally measured density in intact loop between steam generator outlet and pump inlet. 
The next two figures (Figures 48 and 49) show the pressurizer liquid level and pressure. As discussed earlier, there is much better agreement in the parameters between the experimental data and the posttest analysis RELAP4 run. Figure 50 shows an expanded-scale plot of the comparisons of primary system pressure. Agreement is good until just after ECC injection begins.

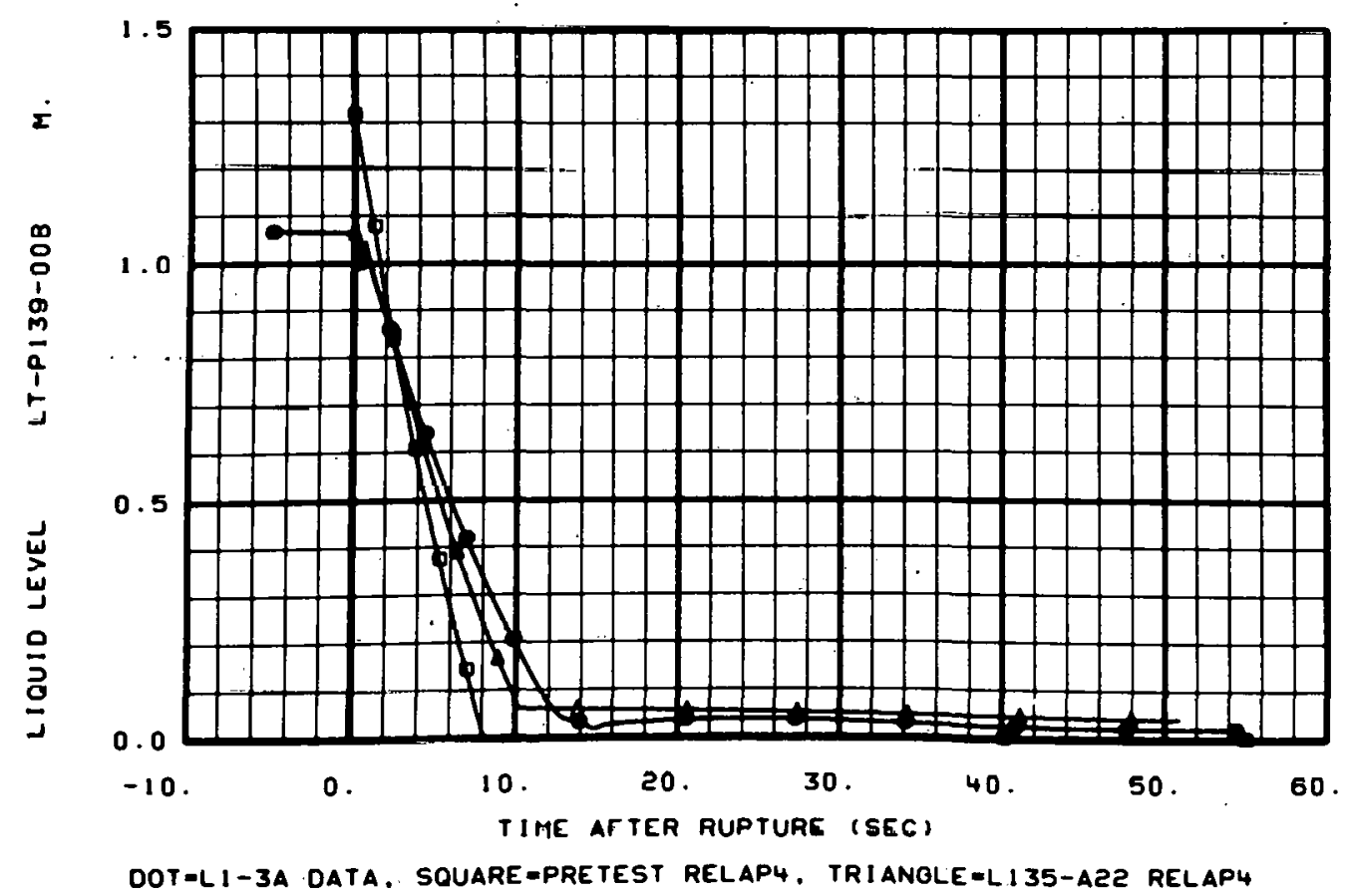

Fig. 48 Comparison of RELAP4 calculated and experimentally measured liquid level in pressurizer. 


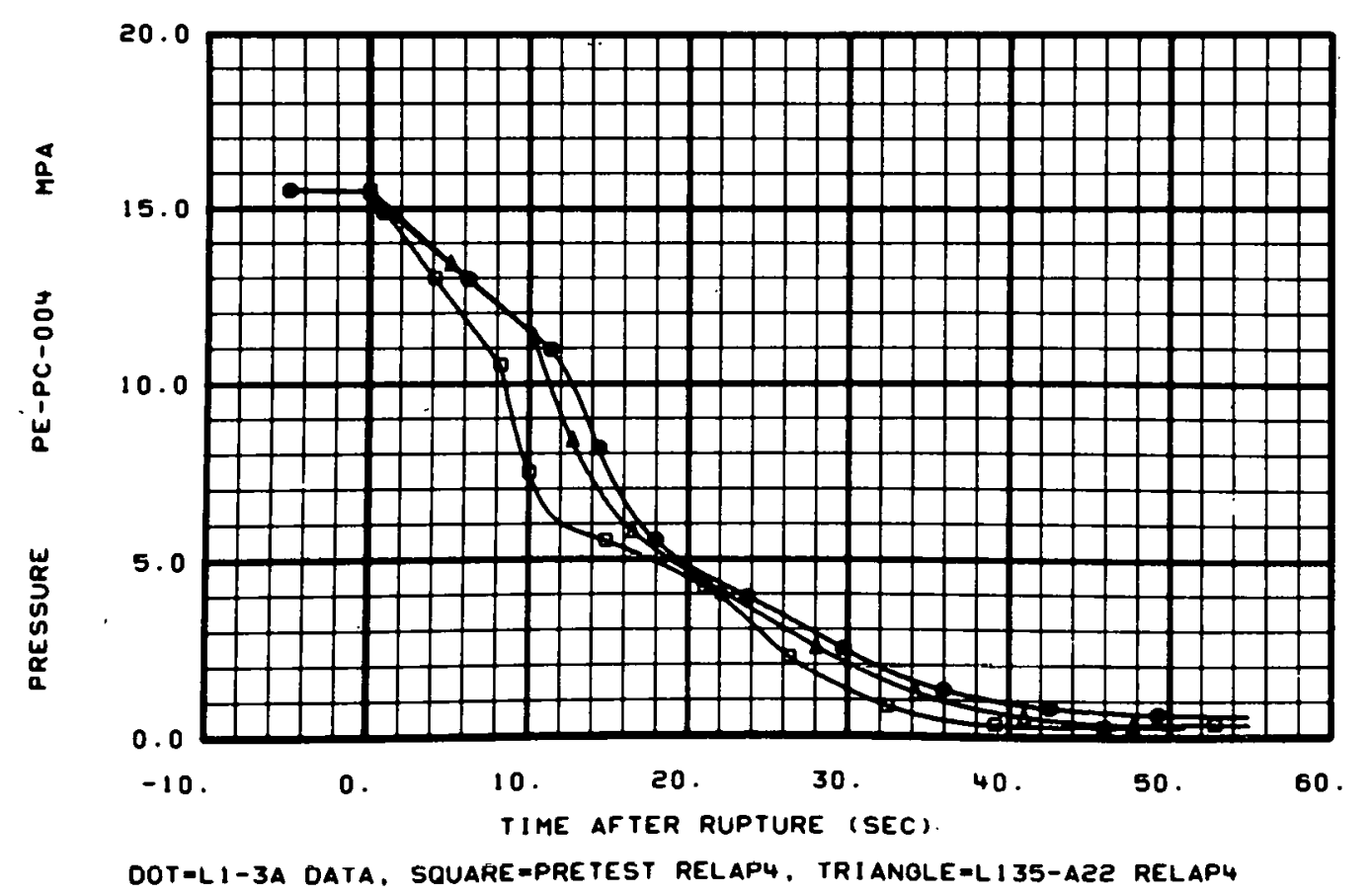

Fig. 49 Comparison of RELAP4 calculated and experimentally measured pressure in pressurizer.

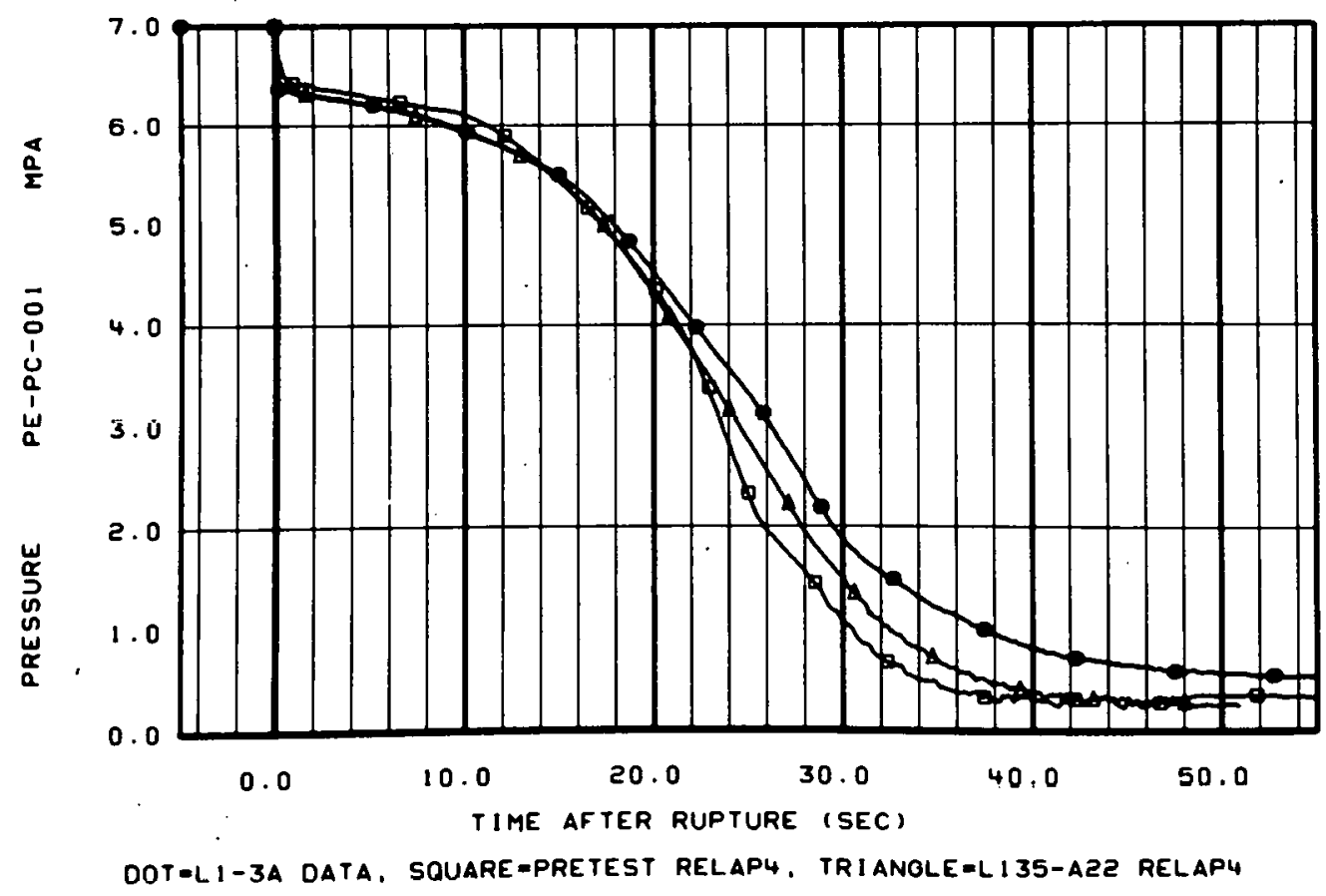

Fig. 50 Comparison of RELAP4 calculated and experimentally measured pressure in primary system. 
Figures 51 and 52 show comparisons of the steam generator secondary pressure and temperature. The pretest RELAP4 run is in better agreement with the experimental data. The natural convection steam generator heat transfer model used in the posttest analysis calculation apparently overpredicts the heat transfer from the steam generator secondary. "The steam generator secondary temperature transducer is located in the downcomer of the steam generator, and may not accurately reflect the true average steam generator secondary fluid temperature. Modeling the LOFT steam generator secondary is presently under review. 


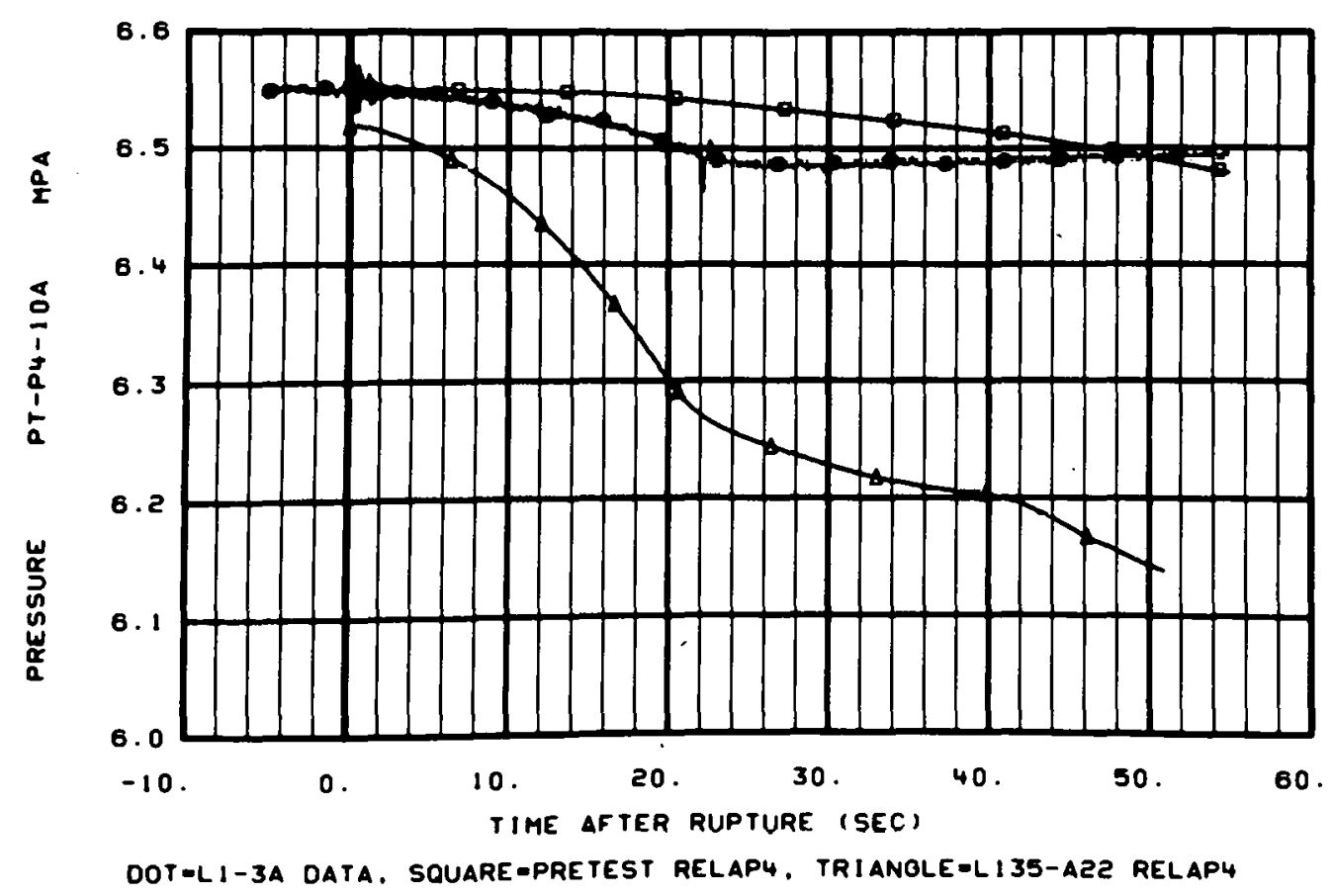

Fig. 51 Comparison of RELAP4 calculated and experimentally measured pressure in steam generator secondary side.

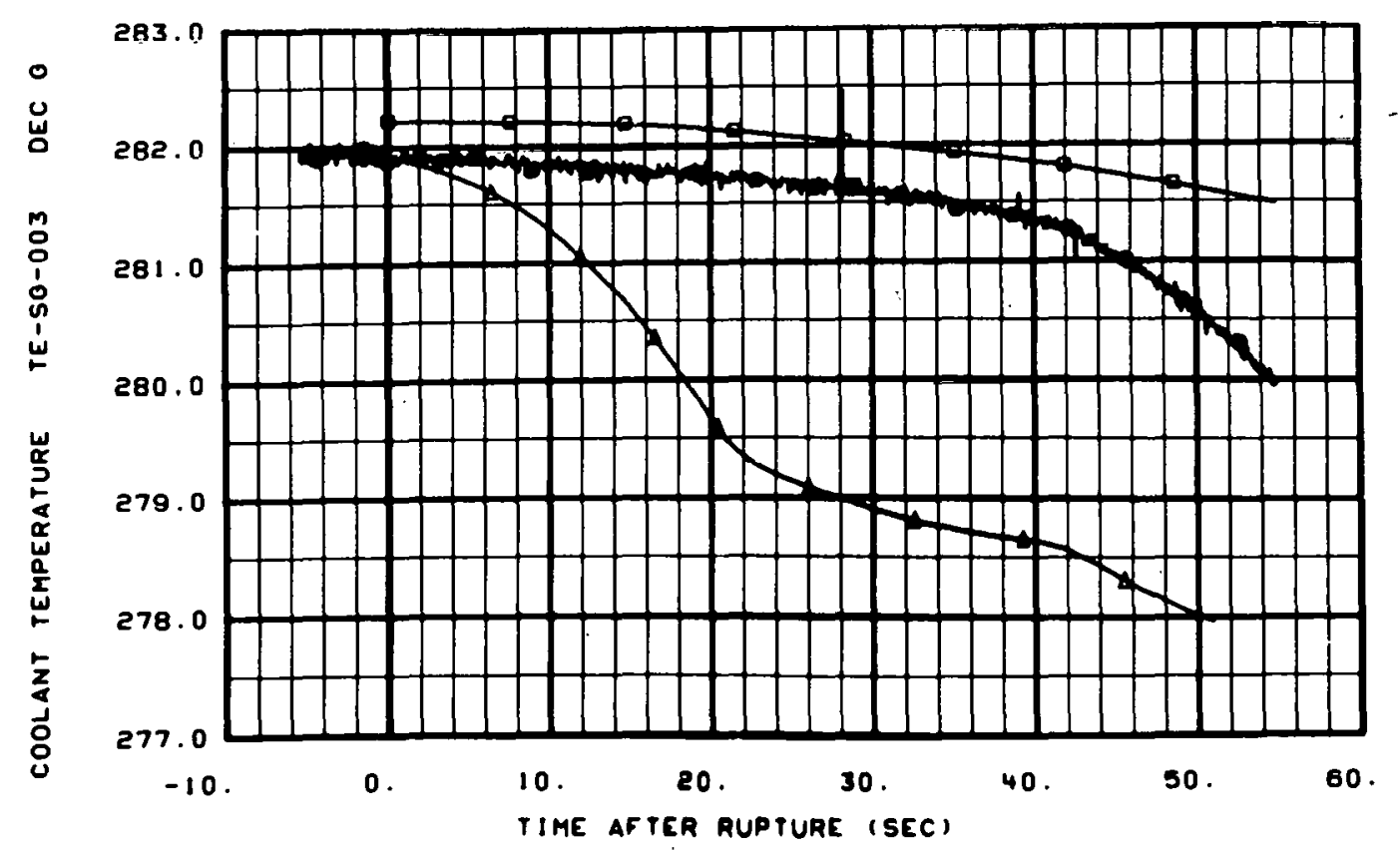

DOT-L1-3A DATA, SQUARE-PRETEST RELAPU, TRIANOLE=L135-AZ2 RELAPU

Fig. 52 Comparison of RELAP4 calculated and experimentally measured temperature in downcomer in steam generator secondary side. 
Figures 53 through 55 show calculated and measured fluid temperatures in the broken and intact loops. The posttest analysis run indicated that superheated steam began to flow from the steam generator outlet at approximately 26 seconds into the blowdown, passed through the pumps, and arrived at Station PC- 1 at approximately 28 seconds. The experimental data suggest that this phenomenon may be occurring, but at a later time than predicted by RELAP4. The overall fluid temperature differences are largely attributable to differences in saturation temperatures, due to the differences in system pressures.

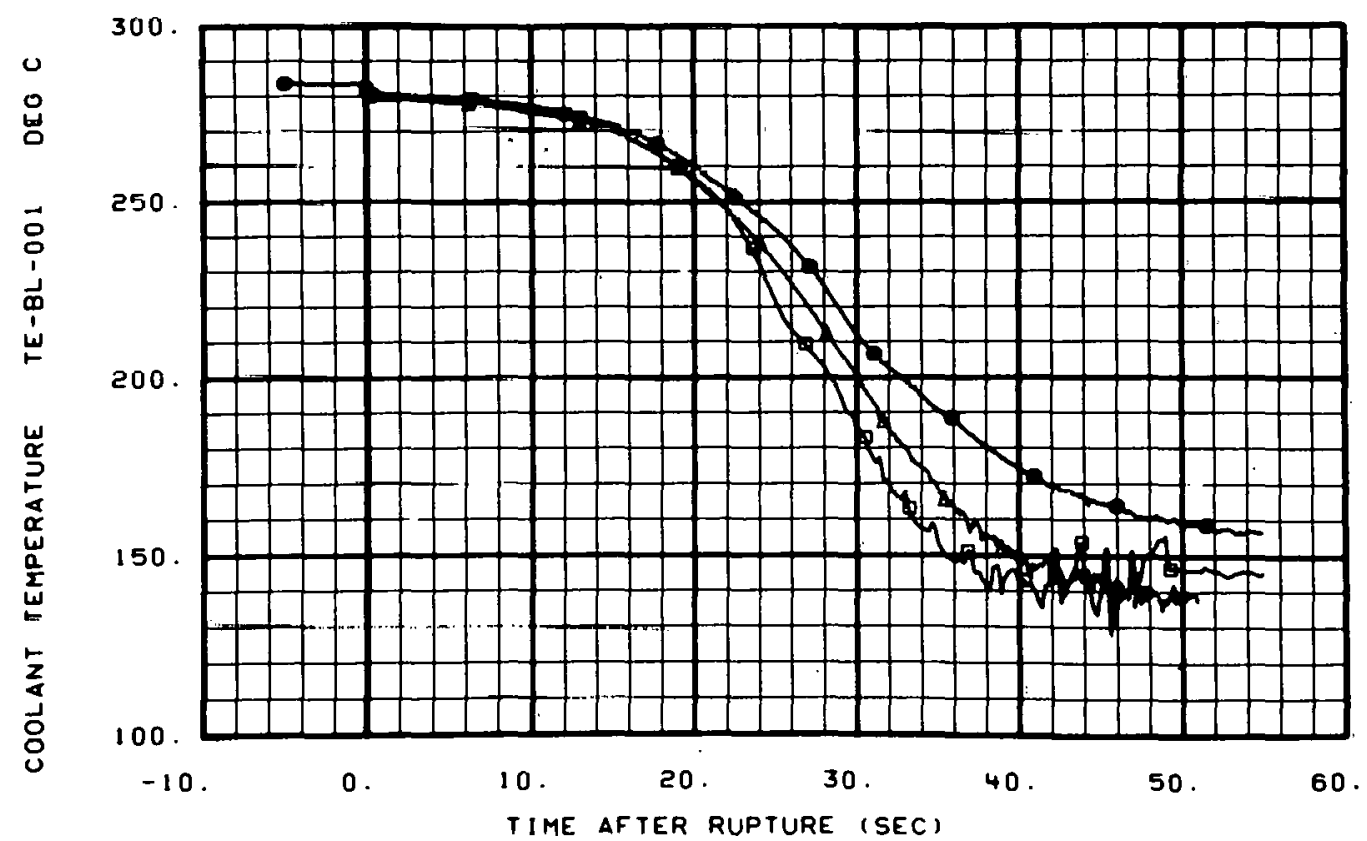

DOT=L I-3A DATA, SQUARE=PRETEST RELAP4. TRIANGLE =L135-AZZ RELAPY

Fig. 53 Comparison of RELAP4 calculated and experimentally measured fluid temperature in broken loop cold leg. 


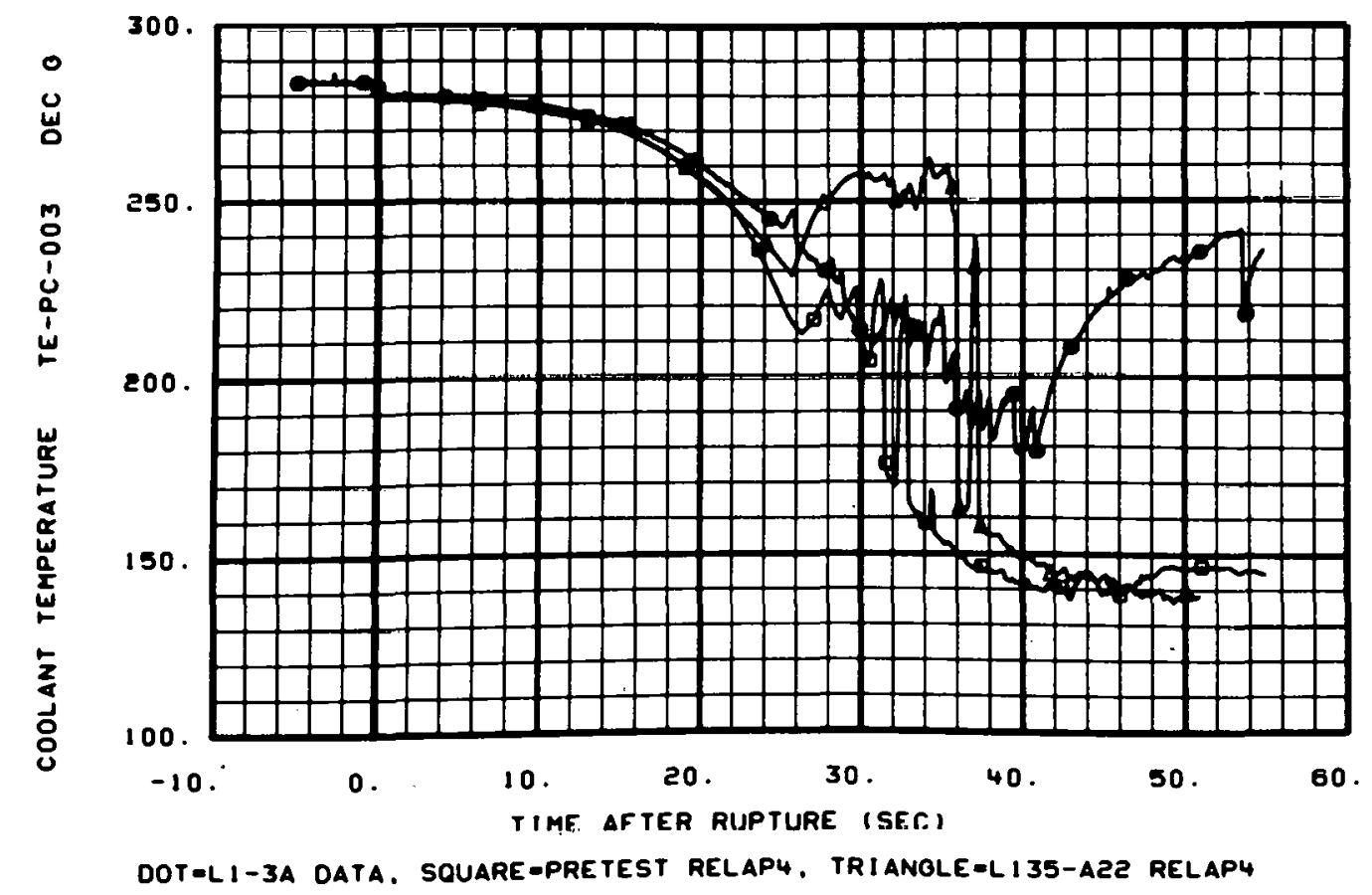

Fig. 54 Comparison of RELAP4 calculated and experimentally measured fluid temperature in intact loop between steam generator outlet and pump inlet.

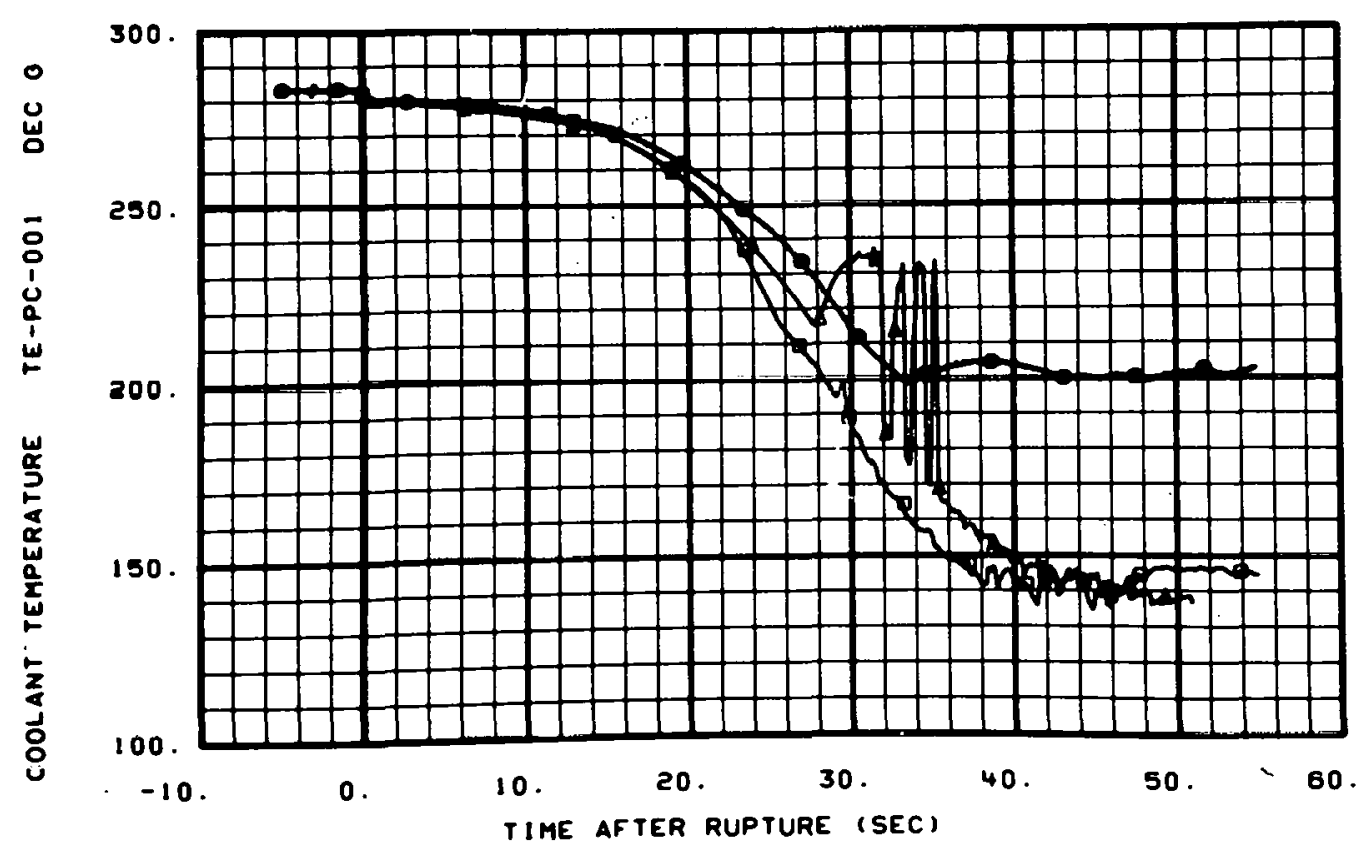

DOT-LI-3A DATA. SQUARE=PRETEST RELAP4, TRIANOLE=L I35-AZ2 RELAP4

Fig. 55 Comparison of RELAP4 calculated and experimentally measured fluid temperature in intact loop cold leg. 
Figures 56 and 57 show the primary coolant pump speed and differential pressure. The primary coolant pump in RELAP4 coasts down faster than the experimental data primarily because the effective inertia of the primary coolant pump in RELAP4 is too low at the higher speeds. A variable inertia pump model was developed for the LOFT Experiment L1-4 pretest prediction which accounts for the speeddependent electrical losses of the LOFT pumps [10]. The pump differential pressure is well predicted by RELAP4 which indicates that once the pumps cavitate, the pump head is no longer a strong function of pump speed. 


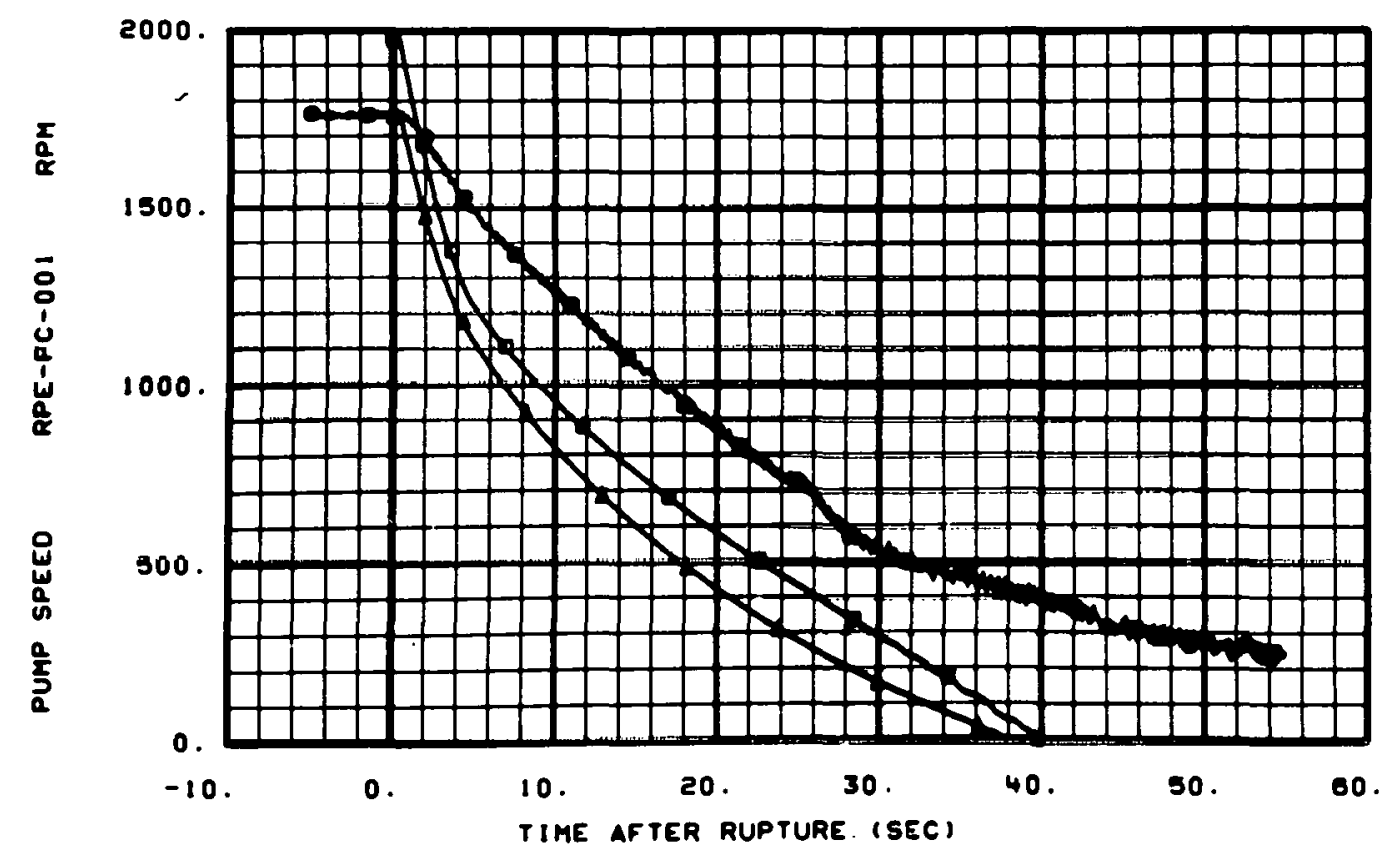

DOT-LI-3A DATA, SQUARE-PRETEST RELAPL, TRIANOLE-L135-A2Z RELAPU

Fig. 56 Comparison of RELAP4 calculated and experimentally measured speed of primary coolant pump 1.

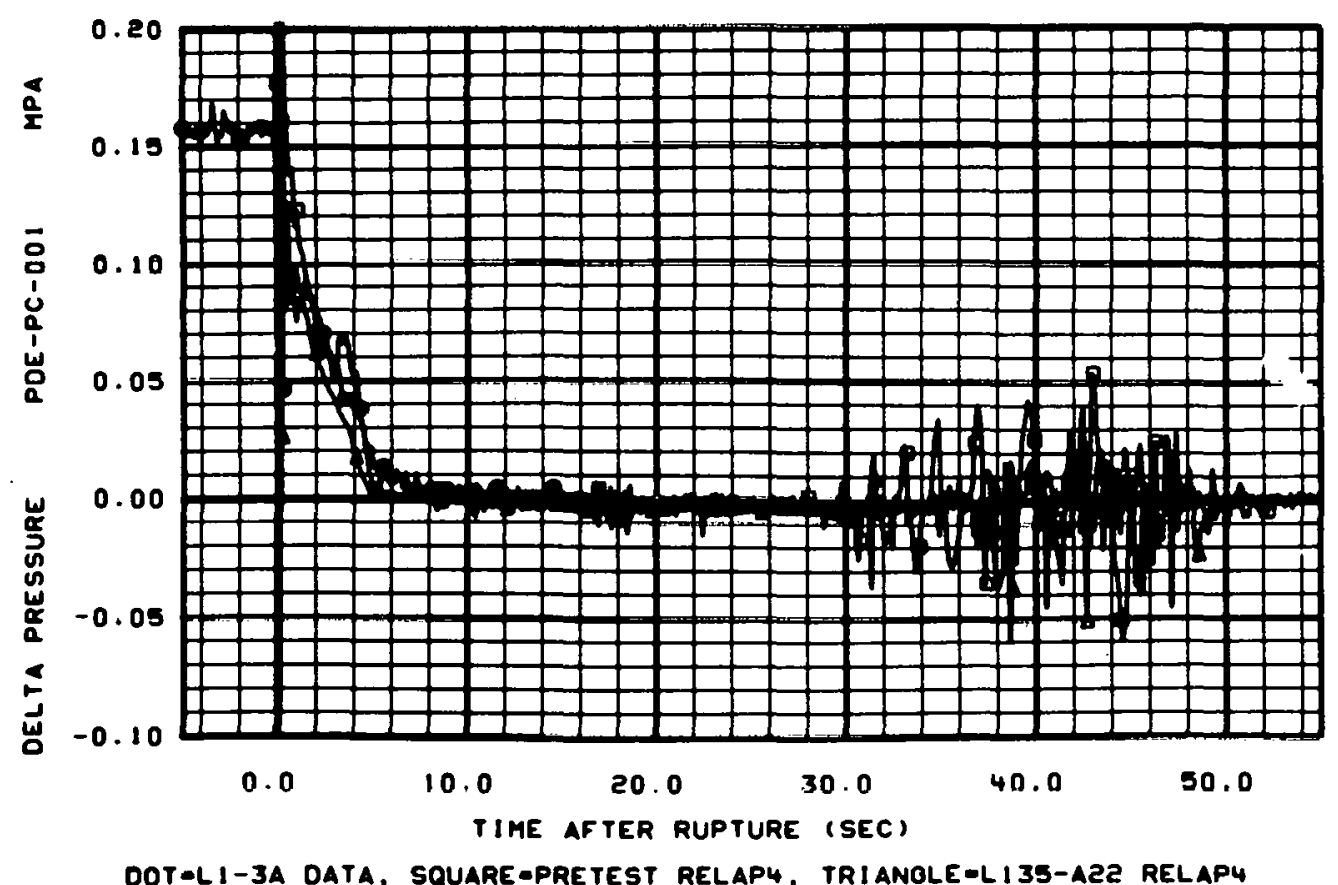

Fig. 57 Comparison of RELAP4 calculated and experimentally measured differential pressure acruss prilldry cuuldnl punips. 
Figures 58 through 61 show velocities and momentum fluxes in the intact loop and reactor vessel. Agreement is generally good until 30 seconds into the blowdown, when the oscillations begin in the RELAP4 calculations. 


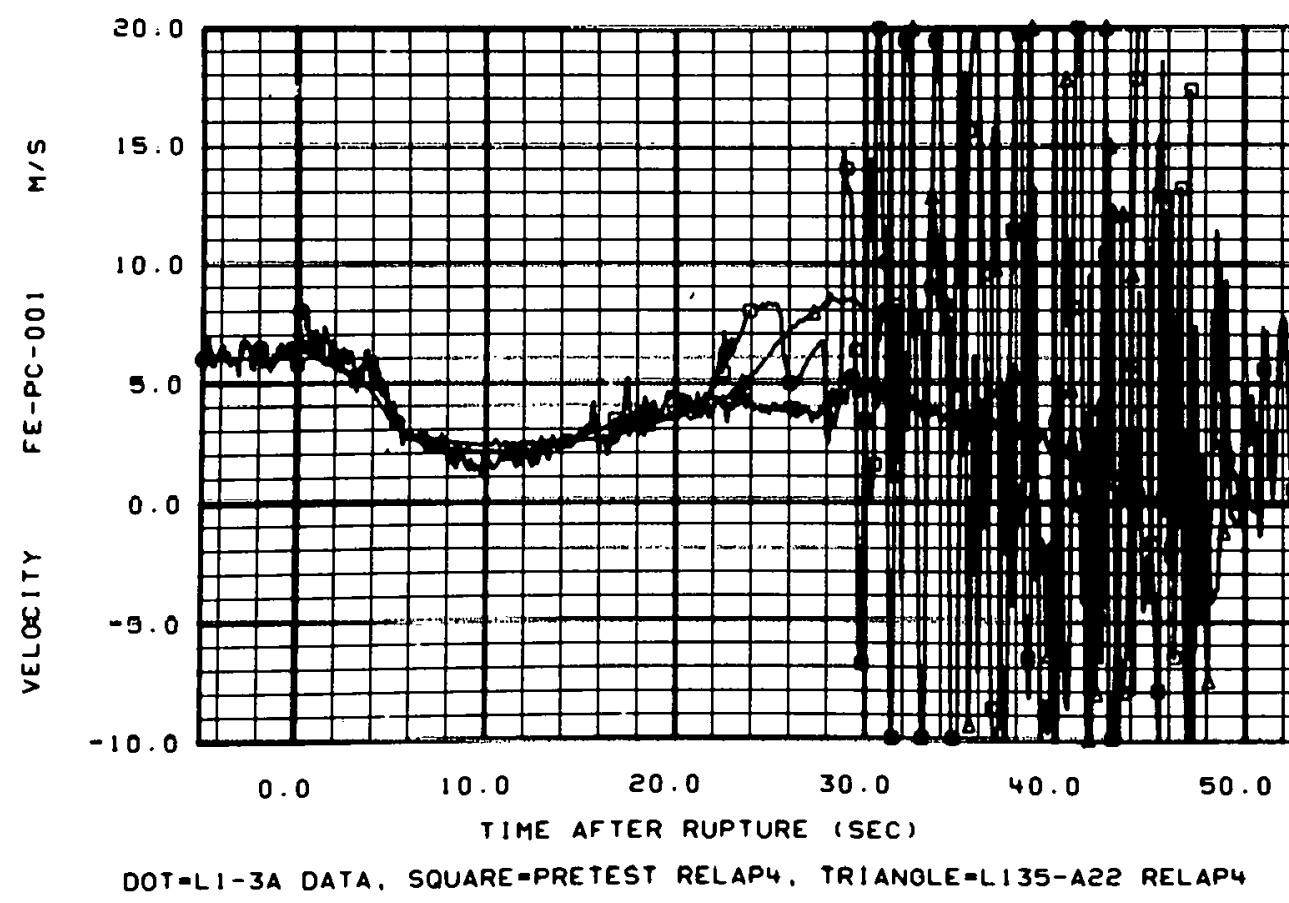

Fig. 58 Comparison of RELAP4 calculated and experimentally measured fluid velocity in intact loop cold leg.

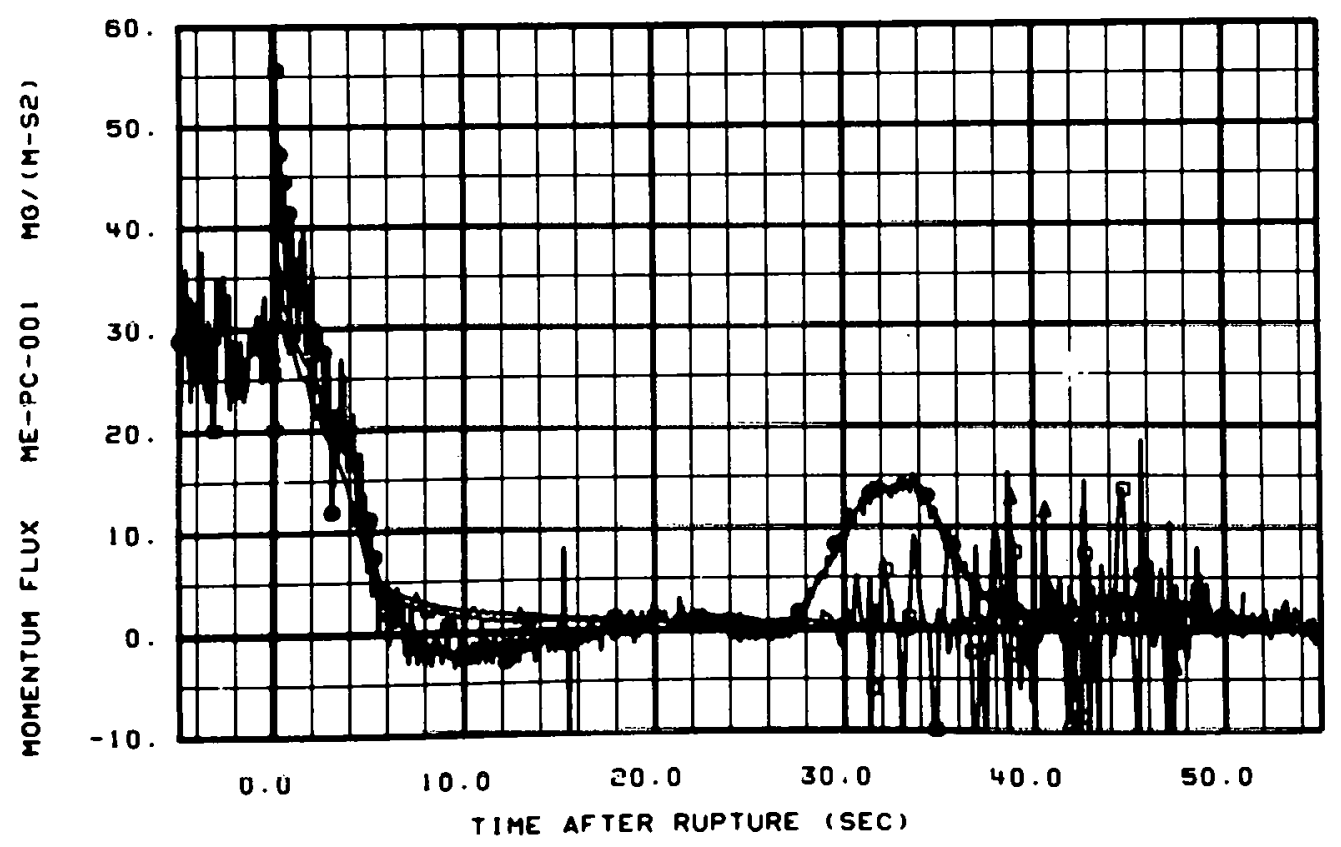

DOT-LI-3A DATA. SOUARE-PRETEST RELAP4, TRIANOLE=L135-AZ2 RELAP4

Fig. 59 Comparison of RELAP4 calculated and experimentally measured momentum flux in intact loop cold leg. 


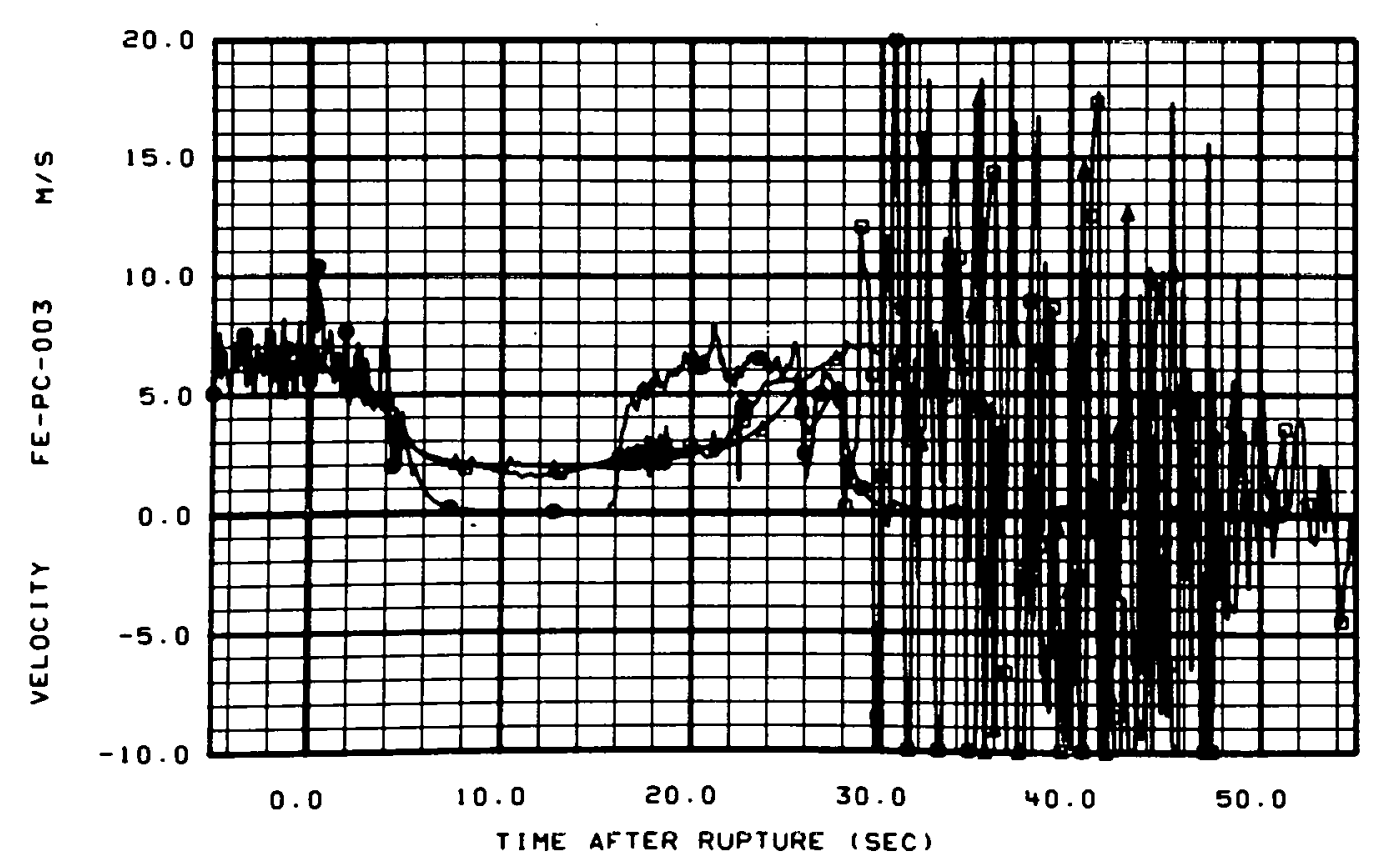

DOT $=$ L1-3A OATA, SQUARE=PRETEST RELAP4, TRIANOLE=L135-A2Z RELAP4

Fig. 60 Comparison of RELAP4 calculated and experimentally measured fluid velocity in intact loop between steam generator outlet and pump intet.

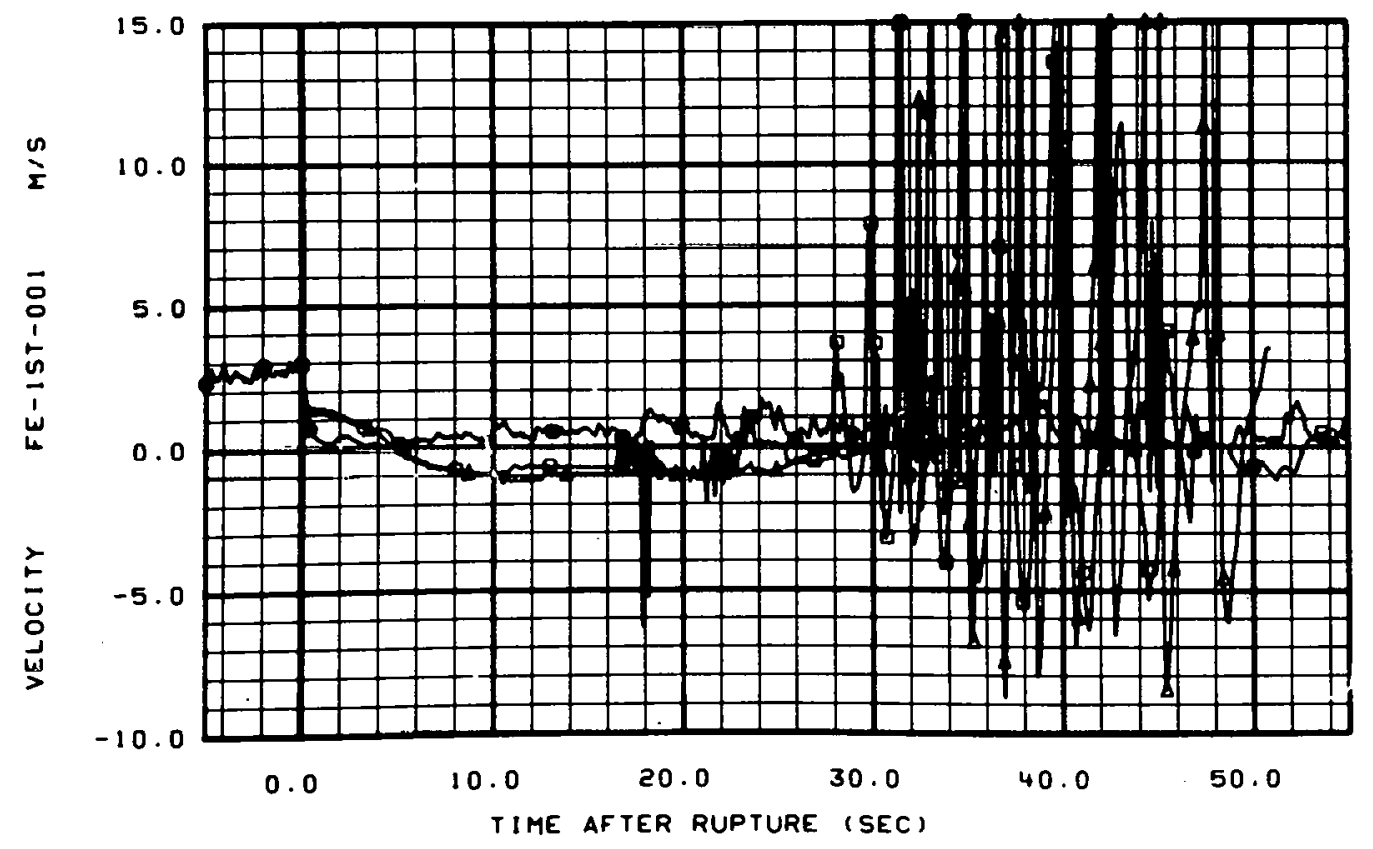

DOH $=L 1-3 A$ OATA. SOUARE $=P R E T E S T$ RELAP4. TRIANGLE $=L 135-A 22$ RELAPU

Fig. 61 Comparison of RELAP4 calculated and experimentally measured fluid velocity in reactor vessel downcomer. 
The next four figures (Figures 62 through 65) concern the broken loop cold leg. Figure 62 shows the RELAP4 calculated and measured velocity in the broken loop cold leg. The agreement is generally good up to near the end of blowdown. As mentioned earlier, the turbine meter is expected to record higher than average velocities because of the stratified and annular flow regimes which are observed in the experimental data[6]. Figure 63 shows a comparison of the calculated and measured mass flows, as recorded from a pair of differential pressure-densitometer measurements. The experimental data show a small uncorrected offset at time zero which is probably attributable to an uncorrected offset in the differential pressure transducer. The data consistency checks also reveal that the experimentally measured mass flow rate for this transducer may be high by approximately $9 \%[6]$. The differential pressure across the flow area reducer is underpredicted by RELAP4. The differential pressure across the cold leg break plane is somewhat overpredicted by RELAP4.

For LOFT Experiment L1-4, additional differential pressure and flow instrumentation has been installed to allow a better understanding of the flow phenomenon upstream of the cold leg break plane. 


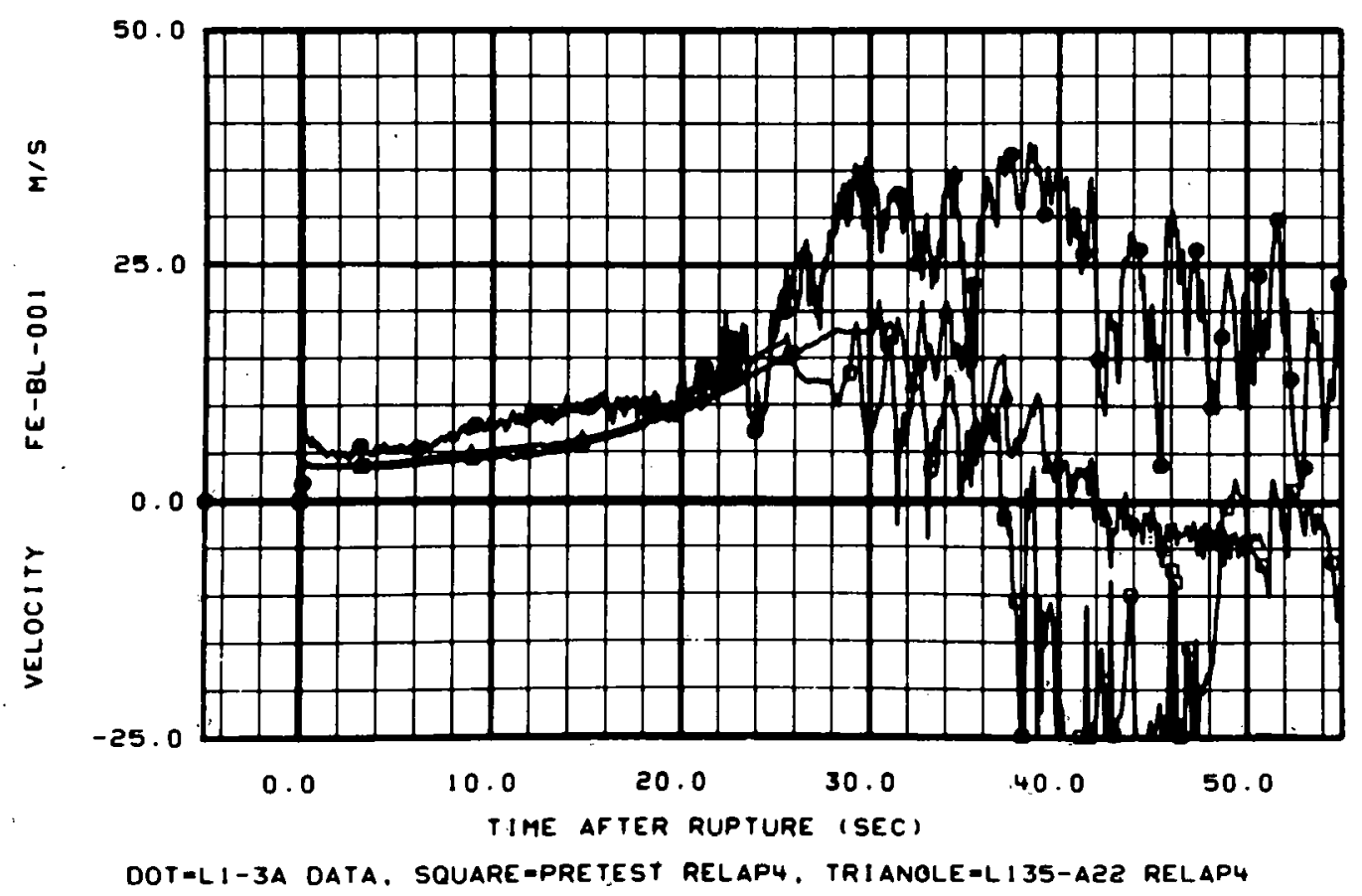

Fig. 62 Comparison of RELAP4 calculated and experimentally measured fluid velocity in broken loop cold leg.

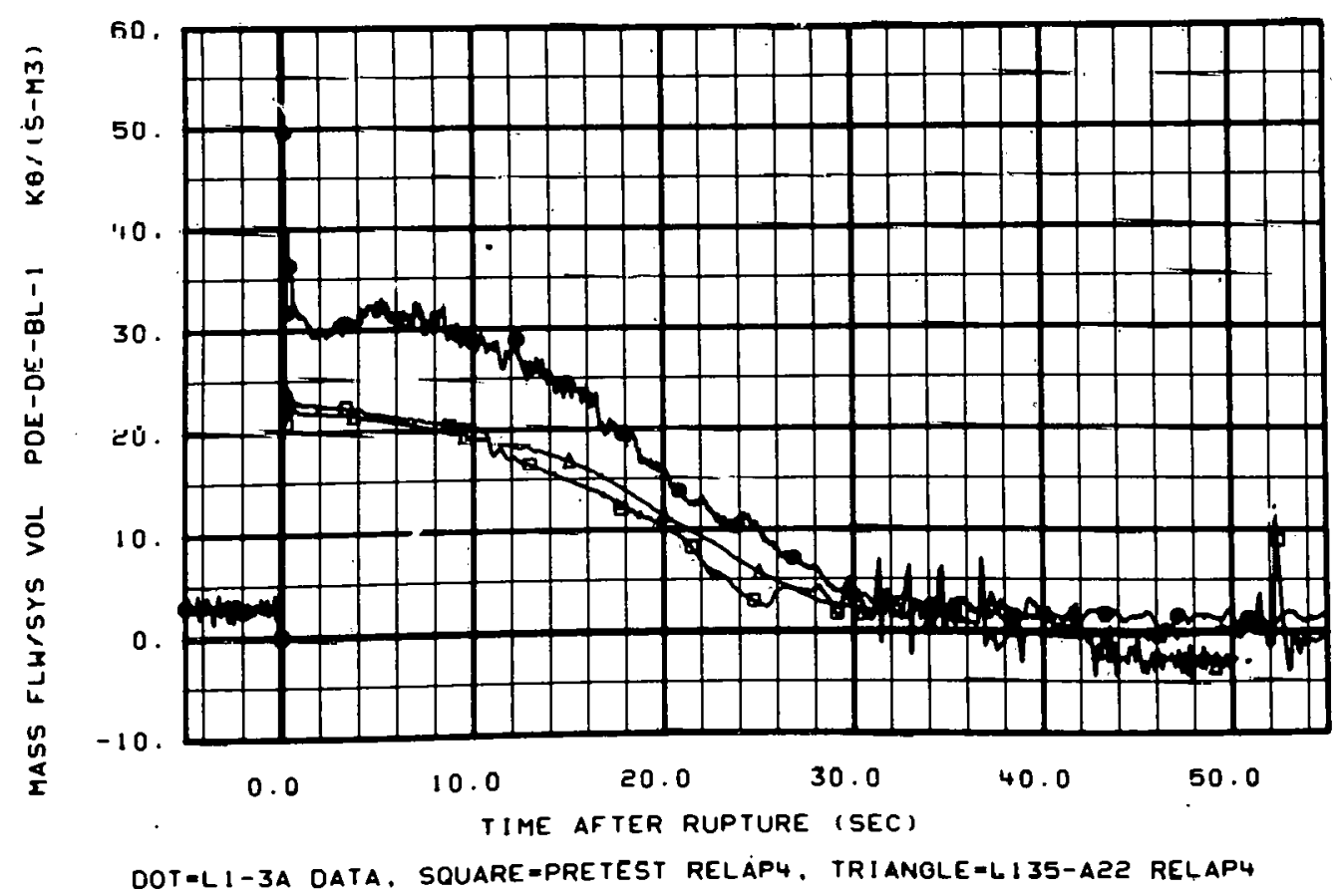

Fig. 63 Comparison of RELAP4 calculated and experimentally measured mass flow rate per system volume in broken loop cold leg. 


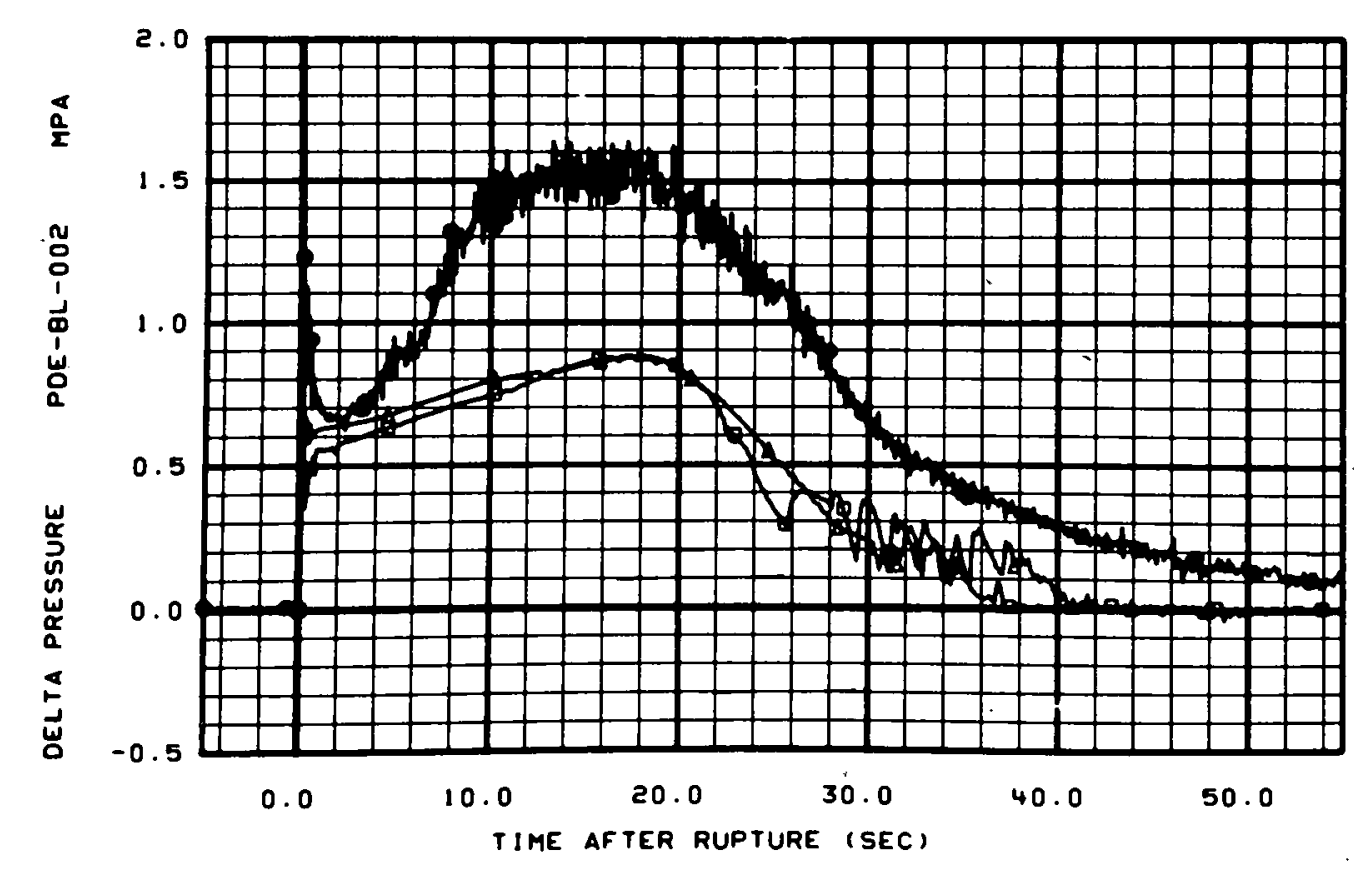

DOT=L1-3A DATA, SOUARE-PRETEST RELAP4, TRI ANOLE=L135-AZ2 RELAP4

Fig. 64 Comparison of RELAP4 calculated and experimentaliy measured differential pressure across broken loop cold leg contraction.

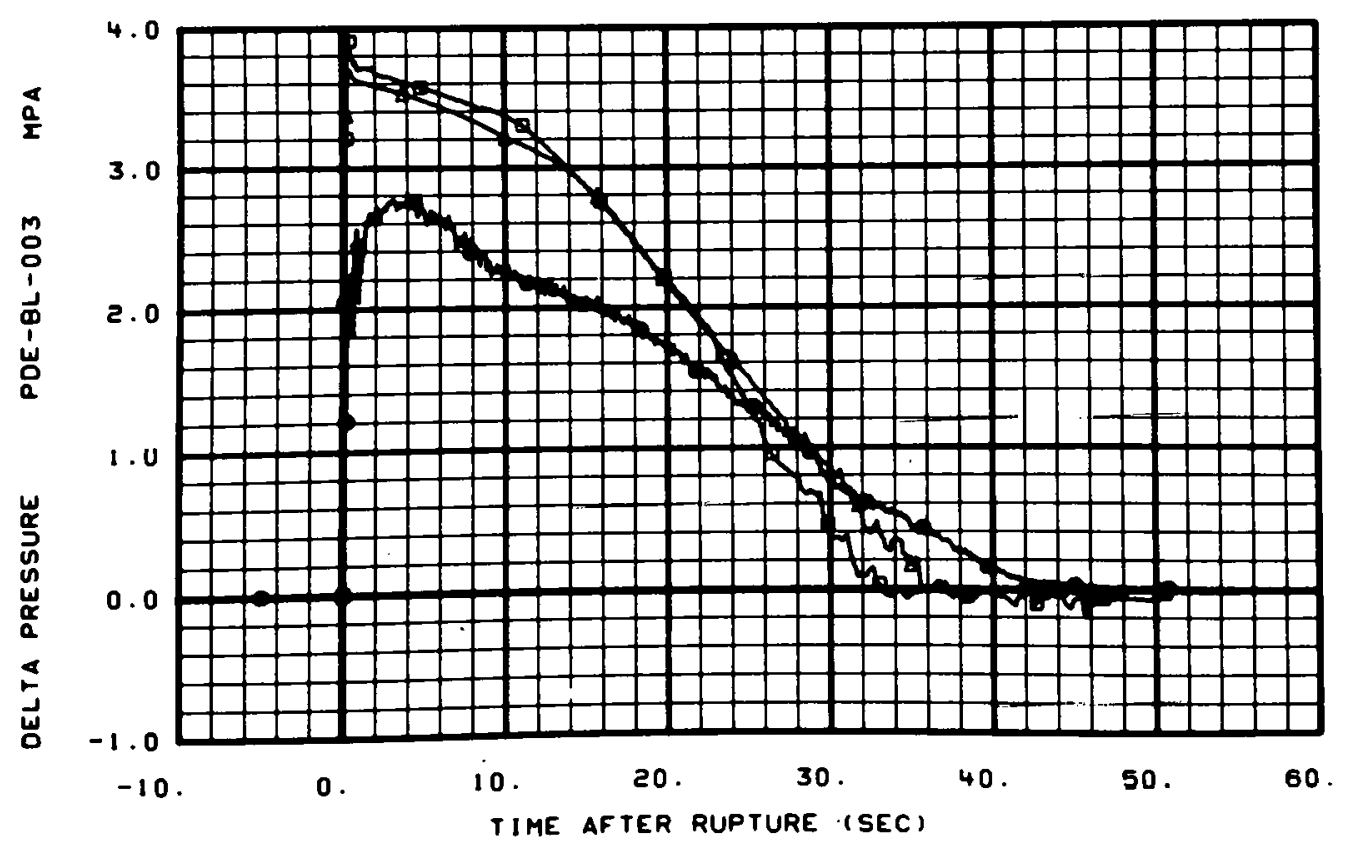

DOT=L1-3A DATA. SOUARE=PRETEST RELAP4, TRIANOLE=L135-AZ2 RELAP4

Fig. 65 Comparison of RELAP4 calculated and experimentally measured differential pressure across broken loop cold leg break plane. 
Figure 66 indicates that the broken loop hot leg mass flow rate is overpredicted by RELAP4 for the first 10 seconds of blowdown. Subsequent modeling studies have shown that the RELAP4 calculated initial mass flow rate is strongly dependent upon the assumed initial temperature distribution in the broken loop hot leg. In both the pretest and posttest RELAP4 analyses, the initial temperature of the fluid in the broken loop hot leg was set at a lower value than indicated by pressure transducers in the broken loop hot leg at the onset of saturated blowdown.

Figures 67 and 68 show comparisons of differential pressures across the steam generator and pump simulators in the broken loop hot leg. Both the pretest and posttest RELAP4 runs are in good general agreement with the experimental data. One would expect the differential pressures to be overpredicted somewhat if the mass flow rate was being overpredicted.

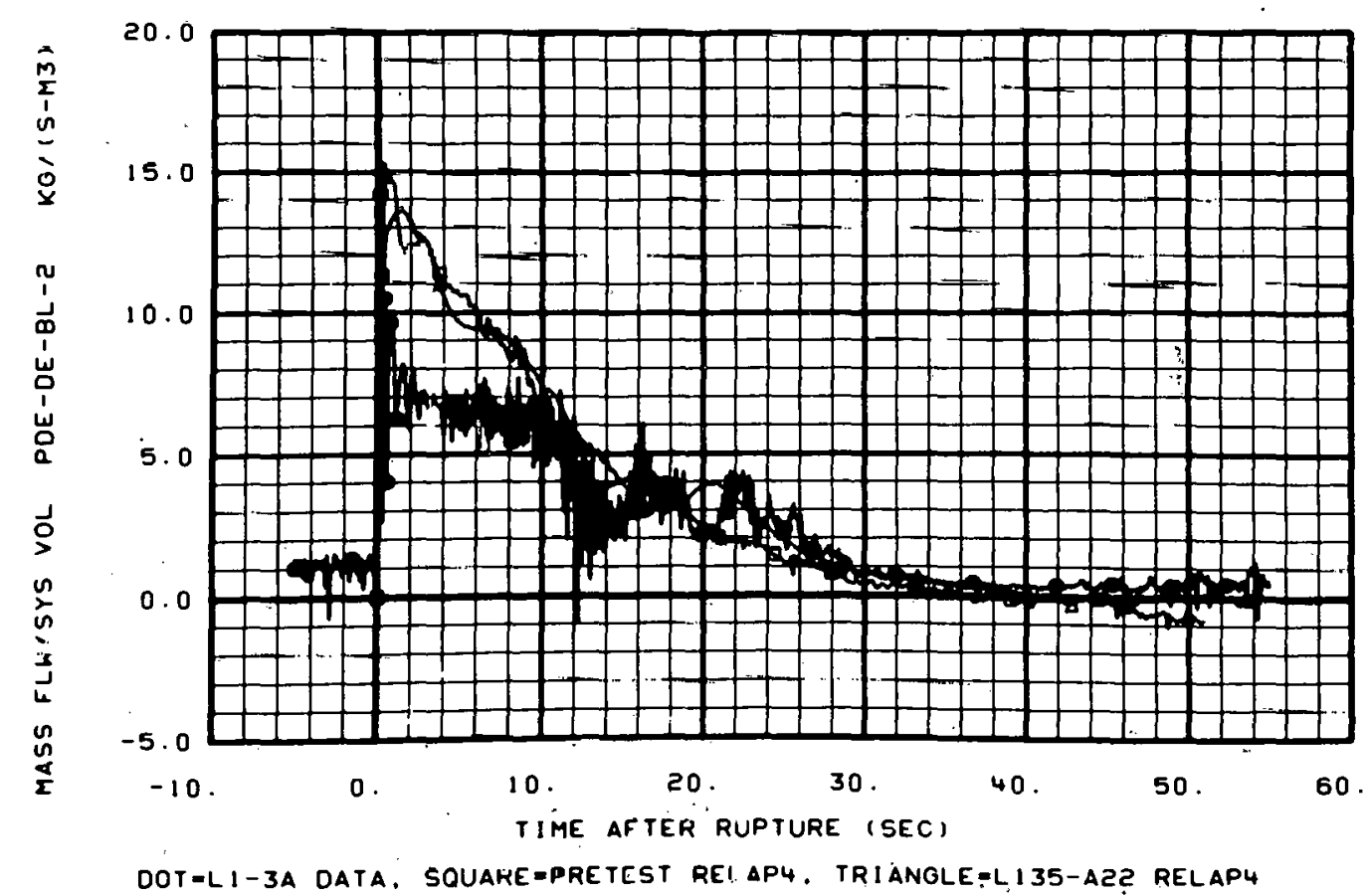

Fig. 66 Comparison of RELAP4 calculated and experimentaliy measured mass flow rate per system volume in broken loop hot leg. 


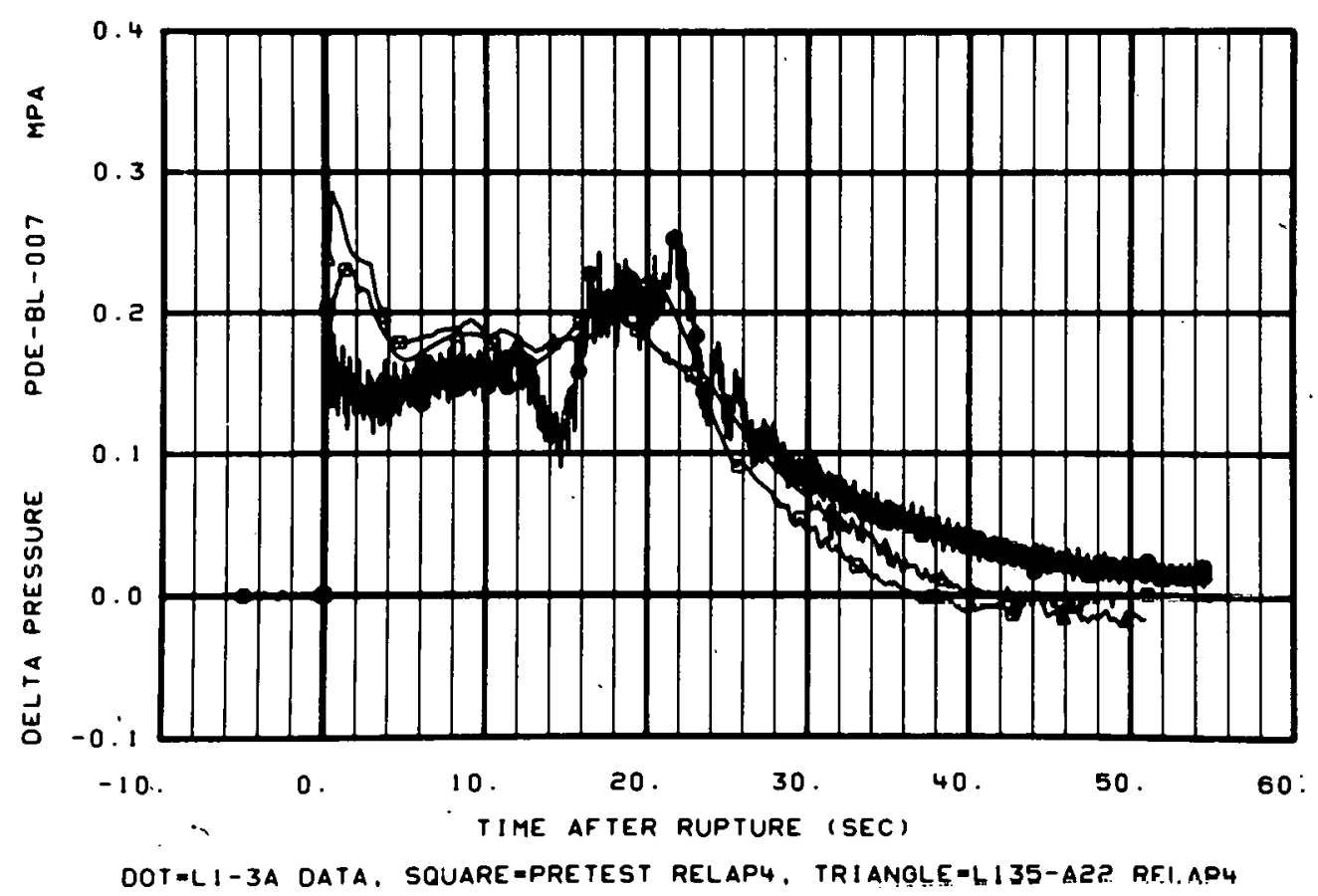

Fig. 67 Comparison of RELAP4 calculated and experimentally measured differential pressure across broken loop steam generator simulator.

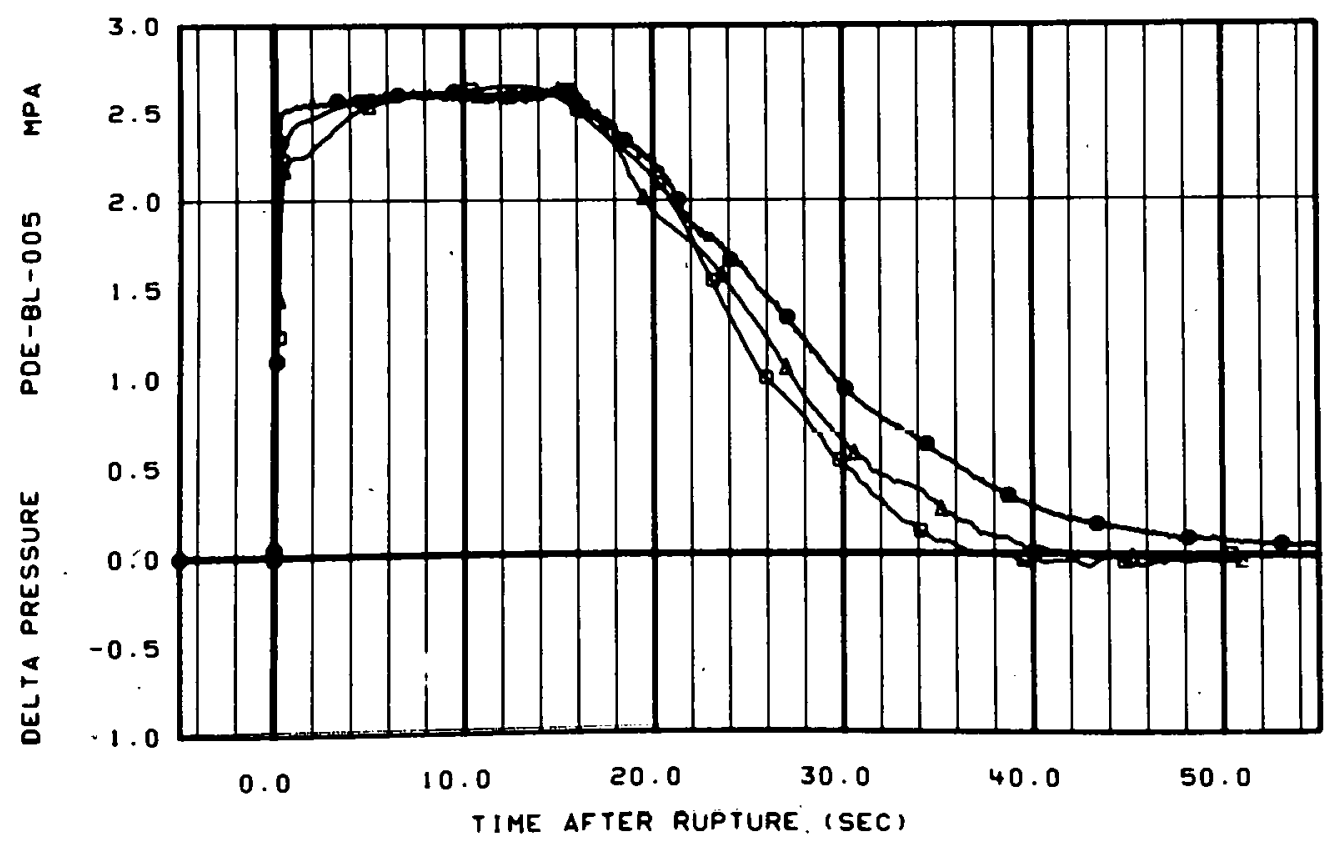

DOT-LI-3A DATA, SOUARE=PRETEST RELAP4, TRIANOLE=LI35-AZ2 RELAPY

Fig. 68 Comparison of RELAP4 calculated and experimentally measured differential pressure across hroken loop pump simulator. 


\subsection{CONCLUSIONS}

Several conclusions can be drawn from the analytical studies that have gone into the preparation of this report. Modeling the pressurizer is important in predicting system behavior during early saturated blowdown for an isothermal LOCE. By more properly modeling the pressurizer, not only cán préssurizer pressure and level be more accurately predicted, but early density, pressure, and flow behavior can be more accurately predicted as well. Proper modeling of the LOFT pressurizer must include all important pressure loss ellects in lie pressurizer surge line. This includes accounting for rough tubing Fanining friction losses, accounting for the form losses of the bends in the surge line tubing, and accounting for two-phase form losses.

The primary system pressure can be better predicted when ECC flows are not overpredicted, and nodalization in the reactor vessè should be such as to minimize steam condensation effects. ECC flows in the L1-3A pretest prediction were overpredicted due to (a) underprediction of primary system pressure after ECC injection began due to excessive steam condensation, (b) overprediction of accumulatur nitrogen pressure due t.i the isoothermal accumulator nitrogen pressure assumption, and (c) failure to account for the total resistance of the accumulator injection line.

Use of measured initial condftions dS opposed to EOS nominal initial conditions had a negligible influence on calculated system response. Using finer nodalization ill dreas where steam condensation was expected to occur was responsible for a better overall prediction of the system pressure history. The manometer oscillations observed between the downcomer and core volumes in both the pretest and posttest calculations were apparentiy driven by unequal steam condensation. Injecting higher enthalpy fluid eliminated the oscillations, as well as the over depressurization observed in both the pretest and posttest analysis. 


\subsection{REFERENCES}

1. T. K. Samuels, Appendix A to Volume 2, LOFT Experiment Operating Specification, Volume 2, Nonnuclear Test Series LI Experiment 3, Aerojet Nuclear. Company, EOS Volume 2, NNE L1-3, Revision 1 (April 1976).

2. T. K. Samuels, Conformed Copy of LOFT Experiment Operating Specification, Volume 2, Nonnuclear Test Series $L l$ Experiments 3 and $3 A$, NNE LI-3 and $-3 A$, Aerojet Nuclear Company, EOS Volume 2, NNE L]-3 and $-3 A$, Revision 2 (September 1976).

3. H. C. Robinson, LOFT System and Test Description (Loss-of-Coolant Experiments Using a Core Simulator), TREE-NUREG-1019 (November 1976).

4. J. K. Jacoby, Appendix A to Volume 1,. LOFT Experiment Operating Specification, LOFT Nonnuclear Experiment Series L-1, Aerojet Nuclear Company, Revision 2 (August 1974).

5. G. L. Singer et al, RELAP4/MOD5 A Computer Program for Transient Thermal-Hydraulic Analys is of Nuclear Reactors and Related SystemsUser's Manual, ANCR-NUREG-1335 (September 1976).

6. G. M. Millar, Experiment Data Report for LOFT Nonnuclear Test L1-3A, TREE-NUREG-1027 (December 1976).

7. J. R. White et al, Experiment Prediction for LOFT Experiment L1-3, Aerojet Nuclear Company, EP LI=3 (June 1976).

8. J. G. Collier, Convective Boiling and Condensation, London: McGrawHill Book Company, Inc., 1972. 
9. Society of Automotive Engineers, SAE Aero-Space Applied Thermodynamics Manual, Section 1, Part B, "Thermodynamics and Compressible Flow" (1969).

10. James R. White et a1, Experiment Prediction For LOFT. Nonnuclear Experiment LI-4, TREE-NUREG-1086 (April 1977). 


\section{APPENDIX A}

INPUT AND TIME $=0.0$ LISTING FOR THE NEW PRESSURIZER MODEL RELAP4 RUN

(RELAP4 RUN L135-A23) 


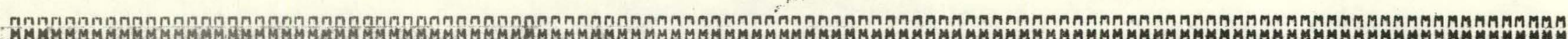

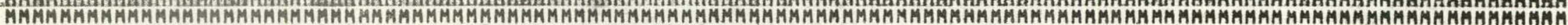
O.JRP TSB L L $135-A 23$ PRE-TEST PRED. WTH NEW PRES. MODEL

ISTING OF INPUT DATA FOR CASE 1 .

$\frac{1}{2}=0 L O E T L 135-A 23$ PRE-TEST PREDICITONS WLTH NEW PRESSURLZER MODEL CONCO=.75

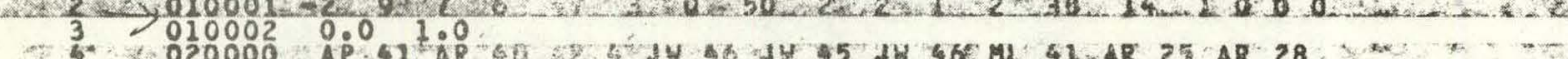

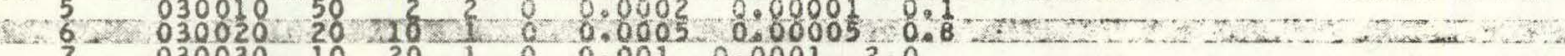

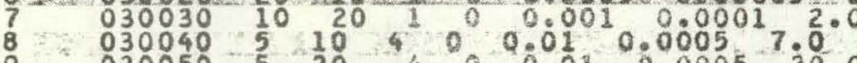

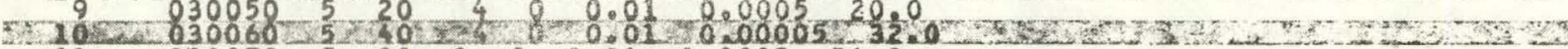

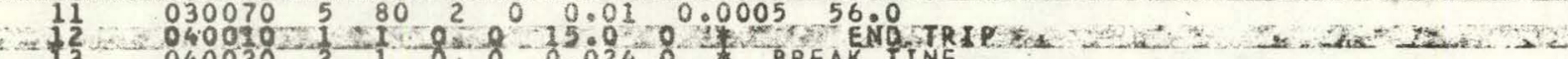

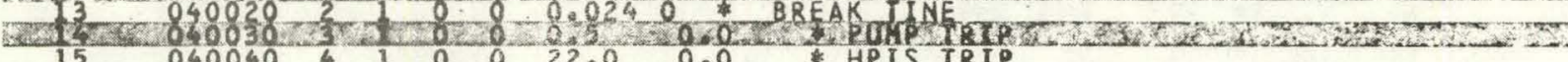

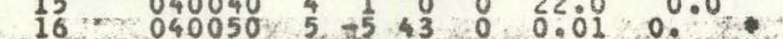

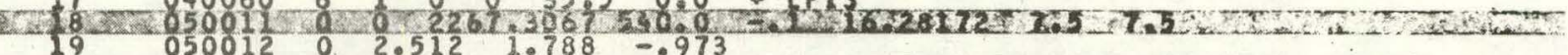

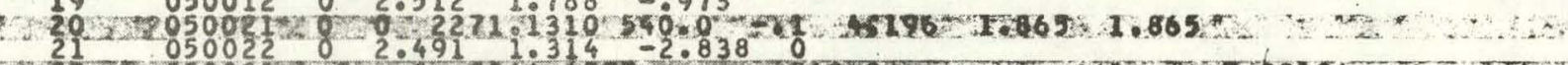

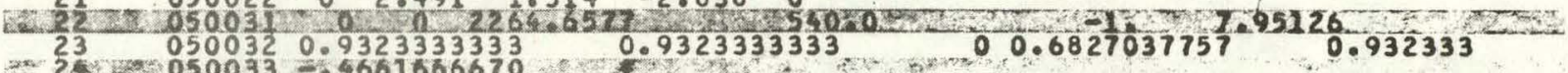
एक 230500320.932333333

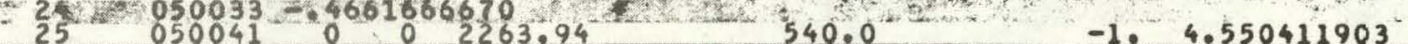

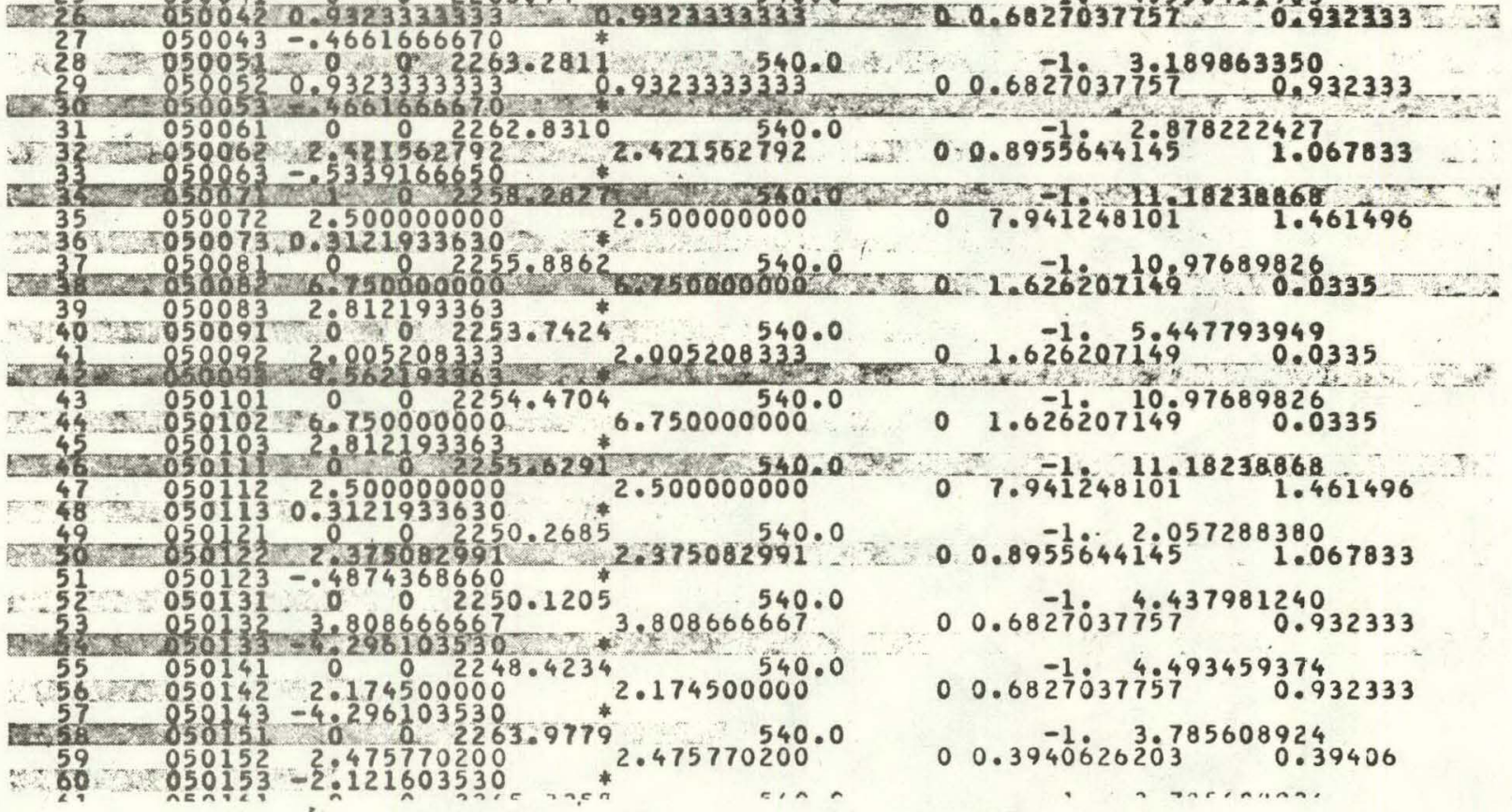




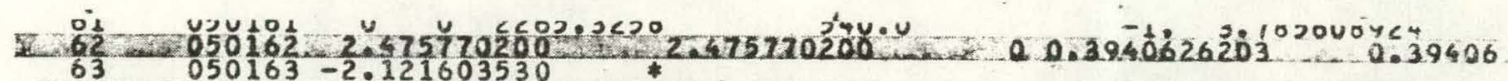

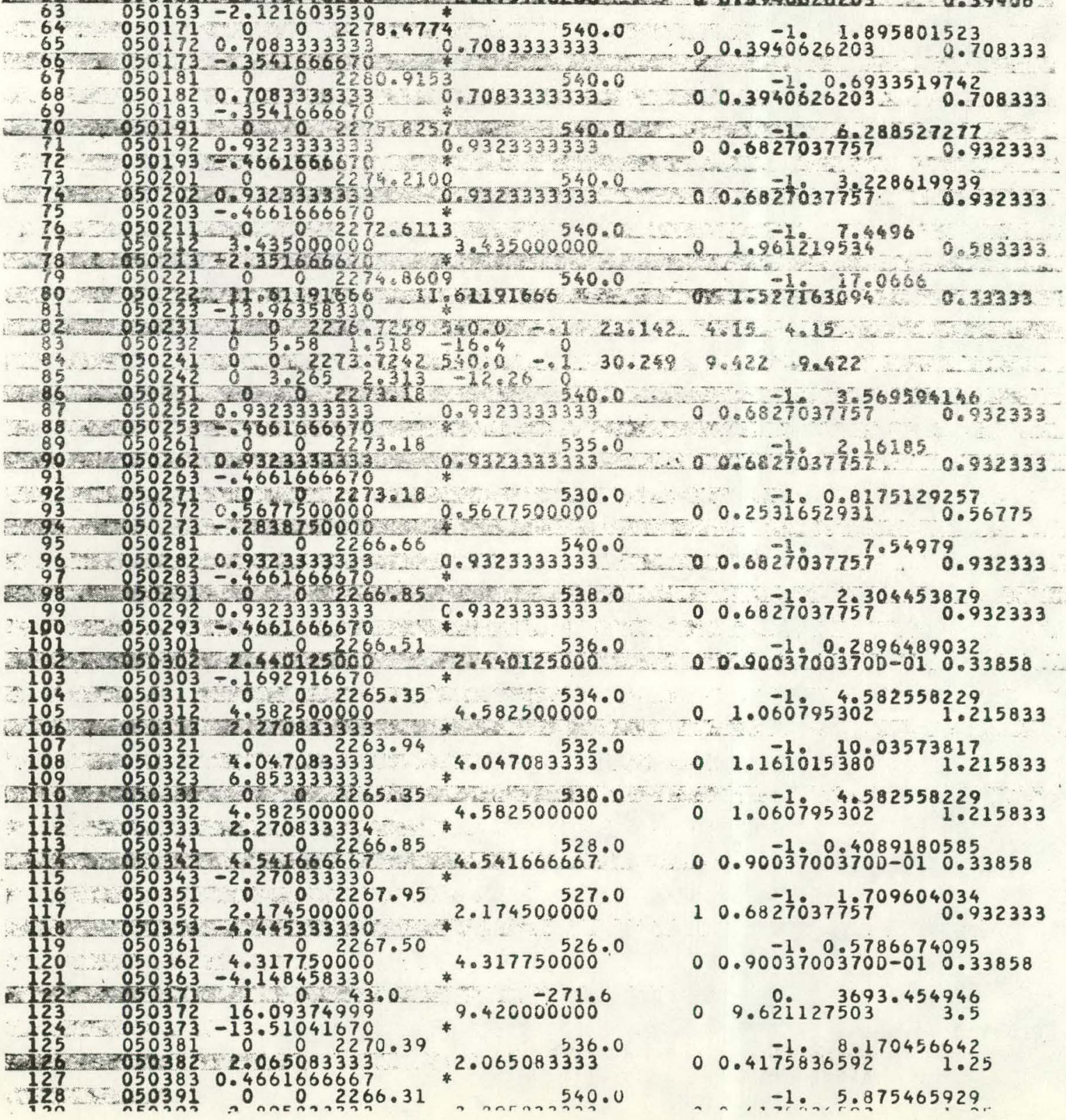




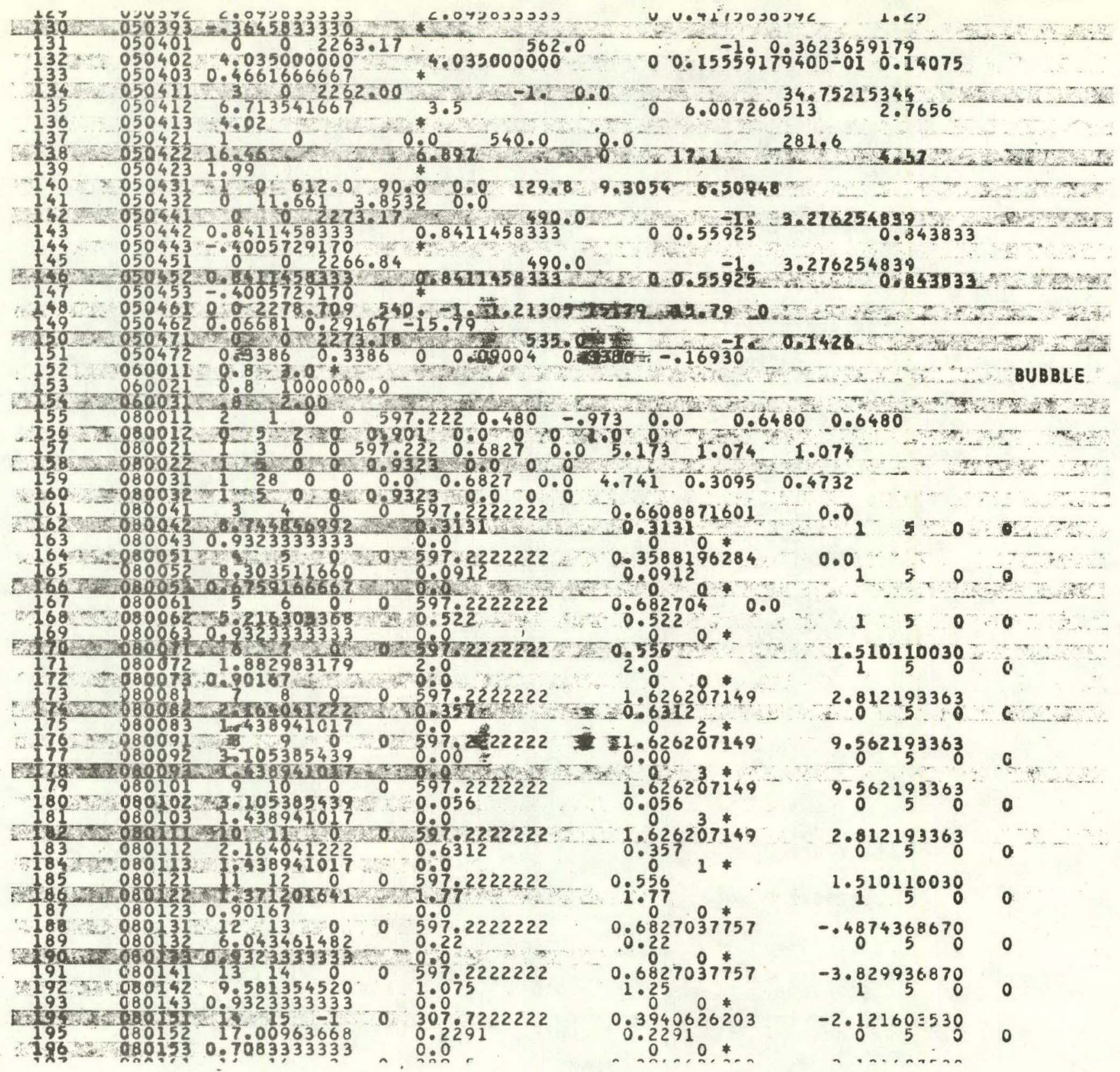




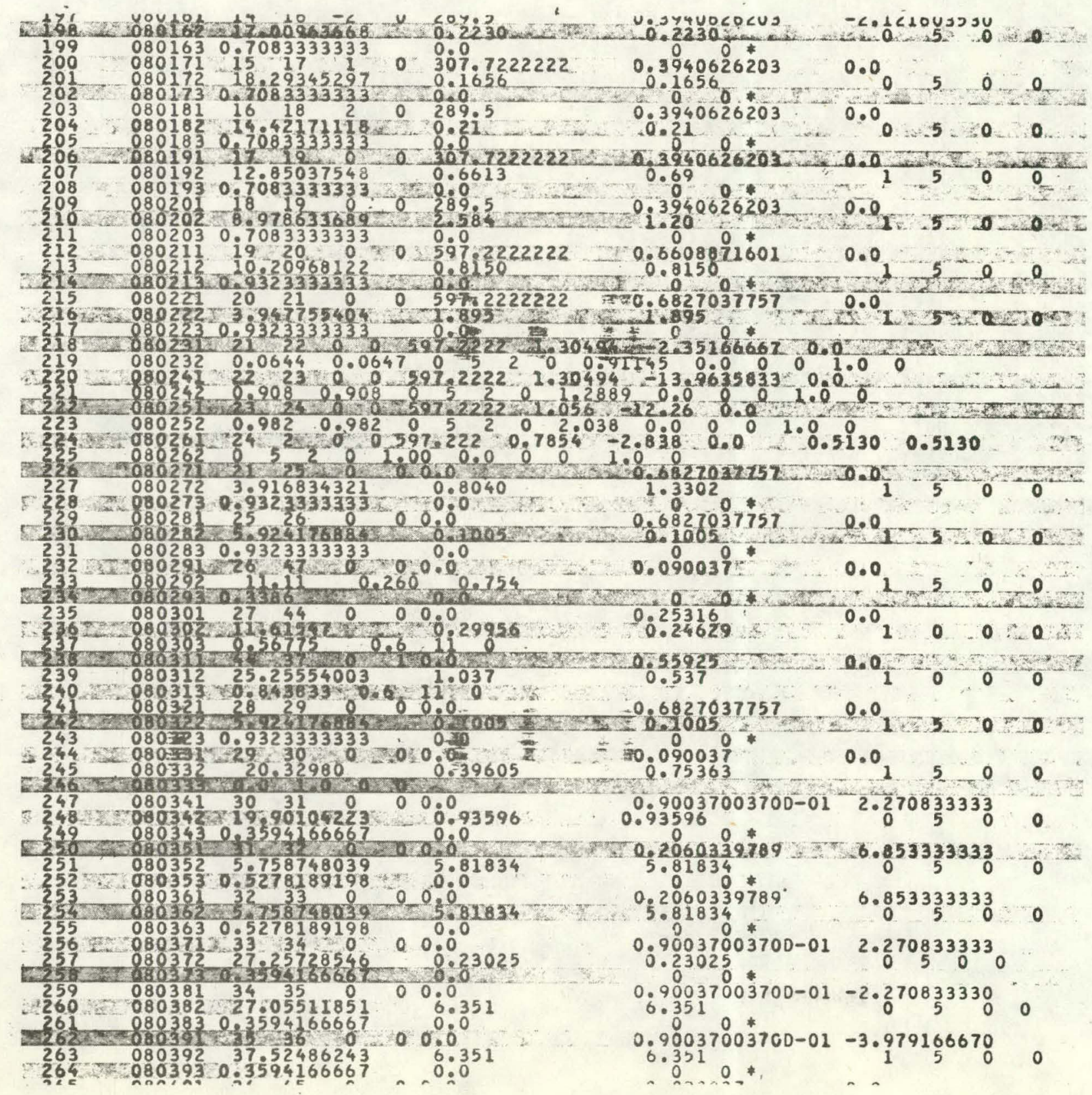




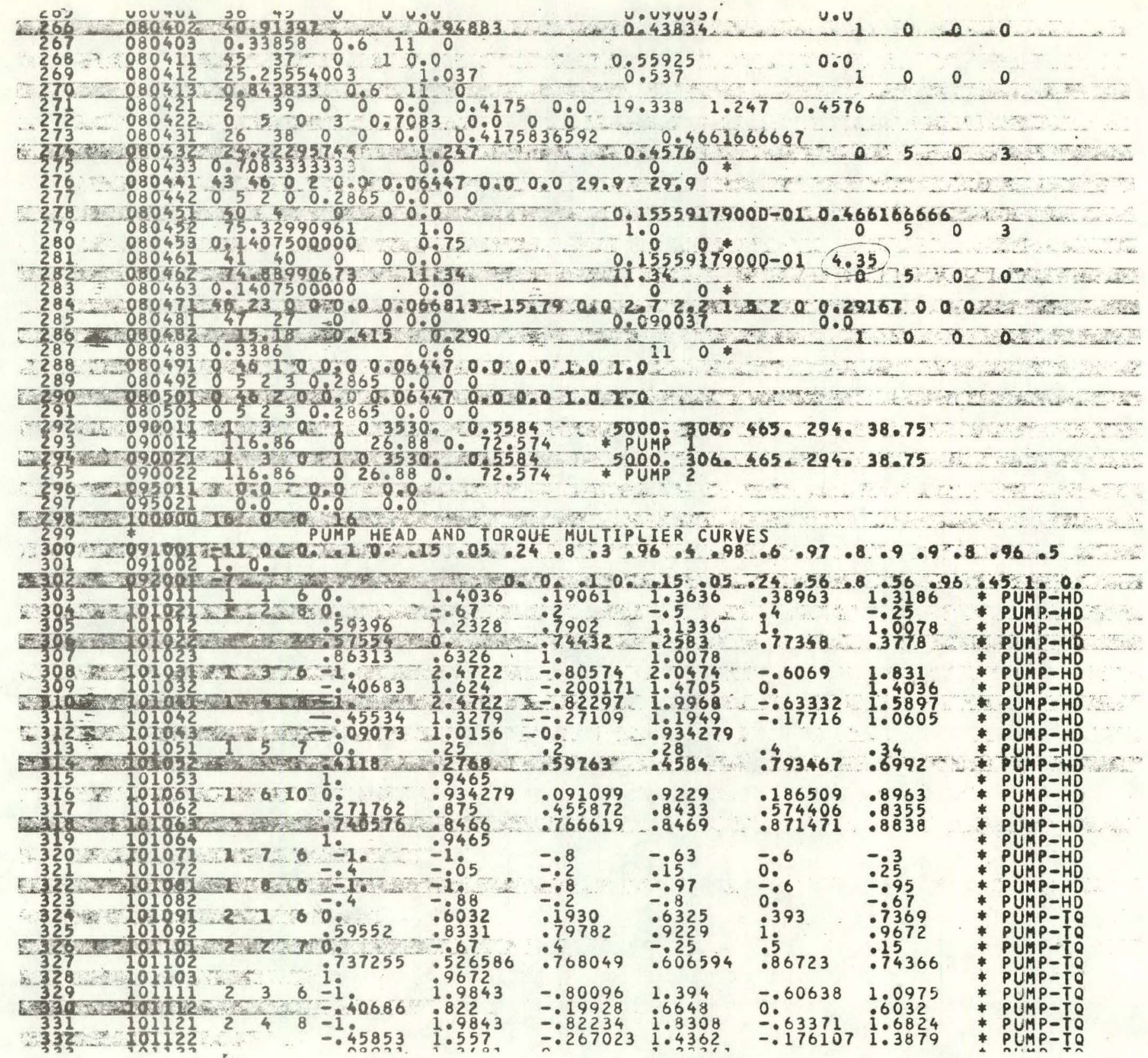




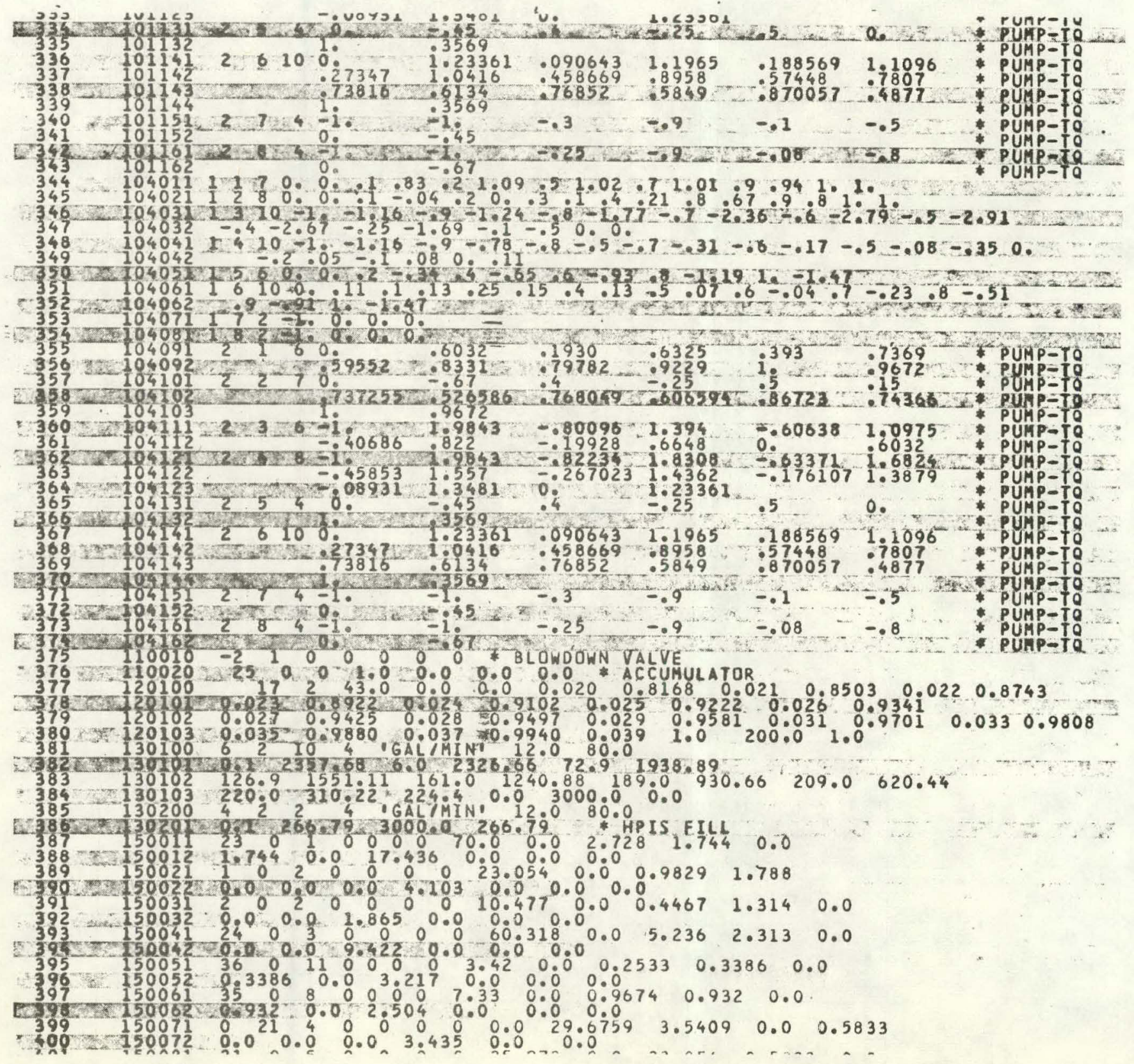




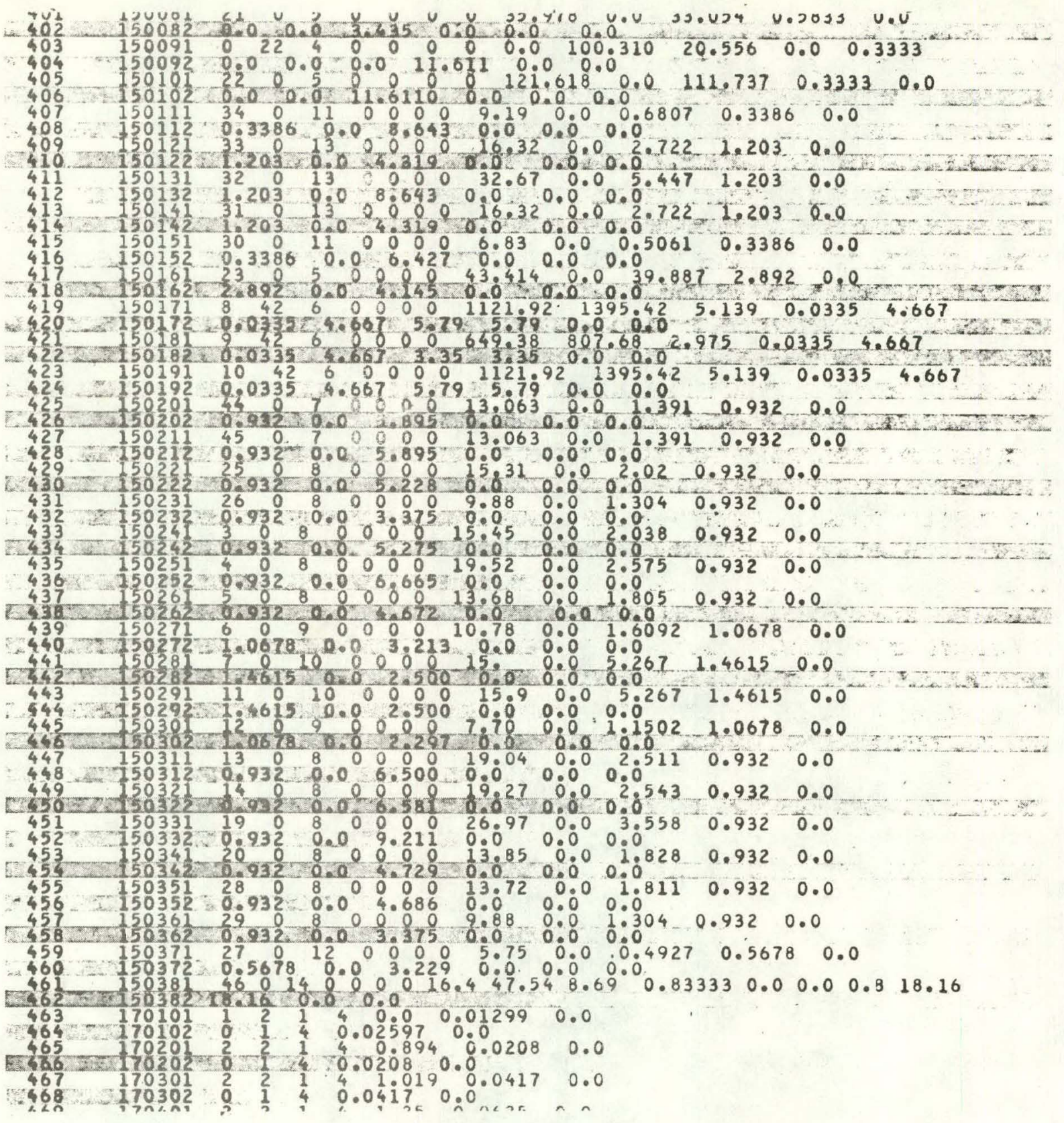




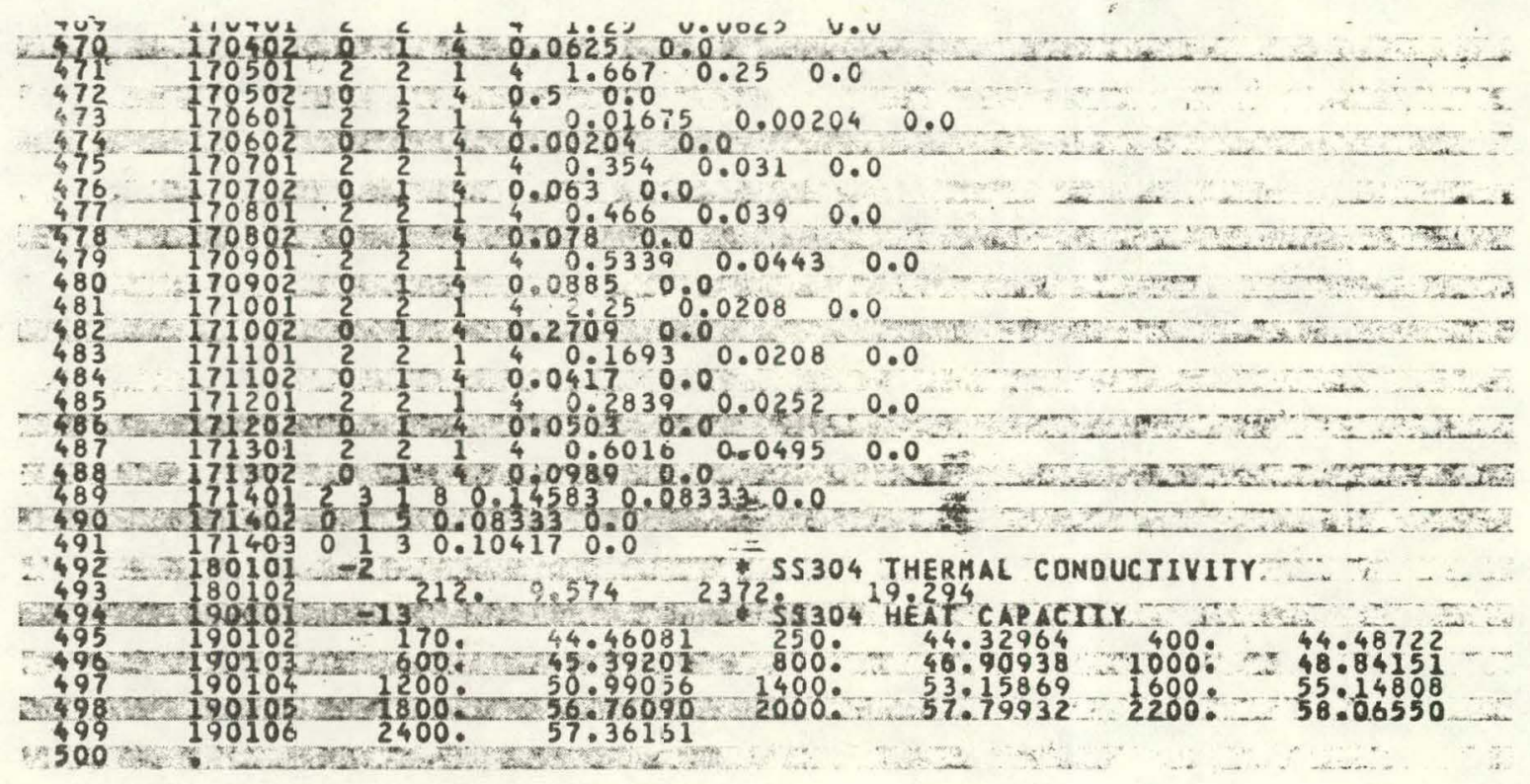


MISCELLANEOUS PROBLEA CONTROL DATA.

TAPE NUM NUM NUM AUM NIM NUM NUM NUH NUM NUM NUM NUM NUA NUM NUM NUM PRODAP EDIT TIME TRIP VOL Q TIME JUN PUMP CHK LEAR FILL HEAT SLAB SLAB CORE HEAT GRAM

$$
\begin{array}{lllllllllllllllll}
-2 & 9 & 7 & 6 & 47 & 3 & 0 & 50 & 2 & 2 & 1 & 2 & 38 & 14 & 1 & 0 & 0
\end{array}
$$

RELAP4/C05 01102176 ( 11 RELAP4 THERMAL HYDRAULIG GODE GONFIGURATION CONTROL \&YES

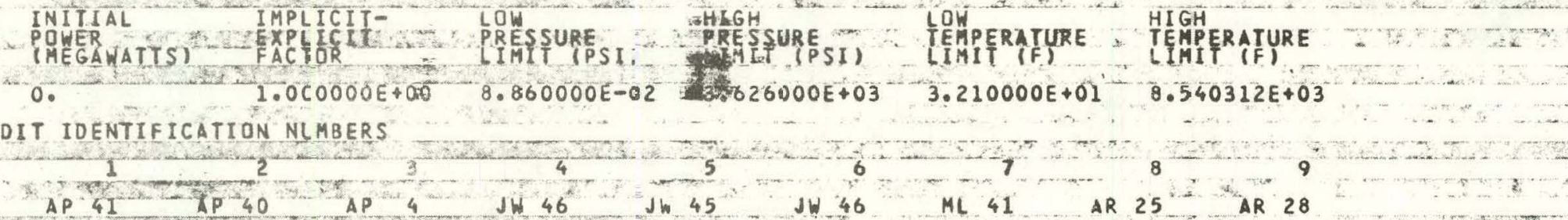

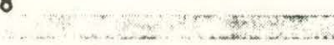

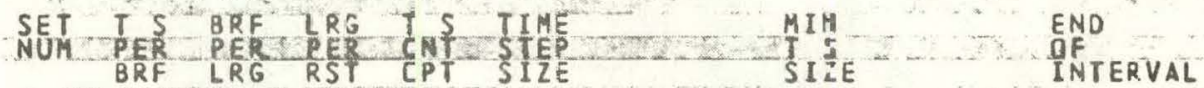

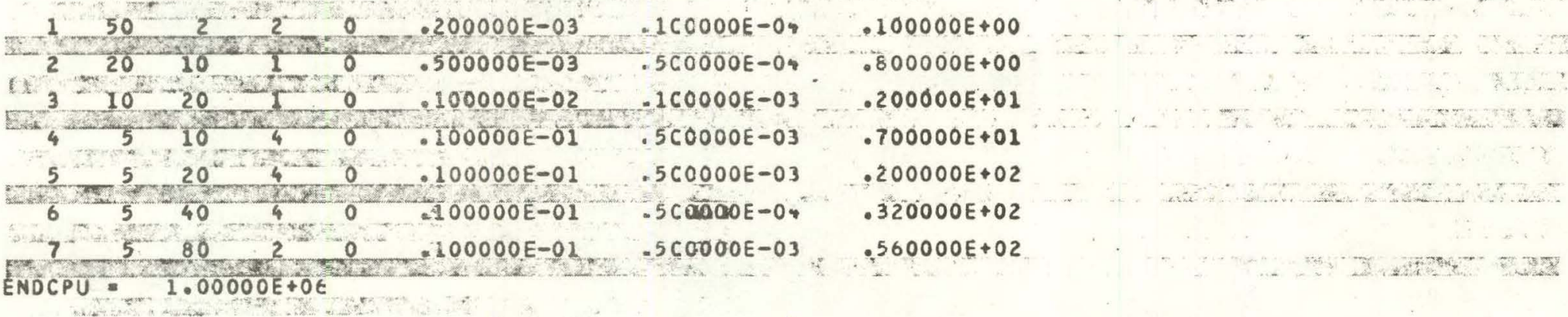




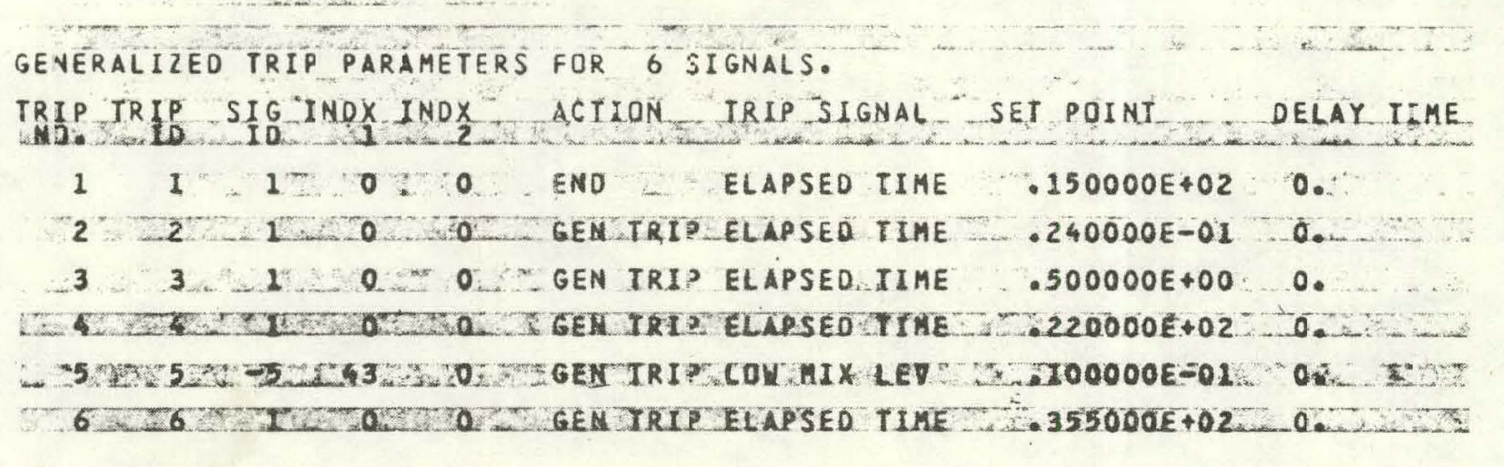


INPUT DATA. FOR 47 VOLUMES.

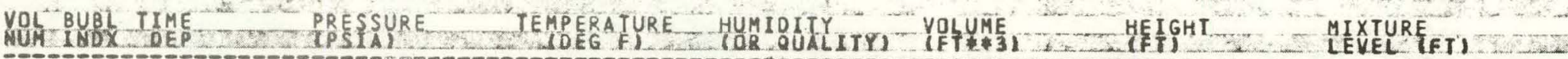

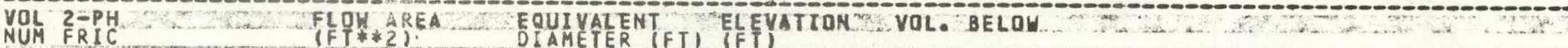

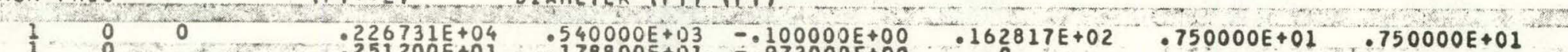

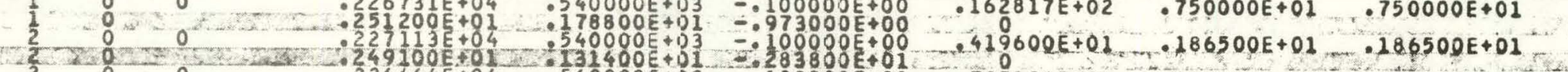

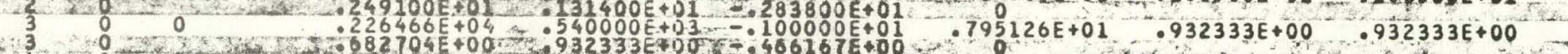

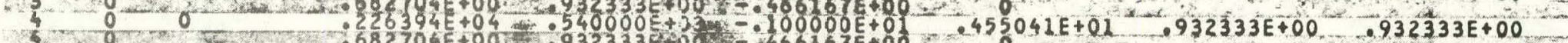

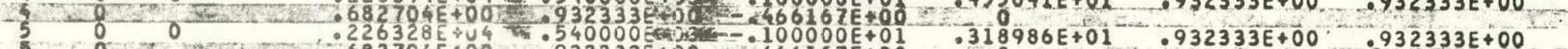

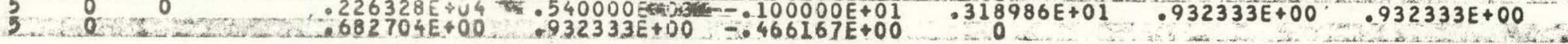
6 60 O

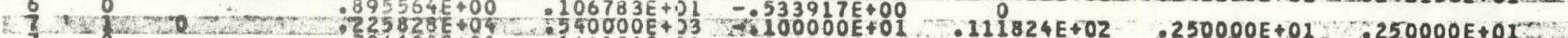

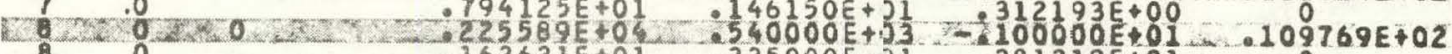

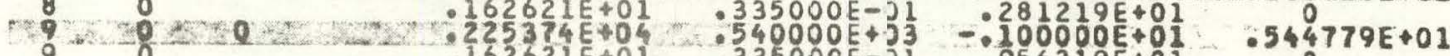

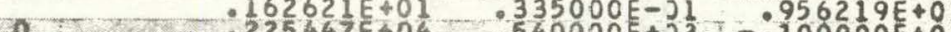

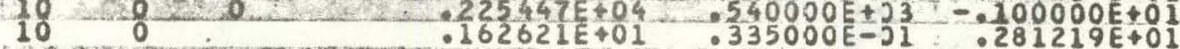

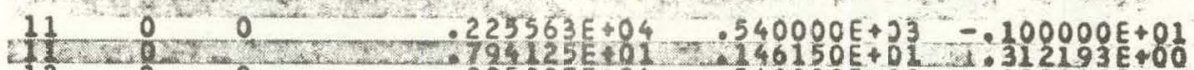

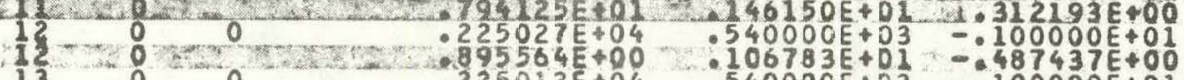
$130000.225012 E+04-054000 E+53=0100000 E+01$

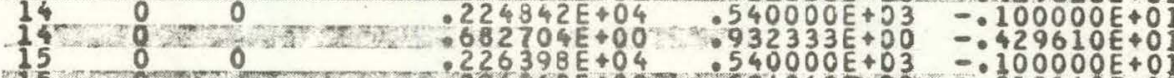

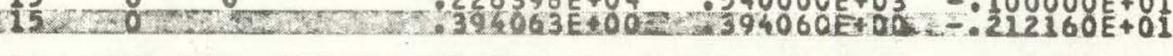

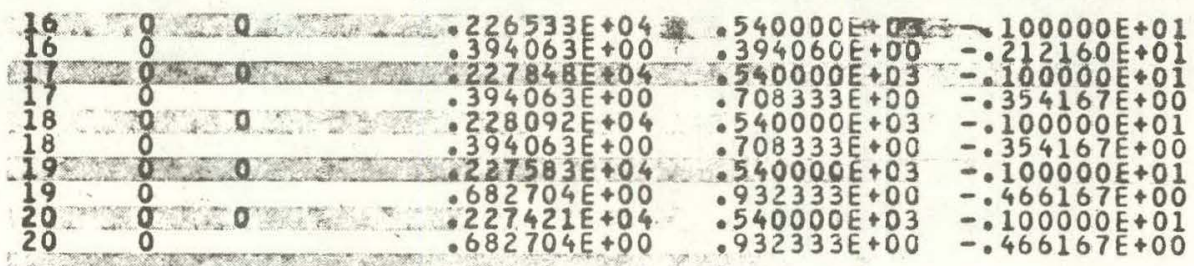

$.109769 \mathrm{E}+02$

$.111824 E+02$ $.205729 E+01$ - $443798 E+01$ $.449346 E+01$ $.378561 E+01$ $.378561 E+01$ $.189580 E+01$ $.693352 E+00$ $.628853 E+01$ $.322862 E+01$ $250000 E+01 \quad .250000 E+01$. $.675000 E+01 \quad 675000 E+01$ $.200521 E+01 \quad .200521 E+01$ $.675000 E+01 \quad .675000 E+01$ $.250000 E+01 \quad .250000 E+01$ $.237508 E+01.237508 E+01$ $.380867 E+01 \quad .380867 E+01$. $.217450 E+01$. $217450 E+01$ $.247577 E+01 \quad .247577 E+01$

$.247577 E+01$ $.708333 E+00$ $.708333 E+00$ $.247577 E+01$ $.708333 E+00$ CR $.708333 E+00$ $.932333 E+00 \quad .932333 E+00$ $.932333 E+00 \quad .932333 E+00$ 


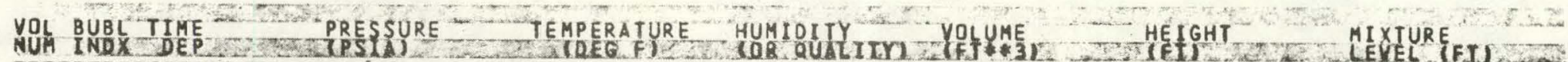
NOL $2-P H$
NUT

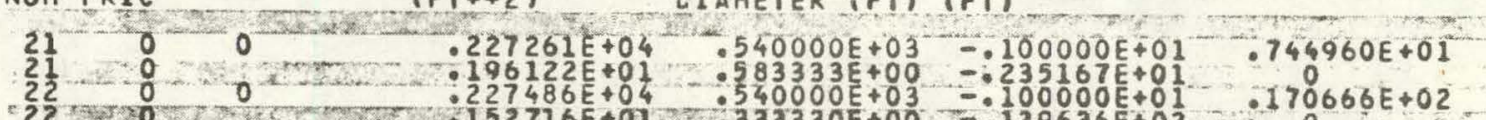

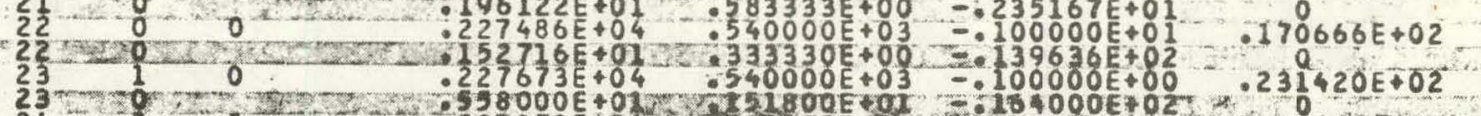

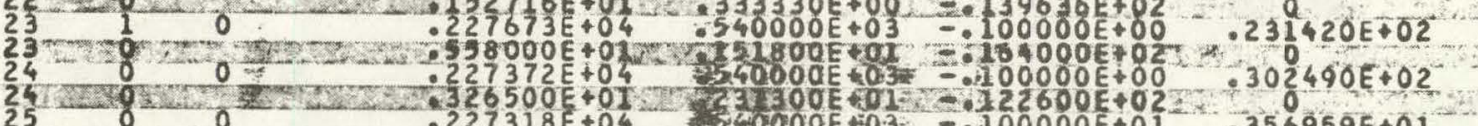

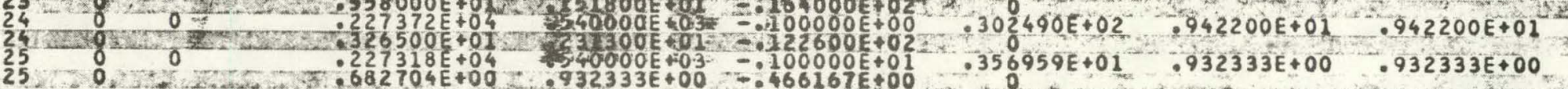

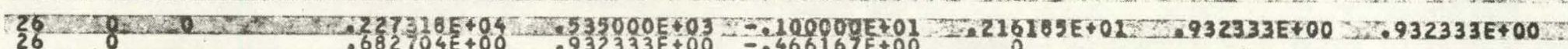

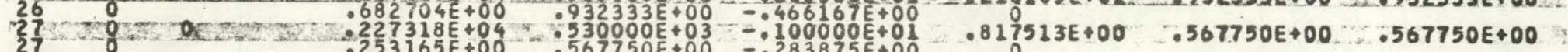

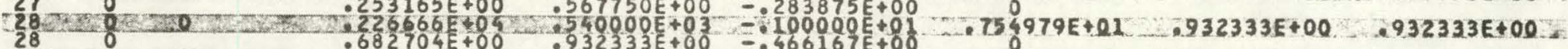

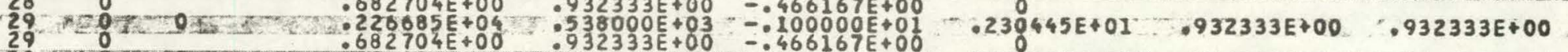

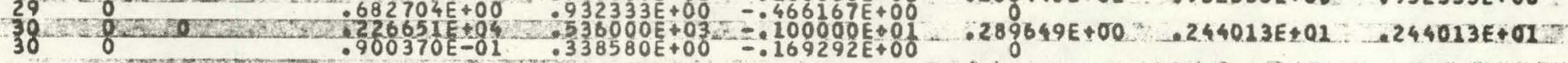
$31 \quad 0 \quad 0226535+04 \quad .534000 E+03=.100000 E+01 \quad .458256 E+01$

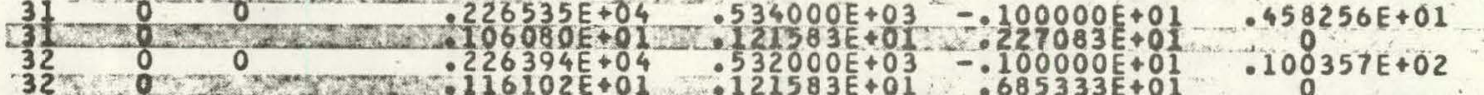
$\begin{array}{lllll}32 & 0 \\ 3 & 0 & 0\end{array}$ $\begin{array}{llll}33 & 3 & 0 & 3\end{array}$

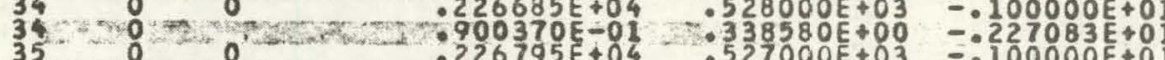

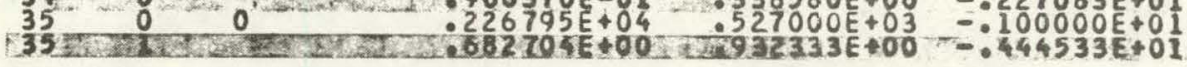
$.408918 E+00$ $.170960 E+01$ $.343500 E+01 \quad .343500 E+01$ $116119 \mathrm{E}+02 \quad 116119 \mathrm{E}+02$ $415000 E+01-415000 E+01$

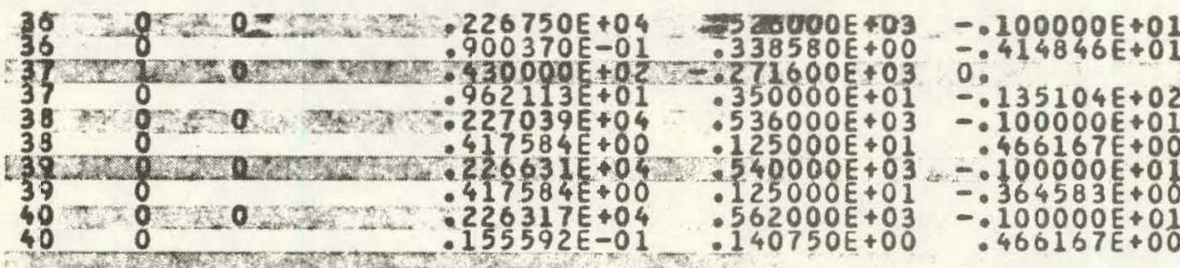

$.578667 E+00$ $.369345 E+04$ $.817046 \mathrm{E}+01$ $.587547 E+01$ $.362366 \mathrm{E}+00$ $.458250 E+01 \quad .458250 E+01$ $.404708 E+01$. $404708 E+01$ $.458250 E+01 \quad .458250 E+01$ $.454167 E+01 \quad .454167 E+01$ $.217450 E+01 \quad .217450 E+01$ $.431775 E+01 \quad .431775 E+01$ $.160937 E+02.942000 E+01$ $.206508 E+01$. $206508 E+01$ $.289583 E+01 \quad .289583 E+01$ $.403500 E+01 \quad .403500 E+01$ 


\begin{tabular}{|c|c|}
\hline $\begin{array}{l}\text { FLJW AREA \& EOUIVALEAT } \\
\text { (FT ELE ELVATION VOL. }\end{array}$ & BELOW \\
\hline 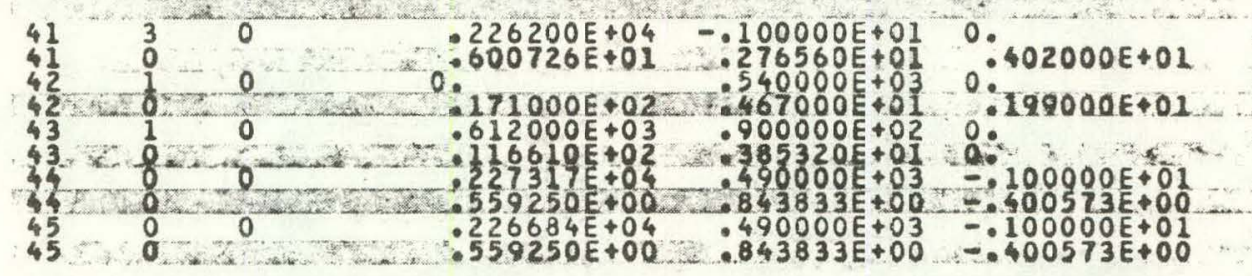 & 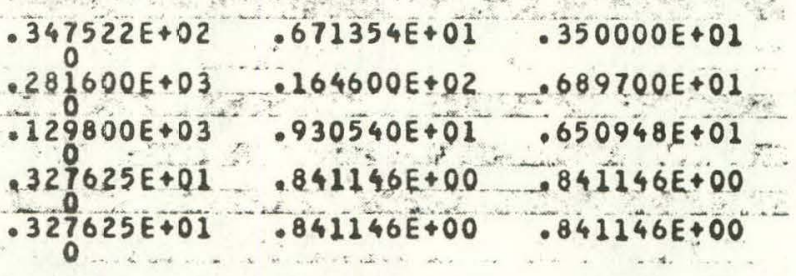 \\
\hline 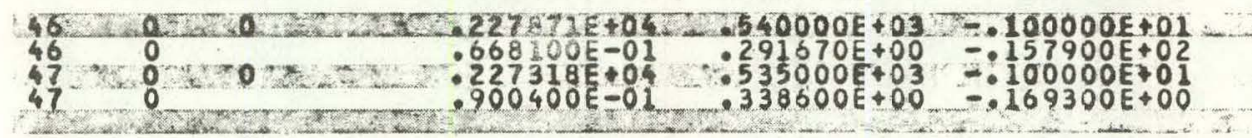 & $\begin{array}{l}.121305 E+015 x-157900 E+02=-.151 \\
.142600 E+00 \quad .338600 E+00 \quad .338\end{array}$ \\
\hline
\end{tabular}




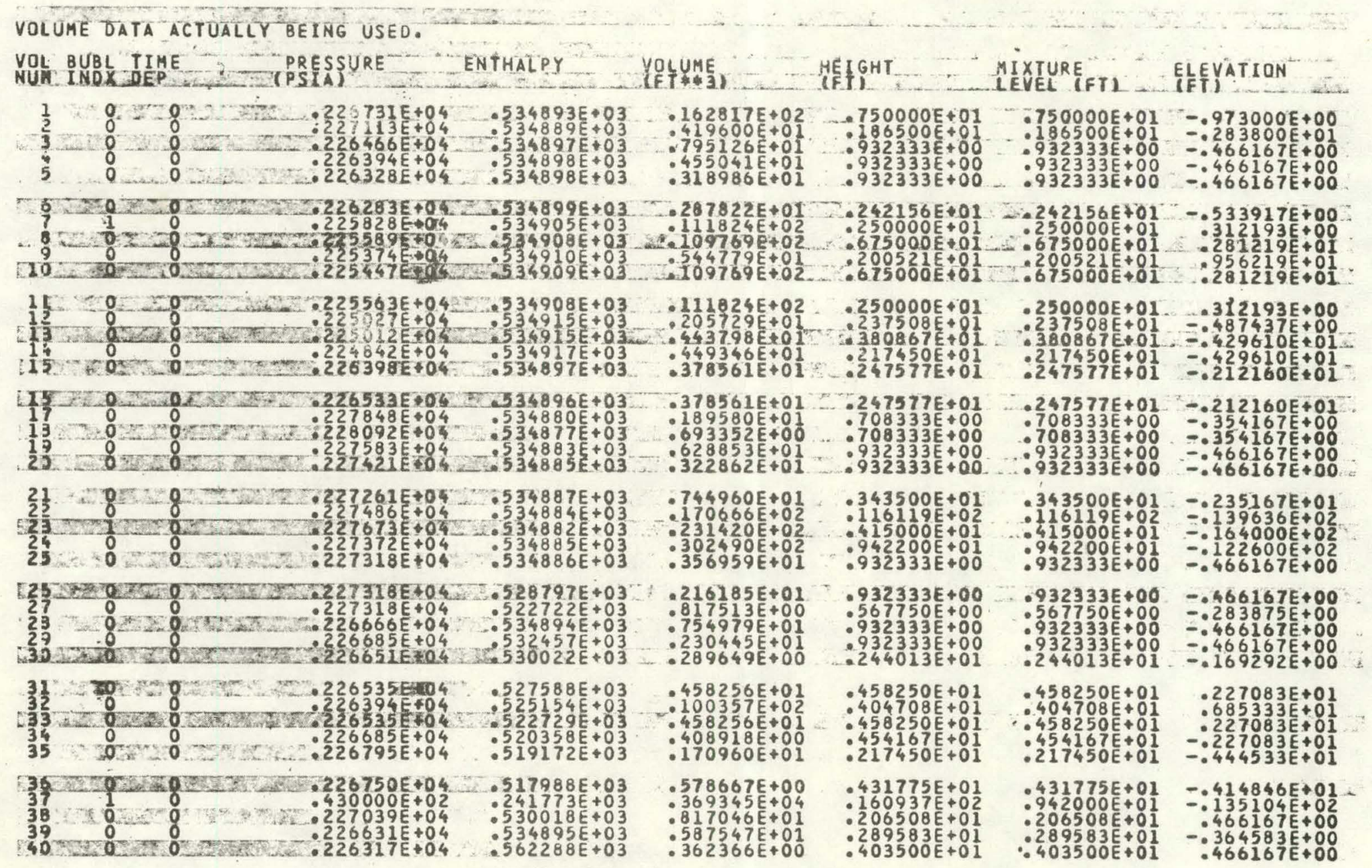


VOLUME DATA ACTUALLY BEING USED.

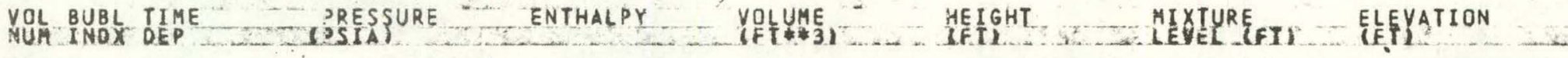

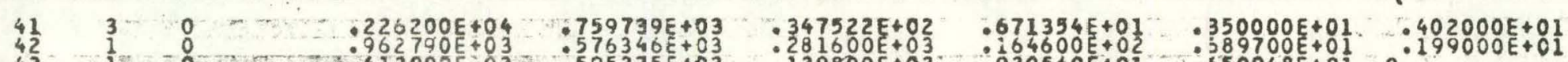

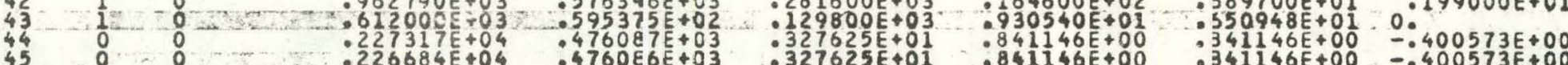

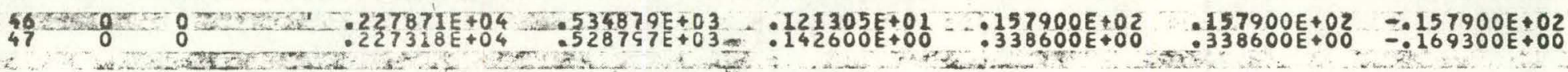


VOLUME DATA ACTUALLY BEING USED.

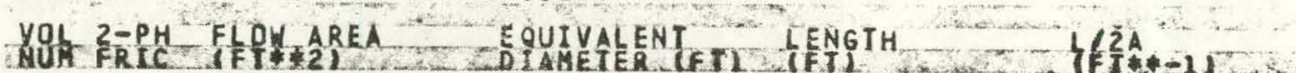

HORI 2. AREA TEMPERATURE

SATURAIION VOL. BELOH

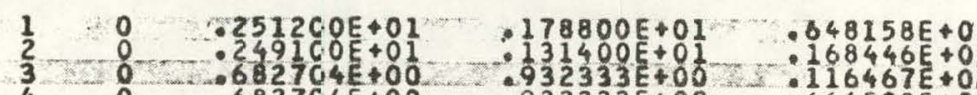

$.122012 E+0$

$.217090 E+01 \quad .540000 E+03$

$540000 \mathrm{E}+03$
$540000 \mathrm{0}$
$540000 \mathrm{O}$ $50.500006+03$

$\begin{array}{lll}4 & 0 & : 62764 E+00 \\ 5 & 0 & 682704 E+00\end{array}$ $066528 \mathrm{E}+01$
$: 467240 \mathrm{O}+01$ $448153 \mathrm{E}+01$ $.852834 E+01$ $.4880677+01$

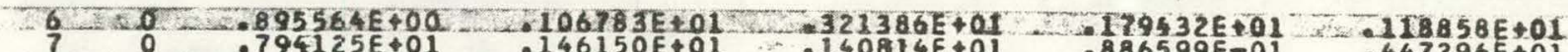

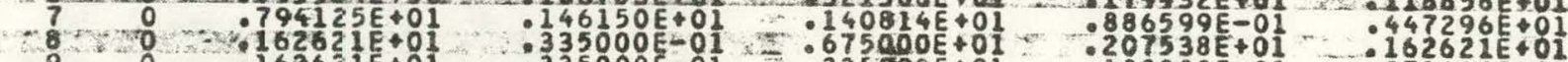

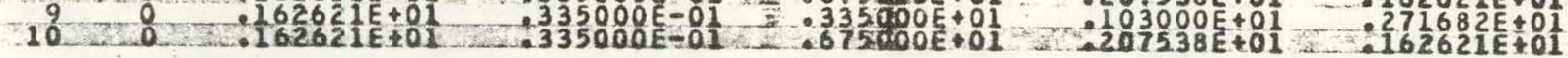

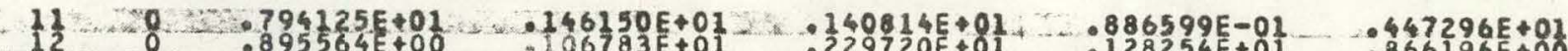

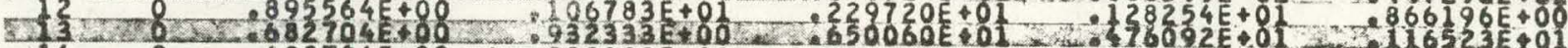

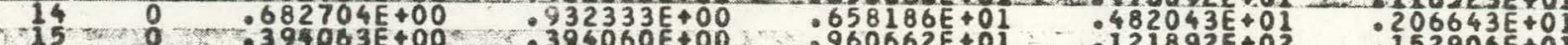

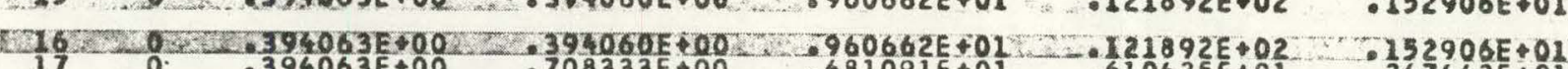

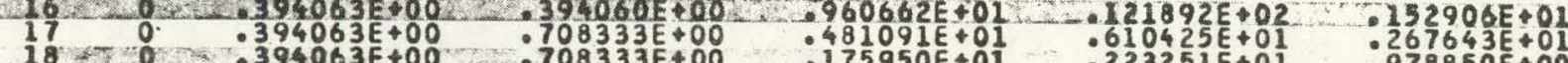

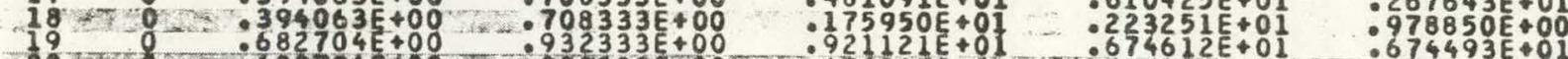

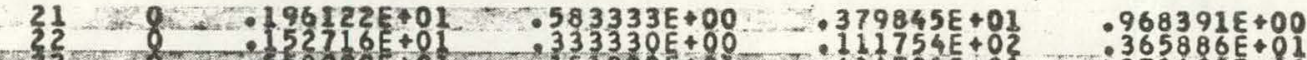

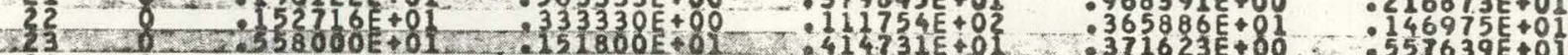

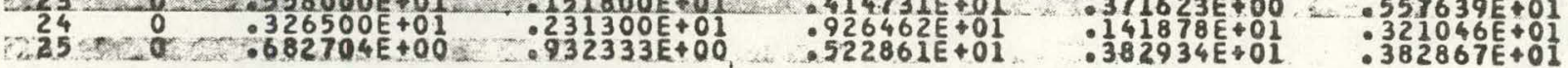

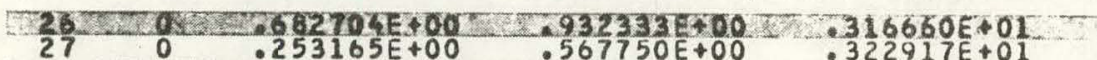
$231916 E+01-231875 E+01$

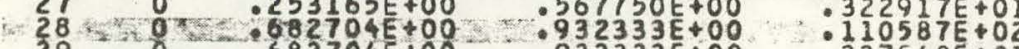

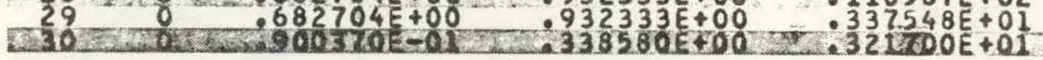

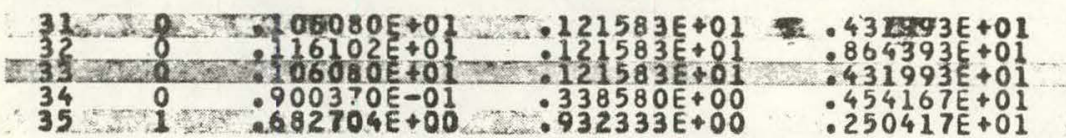
$.637759 E+01 \quad-143992 E+01$ $\begin{array}{lll}247214 E+01 & : 247171 E+01 \\ 178649 E+02 & : 118702+00\end{array}$ - $203617 \mathrm{E}+01$ - $372257 E+01$ $.252211 E+02$ $100001 E+01$ - $14795 \mathrm{E}+01$

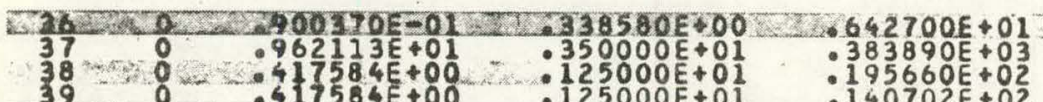
$.356909 \varepsilon+02$ $199504 \mathrm{E}+02$ $168471 E+02$
$: 748418 \mathrm{E}+03$ $: 900370 \mathrm{E}-01$

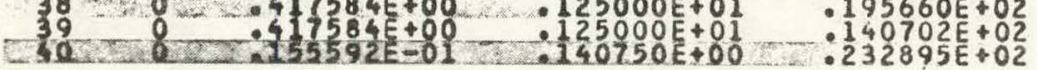
$134021 E+00$
$-229496 E+03$ $: 202894 \mathrm{E}+01$ $.540000 E+03$

.540000E+03 $540000 E+03$ $1540000 \mathrm{E}+03$ $540000 \mathrm{E}+03$

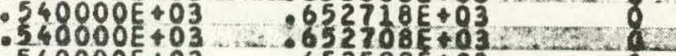
$\begin{array}{lll}540000 \mathrm{E}+03 & 652599 \mathrm{E}+03 & 0 \\ .540000 \mathrm{E}+03 & 653599 \mathrm{E}+03 & 0\end{array}$ $540000 E+03$ 540000 + 103 $540000 \mathrm{E}+03$
$540000 \mathrm{E}+03$ .540000E +03 $540000 \mathrm{E}+03$ $-540000 \mathrm{E}+03$
$.540000 \mathrm{0}$

$.535000 E+03$ $53000+0$ . $538000 \mathrm{E}+03$ $.534000 E+03$ - $5320005+03$ $.528000 \mathrm{E}+03$ $.653813 E+03 \quad 0$ $.654058 E+03 \quad 8$ $.653597 \mathrm{E}+03$
$.653555 \mathrm{E}+03$

-.653526E+03 0 $.653234 \mathrm{E}+03$
$.653079 \mathrm{E}+03$ $.652941 E+03$ 03
$0 \mathrm{O}$ $526000 \mathrm{E}+03$ $.271634 \mathrm{E}+03$ $.540000 \mathrm{E}+03$ $\begin{array}{ll}.653686 E+03 & 0 \\ .654527 E+03 & 0\end{array}$ $.654683 E+03$. $.654358 \mathrm{E}+03$
$.654255 \mathrm{E}+03$ $.654152 E+03$ $.6542965+03 \quad 8$ $.654223 E+03$
$.654189 \mathrm{E}+03 \quad \therefore:$ $.654189 E+03 \quad 20$ 654189 $653762 \mathrm{E}+03$
603 $.653687 \mathrm{E}+03$ $.6535975+03$ $.653783 E+03 \quad 8$

$.653825 E+03 \quad 2 \quad 0$ : $.271634 \mathrm{E}+03$ $.654010 E+03$ $.653749 E+03$
$.653547 E+03$ 
VOLUME DATA ACTUALLY BEING USED.

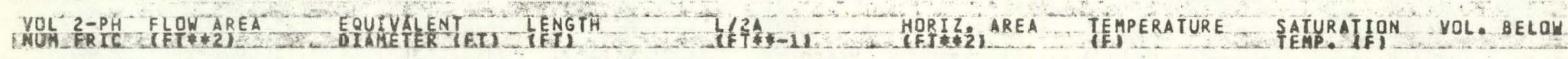

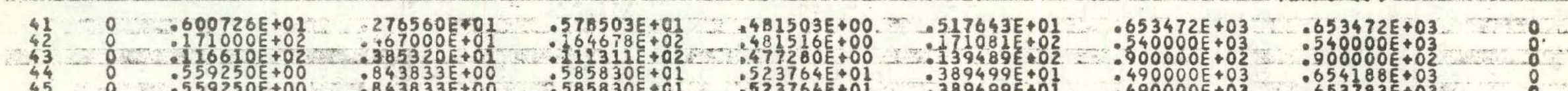

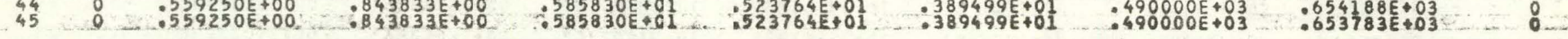

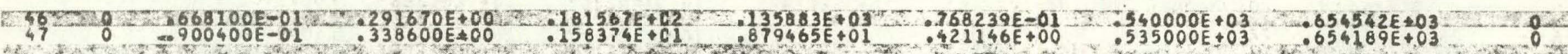

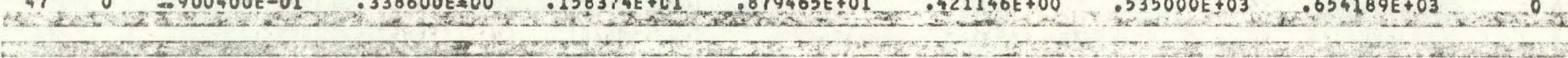




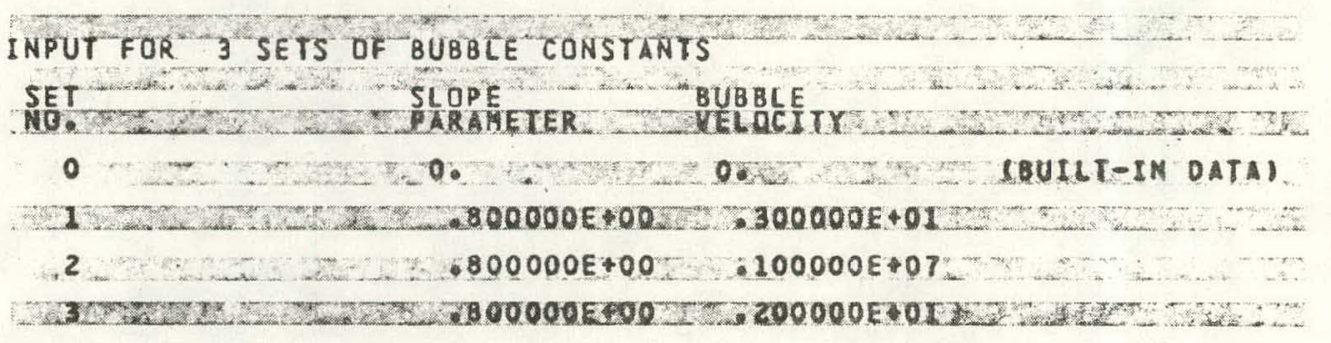


DESCRIPTIONS OF 50 JUNCTIONS.

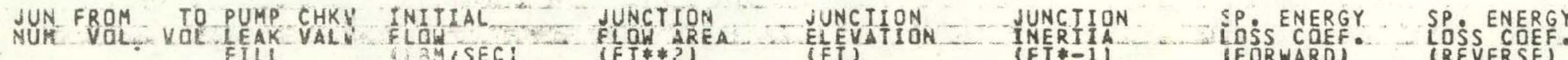

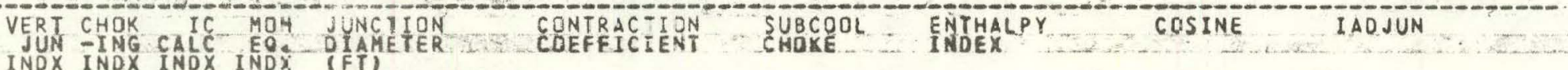
INDX INDX INDX INDX (FT)

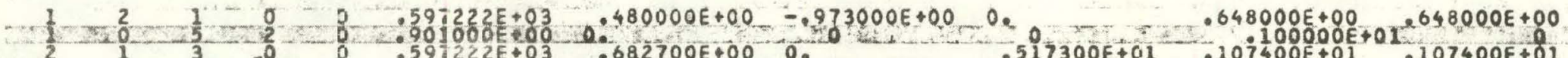

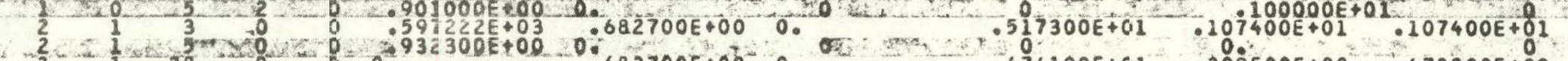

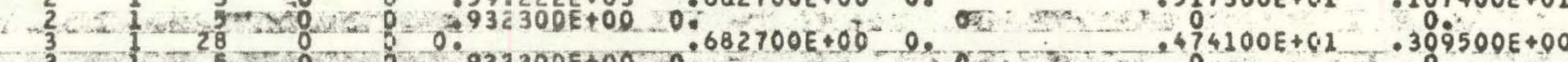
$4 \quad 3 \quad 4 \quad 0 \quad 9 \quad 0597222 E+03 \quad 0610887 E+00 \quad 00 \quad 0874485 E+01.313100 E+00$

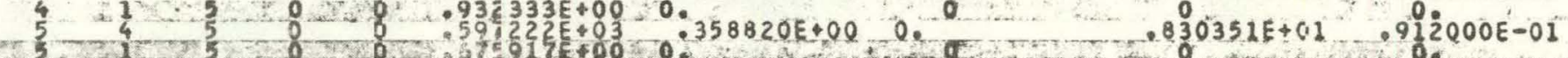

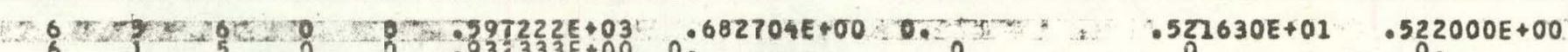

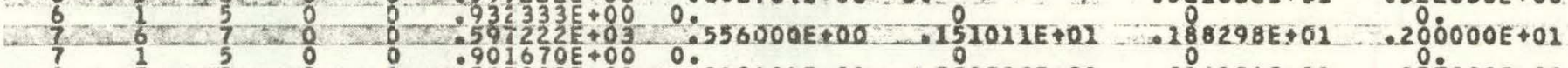

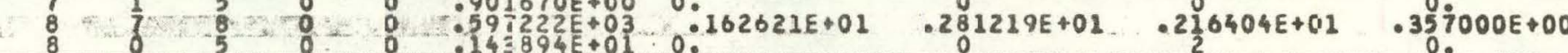

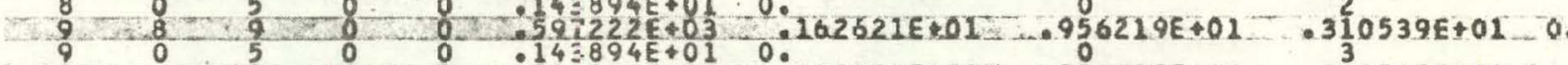

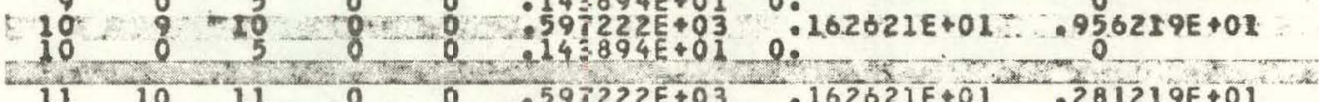
$310539 E+01 \quad .560000 E-01$

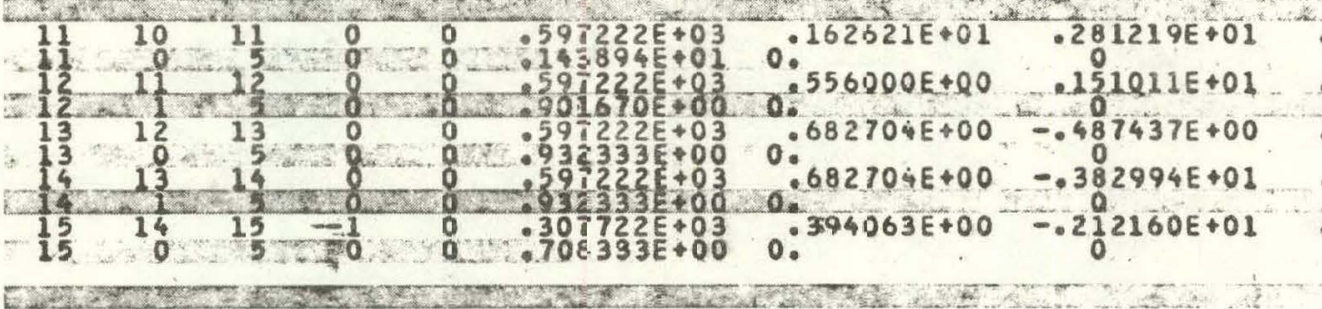
$631200 E \div 0$ $216404 E+01$ $.132120 \mathrm{E}+01$ $.604346 \mathrm{E}+01 \quad .220000 \mathrm{E}+00$ $958135 E+01$ $220000 E+00$ $.170096 E+02$ . $229100 E+00$ $.473200 E+80$ . $313100 E+00$. $.912000 \mathrm{E}-0.1$ $.522000 E+00$ $.200000 E \bullet 01$ $.631200 E+$ DOO Q. - 2 $.560000 E-08$ परत . $357000 E+00$ $.177000 E+01$ $.220000 E+000$ $.125000 \mathrm{E}+\mathrm{O}_{1}$ $.229100 E+0_{0} 0$ 


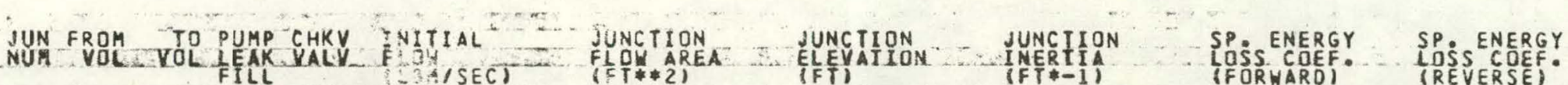
VERT CHOK IC MOM JUNCTION

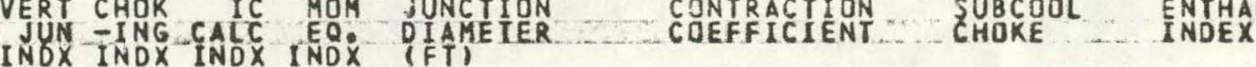

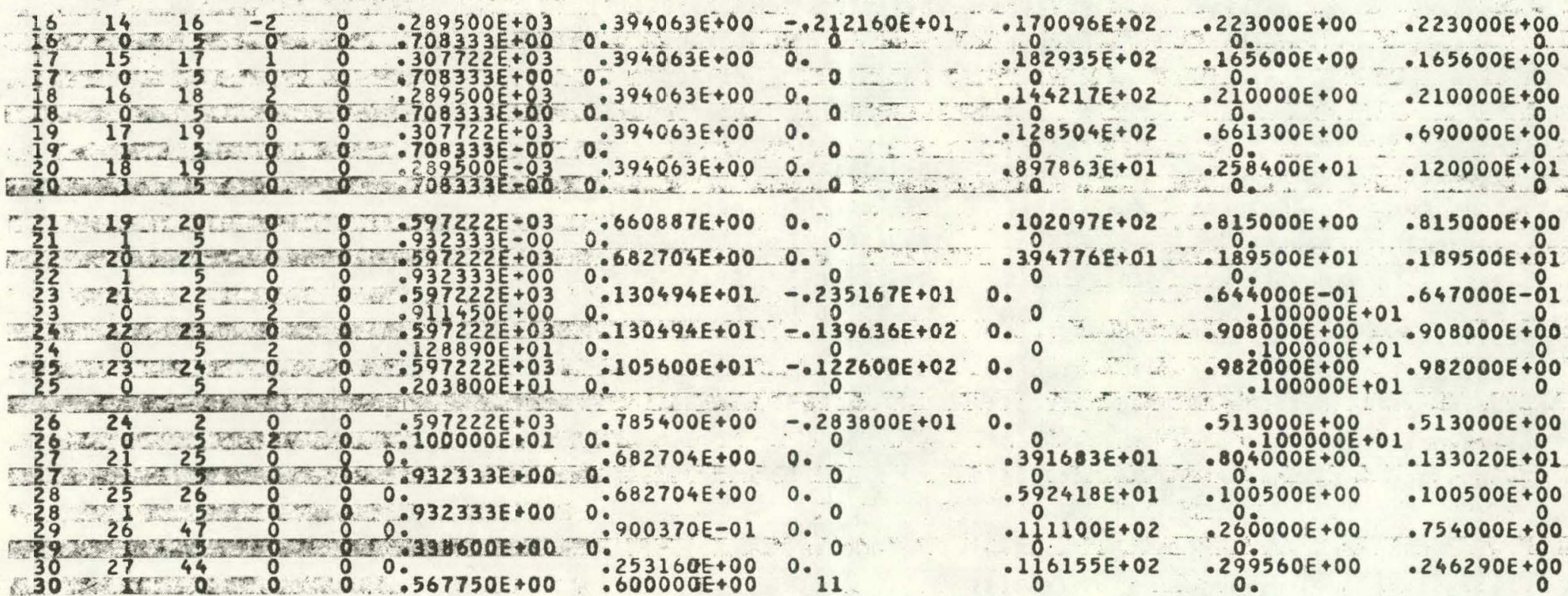




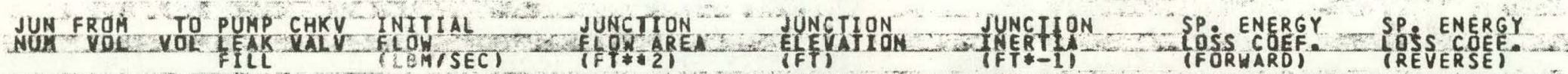
VERT CHOK IC MON JUNCTION CONTFACTION SUBCOOL ENTHALPY IOT COSINE IADJUN JUN ING CALC INDX INDX DIAT)

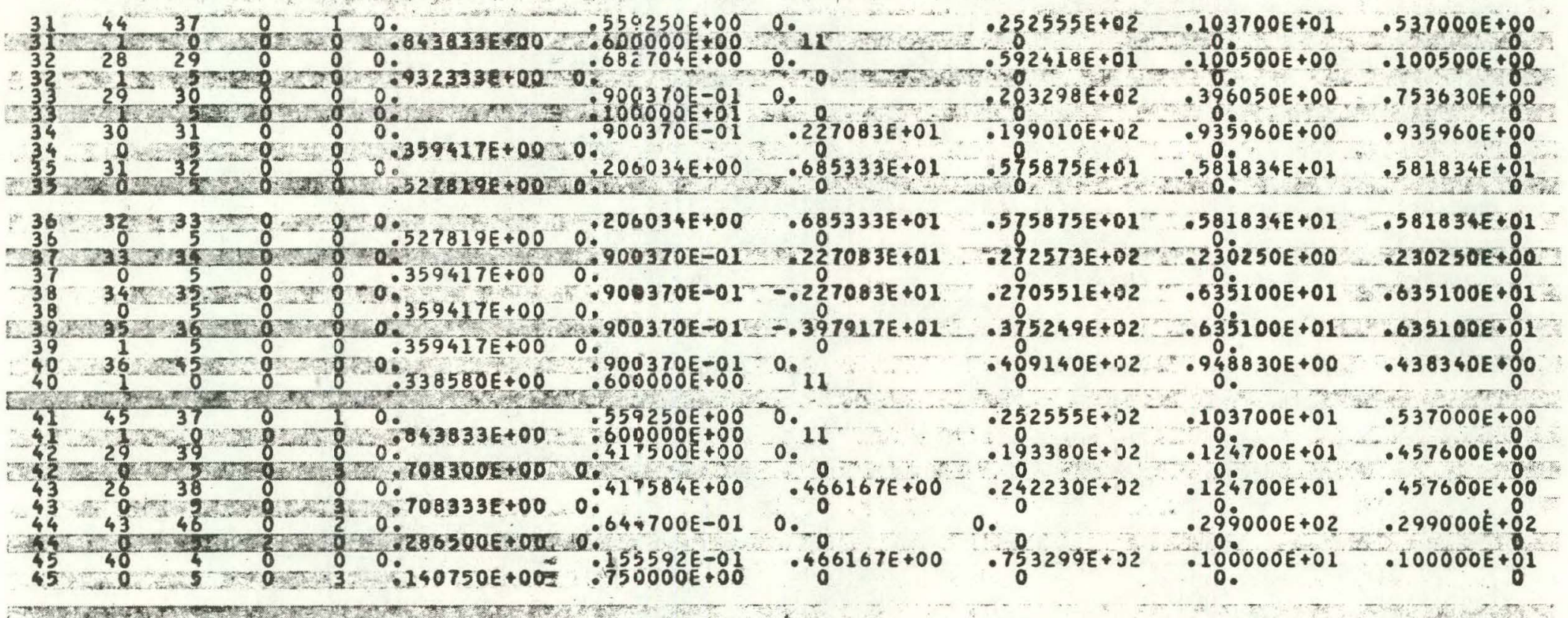




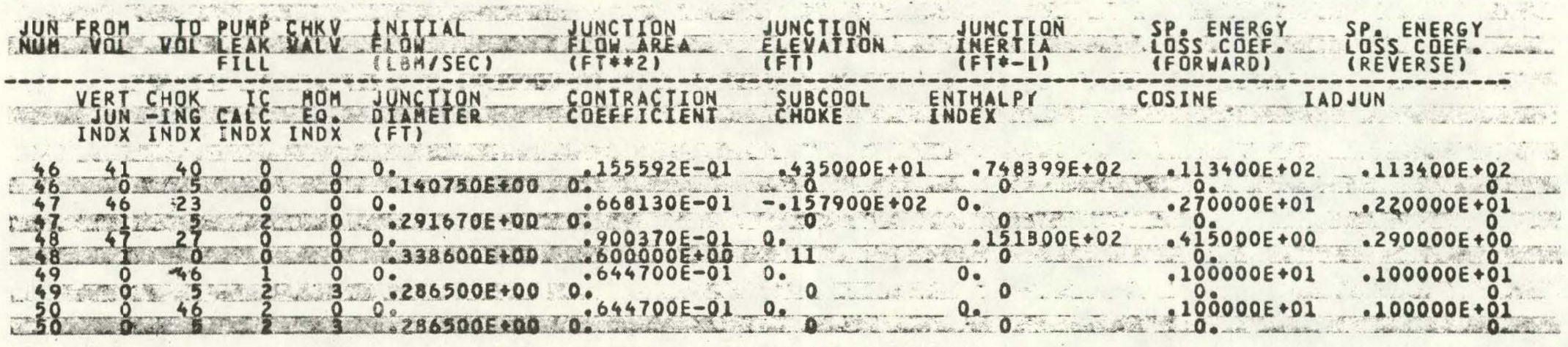




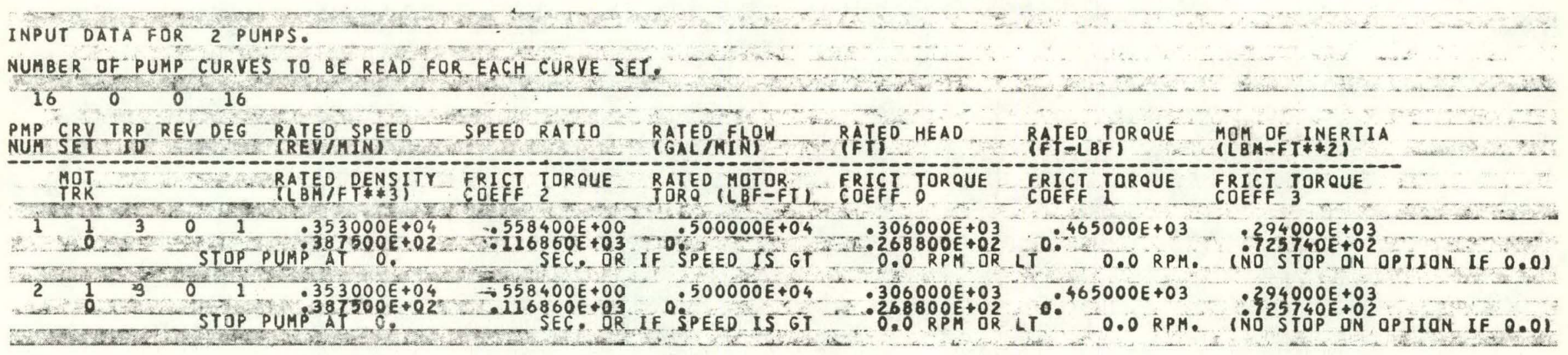


PUMP HEAD MULTIPLIER CURVE

-11 O. 0 .

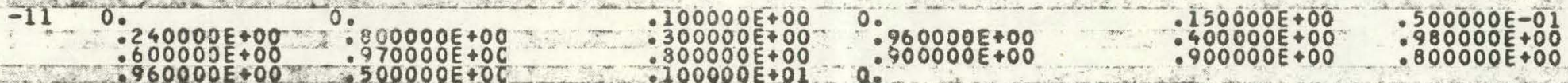
PUMP TORQUE MULTIPLIER CURVE

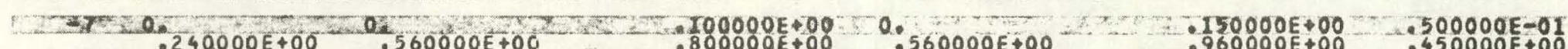

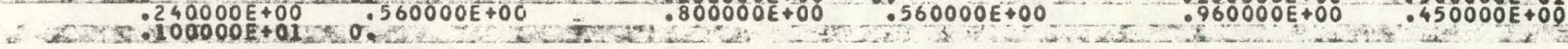


PUMP CURVE SET NUMBER 1 HAS 16 CURVES TO BE READ.

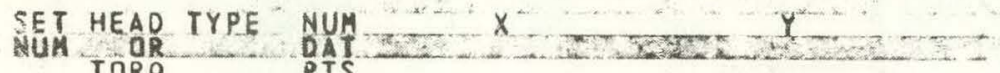

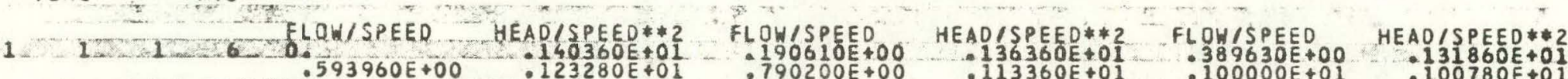

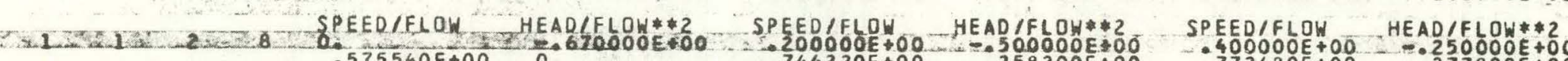

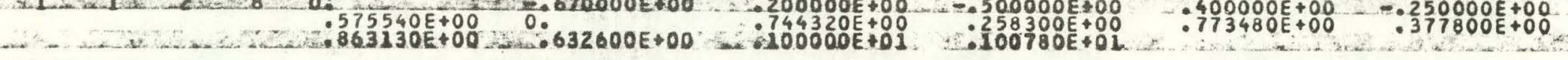

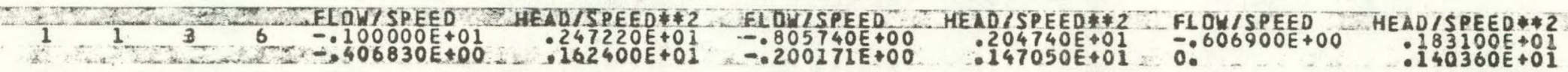

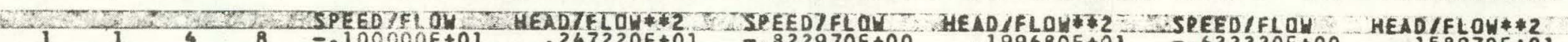

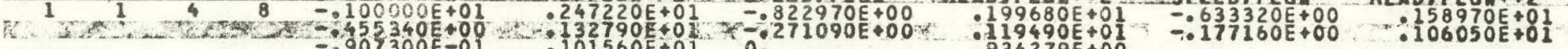
$-907300 \mathrm{E}-01 \quad 101560 \mathrm{E}+01.0$.

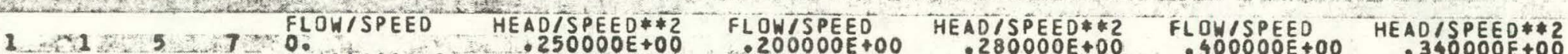

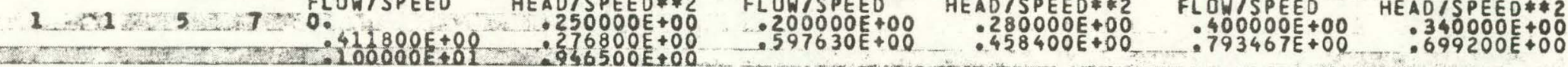
$1-1-6 \quad 10$ SPEEOIFLON HEAD/FLOW*2 SPEED/FLOH HEAD/FLOH*\#2

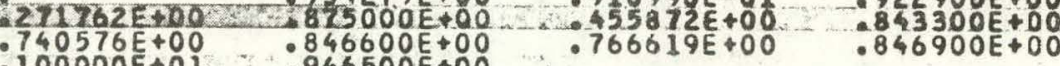

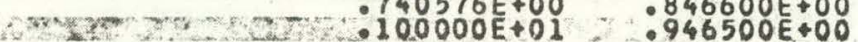

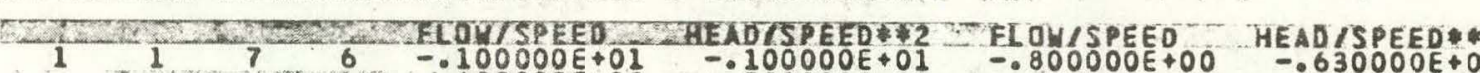

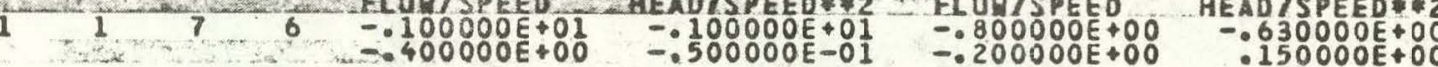

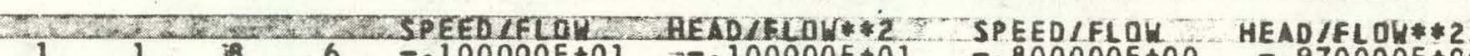
$1-1 \quad 6 \quad 6 \quad-100000 E+01 \quad-100000 E+01 \quad-.800000 E+00 \quad-0970000 E+00$

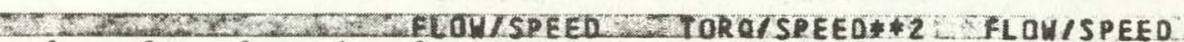

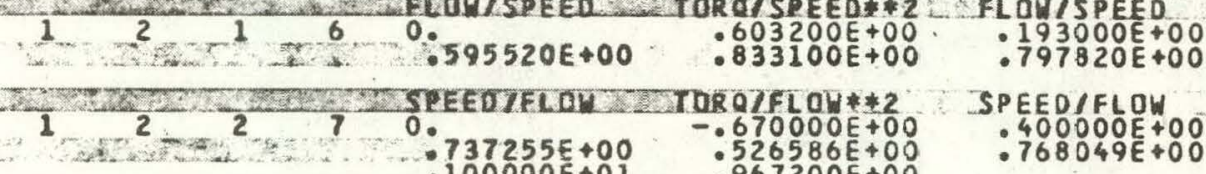
\begin{tabular}{l}
$700000 \mathrm{E}+01 \quad: 967200 \mathrm{9}+000$ \\
\hline
\end{tabular}

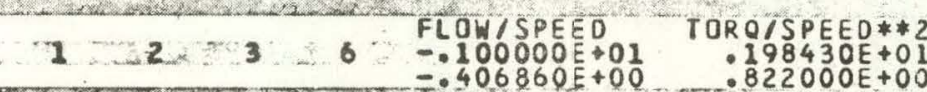
CERSBRE

$12=2-100000+01$ TORQTFLW**2

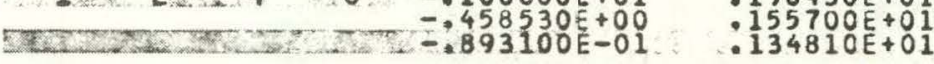
, FLOW/SPEED TORO/SPEED**?

TORO/SPEED * 2 $632500 E+00$
$.922900 \mathrm{E}+00$ TORQPFLOH*
-.25000
-.250

FLOW/SPEED -.800960E +00 SPEED/FLOW $-.822340 E+00$
$-.267023 E+00$

TORO/SPEED * 2 $: 139400 \mathrm{E}+01$

TORQ/FLOW*\#2 - $183080 \mathrm{E}+01$ $: 143620 \mathrm{O}+01$

FLOW/SPEED TORO/SPEED*\#?
SPEEDIFLOW HEAD/FLOW* *2 $\begin{array}{rr}.574406 E+00 & 835500 \mathrm{E}+00 \\ .871471 E+00 & 883800 \mathrm{O}+00\end{array}$ FLOU/SPEED O.

SPEEDIFLOH $.600000 \mathrm{E}+00$

FLOW/SPEED $: 39000 \mathrm{E}+00$ SPEED/FLOW $.867230 \mathrm{E}+0$

\section{FLOH/ SPEED} 0 .

SPEEDIFLOW $-.633710 E+00$ -.176107E +00

HEAD /SPEED * 2 -.300000 + 250000 HEAD IFLOW* *2 -950000E +0

TORO/SPEED $\% 2$ $736900 E+00$
$.967200 E+00$

TORO/FLOH * $* 2$ $150000 E+0$

TOR Q/SPEED**2 $.109750 E+01$

TORO/FLOW* *2 $: 168240 \mathrm{E}+01$

FLOW/SPEED T TORRQ/SPEED**2 


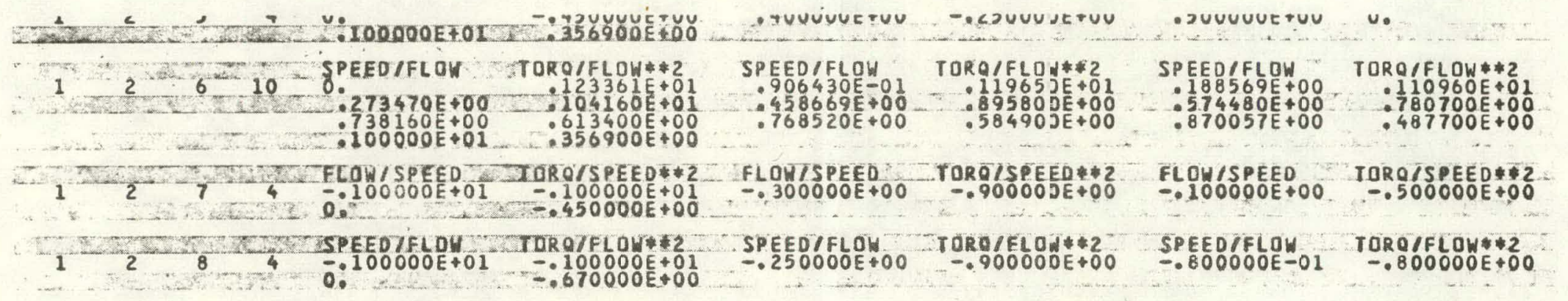




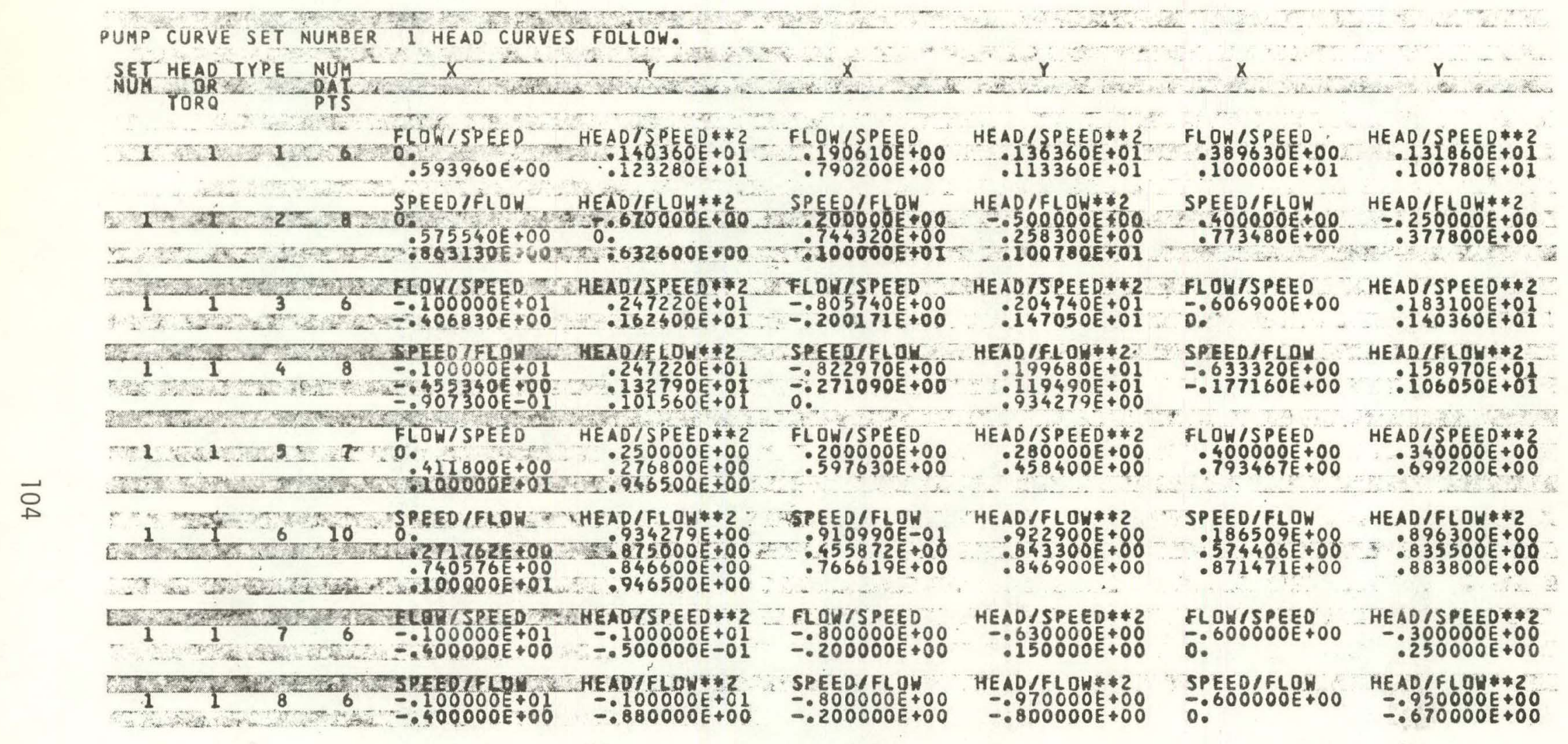




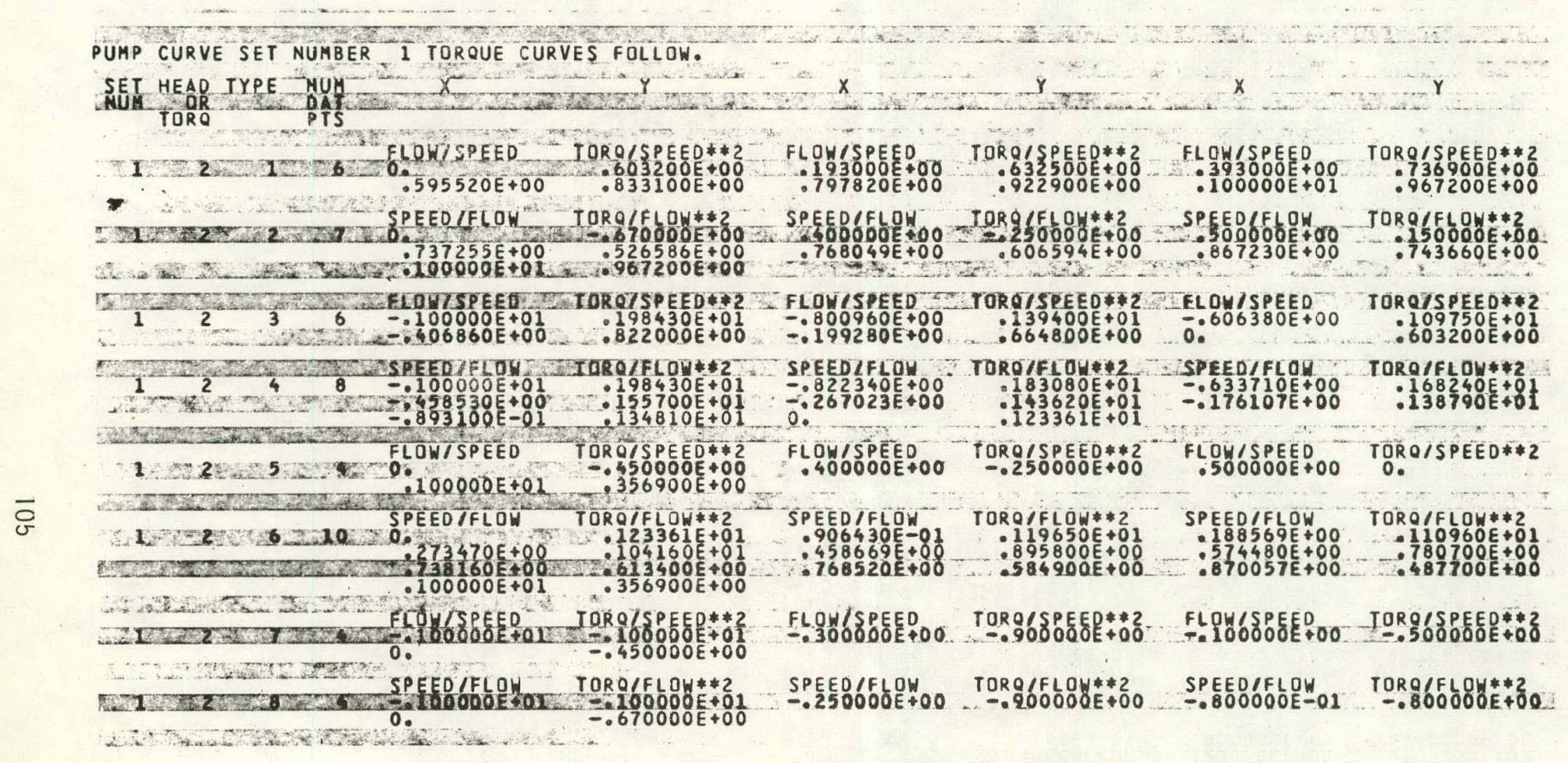


PUMP CURVE SET NUMBER 4 HAS IS CURVES TO BE READ.

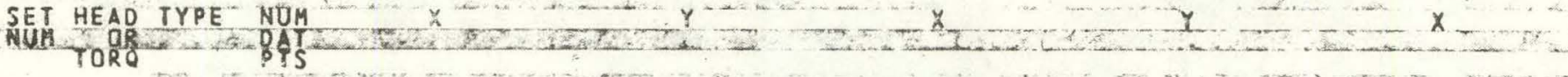

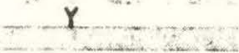

4 FLOW/SPEED HEADISPEED**2 FLOW/SPEED HEADISPEED*Z2 FLOWISPEED

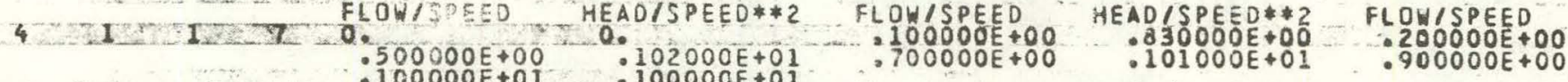

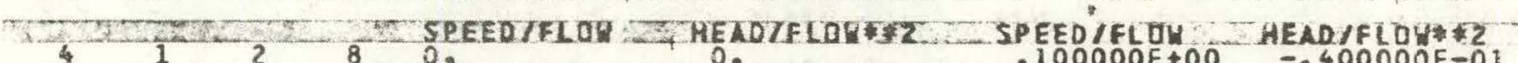

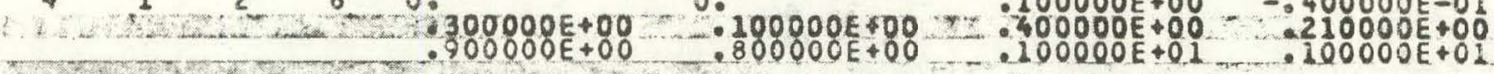

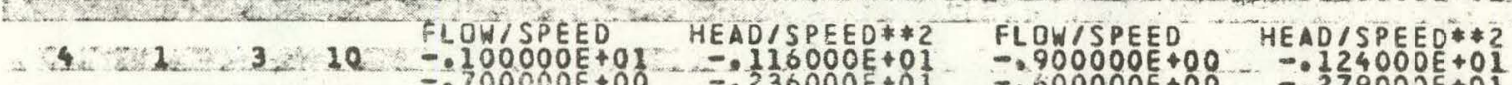

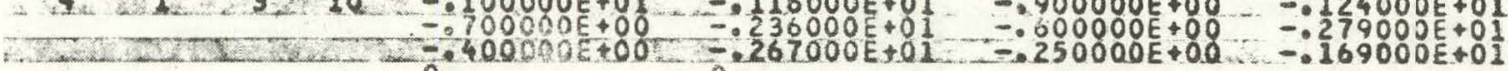

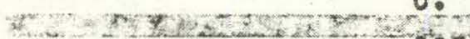
- 10 SPEED/FLOW HEAD/FLOW**2

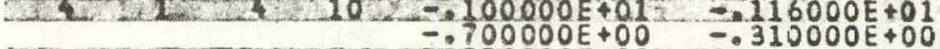

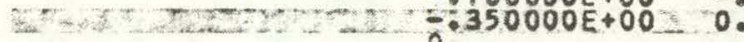

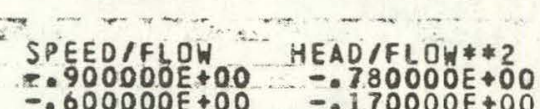
$=.600000 \mathrm{E}+00 \quad-.170000 \mathrm{E}+00$

FLOW/SPEED HEAD/SPEED* *

4 FLOW/SPEED HEAD/SPEED**2 . 80000 E +00 $200000 E+00 \quad-=340000 E+00^{\circ}$
$.800000 E+00 \quad-.119000 E+01$

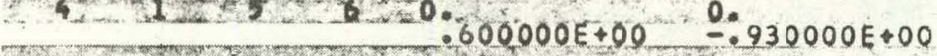
SPEED/FLOW HEADIFLOW $\$$ क

4-1-6-10-0. 10 . $110000+00$

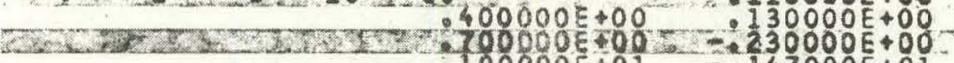

FLOW/SPEED HEAO/SPEED**2 SPEED/FLOW HEADIFLOW* 2

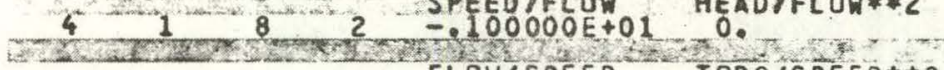
SPEEDTFLOH - 100000 E $\$ 00$ $500000 E+00$
-800000 +

FLOW/SPEED SPEEDIFLOW O.

42 - 1 6 0. $1505200+00$

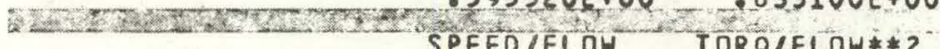
42 2 $2=7$ SPEEDIFLOW TORQ/FLOW**2

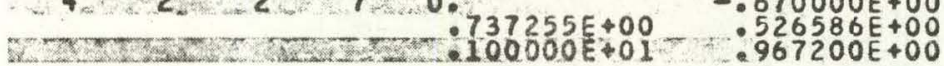
a 3 ELOH/SPEED TORQ/SPEED**2

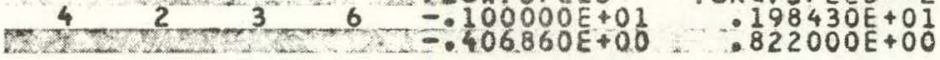

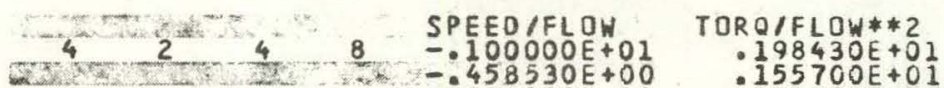

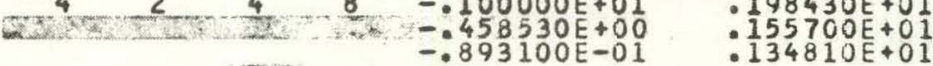

FLOW/SPEED $: \begin{aligned} & 193000 E+00 \\ & : 797820 E+00\end{aligned}$ SPEEDIFLOW $.400000 E+00$

FLOWISPEED $-.800960 E+00$
$-.199280 E+00$ SPEED /FLOW . $822340 E+00$ 0 .
PPEDSFLOG FLOW / SPEEO

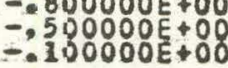

SPE $=D / F L O W$ - $850000 E+00$ $=.55000 E+00$

FLOHISPEED $: 330000 \mathrm{E}+01$ SFEED/FLOW - $250000 E+00$ 600000 +
$.920000 \mathrm{E}$

FLOW/SPEED

HEAD/SPEED * *

HE $.632500 \mathrm{E}+0$

TORO/FLOH*

$.250000 E+00$
$.606594 \mathrm{E}+00$

TORQ/SPEED**2 $11394 \mathrm{COE}+01$
$664800 \mathrm{O}+00$ TORQ/FLCW**? $0143620 \mathrm{E}+01$

SPEED/FLOW

FLOW / SPEEO $1100000 \mathrm{E}+01$

SPEEDIFLOW $.500000 E+00$
$.867230 E+00$

FL ONISPEED $-.606380 \mathrm{E}+00$
HEAD/SPEED**2 :109000E +01

HEADIELOUE 2 . . $670000 E+00$

HEAD ISPEED * *2

- $291000 \mathrm{E}+01$

- $500000 \mathrm{E}+00$.

HEAD/FLOW**2 - $500000 E+00$ -.800000E-01

HEAD / SPEED \#*2 $-.650000 E+00$
$-.147000 \mathrm{E}+01$ HEAD / FL OW * 2 - 15000 E+OO - $400000 \mathrm{E}-01$

HEAD/SPEED **2

HEAD/FLOW* 2

TORO/SPEED**2 $736900 E+00$
$967200 \mathrm{E}+00$

TORO/FLOW* *2 $\begin{aligned} & 150000 E+00 \\ & .743660 E+00\end{aligned}$

TORO/SPEE O**2 $.109750 \mathrm{E}+01$

SPEED/FLOW TORQ/FLOW**2 $\begin{array}{ll}-\rightarrow 33710 E+00 & 168240 E+01 \\ -.176107 E+00 & 138790 E+01\end{array}$ 


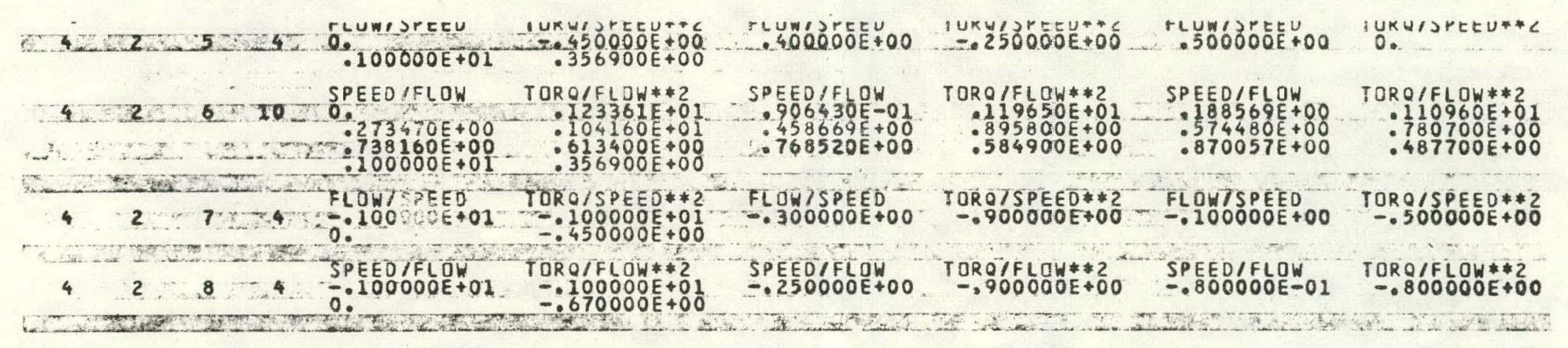




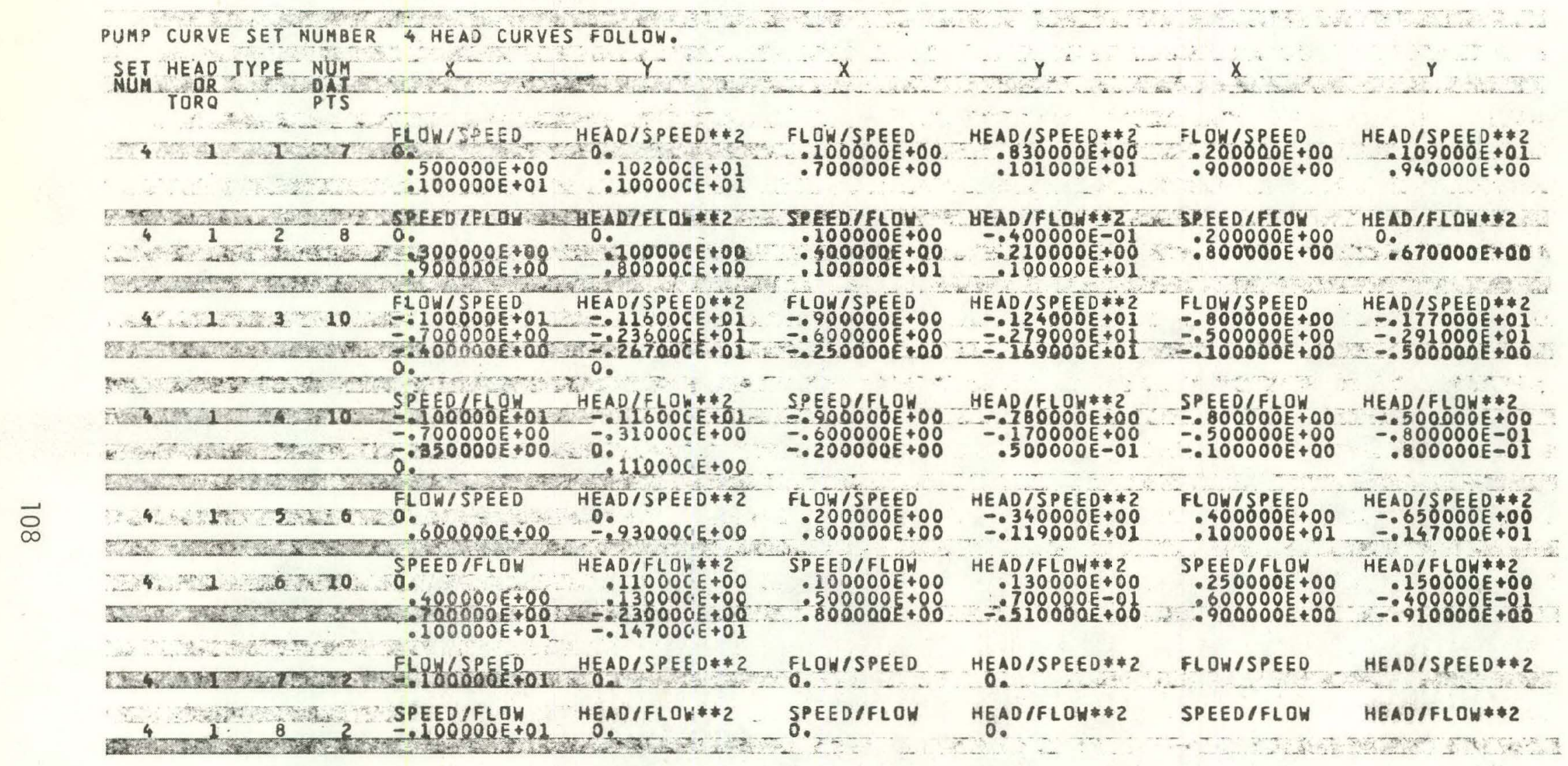




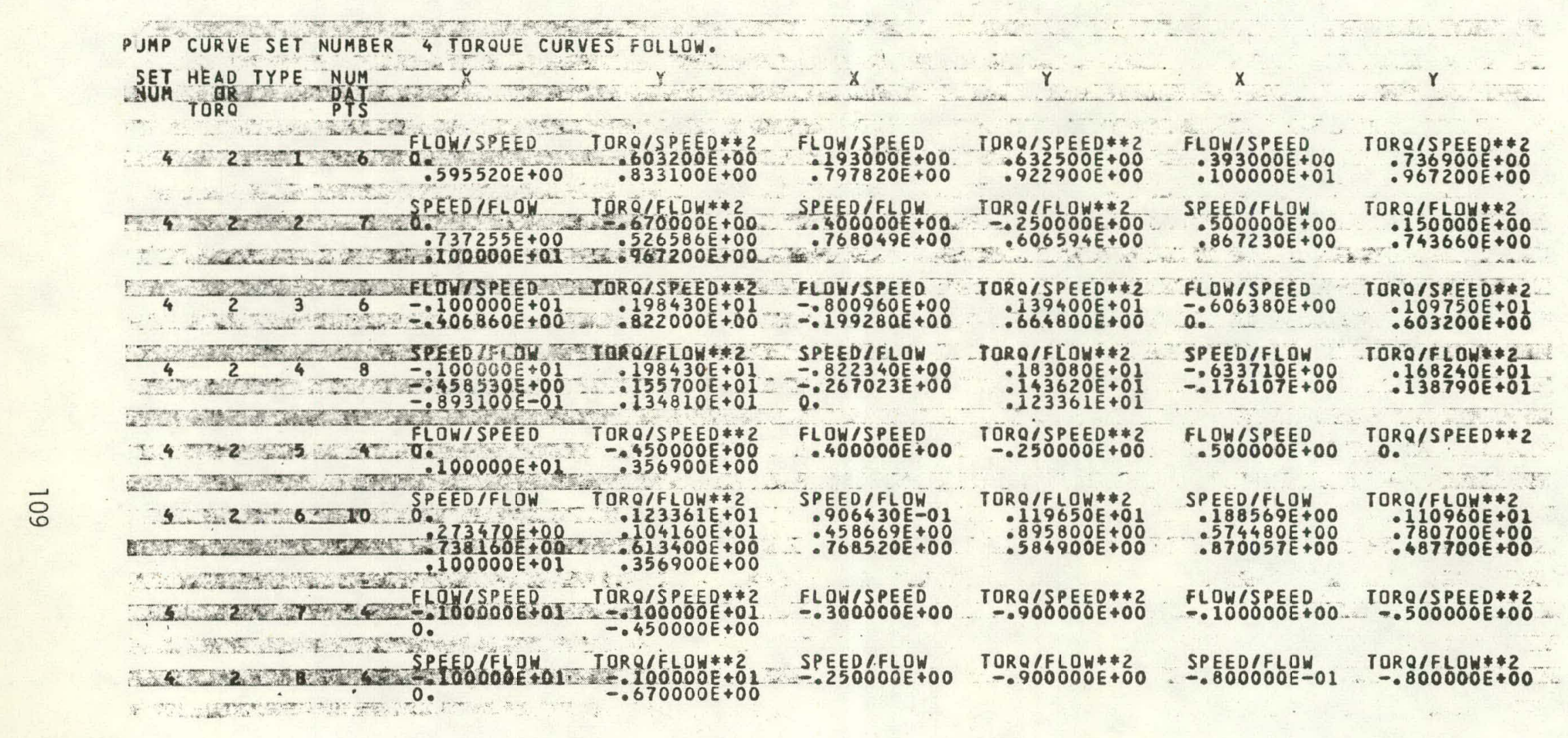


PARAMETERS FOR 2 CHECKVALVES. VALY TRIP AREA CATCH BACK PRESSURE FORWARD OEF OPEY REVERSE CLOSED REVERSE

$\begin{array}{llllllll}1 & -2 & 1 & 0 & 7_{0} & 0 & 0 & 0\end{array}$

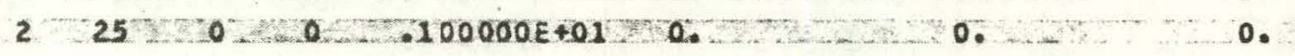




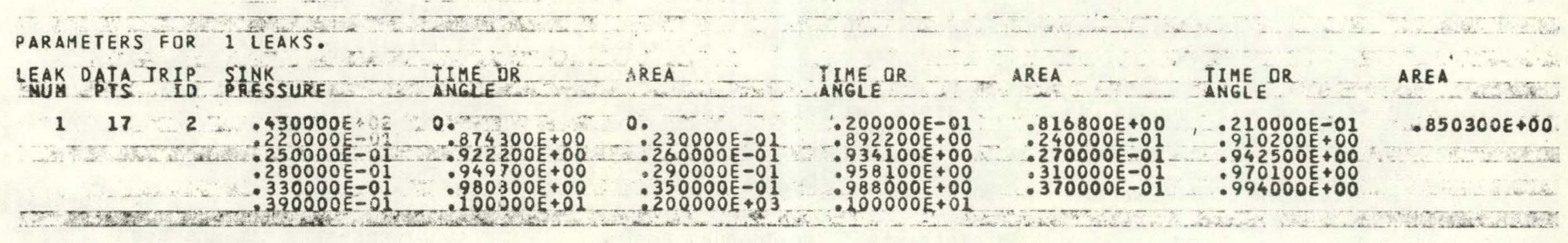




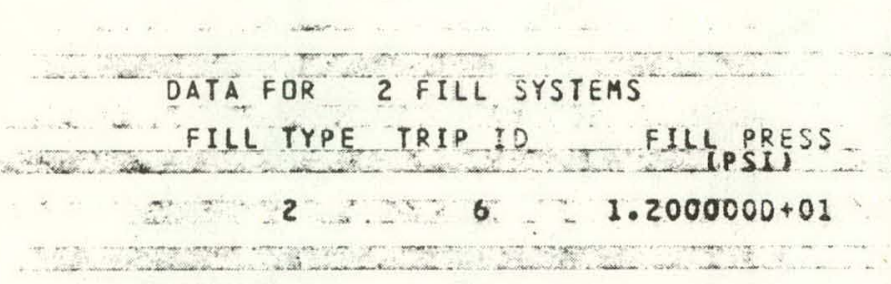
FILLENTHALPY AIR FRACIION
$\dot{4} .8067750+01 \ldots 0$.

* Fill table **

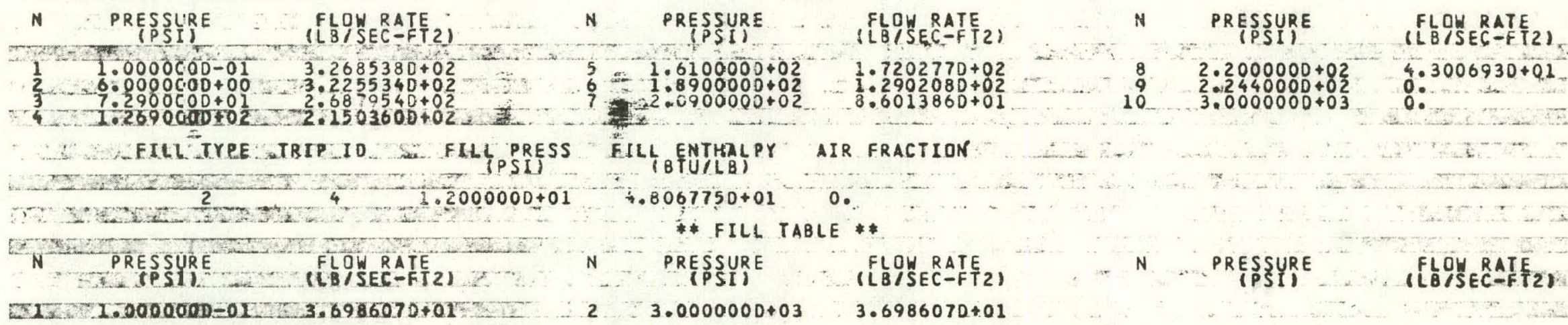

** WARNING ** POSSIBLE INITIAL ENTHALPY IMBALANCE

THE JUNCTION ENTHALPY GALCULATED LIES OUTSIDE THE RANGE OF THE THO VOLUMES IT CONNECTS. T. VOL.A YOL.
9

* * WARNING *** POSSIBLE INYTIAL ENTHALPY IMBALANCE

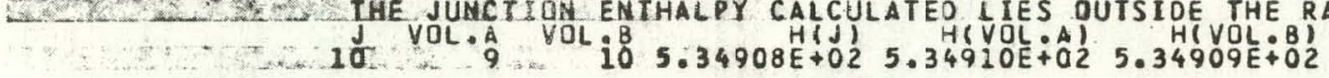

* HARNTWG W POSSTBLE INITIAL ENTMLPY IHBAEANCE

DHE JUNCTION ENTHALPY CALCULATED IIES OUTSIDE THE RANGE OF THE TWO VOLUMES IT GONNECTS.

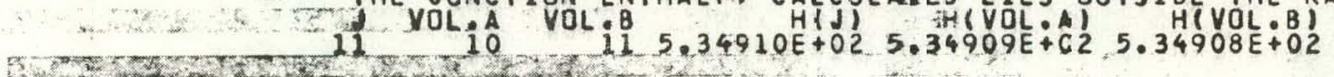




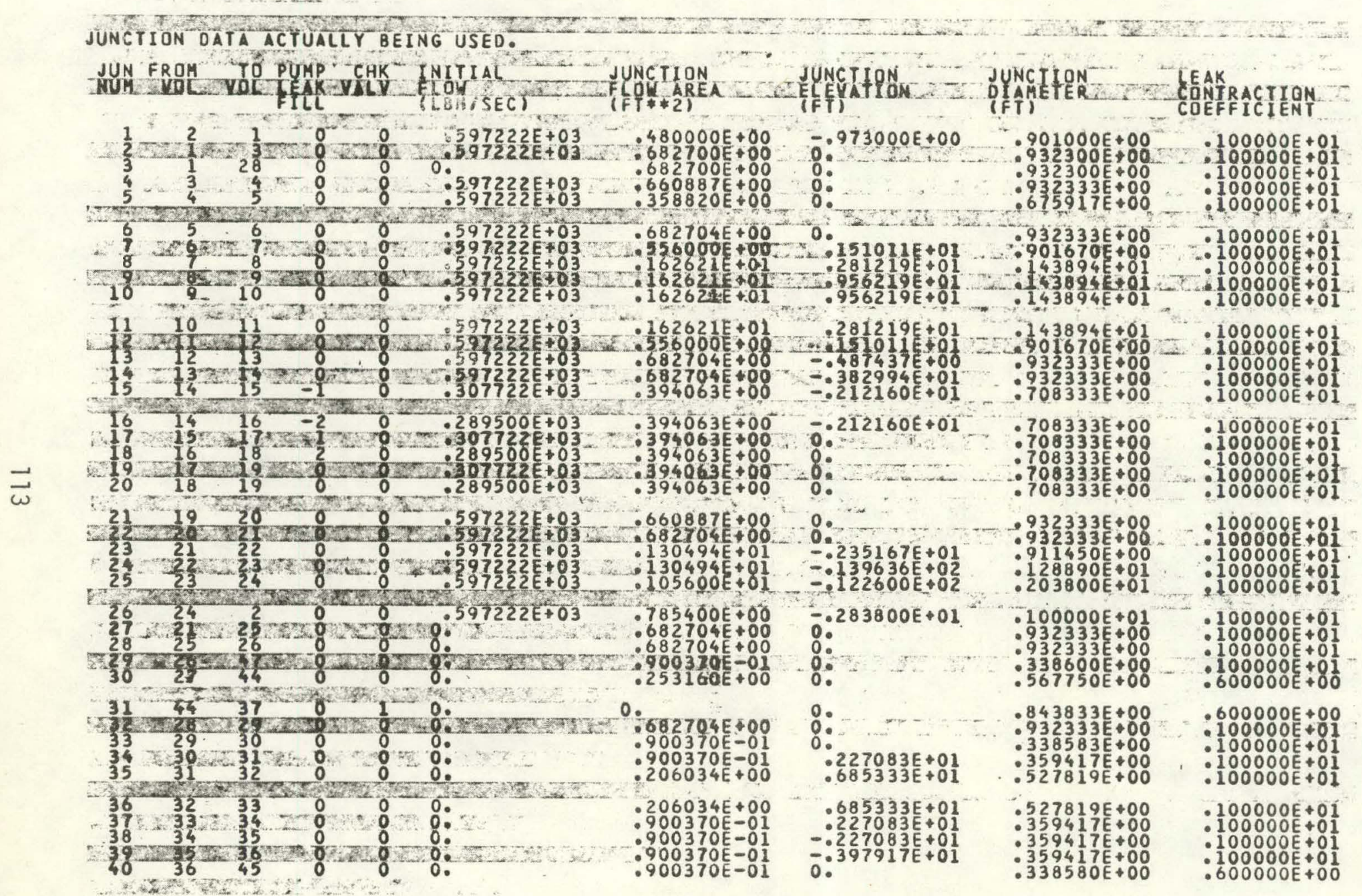




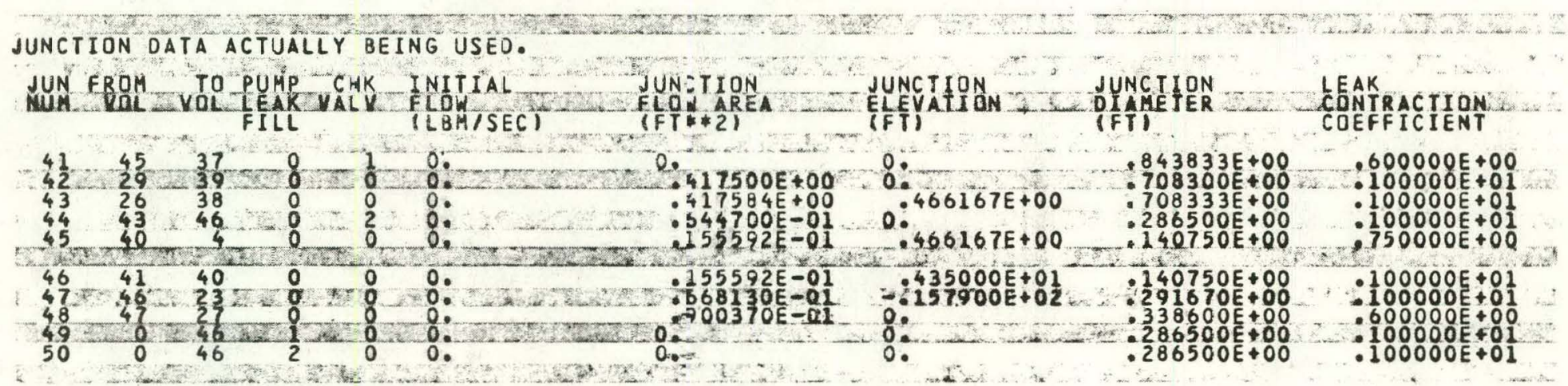


JUNCTION DATA ACTUALLY BEING USED.

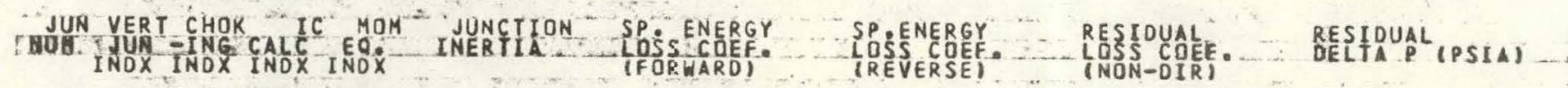

ENTHALPY TRANS ANGLE

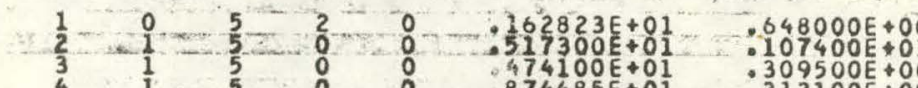

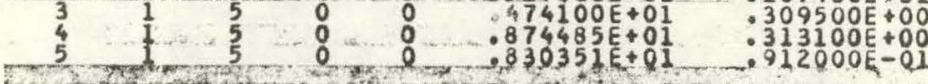

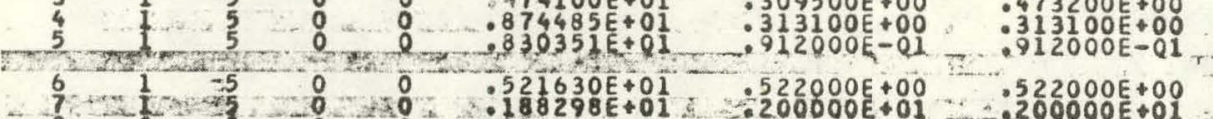

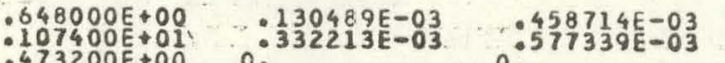

$: 313100 \mathrm{E}+00 \quad: 254241 \mathrm{E}-03 \quad 0.471499 \mathrm{E}-03$

INLET OUTLET

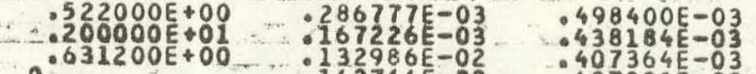

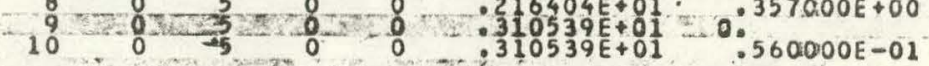

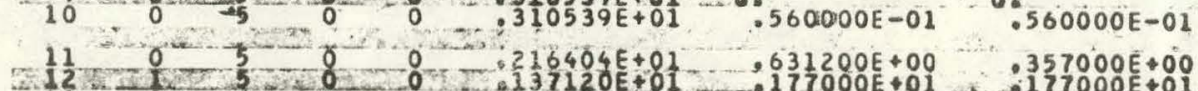

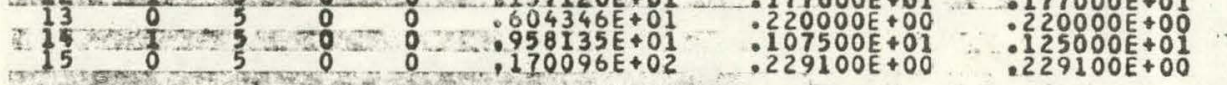

$142764 E-02$
$: 120133 E-02$

$: 112452 E-02$

$255313 E-03$
$250448 E-03$

$.437331 \mathrm{E}-03$
$.368015 \mathrm{E}-03$

$344484 \mathrm{E}-03$
$532936 \mathrm{E}=03$

$: 43796-03$
$: 435341 E-03$
$1143098 E+00$

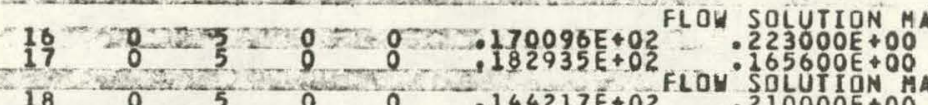

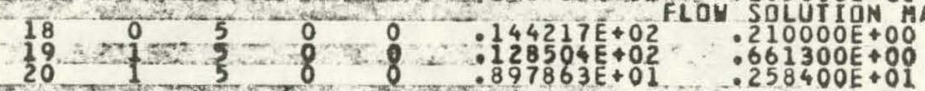

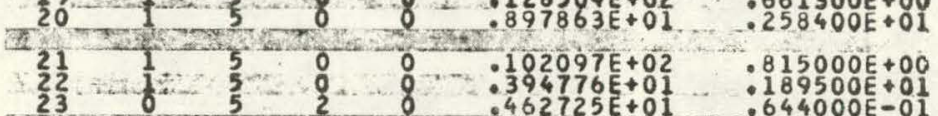

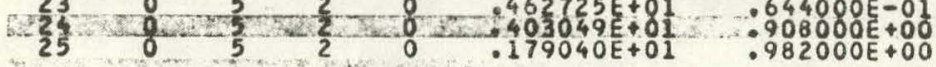

E UNSTABLE DUE TO HIGH NEGATIVE

TO HIGH NEGATIVE RESIDUAL

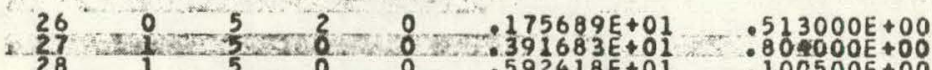

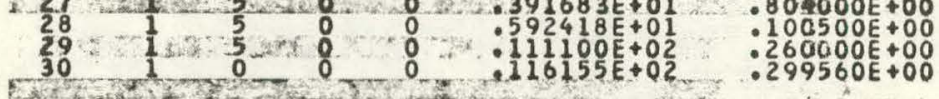

$31 \quad 1 \quad 0=0 \quad 0 \quad 0252555 \mathrm{E}+02$

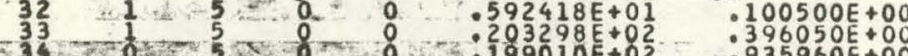

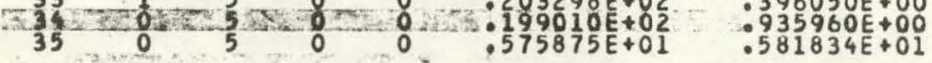
$.223000 \mathrm{E}+00$

.210000 LE DUE TO HIGH NEG HIVE RESIDUAL.

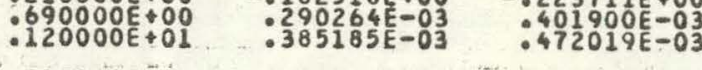

(15000

$.476259 E-03$

$: 189500 \mathrm{E}+0$

$\because 908000 \mathrm{E}+0 \mathrm{O}$

$256846 E-0$
$252332 \mathrm{E}-\mathrm{O}$

$.668589 \mathrm{E}-03$

$.513000 E+00 \quad .335595 E-03$

$.100500 \mathrm{E}+00$

$.246290 \mathrm{E}+00$

0 .

0.

$100500 \mathrm{E}+00$

$.753630 \mathrm{E}+00$

$9935960 E+00$
$.581834 E+01$

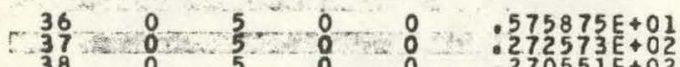

$581834 E+01$
$.230250 E+00$

$\begin{array}{rlll}39 & 0 & 5 & 0 \\ 40 & 1 & 5 & 0 \\ 41 & 0 & 0 \\ 41 & 0 & 0 & 0\end{array}$

$: 375249 \mathrm{E}+02$

$.635100 E+01$

$.581834 E+01$
$.230250 E+00$

.635100 +

$.438340 E+00$

$.252555 E+02 \quad \partial$

0.

$.535282 \mathrm{E}-03$

:440626E-03

$0:$

NO NO NO $0: 100000 E+01$

ND

NO

NO NNO rOO NO

NOS YES YES OD O

YES NO 8 -

(

***** WARNING。

ND WO HO

*** WARNING.

No

NO

NO

NO

No - ....

NO

NO

No

NO

0

NO

::

o.

$0:$

0.

o.

o.

::

0.

0. - यू-

0.

(a)

O.

$0.100900 \mathrm{E}+01$

:100000E+01

$0.100000 E+01$.

:0:

- i is ?

:0:

::

0..

:-

0 . 


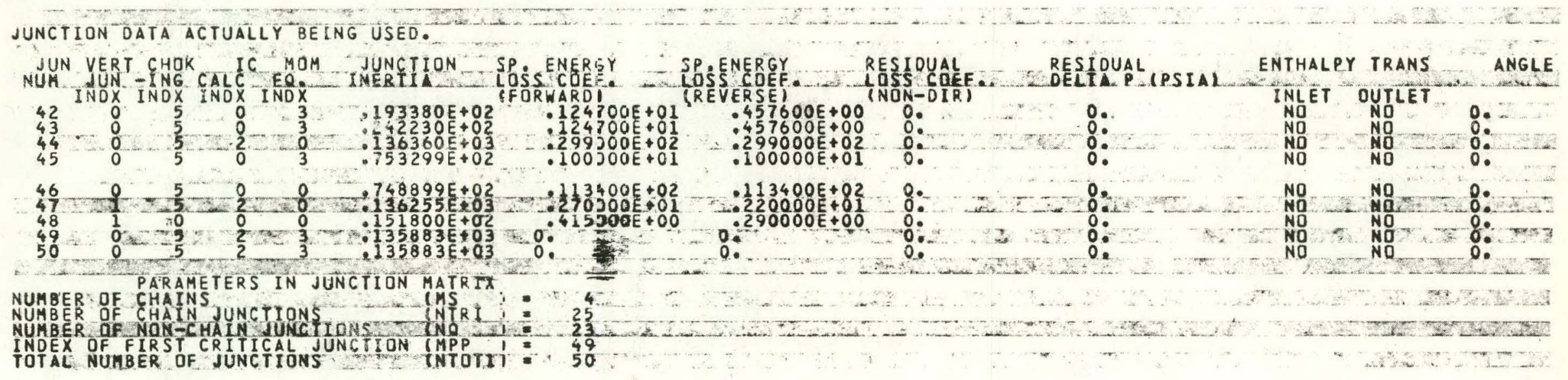


DATA FOR 38 HEAT CONDUCTING SLABS.

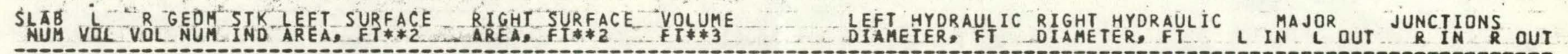
LOC X INC R C LFT HETED EQ RHT HEATED EO LEFT CHATN

LENGTH, FI R (L) YOL, FT R (L) VOL, FI

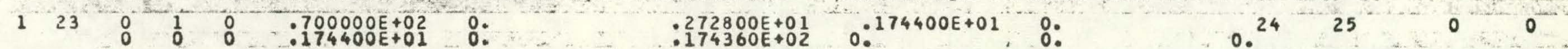

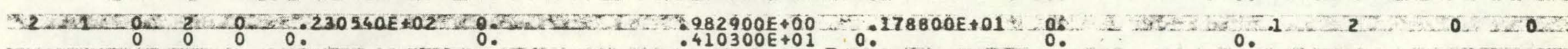

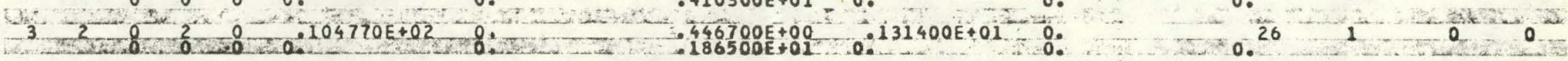

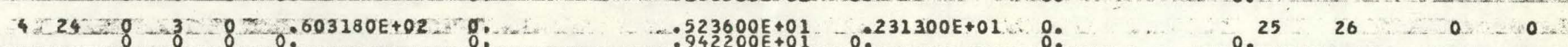

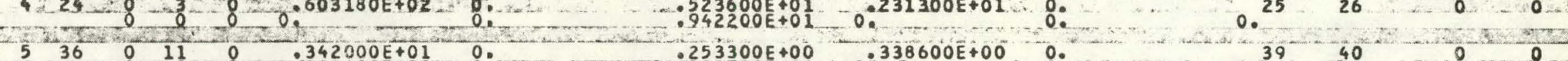

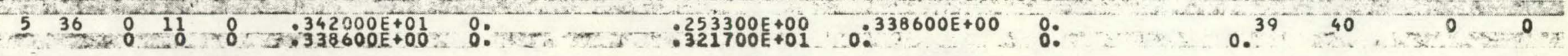

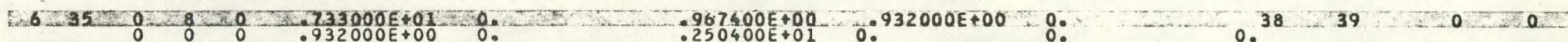

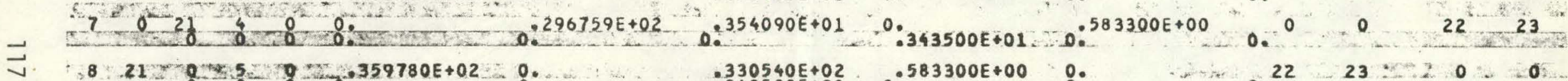

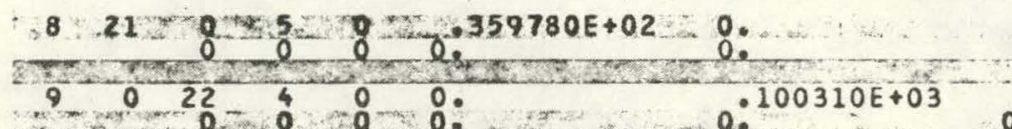
$.330540 E+02$ -..... -

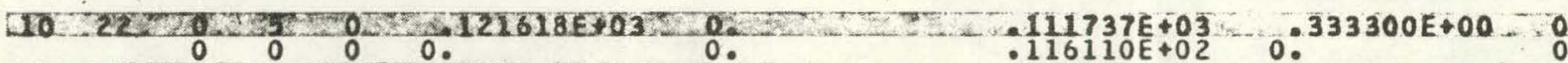

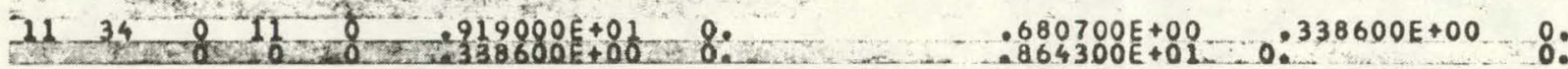

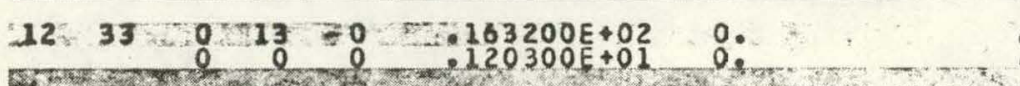
$13-32 \quad 0 \quad 13=0 \quad-326700 \mathrm{E}+02$

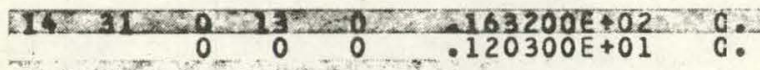

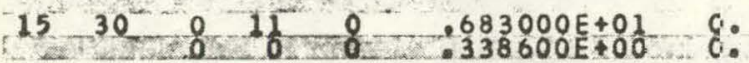

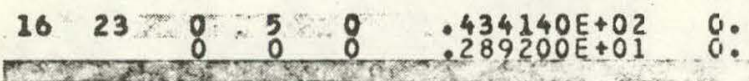
$398870 E+02$
$.4145 C 0 E+01 \quad 0.289200 E+01$

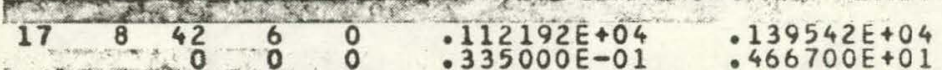
$\begin{aligned} & 272200 E+01 \\ & 431900 E+01\end{aligned} 0: 120300 E+01 \quad 0$ $544700 \mathrm{E}+01$
$864300 \mathrm{E}+01$ $: \begin{array}{lll}272200 E+01 & 0.120300 E+01 & 0 .\end{array}$ $.506100 E+00 \quad 0.338600 E+00$. $\begin{array}{lll}.5139 C 0 E+01 & .335000 E-01 \\ .579000 E+01 & .579000 E+01 & 0.466700 E+01\end{array}$ ESEMA IT EXTENDS BEYOND TOP OR BOTTOM OF 1 VOLUME. IF IXLO GT 0 , EXECUTION IS DELETED.

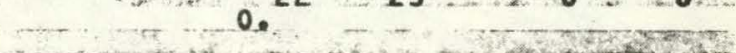

$.333300 E+00$ Q. $23 \quad 24 \quad-\quad 0 \quad 0$ : 0. $37 \quad 38 \quad 0 \quad 0$ $0.36 \quad 37 \quad 0 \quad 0$ $\begin{array}{llll}35 & 36 & 0 & 0\end{array}$ $34 \quad 35=0 \quad 0=0$ $\begin{array}{llll}33 & 34 & 0 & 0\end{array}$ $0^{24} 25 \quad 00$ $8 \quad 9-0=0$ 
10. TE : SLAB 18 EXTENOS BEYOND TOP QR BOTTOM OF 1 VOLUME. IF IXLO GT O, EXECUTION IS. DELETED.

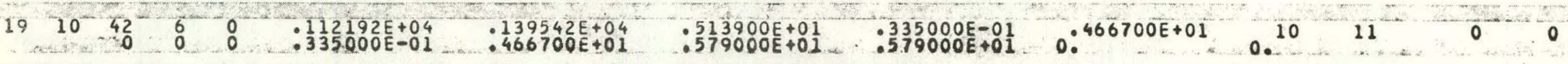

SLAR 19 EXTENDS BEYOND TOP OR BOTTOH OF 1 VQLUME. IF LXLO GT O, EXECUTION IS OELETED.

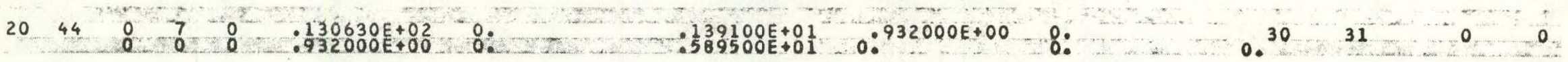

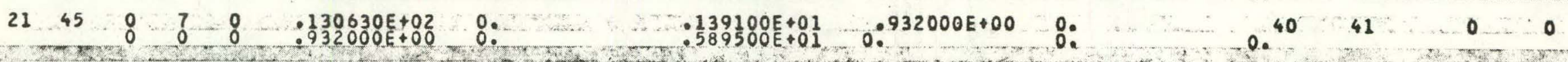

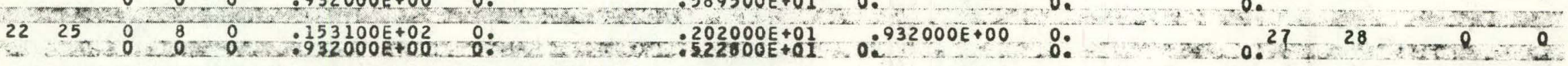

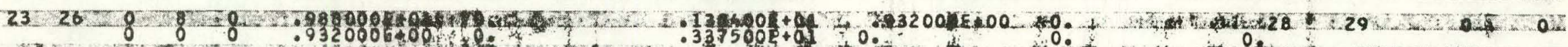

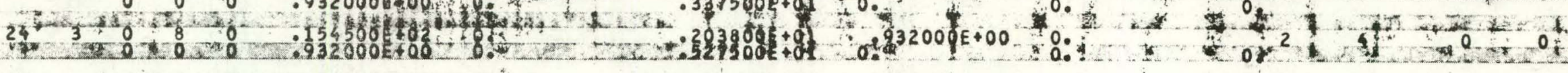

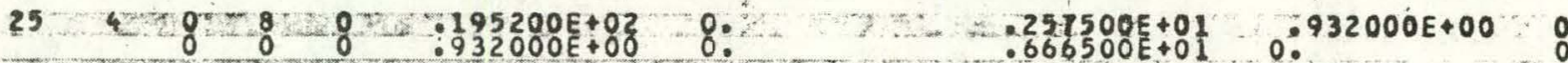

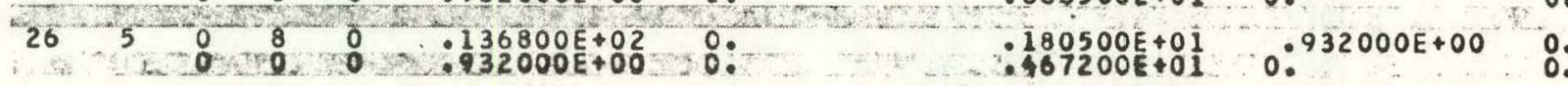
$.160920 E+01 \quad 0.106780 E+01 \quad 0$

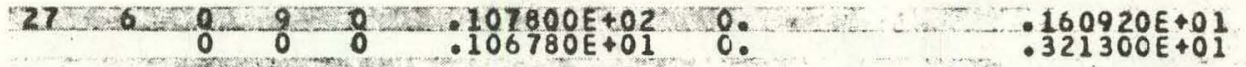

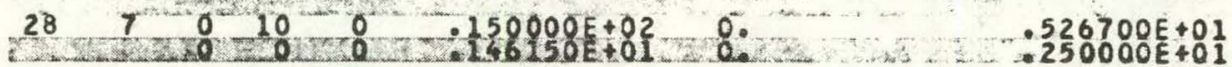

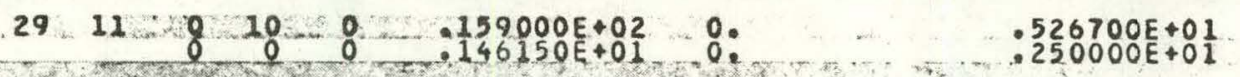
$3012 \quad 0 \quad 9 \quad 0 \quad 770000 E+01 \quad 00 \quad 0115020 E+01$

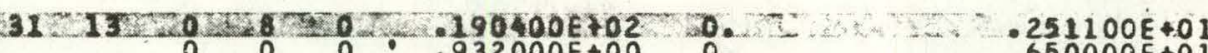

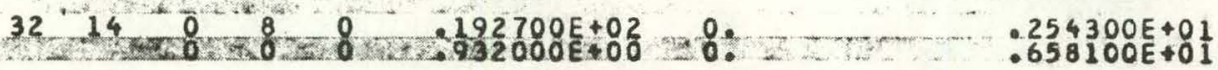

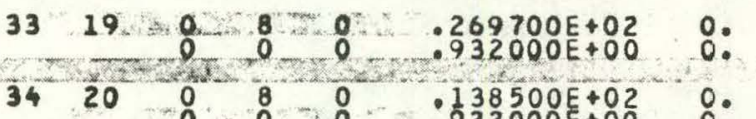
$: \begin{array}{r}355800 E+01 \\ 921100 E+01\end{array}$ $: \begin{aligned} & 182800 E+01 \\ & : 472900 E+01\end{aligned}$ 0.

$0.146150 E+01$ $-0$. $0: 146150 E+01 \cdot 8:$ $0: 106780 E+01$ :: $.0932000 E+00$ 0.

$0.932000 E+00$ $0: 932000 E+00 \quad$ : $0: 932000 E+00 \quad 8:$ $181100 E+01$
$468600 E+01$

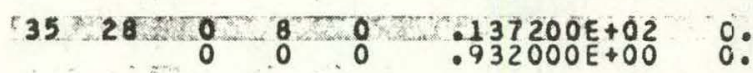
$3629=8-8=988000 \mathrm{E}+01 \quad 0$. $\begin{array}{llllll}37 \quad 27 & a & 12 & 0 & : 575000 E+01 & 0\end{array}$ $130400 E+01$ $.337500 E+01$ $0.932000 E+00$ 0. $0.932000 E+00 \quad 0$ $492700 E+00$
$.322900 E+01$ $0: 567800 E+00 \quad:$ :

$\begin{array}{llll}0.4 & 5 & 0 & 0 \\ 0.5^{5} & 6 & 0 & 0 \\ 0.0^{6} & 7 & 0 & 0 \\ 0.7 & 8 & 0 & 0 \\ 0.0^{11} & 12 & 0 & 0 \\ 0.1^{12} & 13 & 0 & 0 \\ 0.13 & 14 & 0 & 0 \\ 0.0^{14} & 15 & 0 & 0 \\ 0.0^{19} & 21 & 0 & 0 \\ 0.0^{21} & 22 & 0 & 0 \\ 0.0^{3} & 32 & 0 & 0 \\ 0.0^{32} & 33 & 0 & 0 \\ 0.0^{48} & 30 & 0 & 0\end{array}$




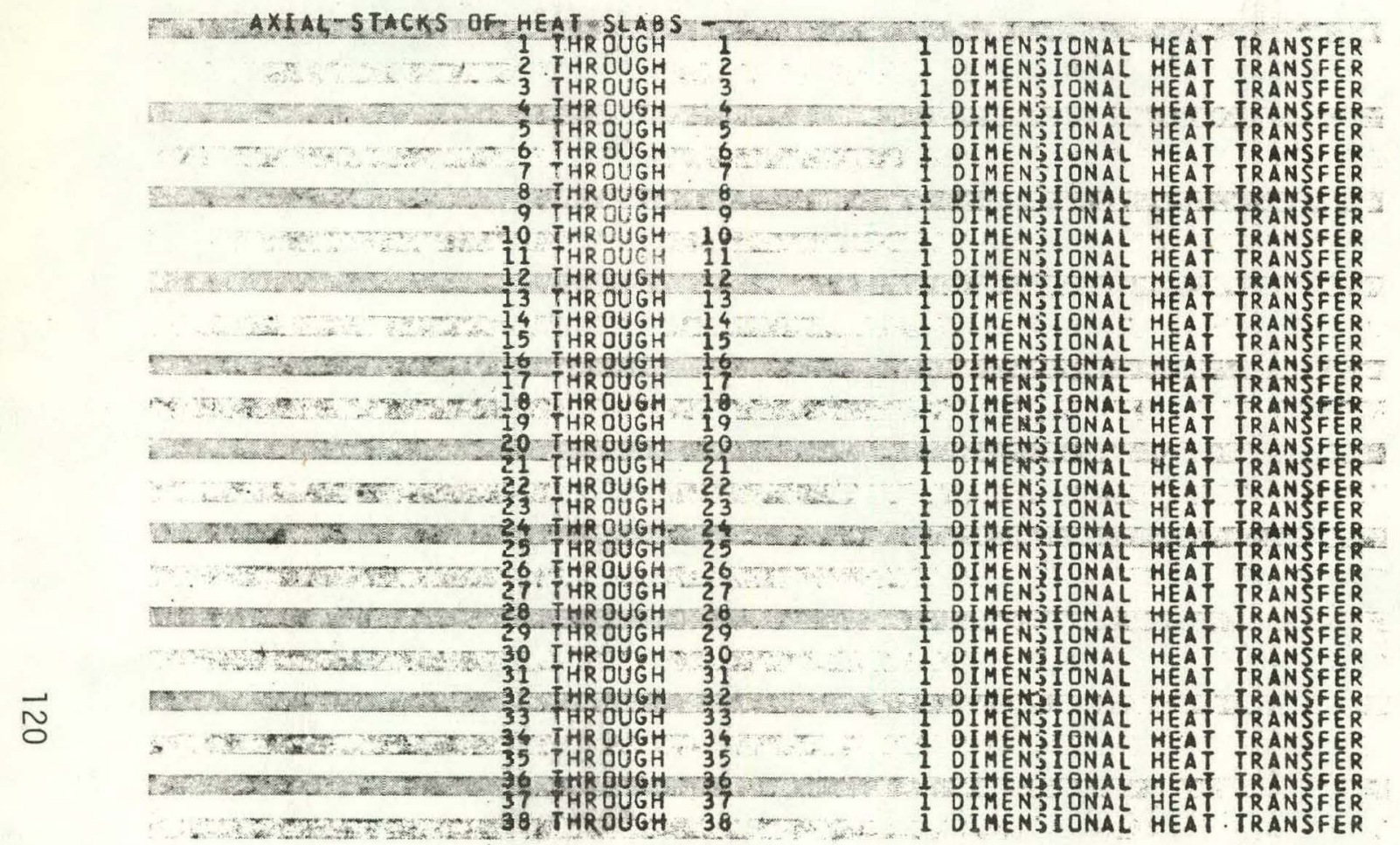


DATA FOR 14 HEAT SLAB GEOHETRIES QWE A GEOM REG GAP MAT NO XO-TO NEL WE REGION HIOTH POUER ERAC

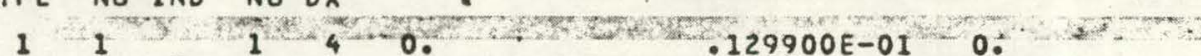

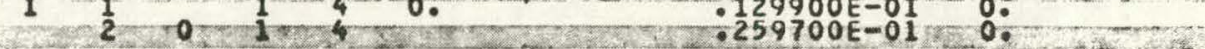
SUA OF POWER FRACTIONS IS 0.

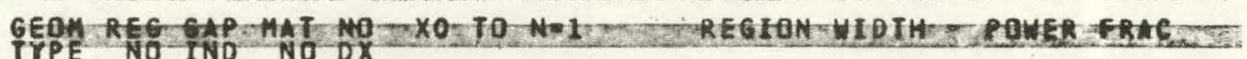
$2^{2}{ }_{2} \quad 1 \quad 4 \quad .894000 \mathrm{E}+00 \quad .208000 \mathrm{E}-01 \quad 01$

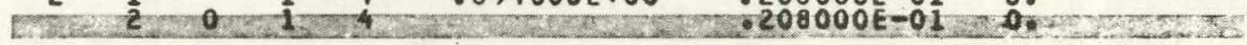

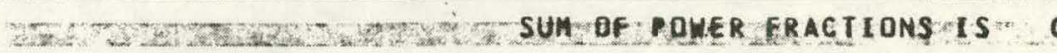

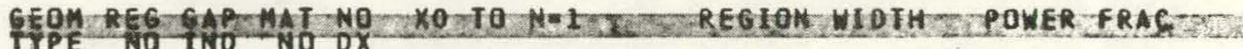

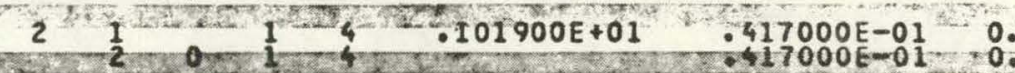

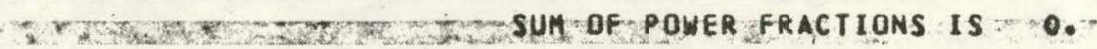

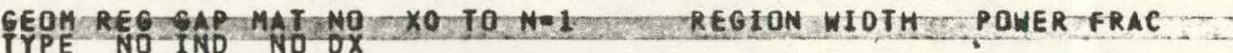

$2 \frac{1}{2} 1_{4} \cdot 125000 E+01 \quad .625000 E-01 \quad 0$

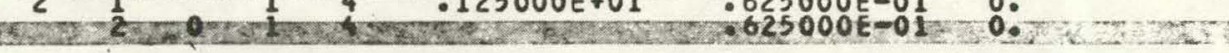

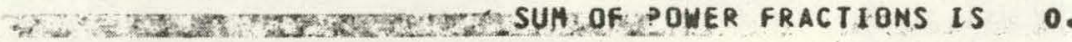

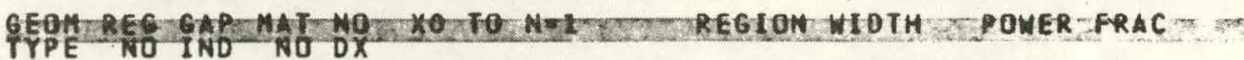

$2-\frac{1}{2}-166700 E+01 \quad .250000 E+00 \quad 0$.

SUM OF-POHER FRACTIONS IS 0

GEOM REG GAP MAI NO

$2=1^{2}-1 \quad 4 \quad 167500 \mathrm{E}-01$ \& $.204000 \mathrm{E}-02 \quad 0$.

SUM OF POWER FRACTIONS IS 0

GEOM REG GAP MATNG XO TO N=1 NO REGION WIOTH POHER FRAC

$\begin{array}{rrrr}2 & 1 & 1 & 4 \\ 2 & 354000 E+00 & .310000 E-01 & 0 .\end{array}$

SUM OF POWER FRACTIONS IS 0.

TYPE REO INO HAT NO XO TO N=1 REGION WIDTH POWER FRAC 


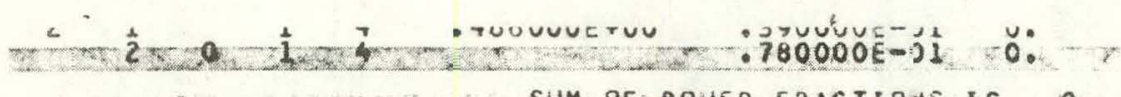
SUM OF POWER FRACTIOAS IS 0. GEPM REG GAP MAT NO XO TO NEI NO REGION WIOTH PONER FRAC

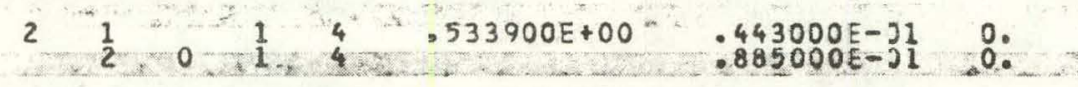
SUA OF POWER FRACTIONS IS 0.

GYOM REG GAP AAT NO XO TO N=I RO REGION WIOTH POWER FRAC

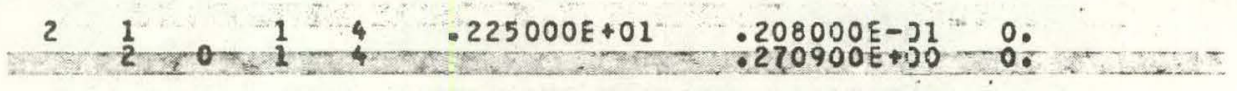

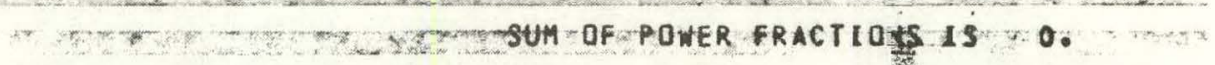
GEOH REG GAP MAT NOTXOTO N=1 RY REGION WIOTS

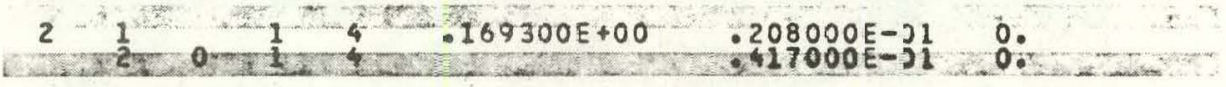
- SUM OF POWER FRACTIONS IS 0. GEOM REG GAP MAT NO KO TO NOL

$\begin{array}{lllllll}\frac{1}{2} & 0 & \frac{1}{1} & 4 & -283900 \mathrm{E}+00 & 252000 \mathrm{E}-01 & 0 .\end{array}$

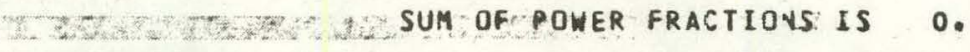

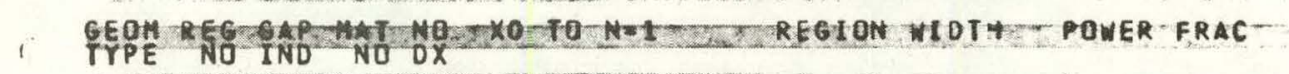

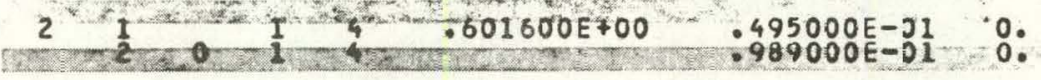
DUW OF POWER FRACTIONS IS 0.

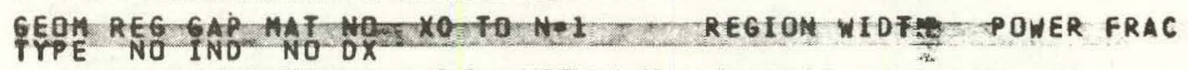

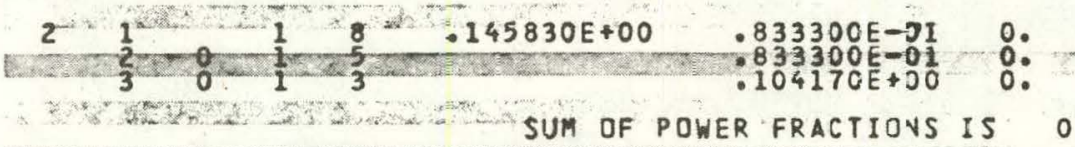

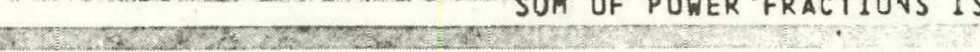




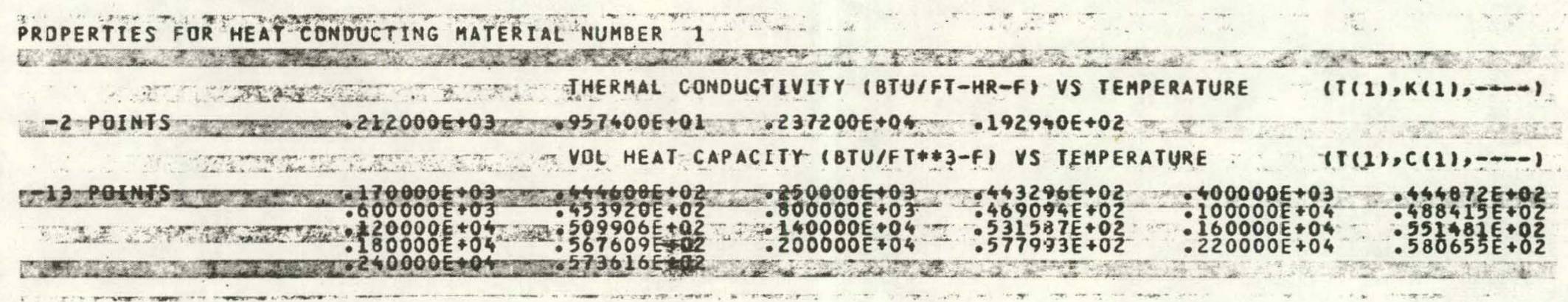


RELAP4/CO5 01102176 T TI
LOFT LI35-A23 PRE-TEST PREDICTIONS WITHELAP4 THERMAL HYDRAULIC CODE PRESSURILER MODEL CONCOE.75 CONFIGURATION CONTROLSYES

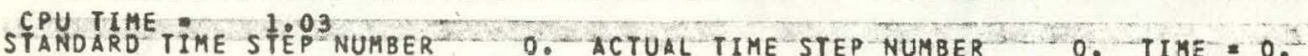

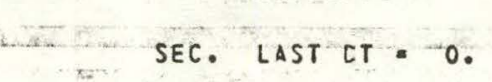

\begin{tabular}{|c|c|c|c|c|c|c|c|c|}
\hline 1.00000E +00 & $\begin{array}{l}\text { (Mw) } \\
0 .\end{array}$ & $\begin{array}{l}\text { (8TU } / H R)^{-1} \\
\text { O. }\end{array}$ & $\begin{array}{l}\text { ENGY, LEAK } \\
\text { (BTU) } \\
0 .\end{array}$ & $\begin{array}{l}\text { HASS LEAK } \\
\text { (IB) }\end{array}$ & $\begin{array}{l}\text { ENGY BAL. } \\
\text { (BTU) } \\
4.77463 E+07\end{array}$ & $\begin{array}{l}\text { MASS MAL. } \\
\text { (LB B ALE+05 } \\
1.5 C 522 E+05\end{array}$ & $\begin{array}{l}\text { TOI. REAC } \\
\text { O5: }\end{array}$ & $\begin{array}{l}\text { REAC T } \\
\text { SEC. } \\
\text { O. }\end{array}$ \\
\hline 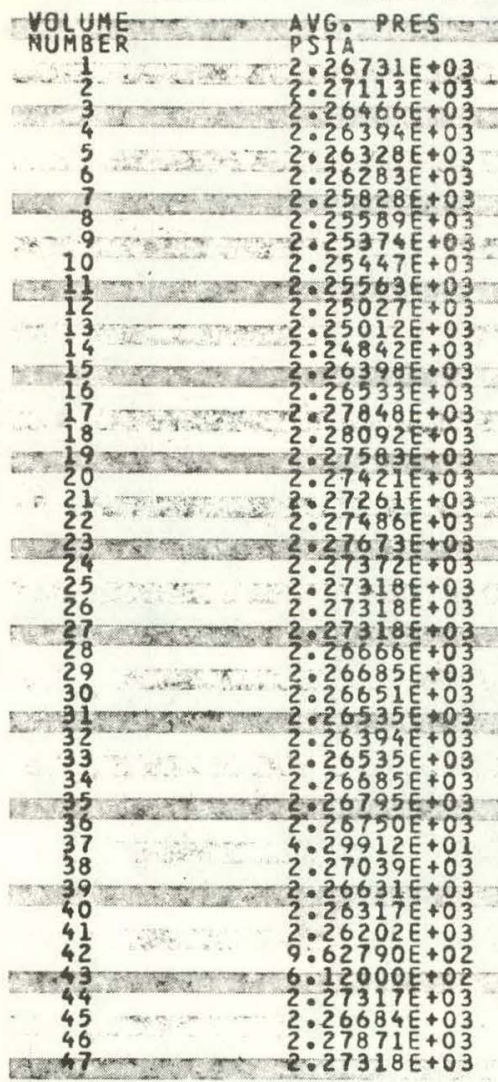 & 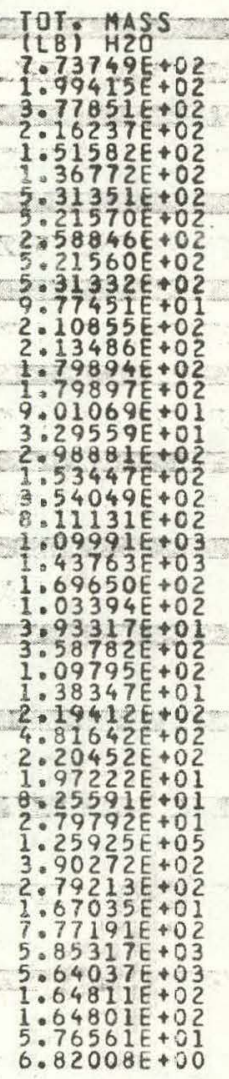 & 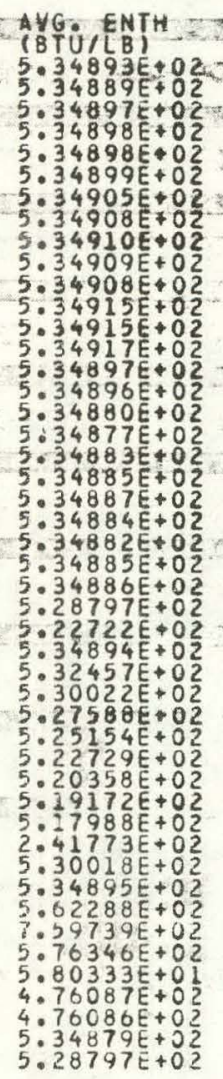 & 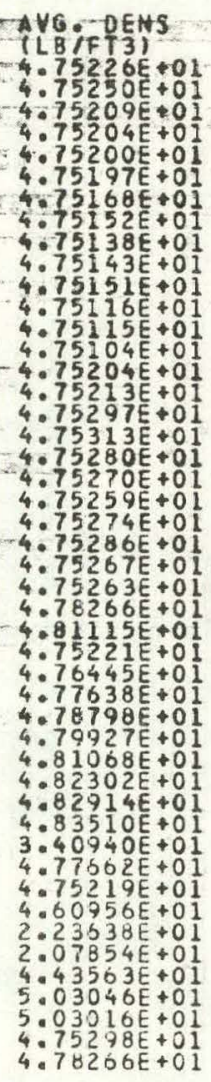 & 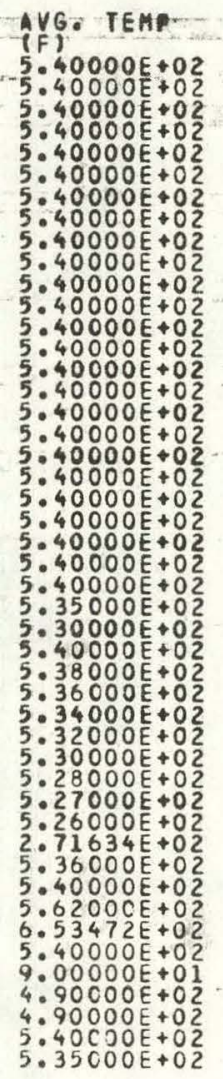 & 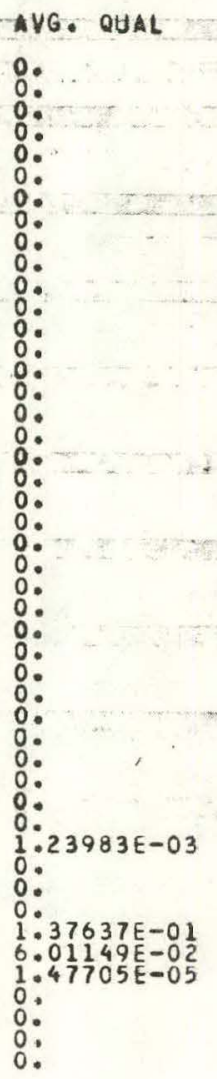 & 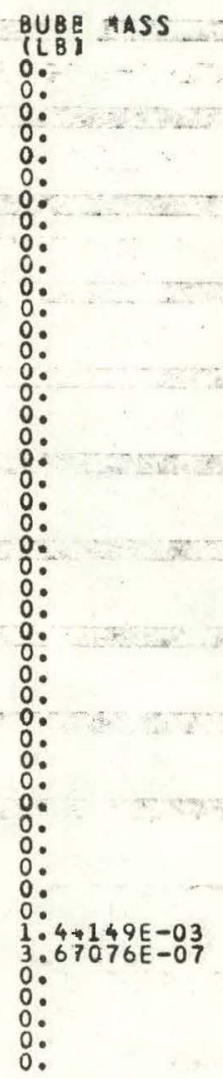 & 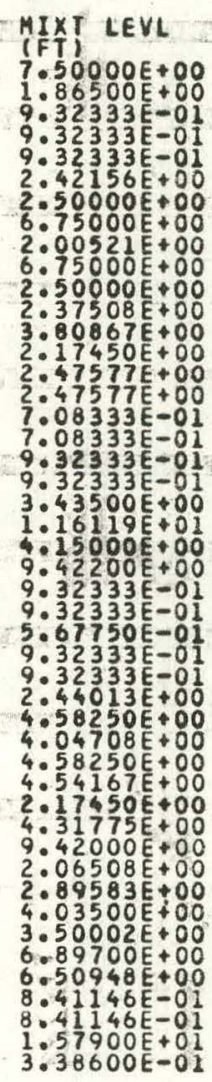 & $\begin{array}{l}M A S S \\
49 E+02 \\
15 E+02 \\
51 E+02 \\
37 E+02 \\
82 E+02 \\
72 E+0.02 \\
51 E+02 \\
70 E+02 \\
46 E+02 \\
60 E+02 \\
32 E+02 \\
51 E+01 \\
55 E+02 \\
86 E+02 \\
94 E+02 \\
97 E+02 \\
69 E+01 \\
59 E+01 \\
81 E+02 \\
47 E+02 \\
49 E+02 \\
31 E+02 \\
91 E+03 \\
63 E+03 \\
50 E+02 \\
94 E+02 \\
17 E+01 \\
82 E+01 \\
95 E+02 \\
47 E+01 \\
12 E+02 \\
42 E+02 \\
52 E+02 \\
22 E+01 \\
91 E+01 \\
92 E+01 \\
68 E+05 \\
72 E+02 \\
13 E+02 \\
35 E+01 \\
21 E+02 \\
30 E+03 \\
28 E+03 \\
11 E+02 \\
01 E+02 \\
61 E+01 \\
08 E+00\end{array}$ \\
\hline
\end{tabular}




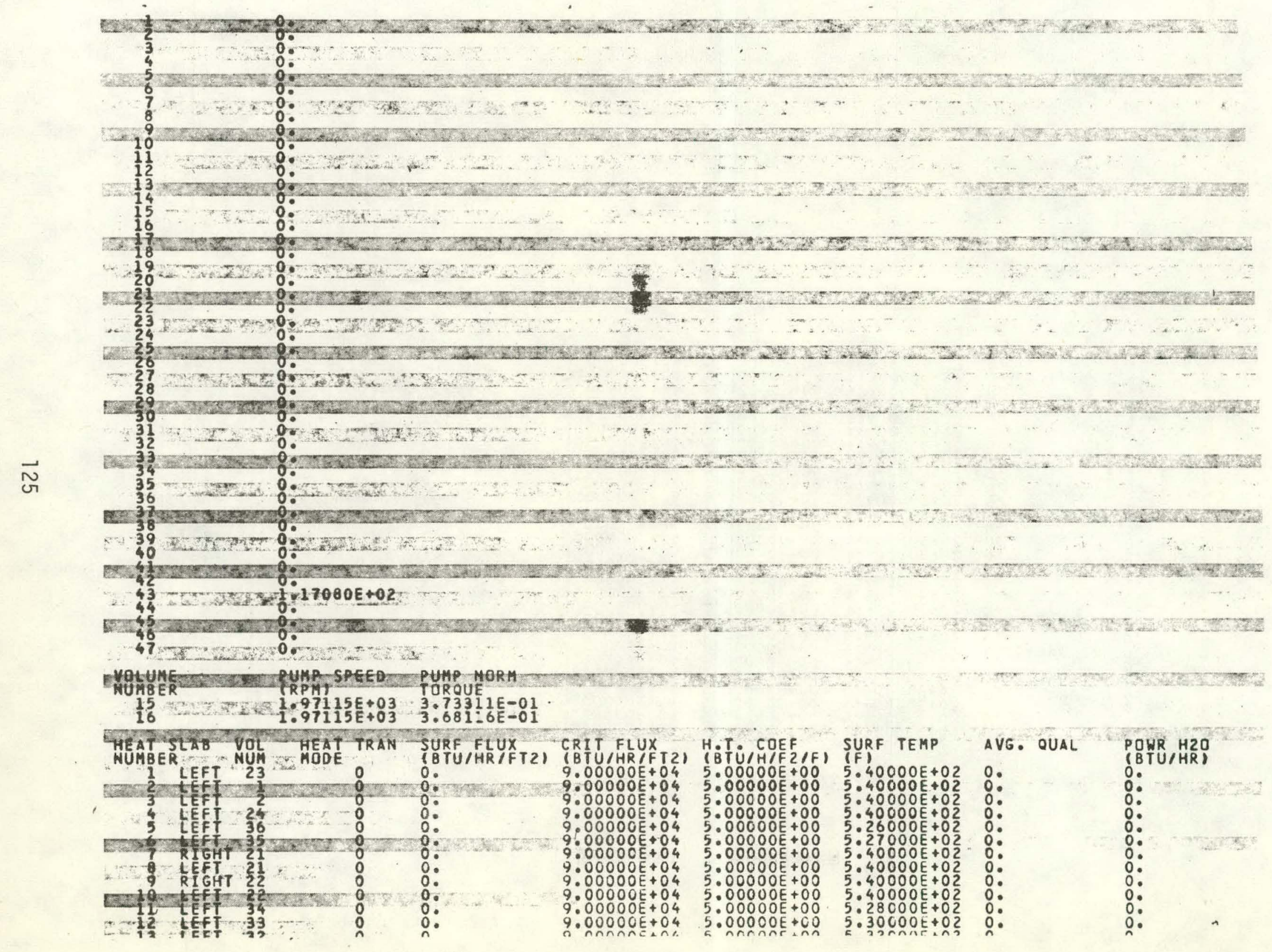




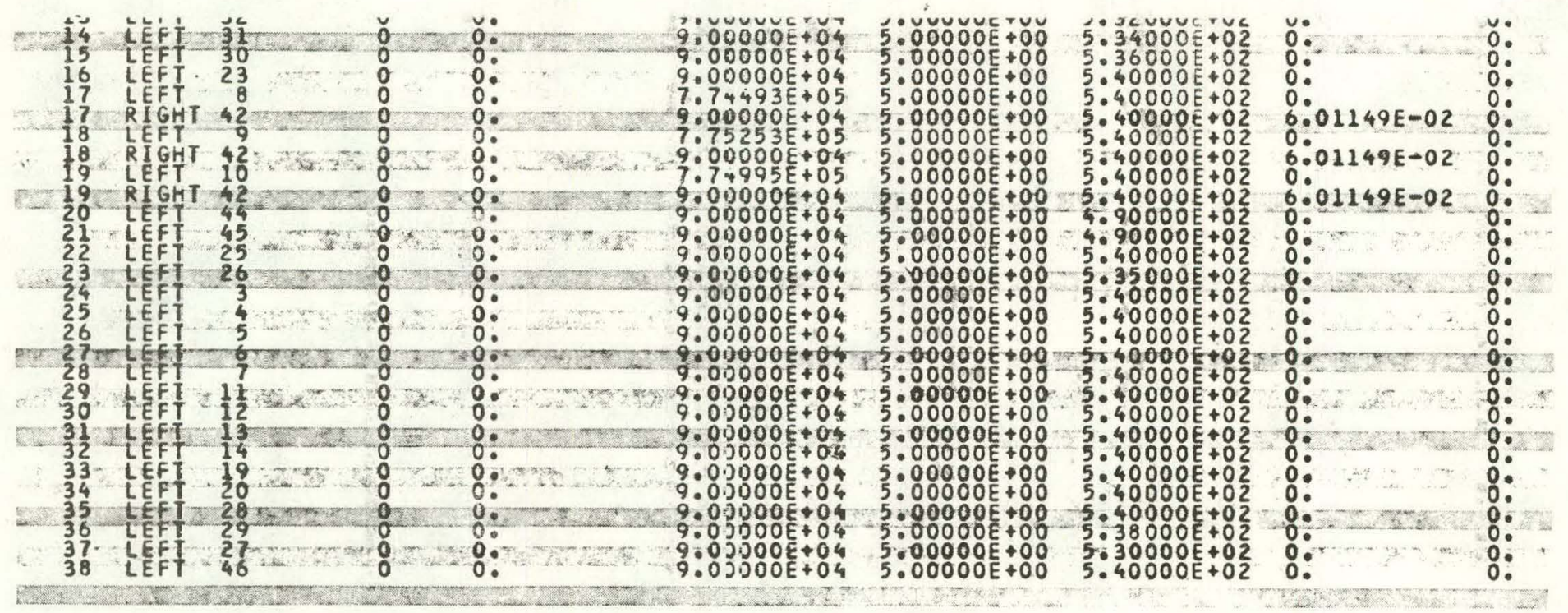




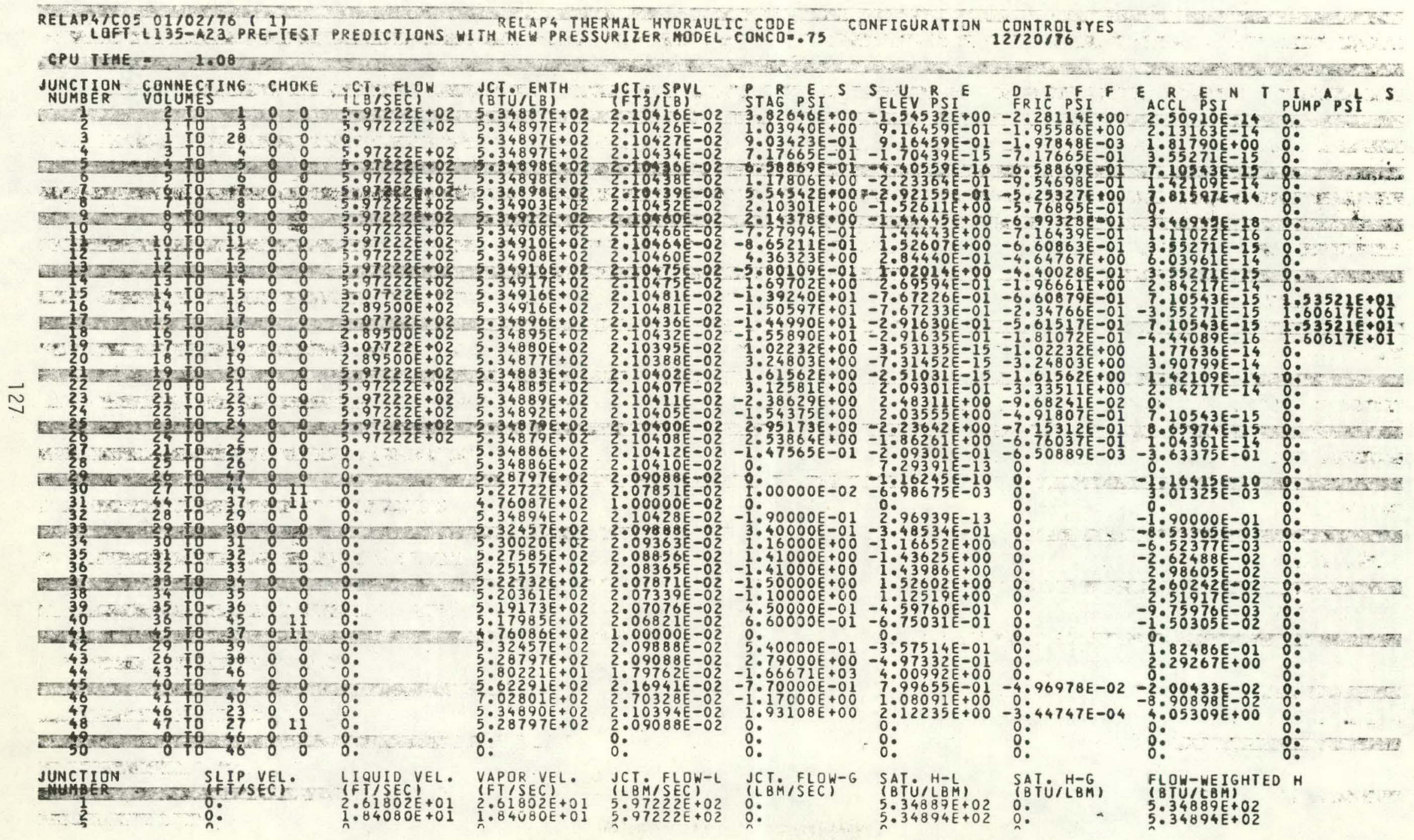




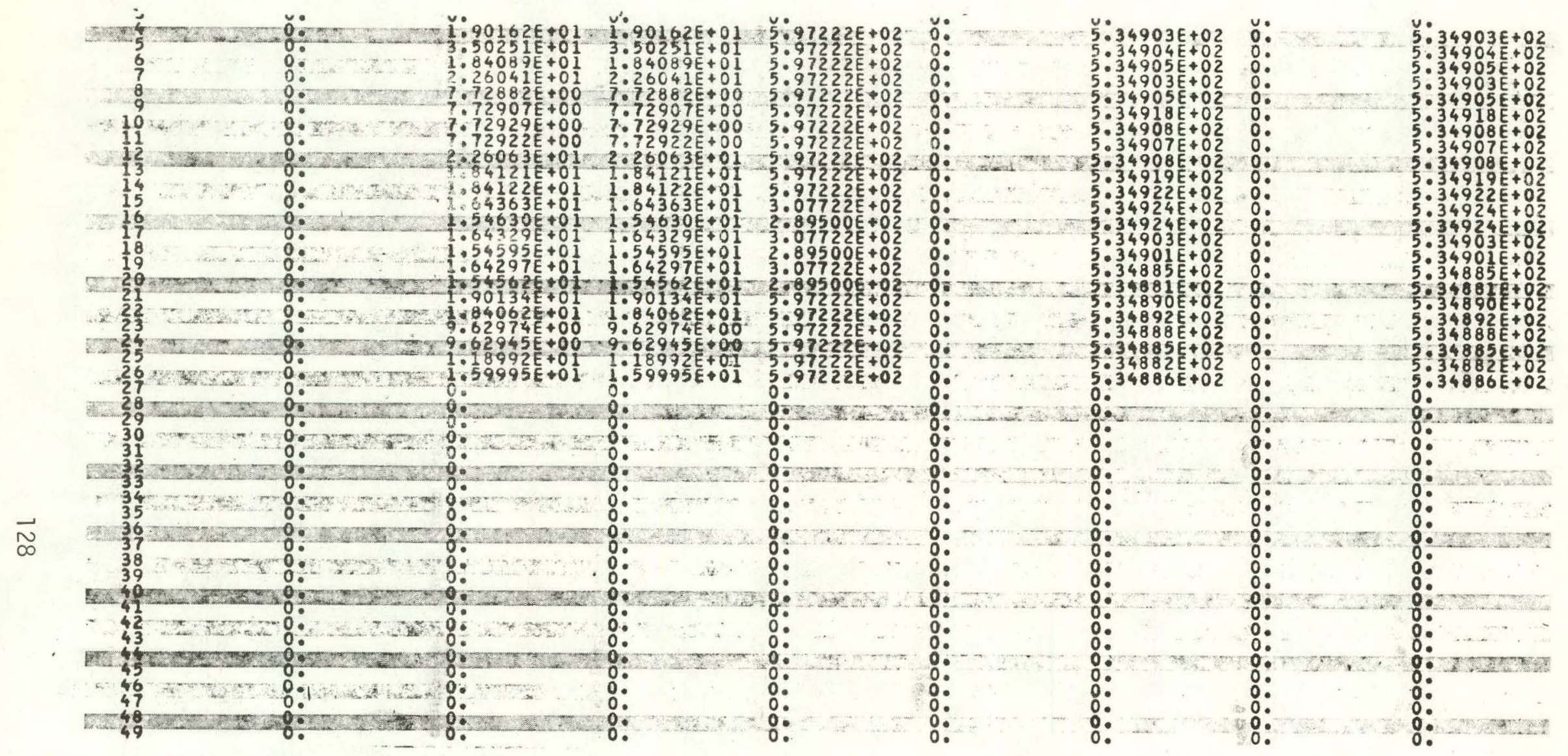




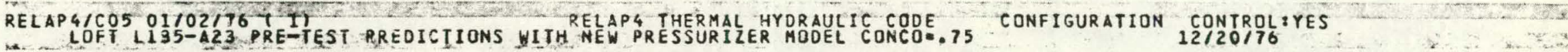

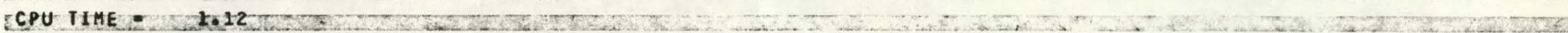

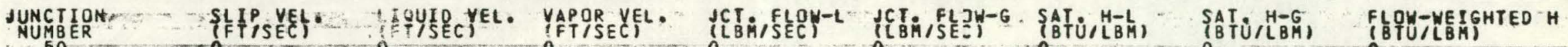

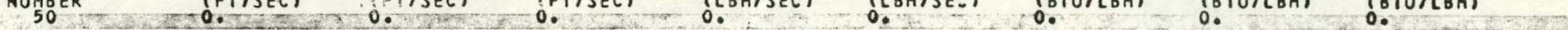
PLOT RECORD NUMBER $=\square O=$

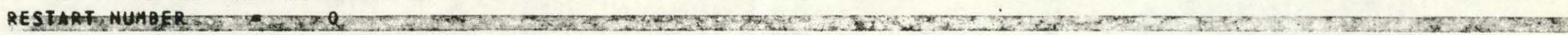




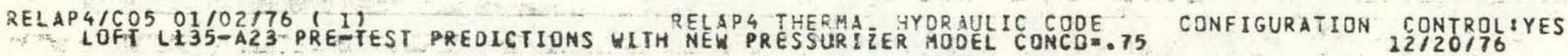

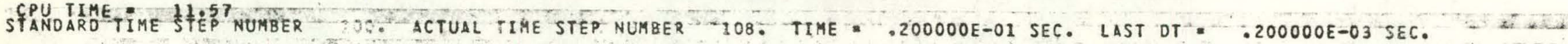

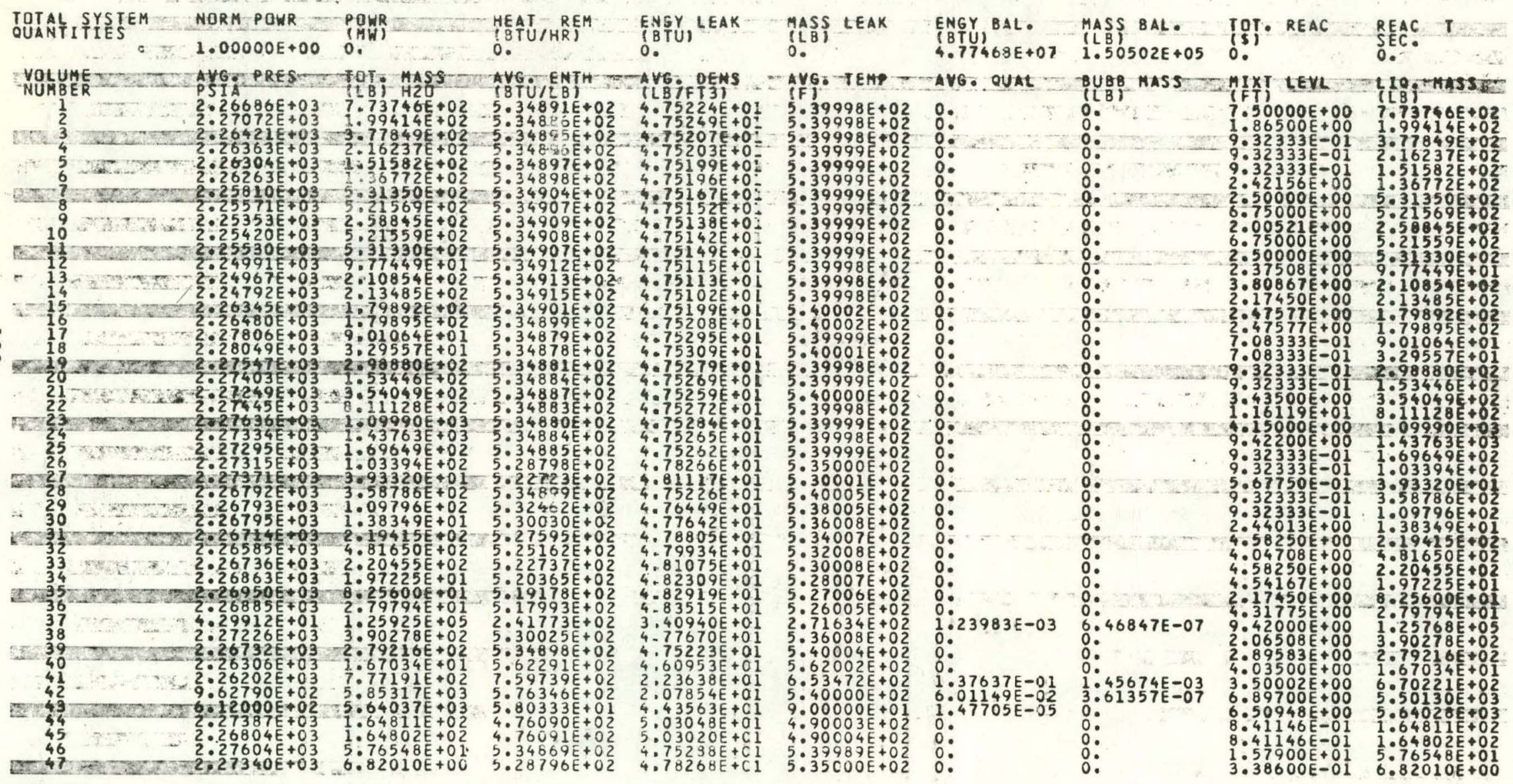




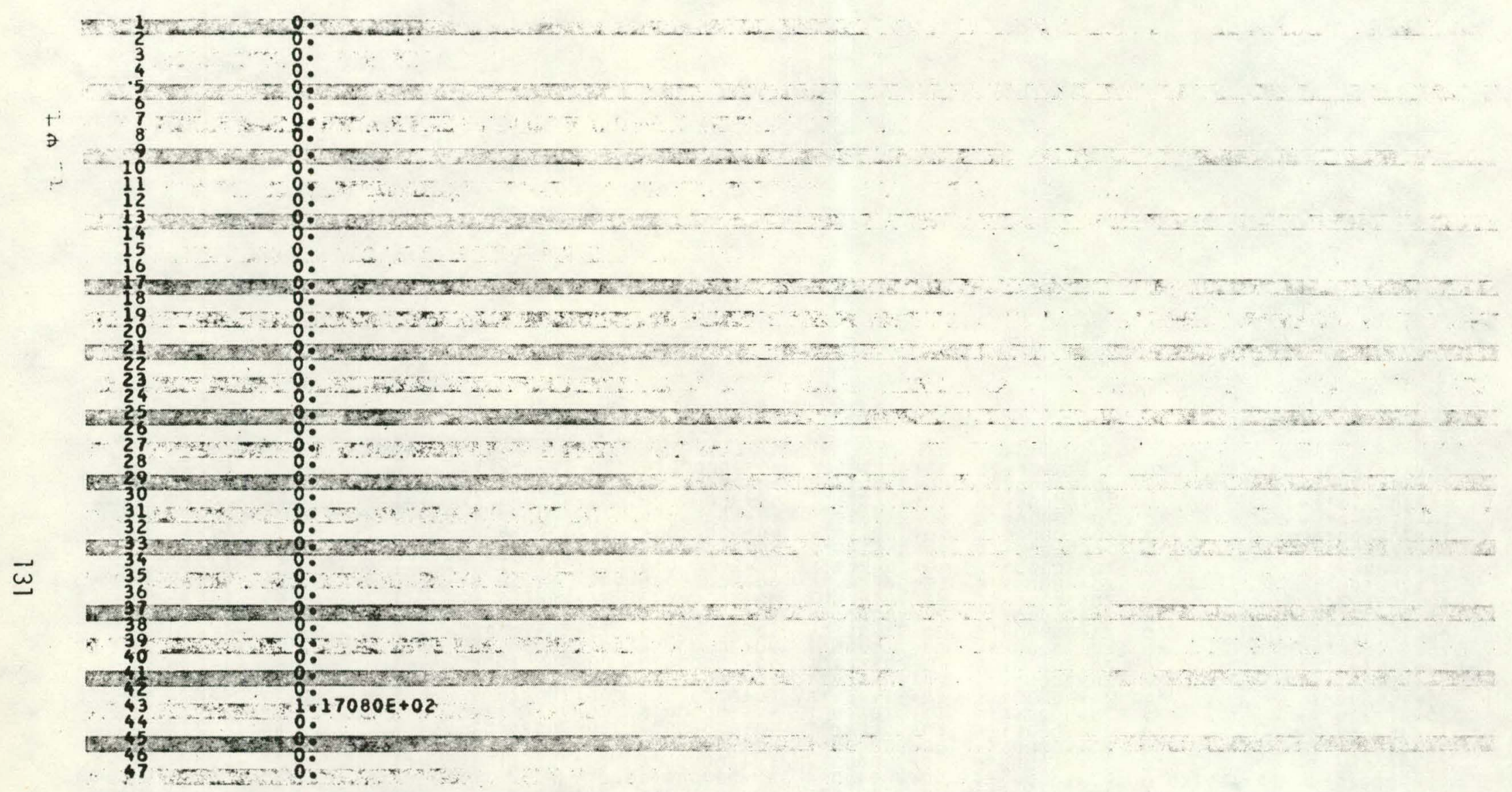

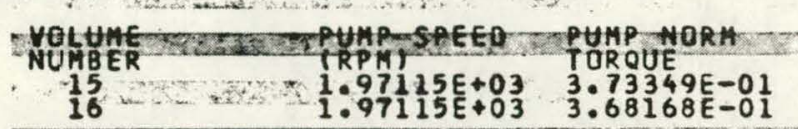

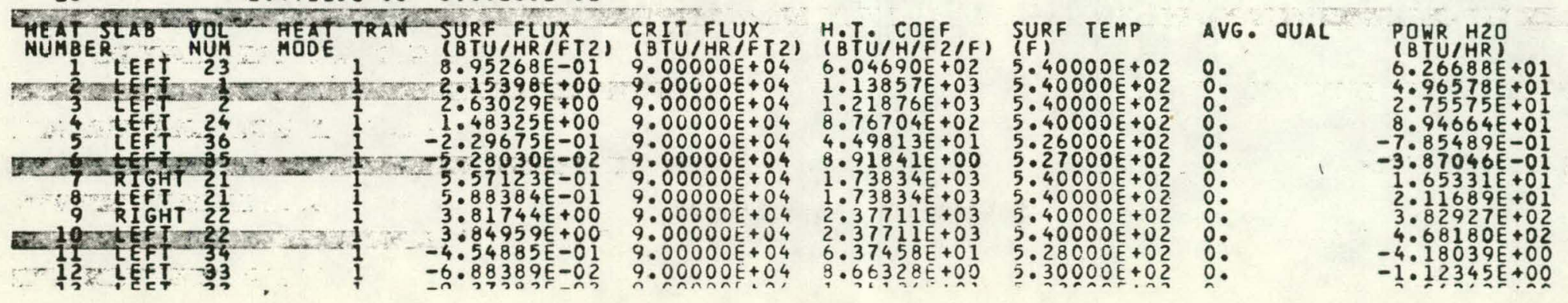




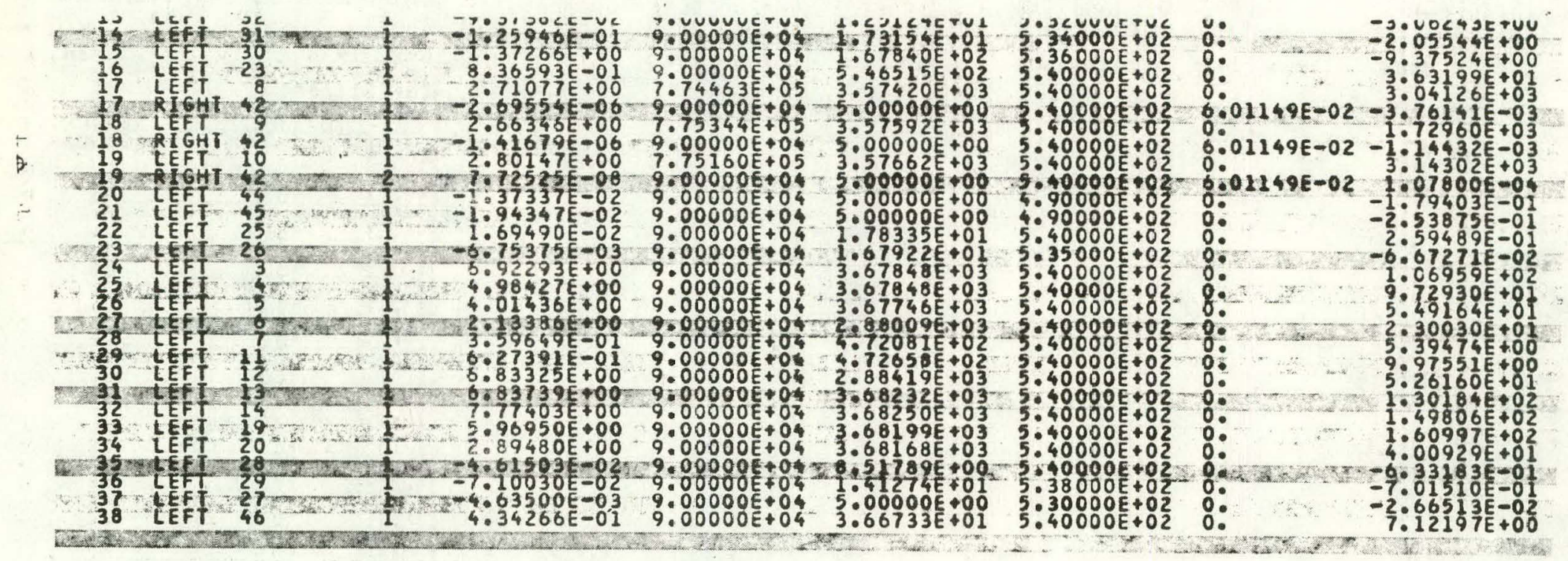




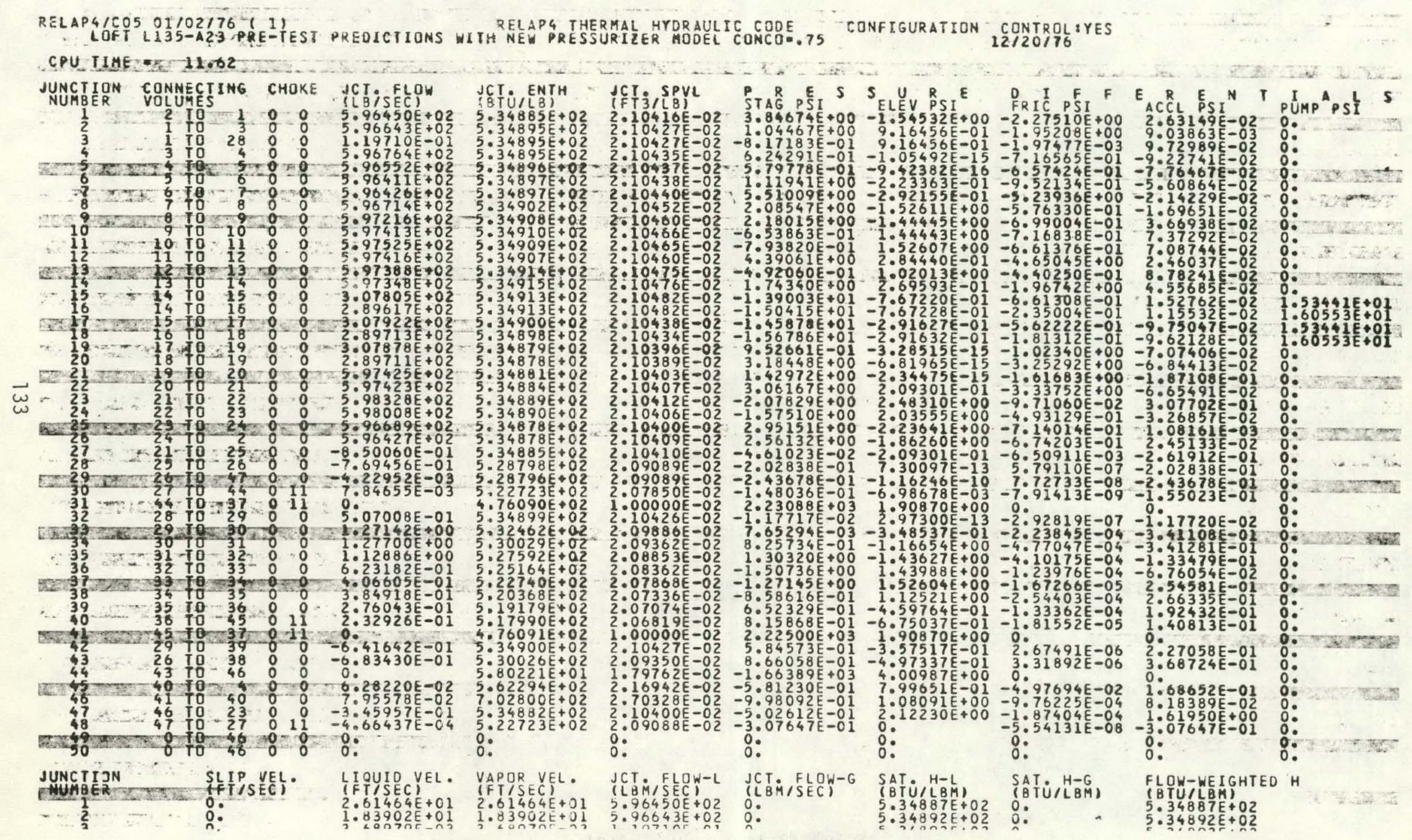



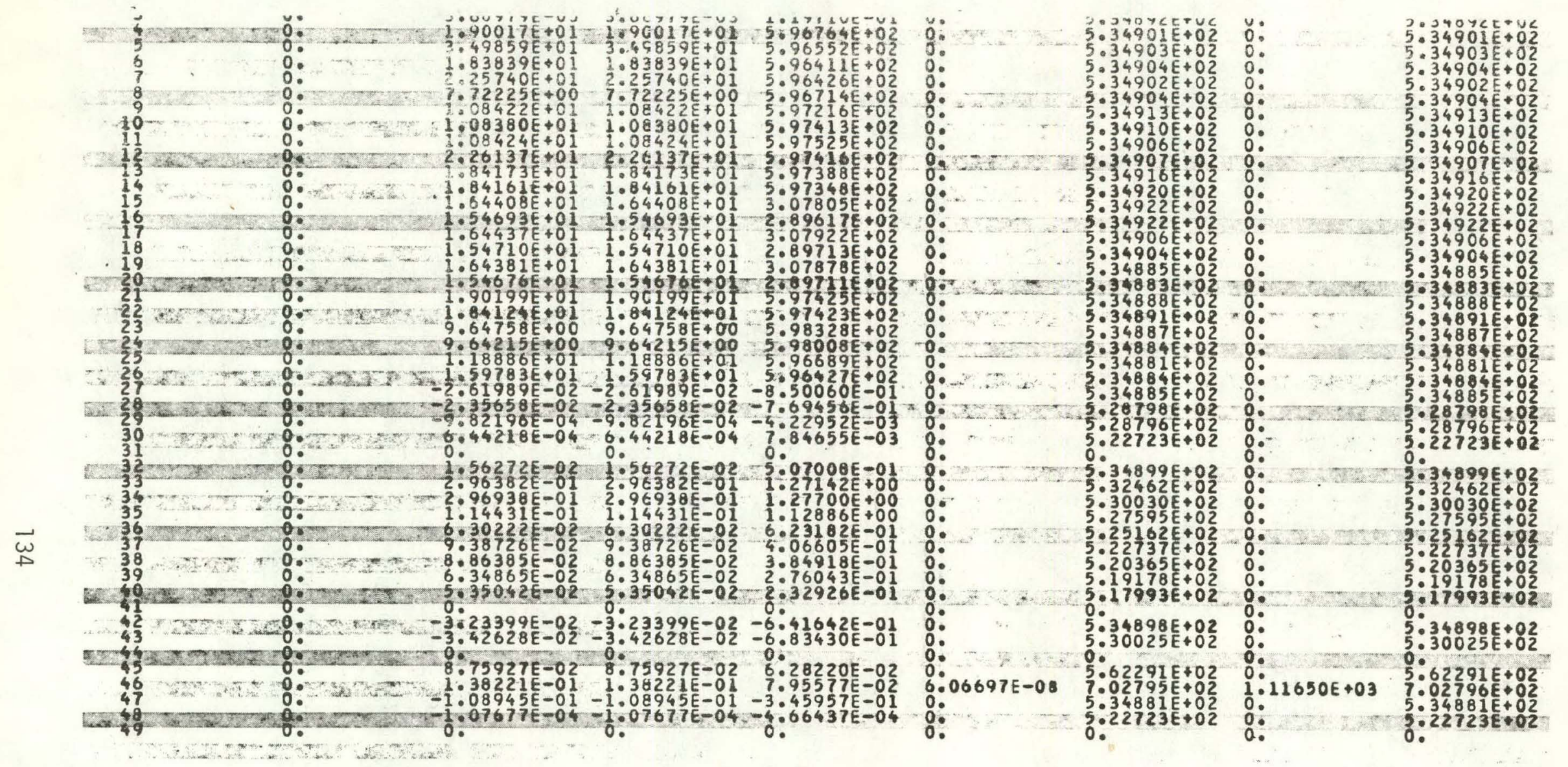


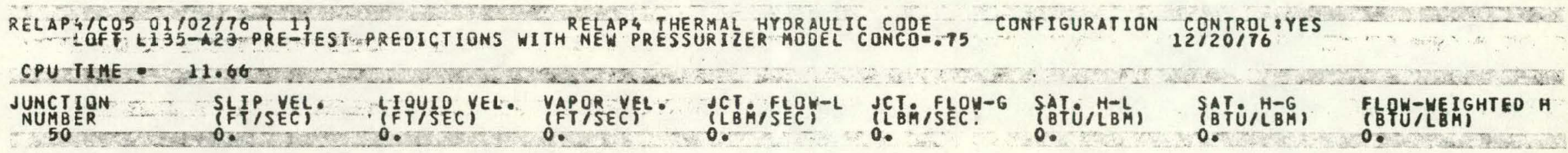
PLOT RECORD NUMBER - 2 
THIS PAGE

\section{WAS INTENTIONALLY LEFT BLANK}




\section{APPENDIX B}

INPUT AND TIME $=0.0$ LISTING FOR THE POSTTEST ANALYSIS RUN

(RELAP4 RUN L135-A22) 
ISTING OF INPUT DATA FOR CASE I E

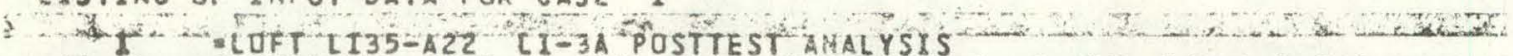

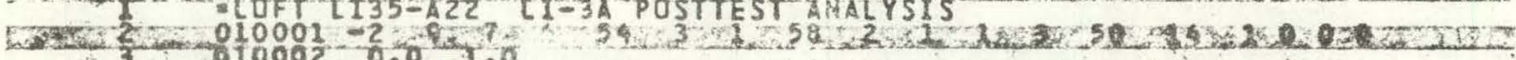

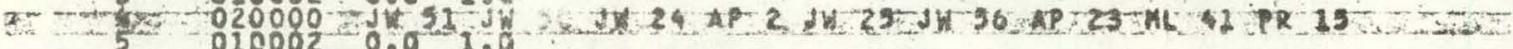

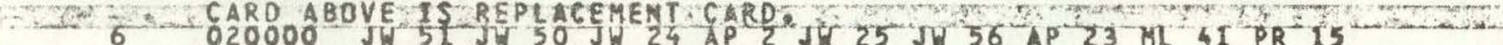
5. 7 CARD ABOVE IS REPLACENENT CARD rpis

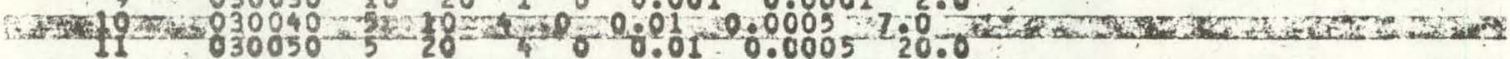
5.

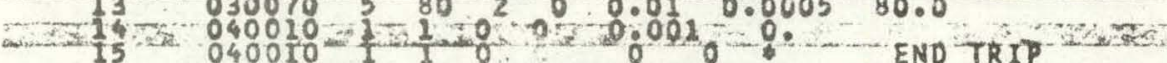

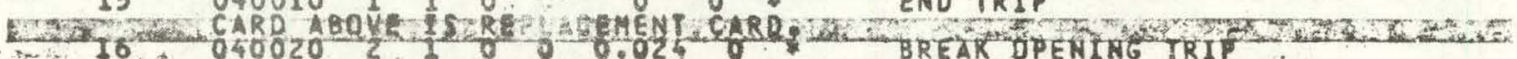

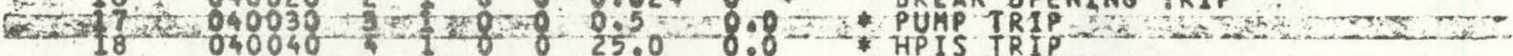

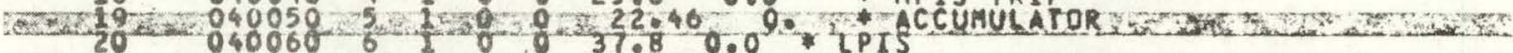

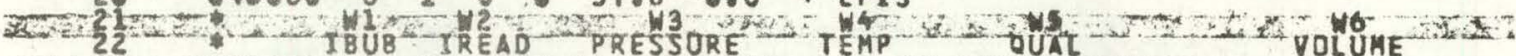

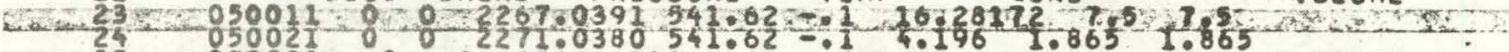

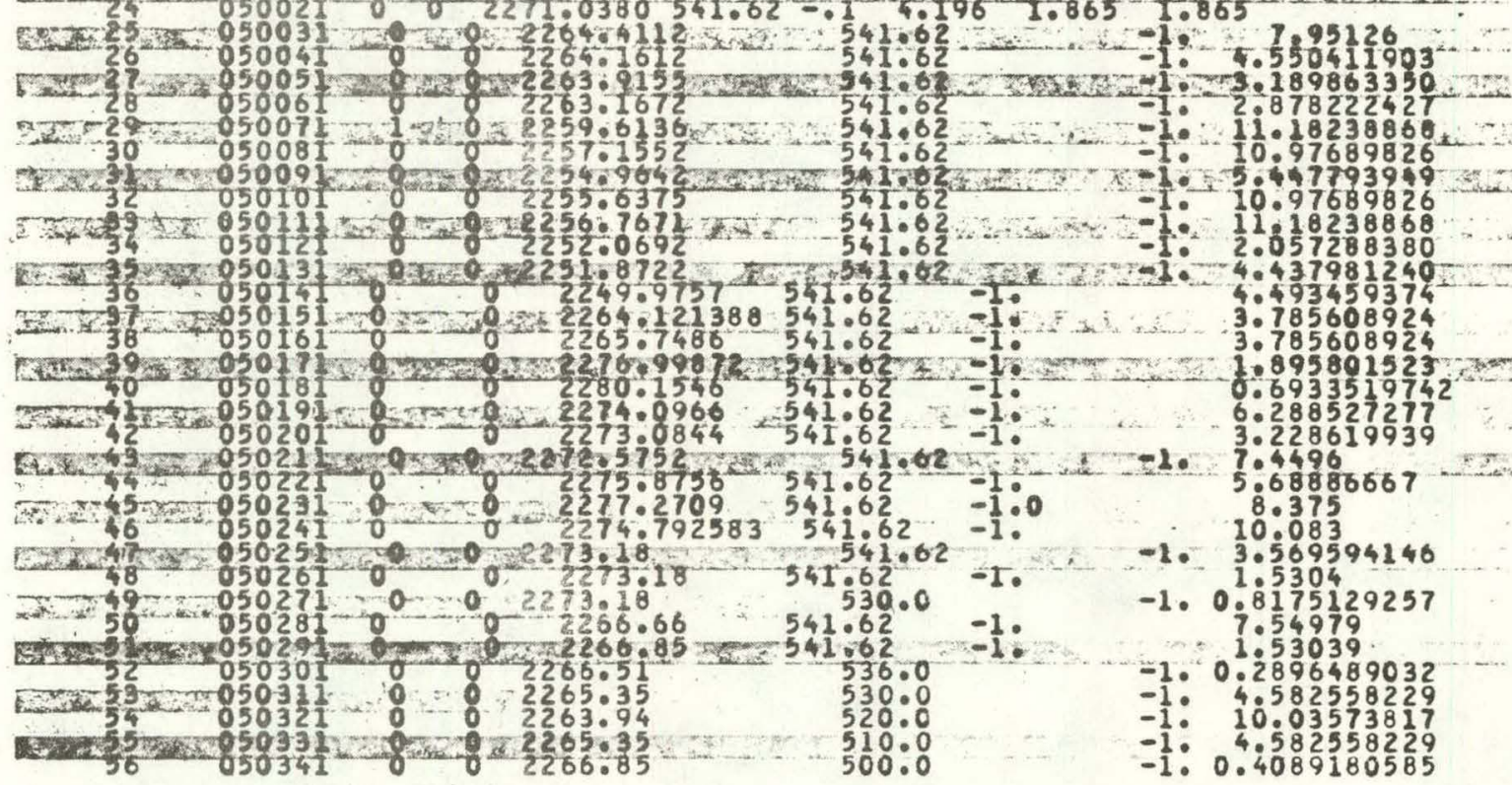




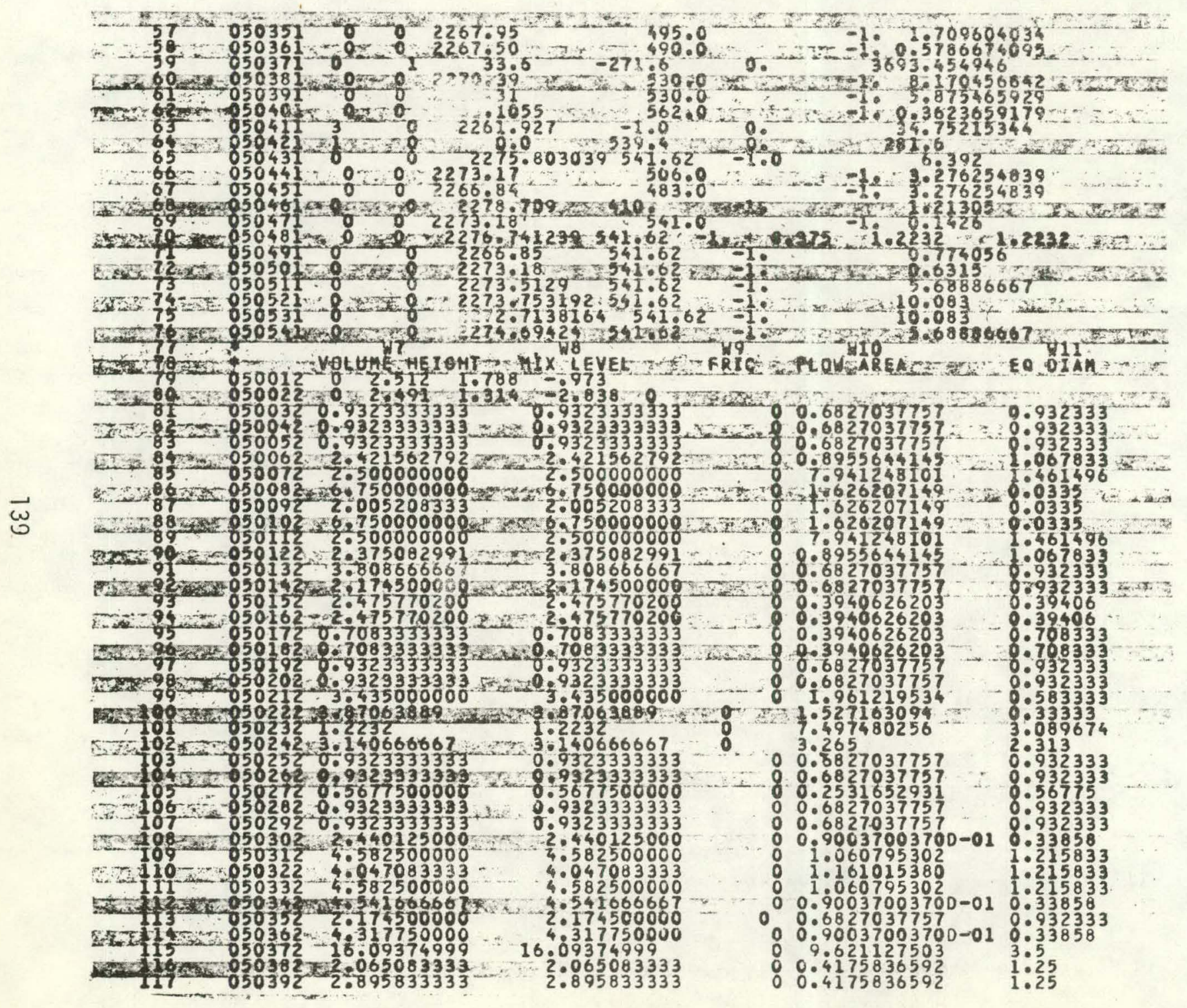




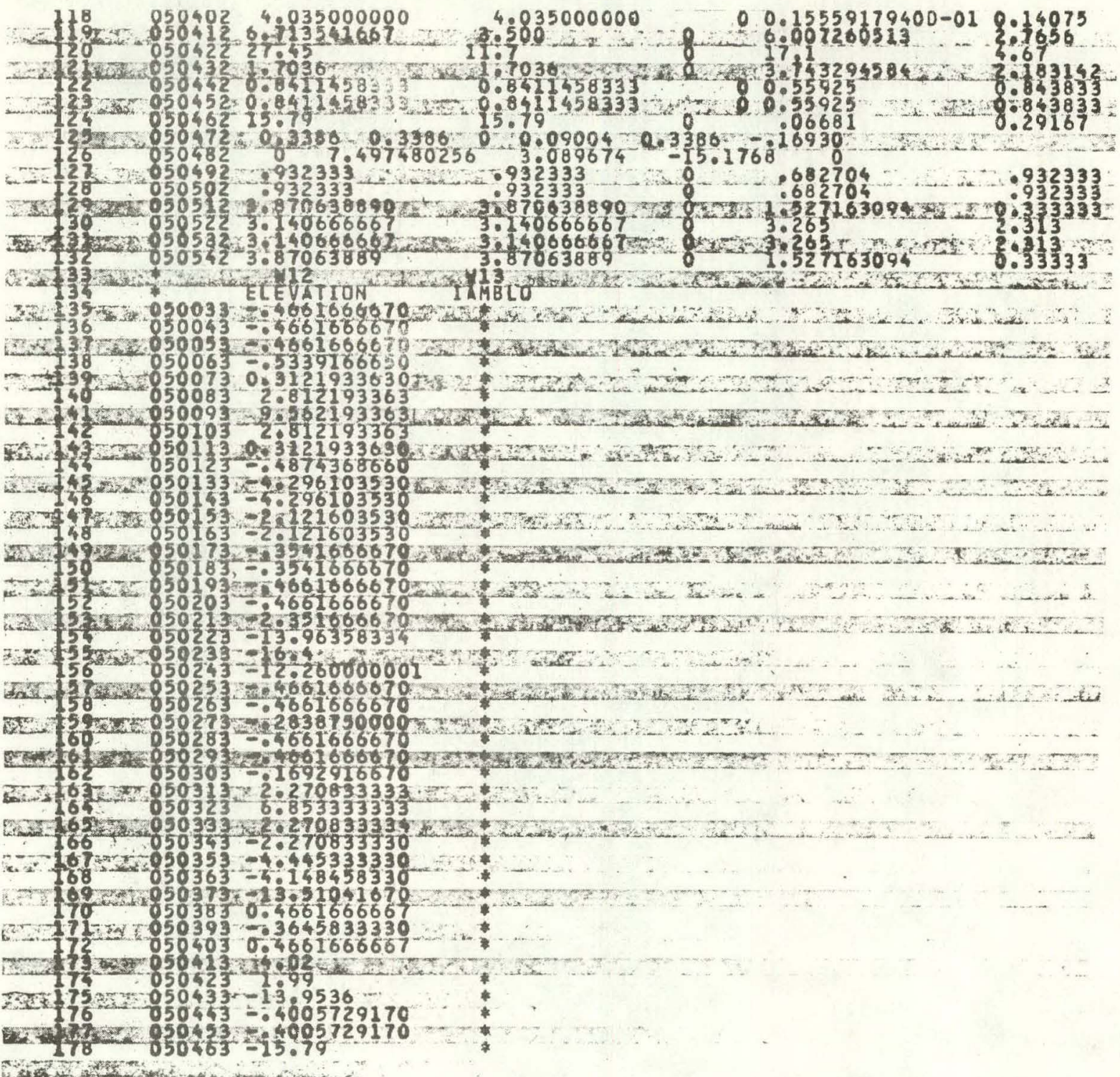

5. 


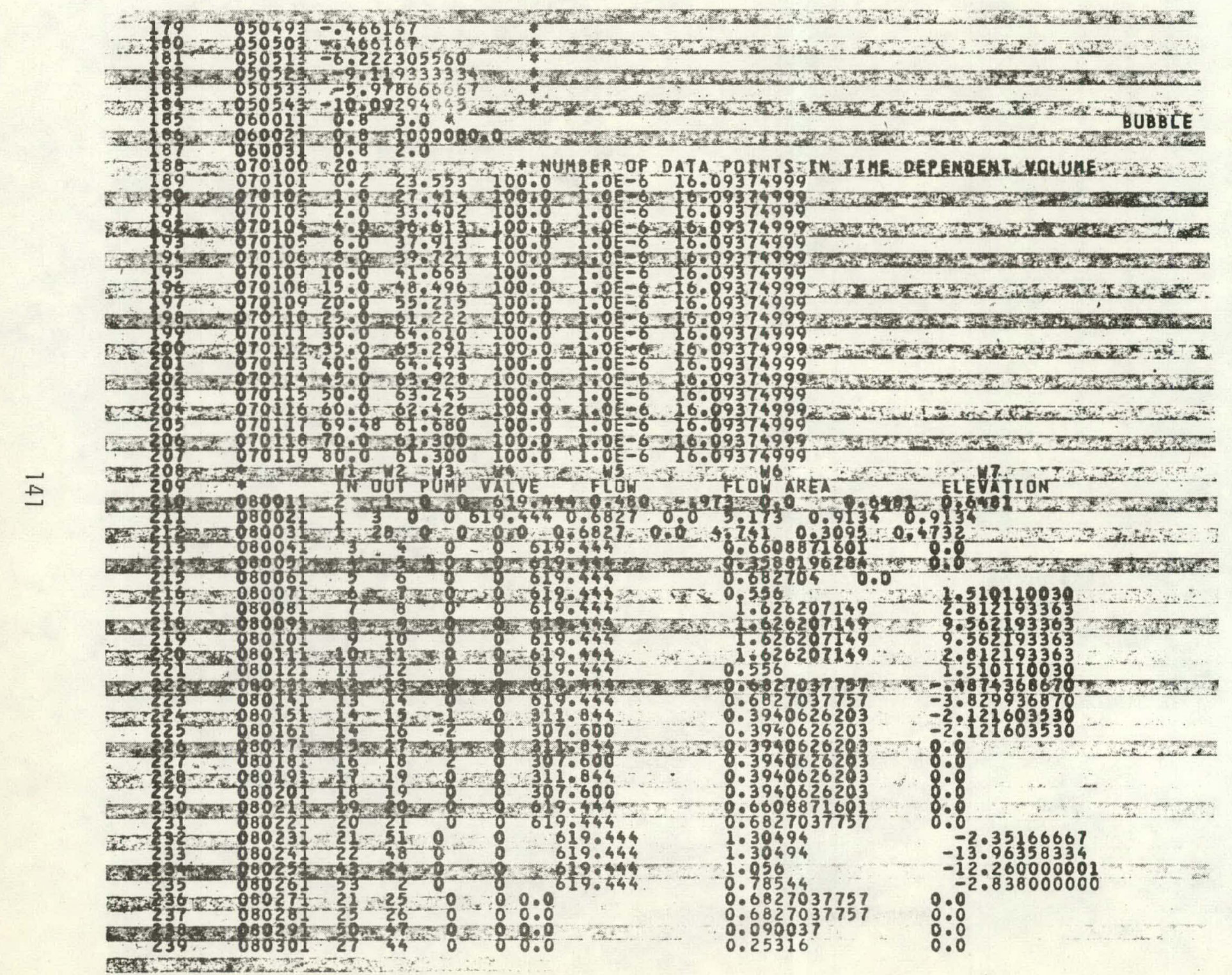




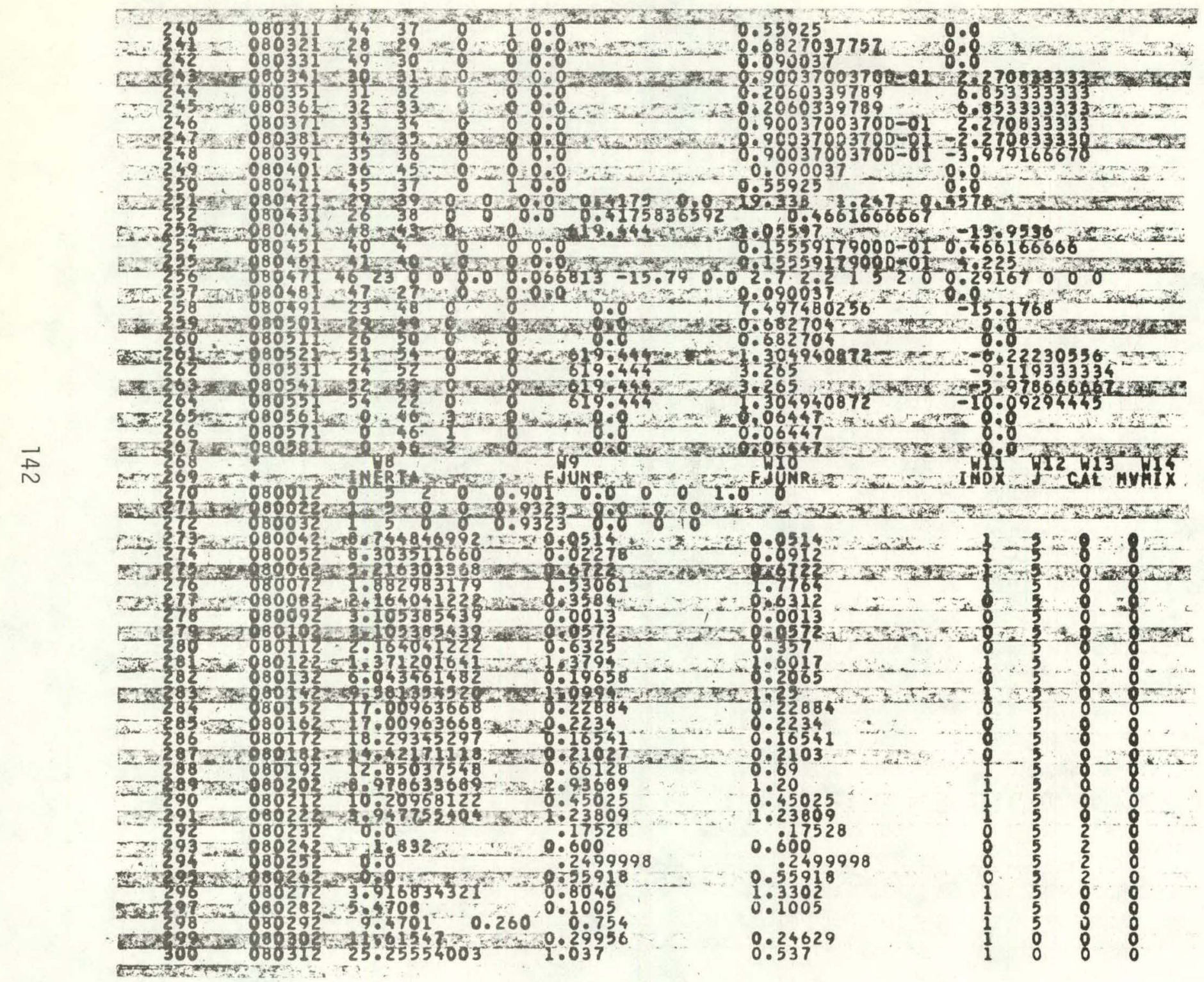




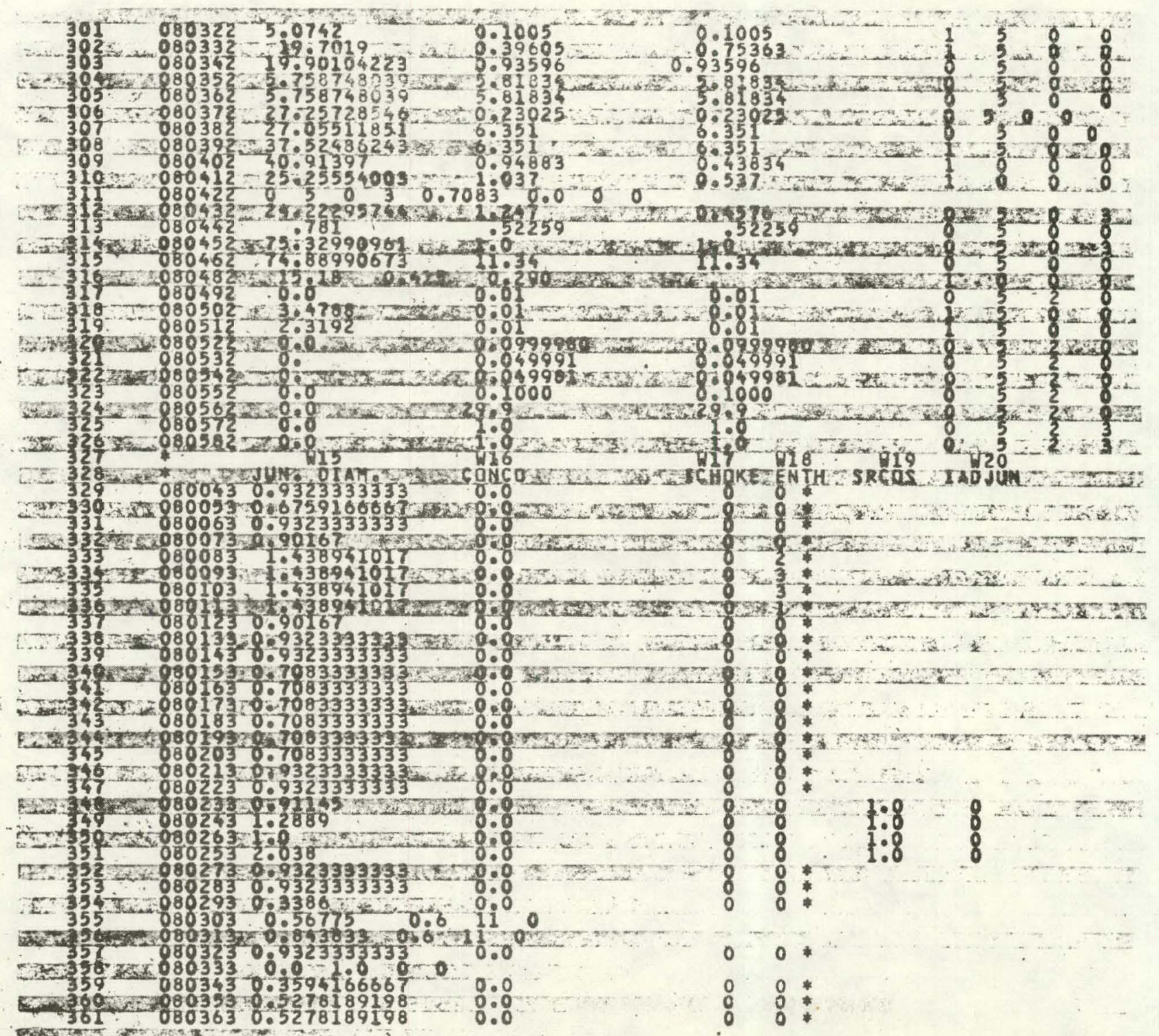




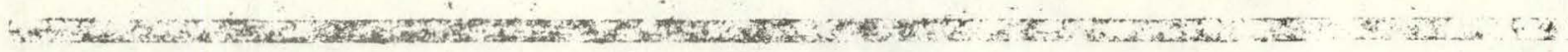

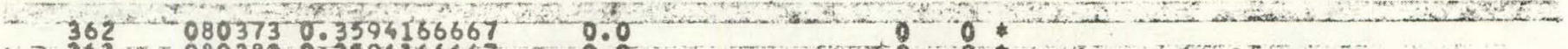

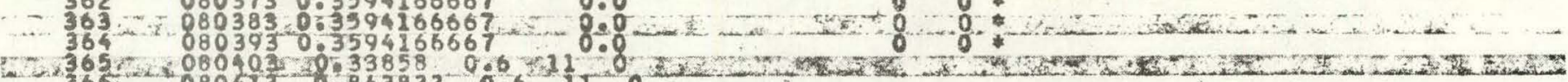

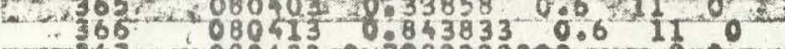

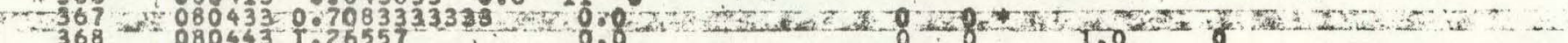

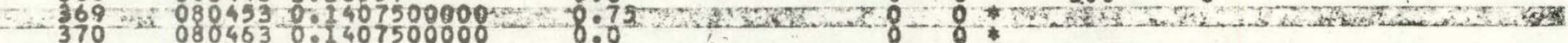

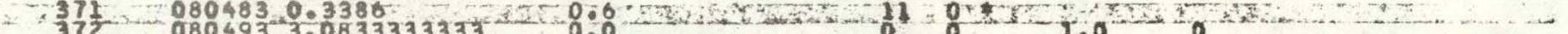

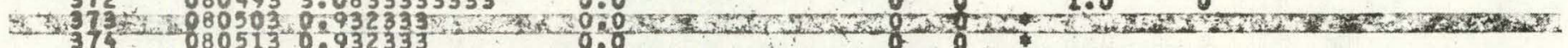

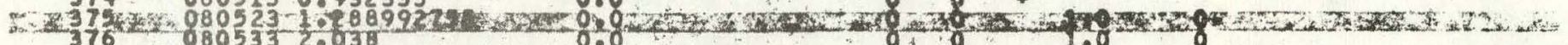

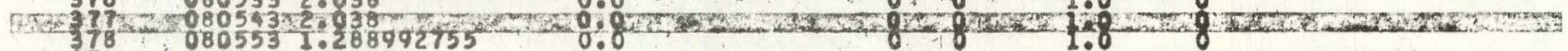

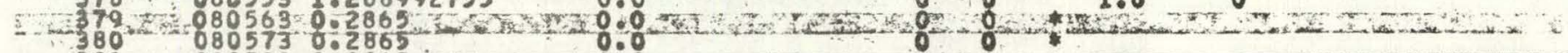

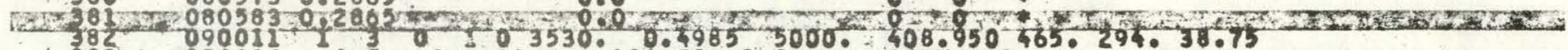

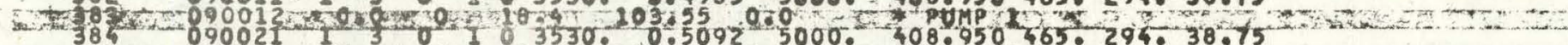

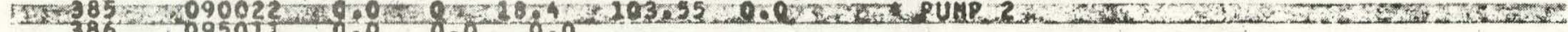

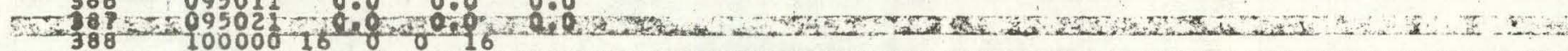

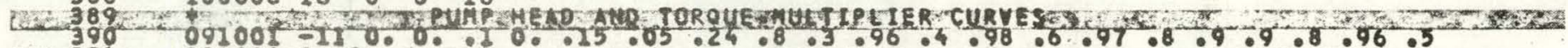

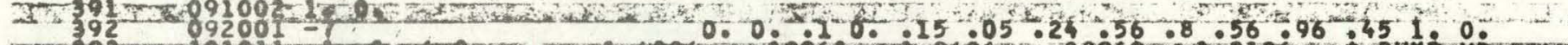

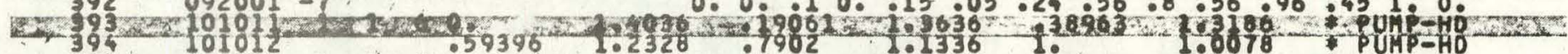

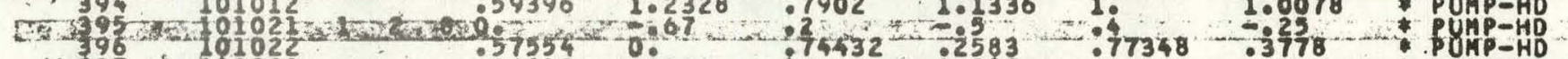

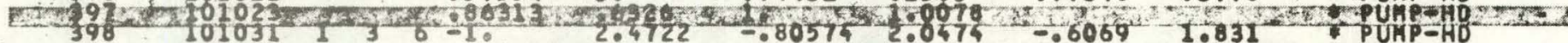

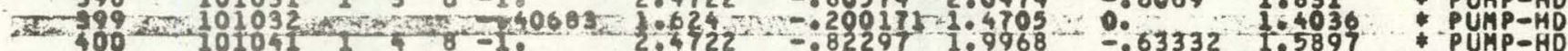

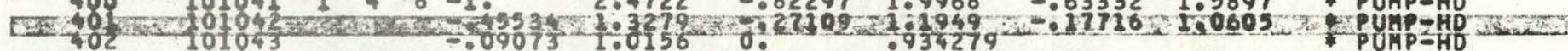

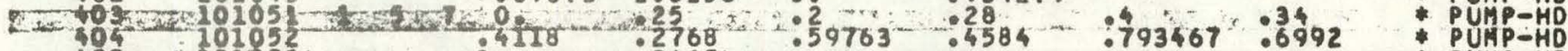

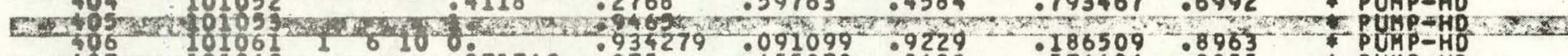

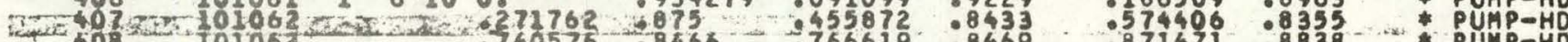

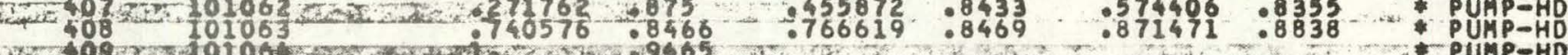

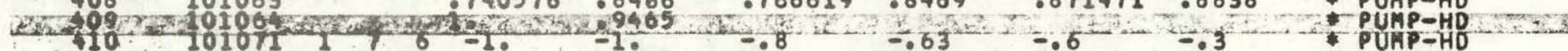

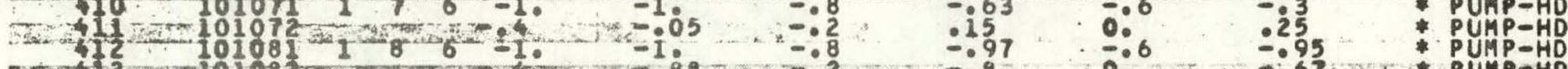

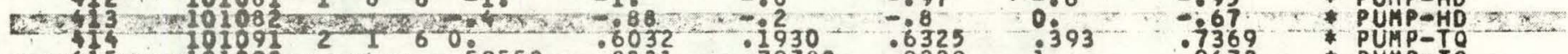

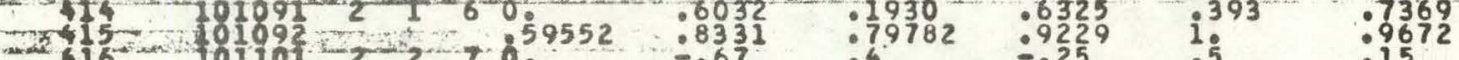

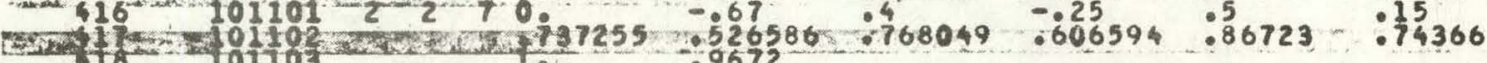

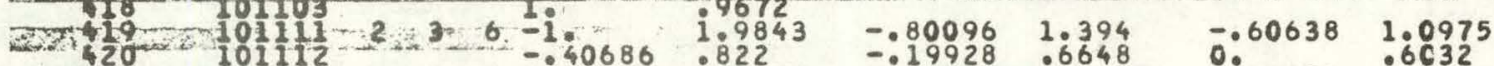

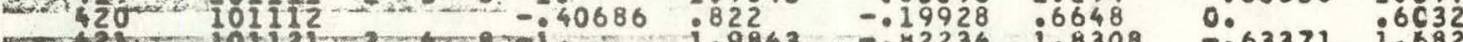

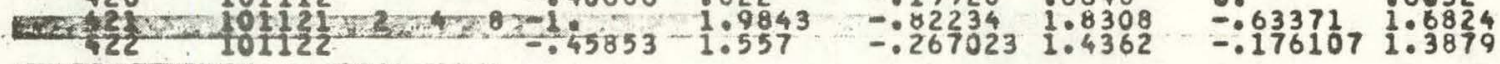

* PUMP-IO

PUMp $\rightarrow$ To

PUMP $=$ TO

- PUMP=to

and 


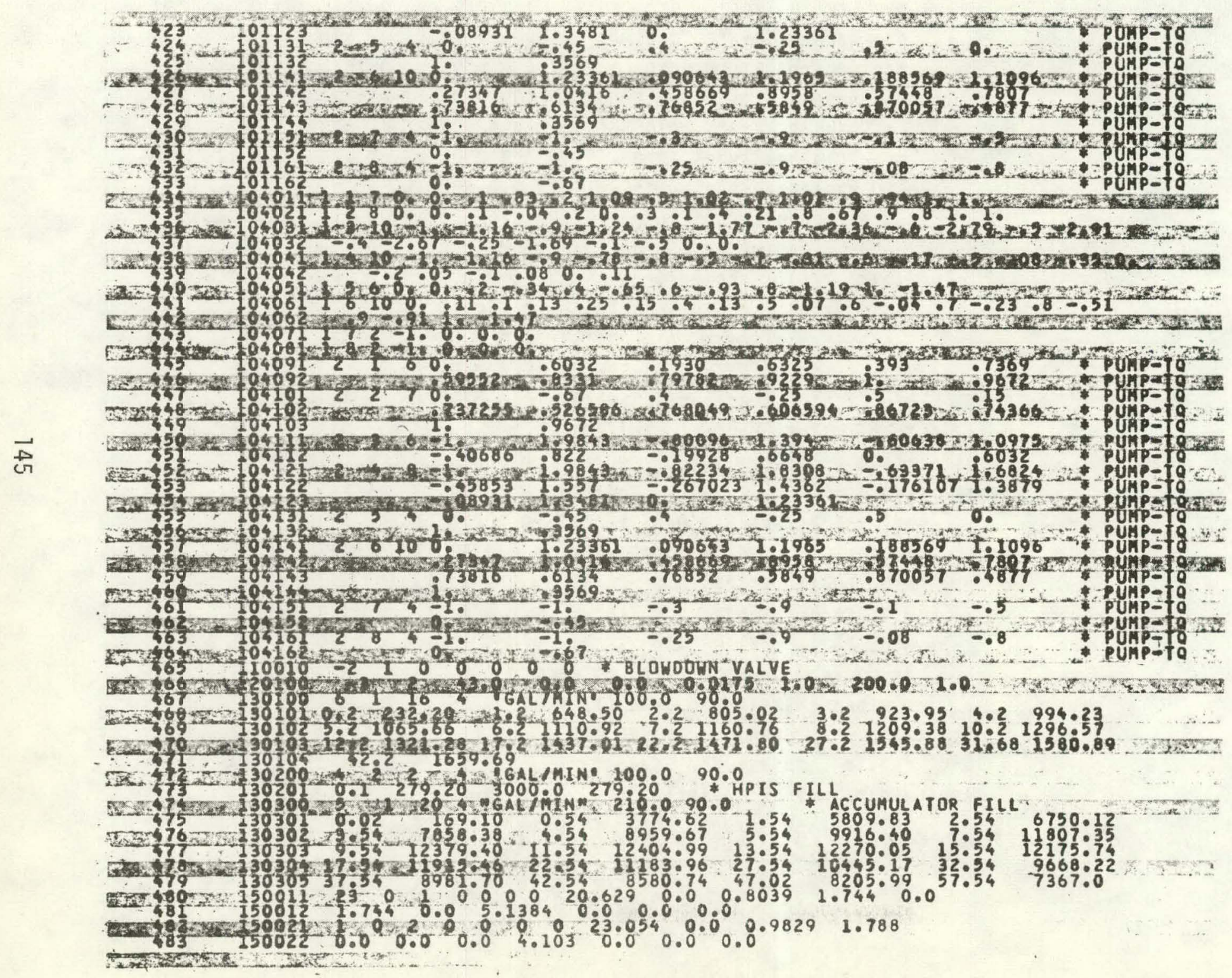




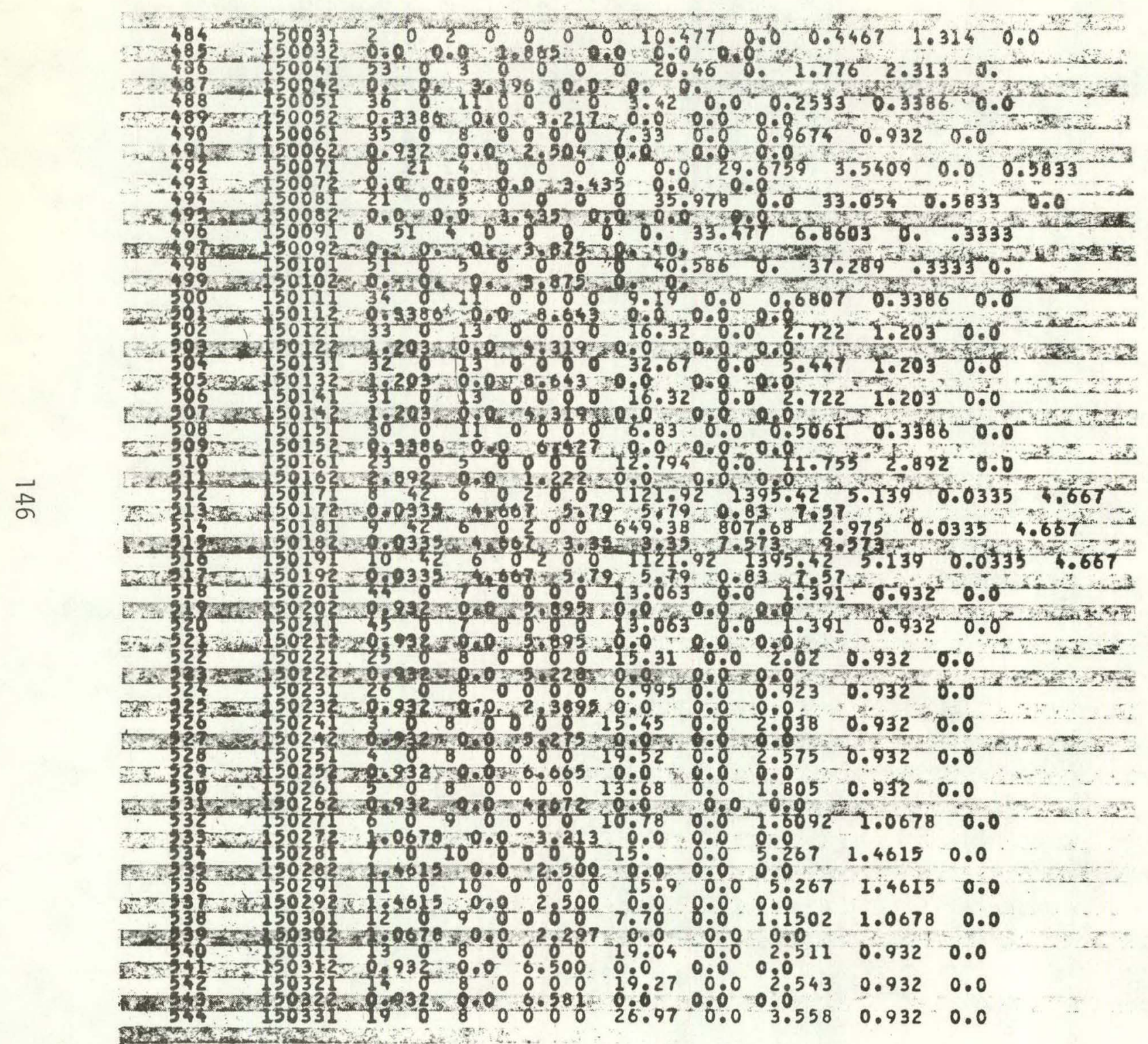




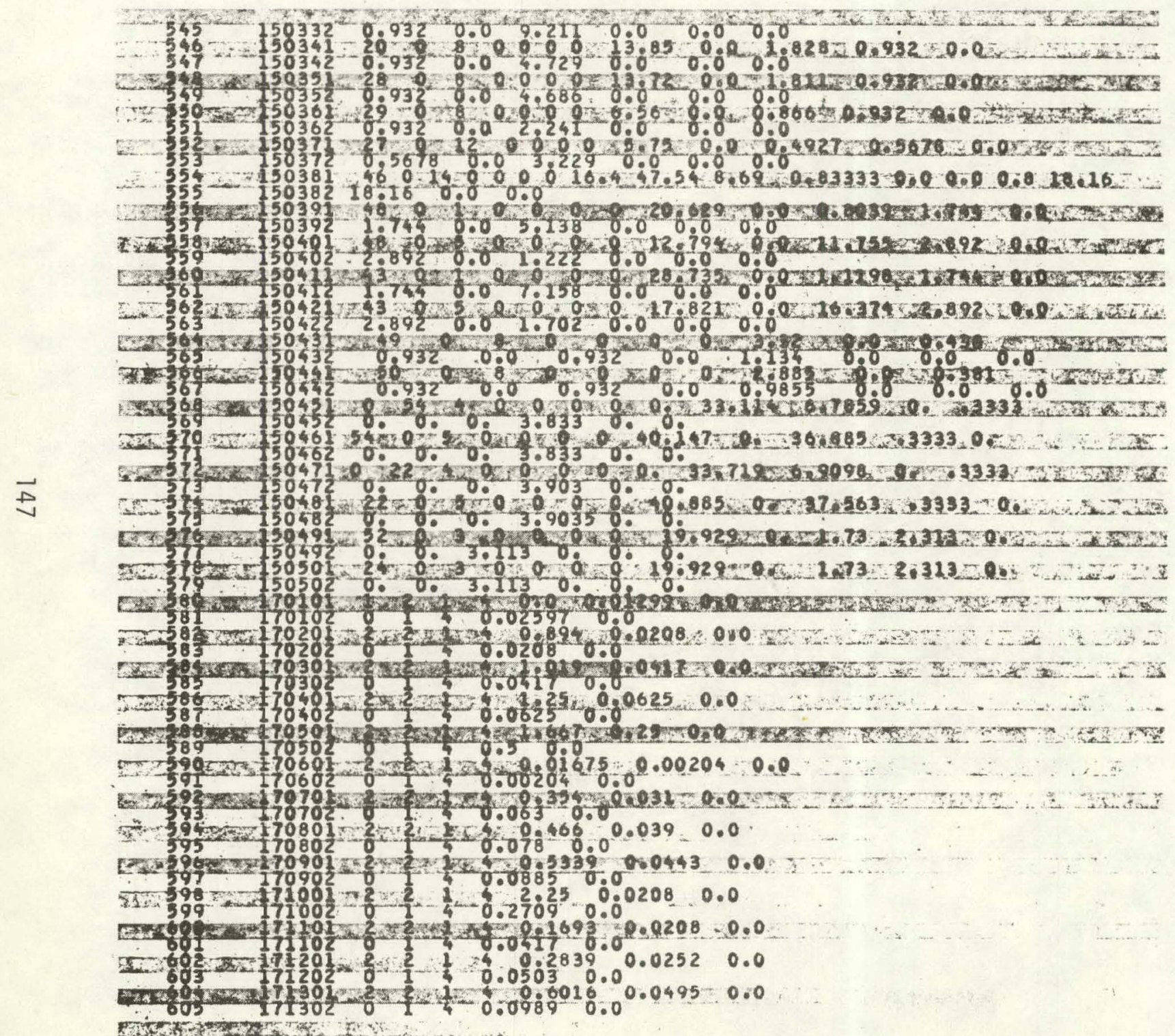




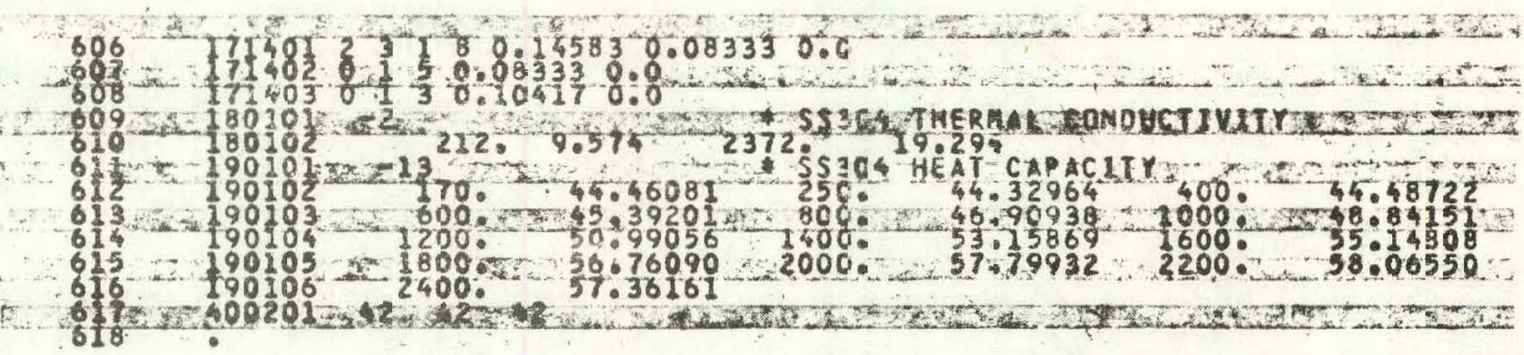




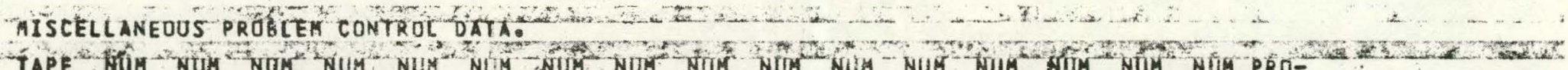

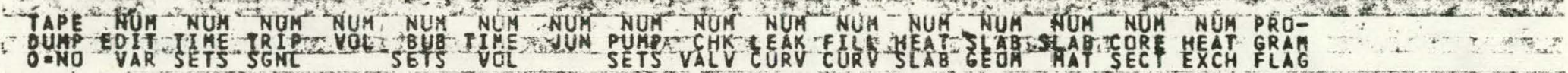

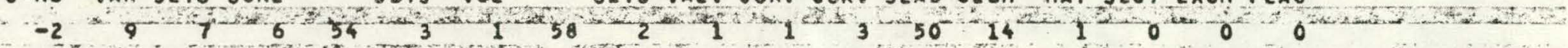
EXPJPA/C E TEPERIAENTAL RELAPG TYPE PROGRAH CONFIGURATION CONTROL NO 


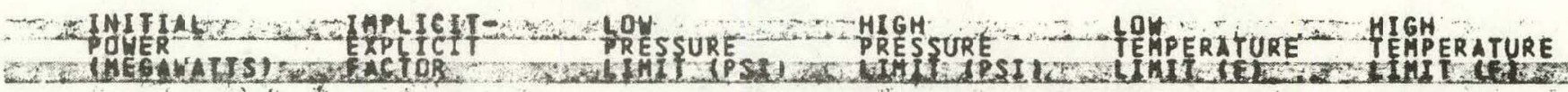

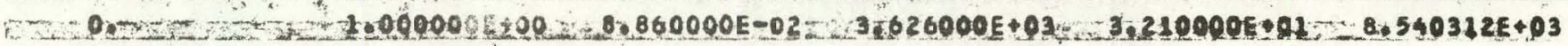

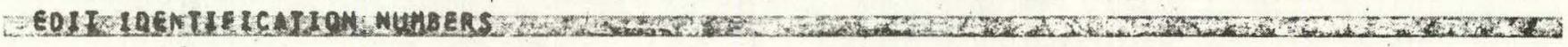

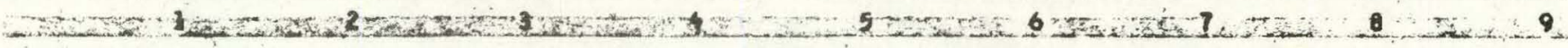
5.

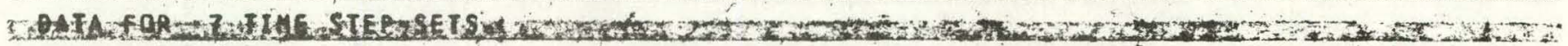

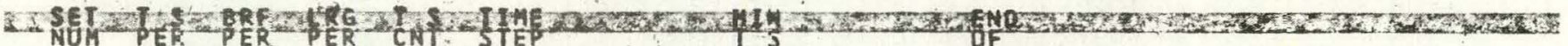

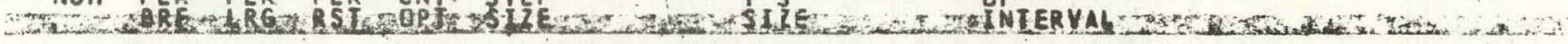

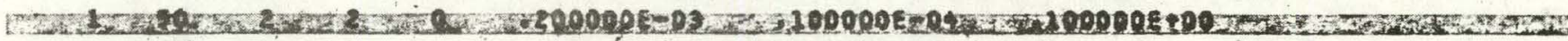

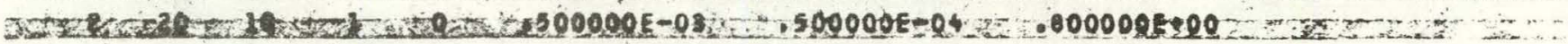

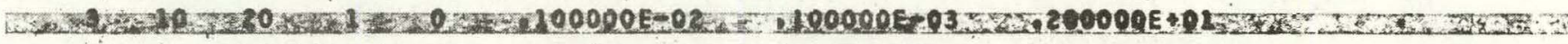

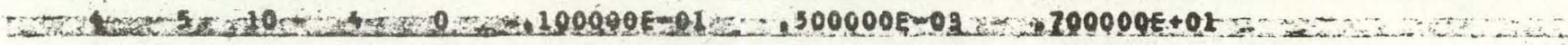

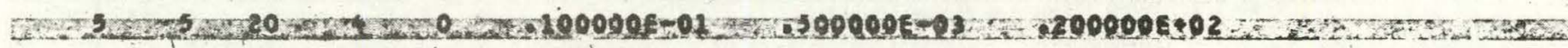

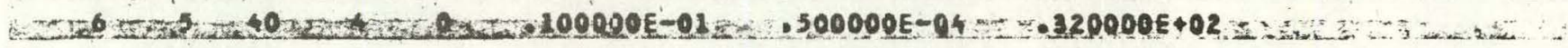

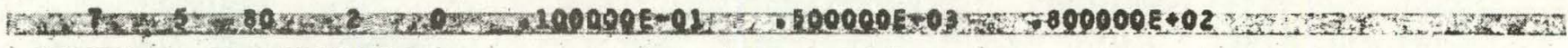

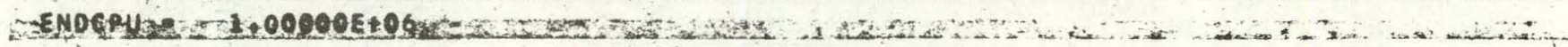

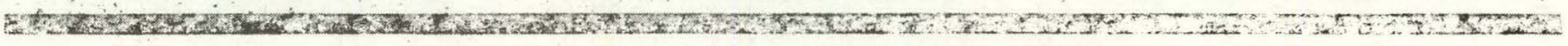




\begin{abstract}
GERERALTZEO TRIP PARAFETERS FOR 6 SIGNALS.

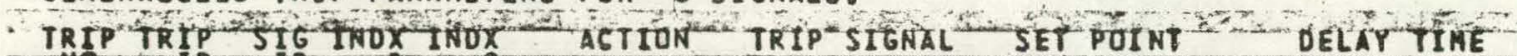
5.

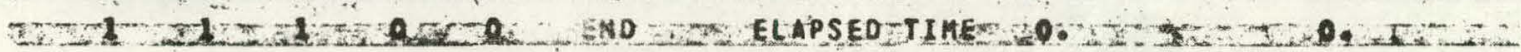

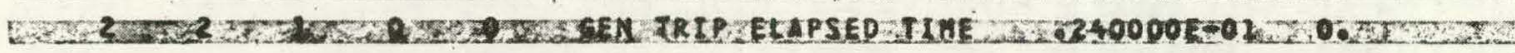

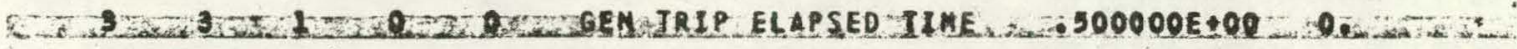

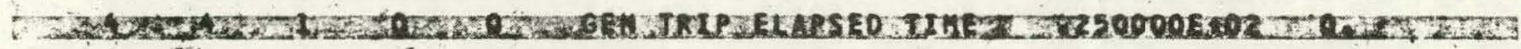

TESEt

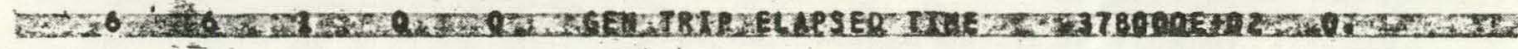


INPUT OATA FOR 34 POLUMES.-

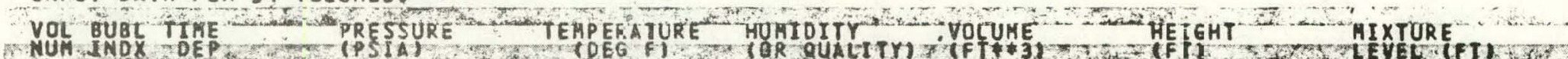
-

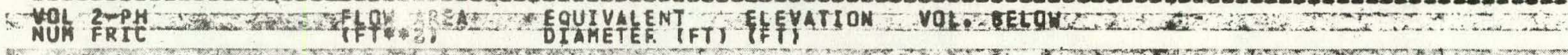

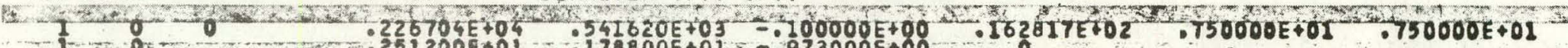

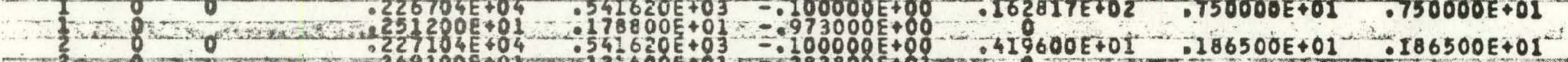

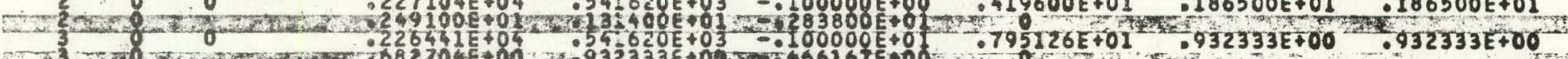

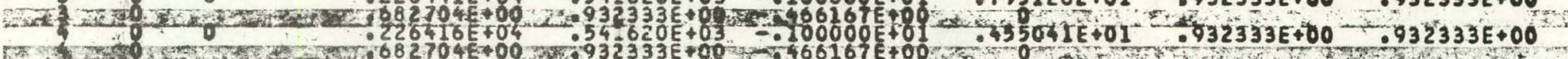

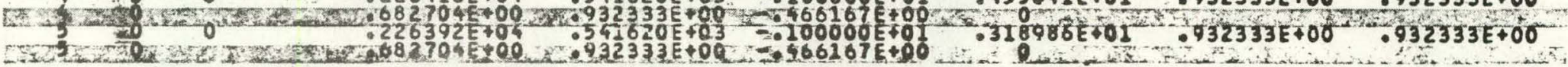

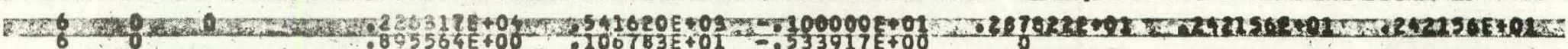

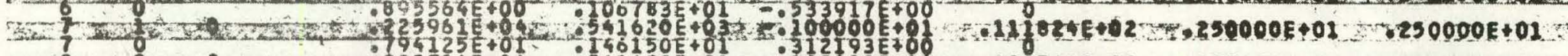

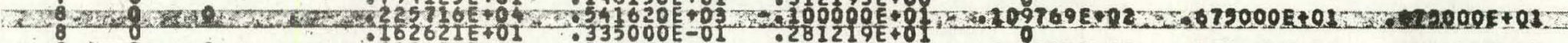

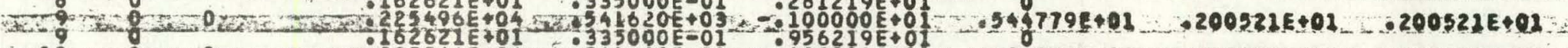

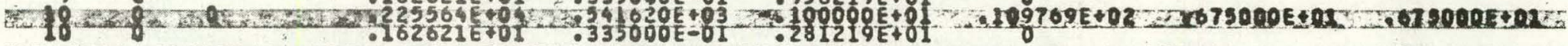

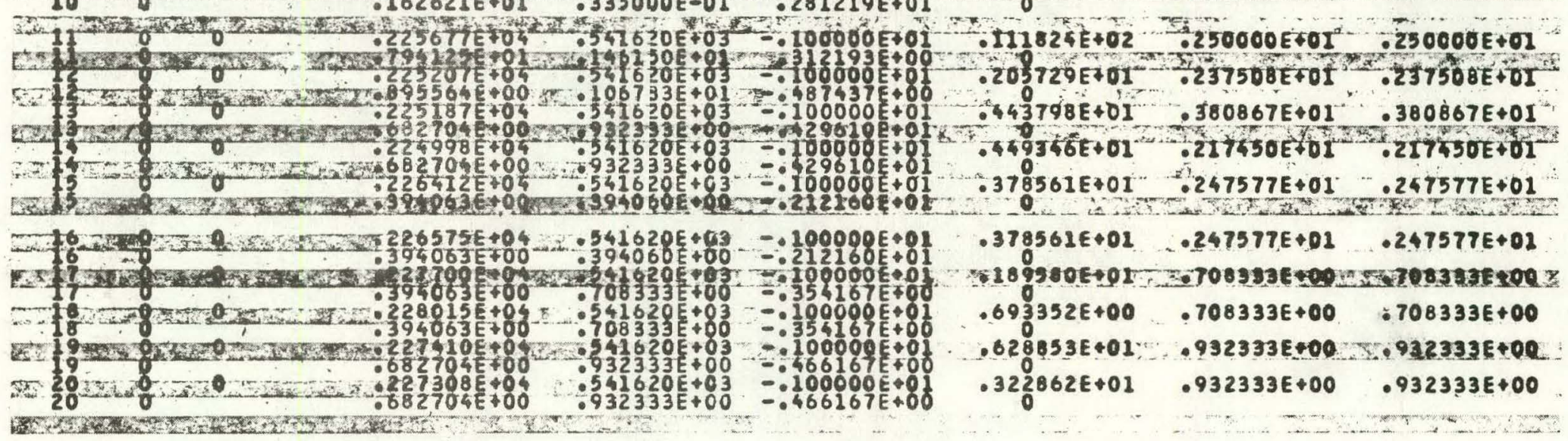




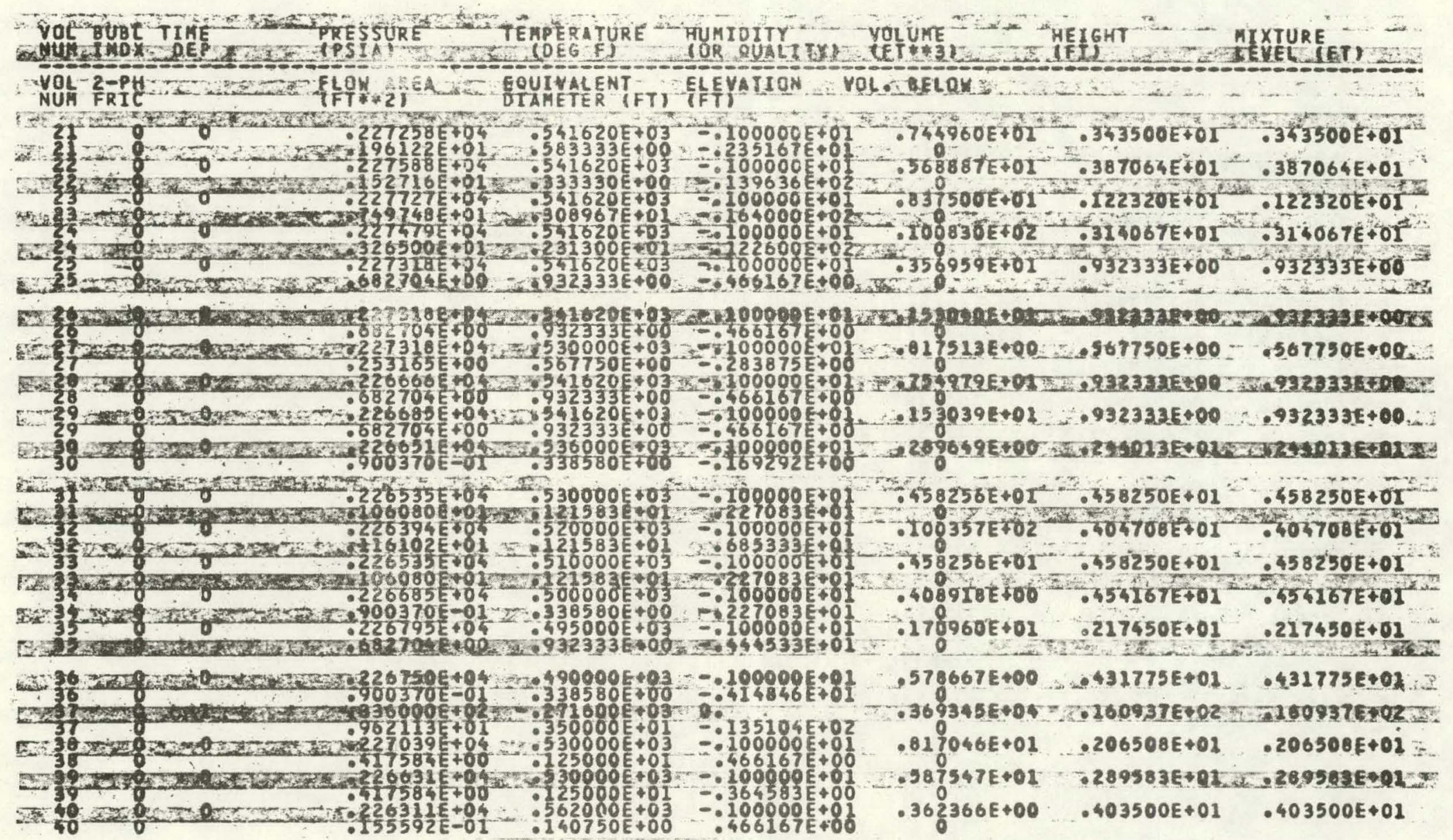




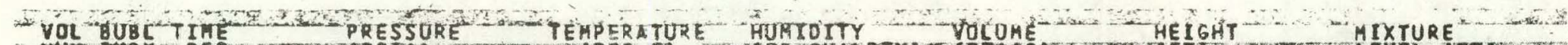

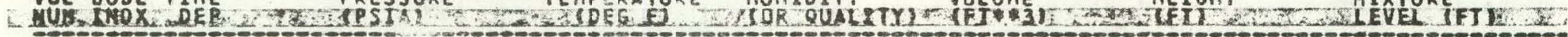

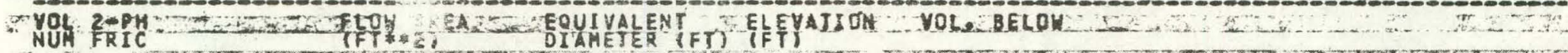

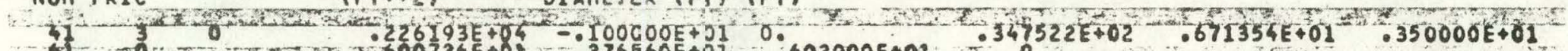

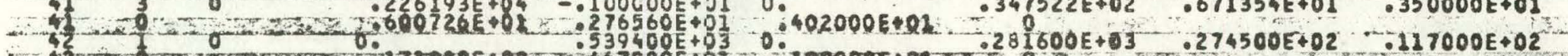

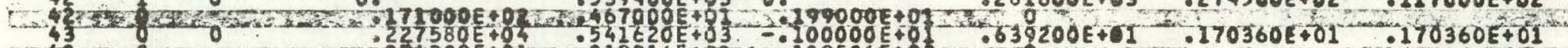

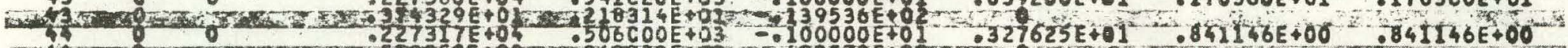

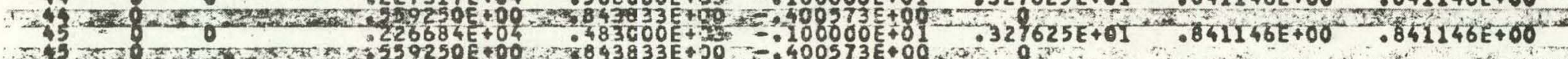

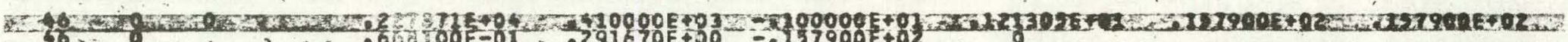

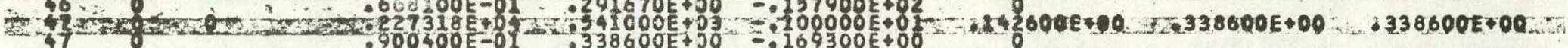

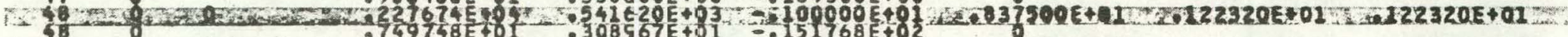

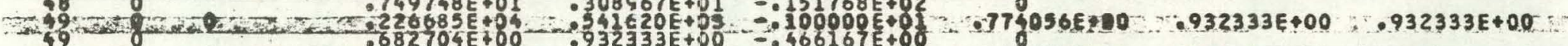

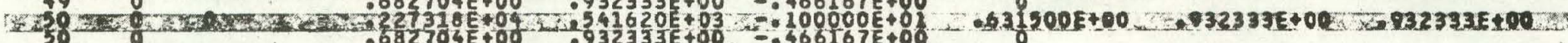

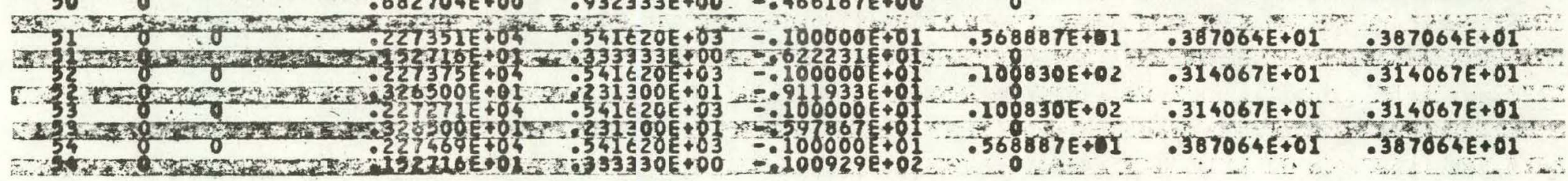




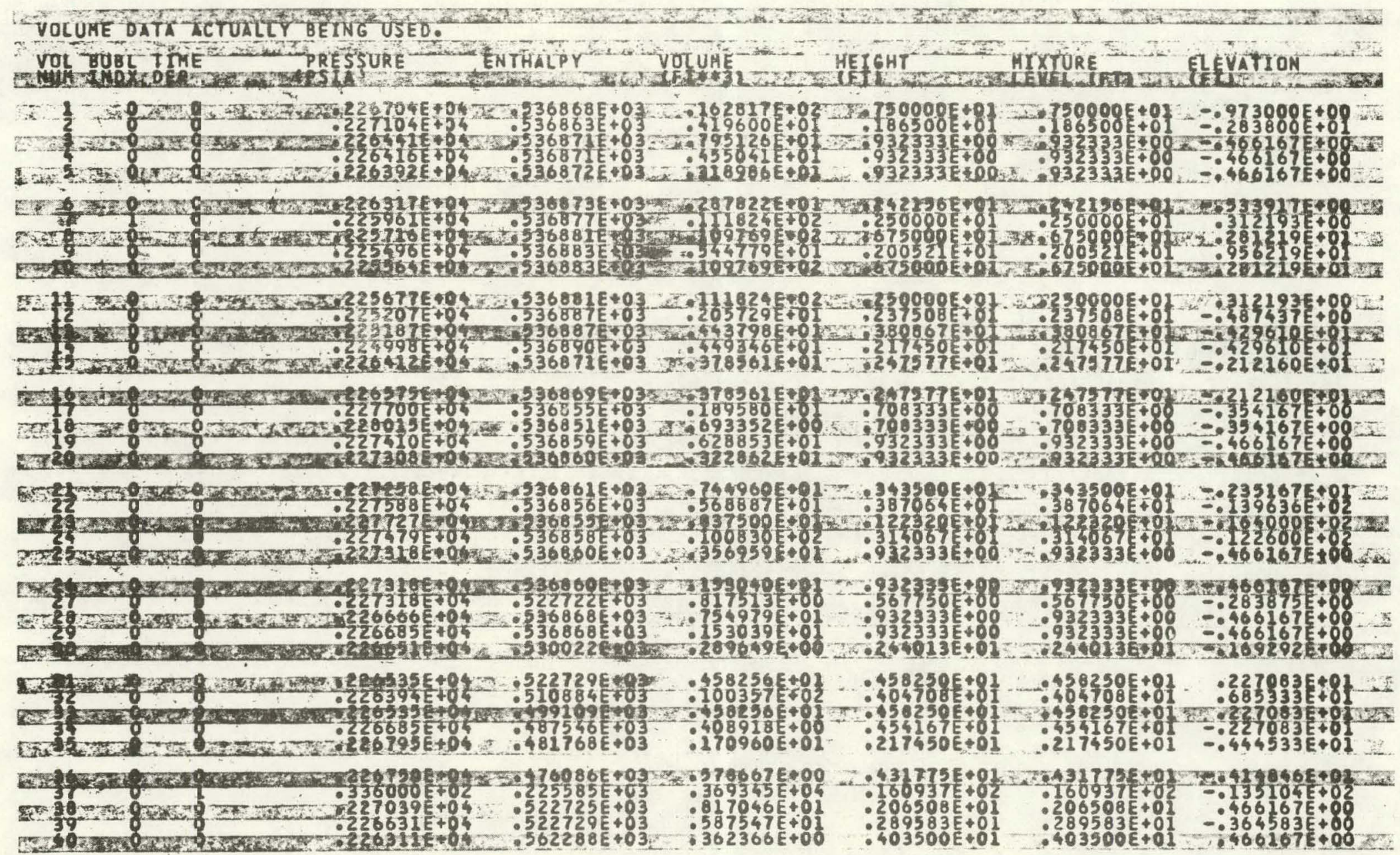




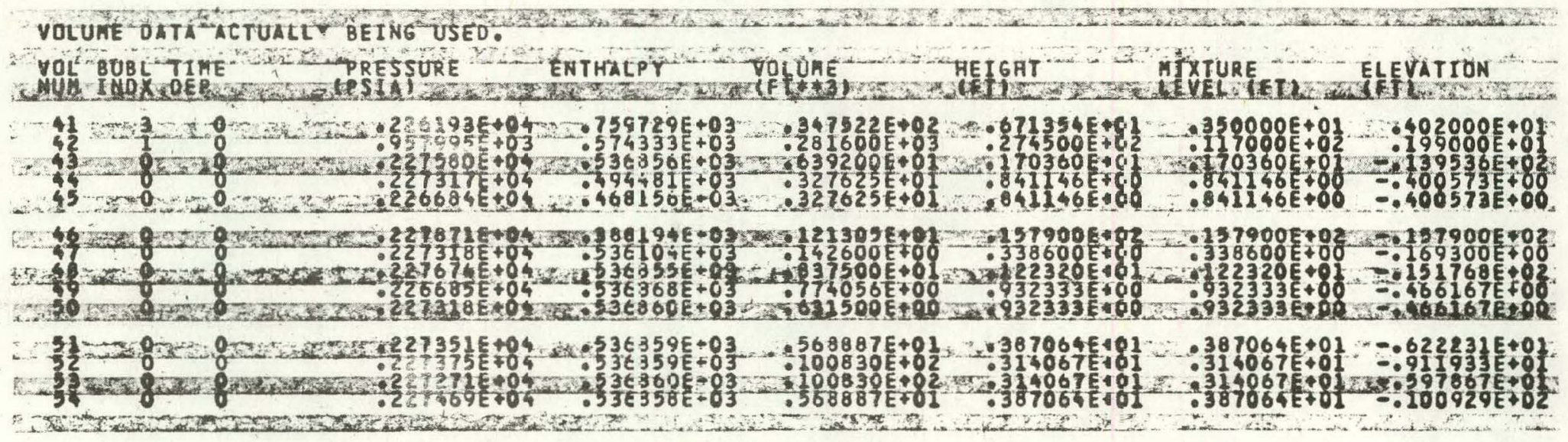


VOLUHE OATA ACTUACTY BERNG USED.

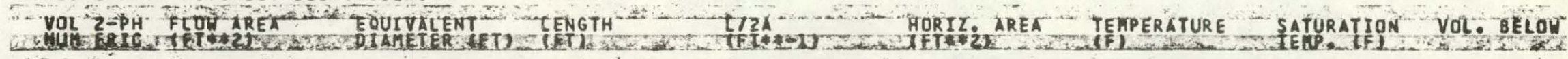

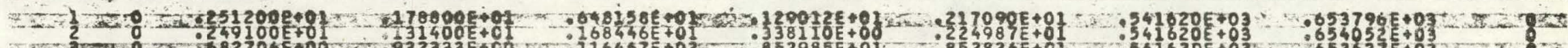

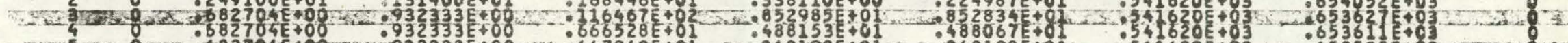

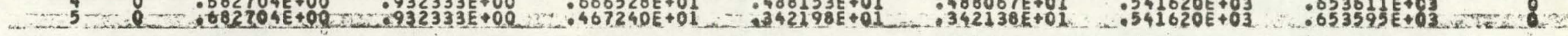
WWU - F s

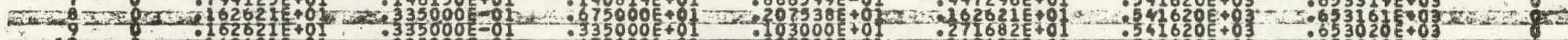

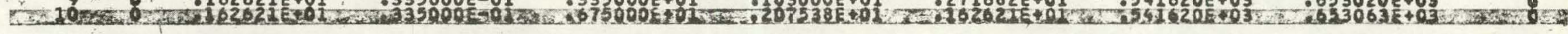

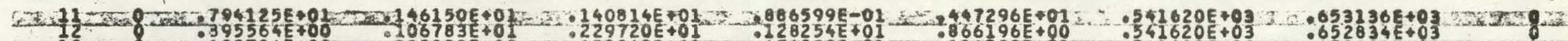

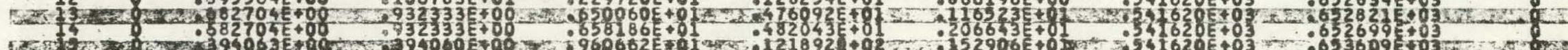

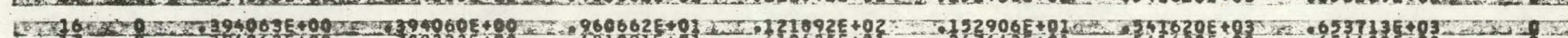

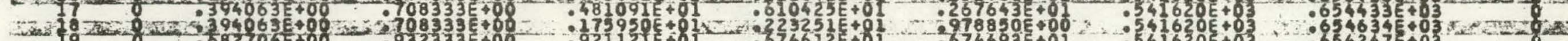

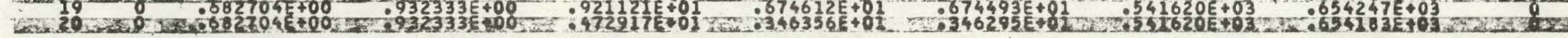

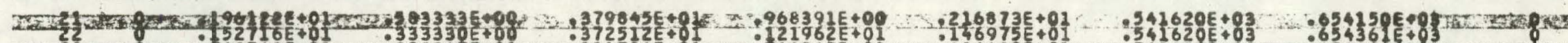

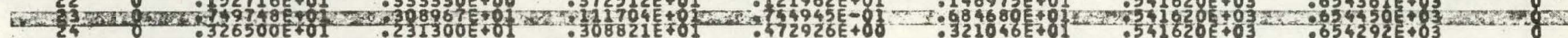

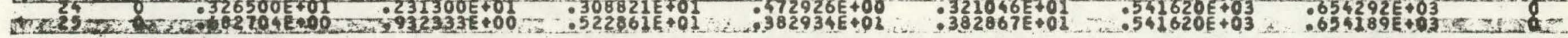

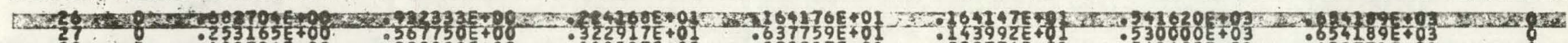

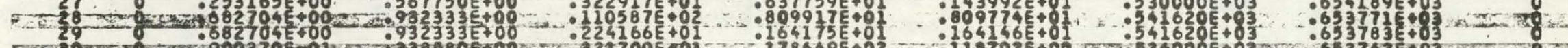
EL2030

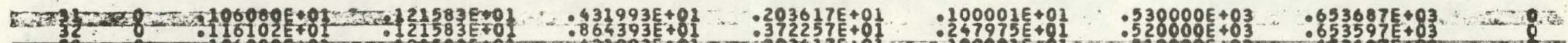

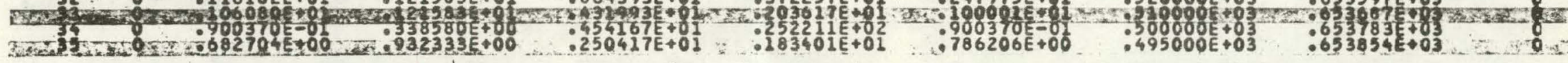

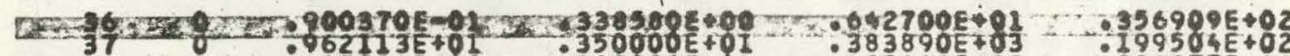
20-30

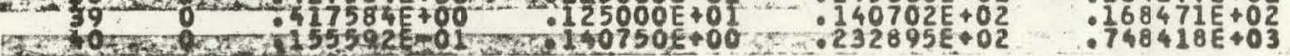

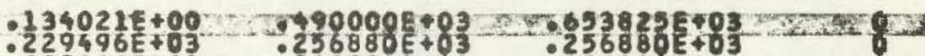

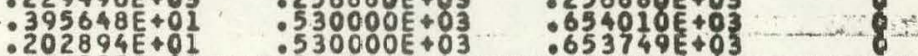

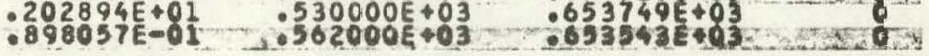




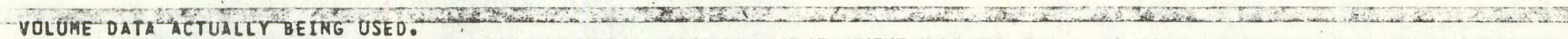

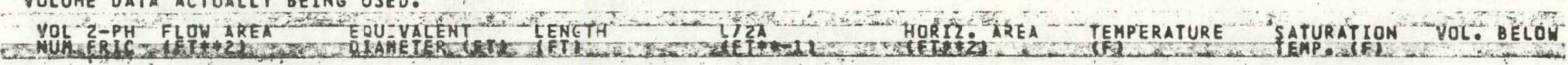

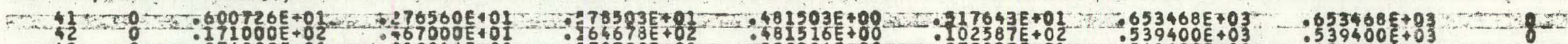

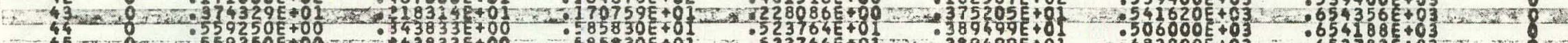

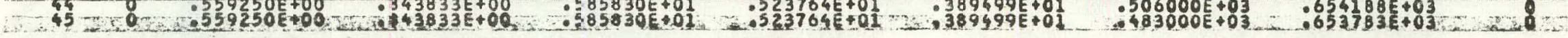

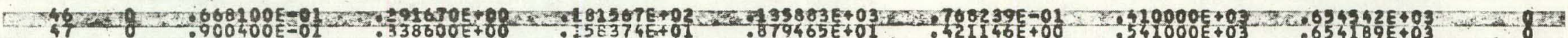

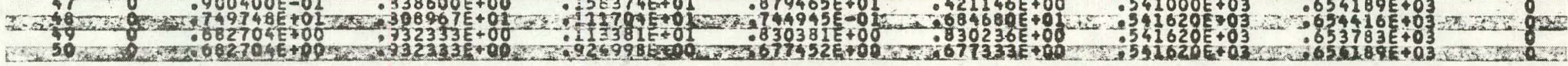

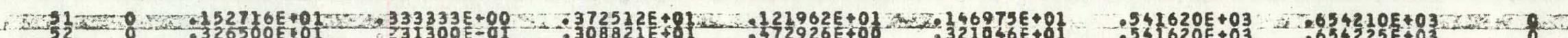

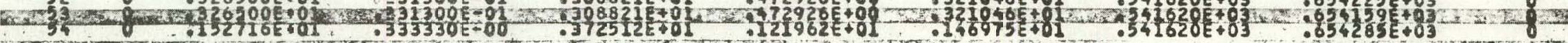

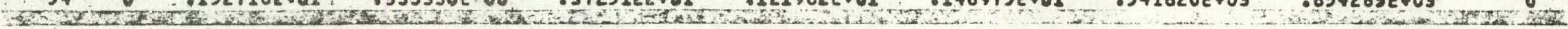




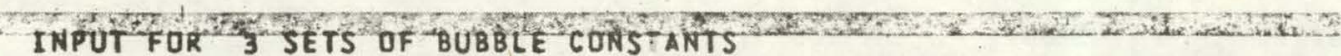
SEt a 0 Q Q7R 1 EC 4 WE

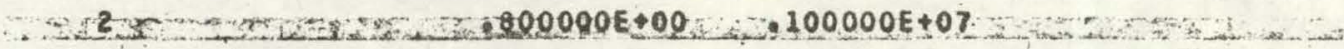

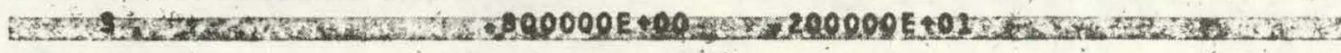


TIÄE DEPENDENT TABLES FDR I VOLUMES,

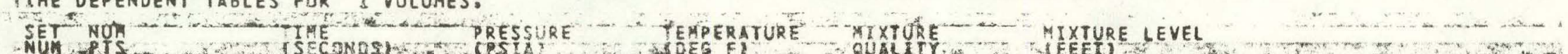

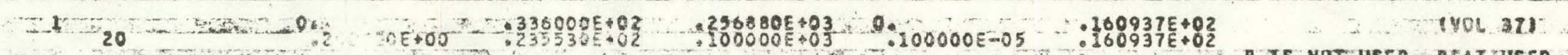

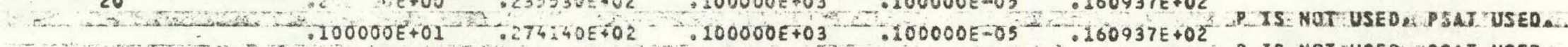

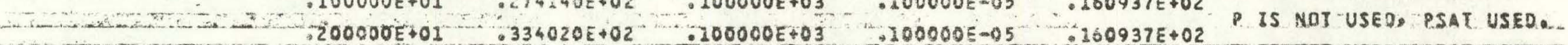

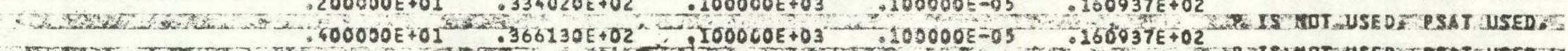
- SEA

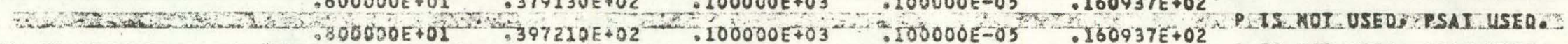

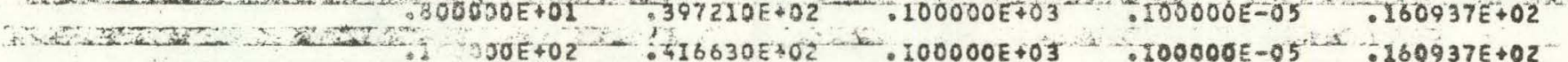

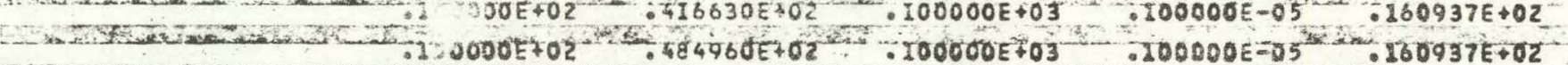

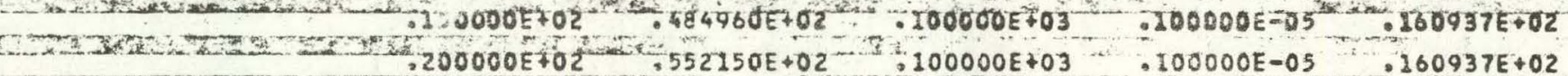

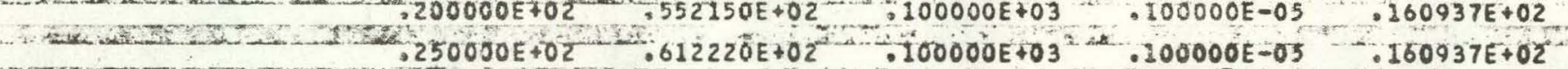

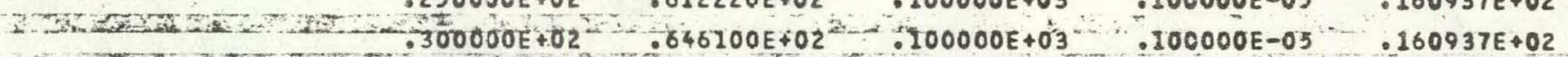

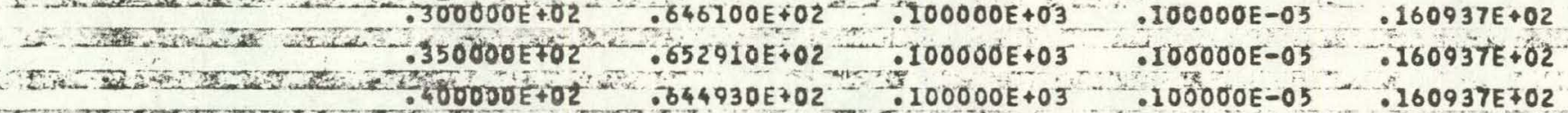

P. IS NOT USED 2 PSAT USER. PWS NaT USEDALESAT USEREZ $P$ IS NOT USED, PSAT USEDED PTS.NOT USED, PSAT USED.Z P. IS NDT USEQ PSAT USEDG

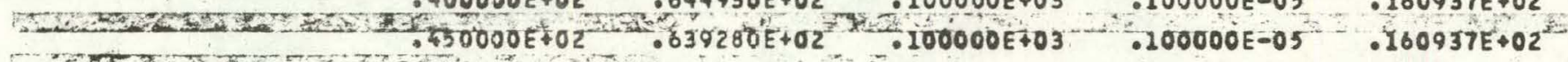

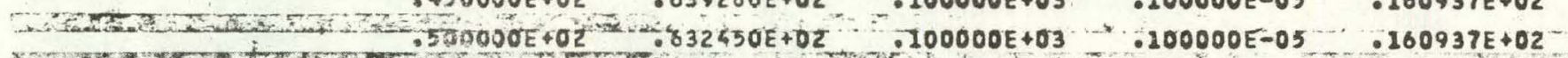

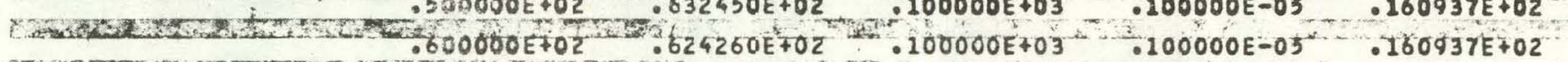

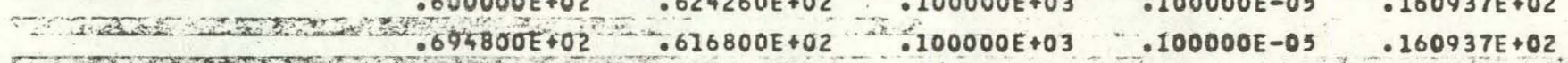
E.1.4FE EVI Tras P. IS NQT USED. PSAT USED.

P. IS NOT USED PSAT USEDE: P. IS.NOT USEDEX PSAT USED. P. IS NAT USED. PSAT USED. R IS NOT USEDR.PSAT USED P. IS NOT USEO, PSAT USED E. $P$ IS NOT USED PSAT USEO

$P$ IS NOT USED, PSAT USEO. P IS NOT USEOE ESAT:USEDa! 
DESCRTPTIONS OF 58 JUNCTIONS.

JUN FROA TO PUTP CHKY TNITIAC- JUNCTION JUNCTION - JONCTION SP ENERGY SP ENERGY

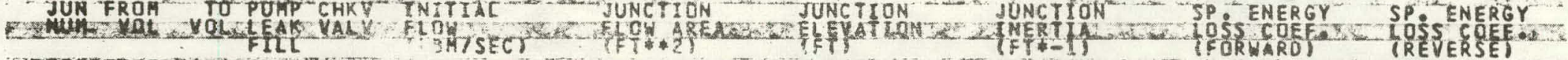
VERT CHOK IC MOM ICTION CONTRACTION SUBCOOL ENTHALPY

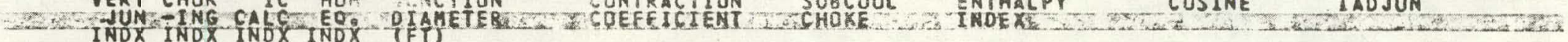

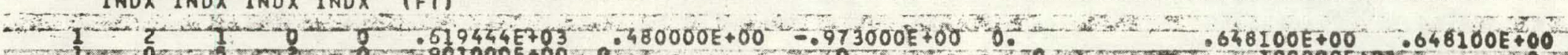
$\begin{array}{ll}1 & 2 \\ 2 & 1 \\ 2 & 0\end{array}$

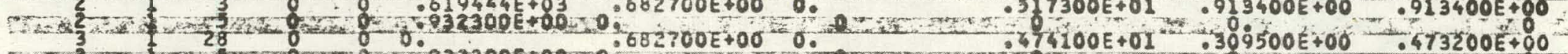

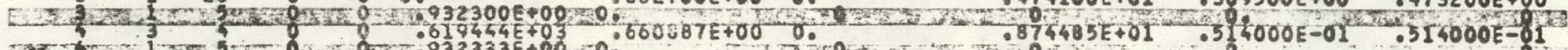

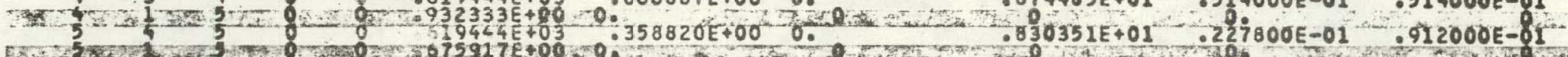

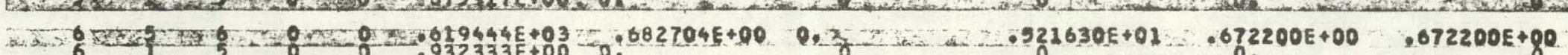

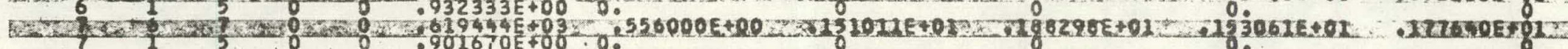
ब-

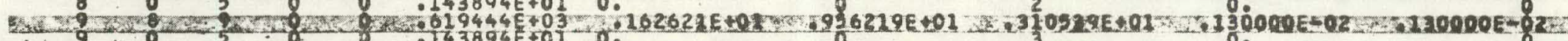

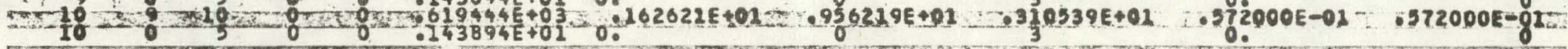

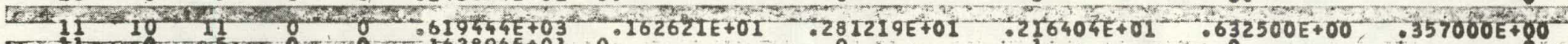

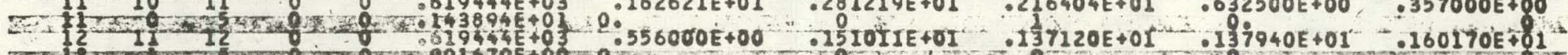

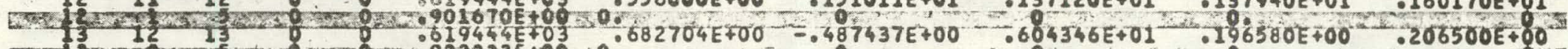

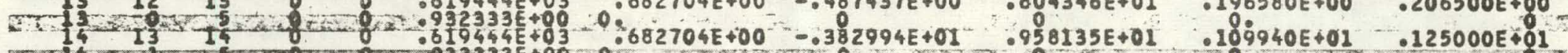

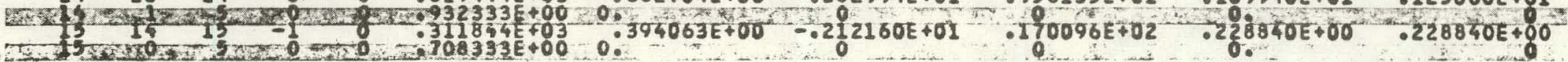




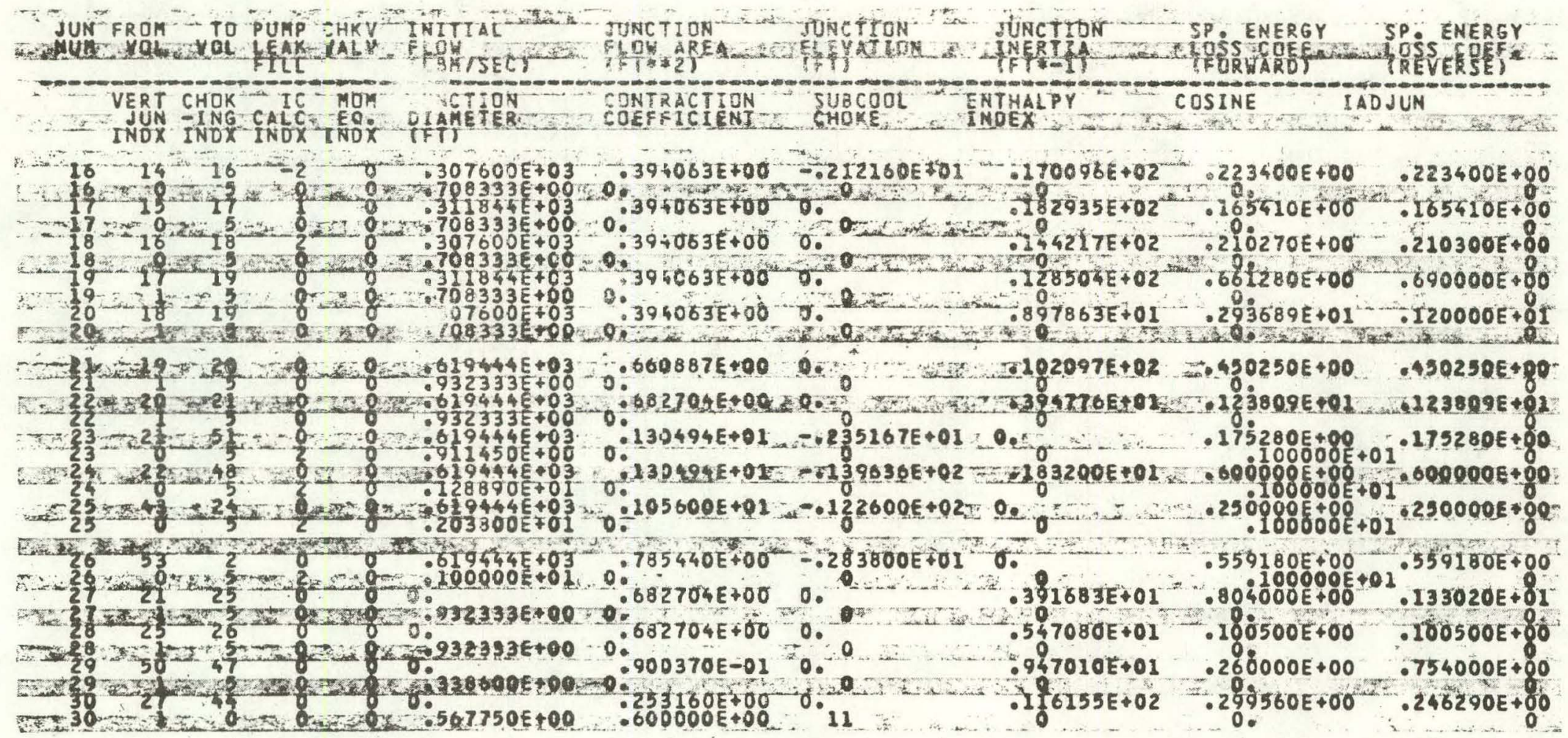




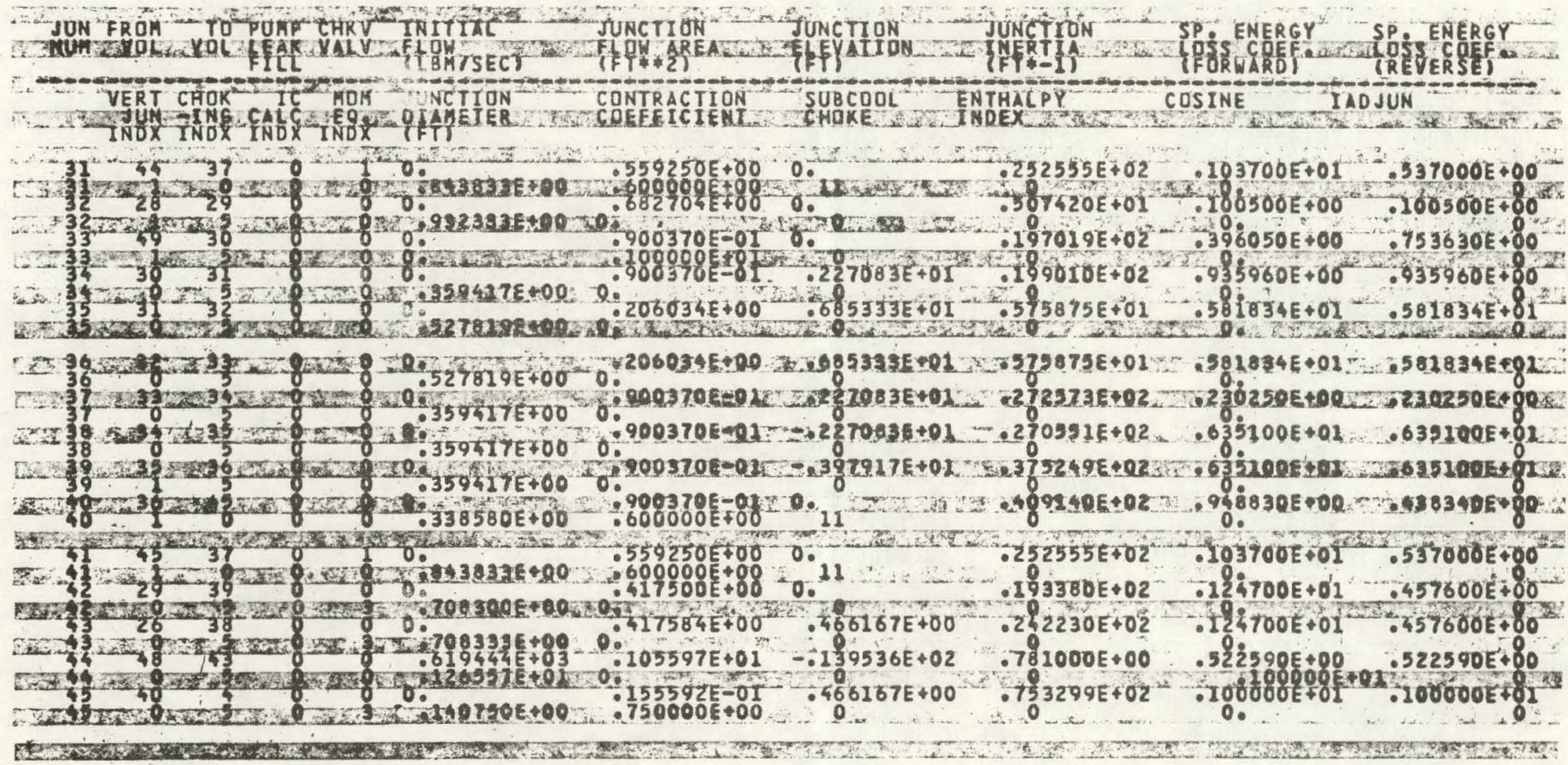




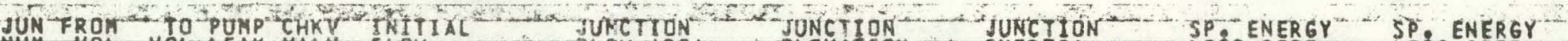

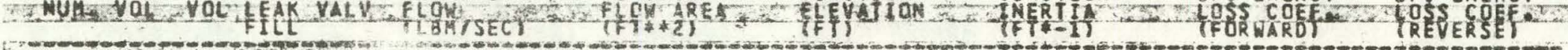

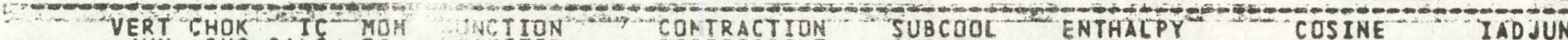

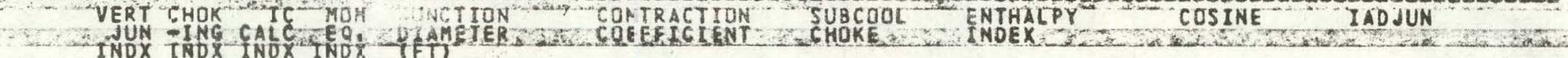

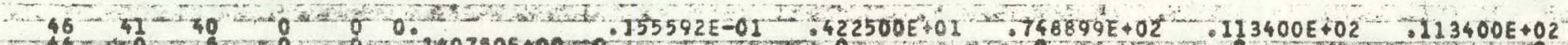

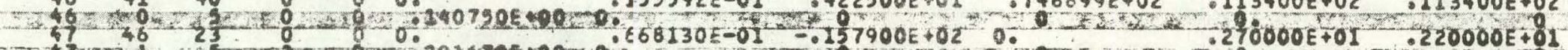

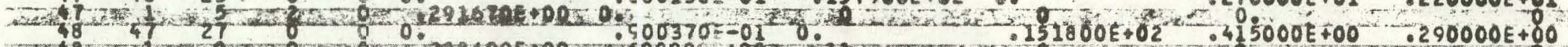

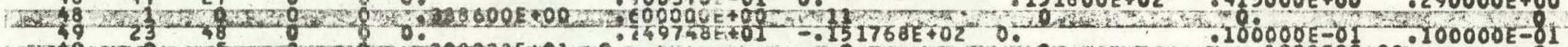

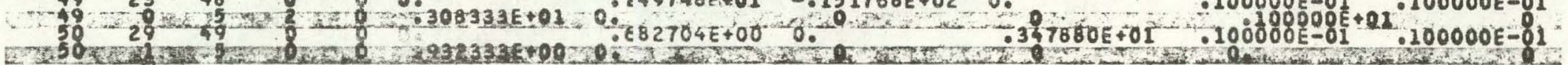

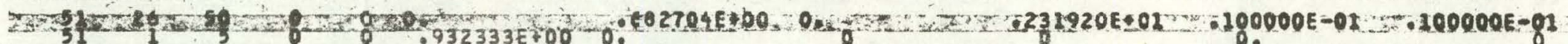

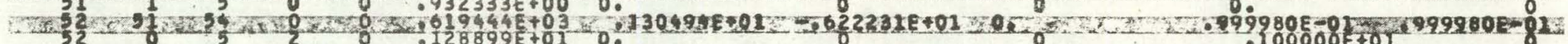

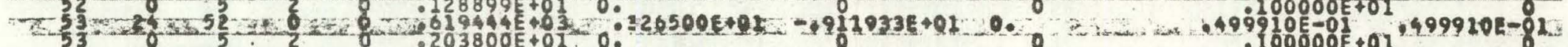

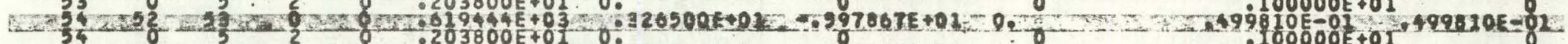

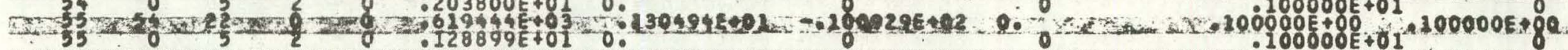

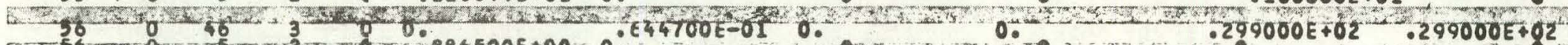

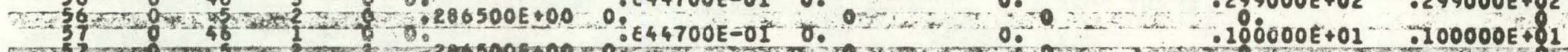

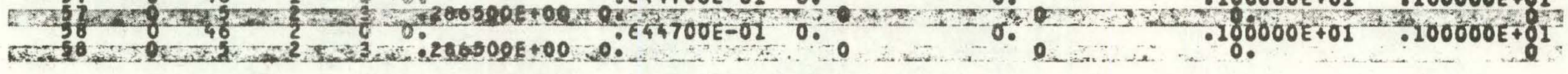


INPUT DATA FOR 2 PUMPS. NUMBER OF PUMP CURVES TO BE REAO FOR EACH CURVE SET

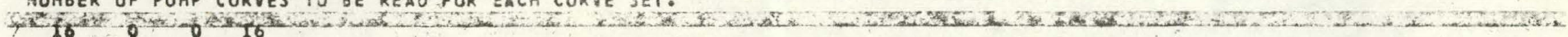

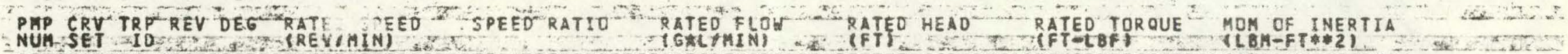

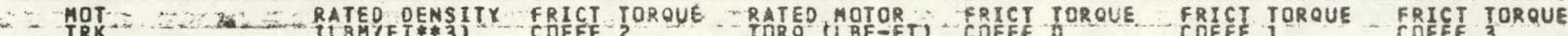

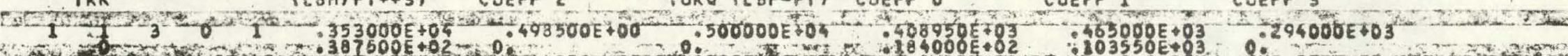

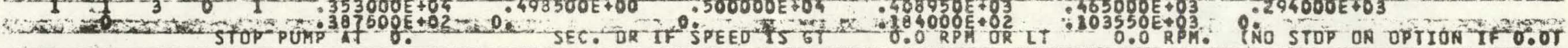

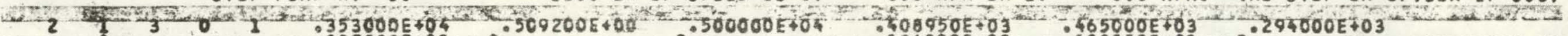

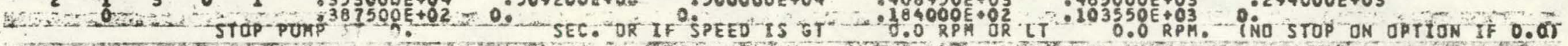

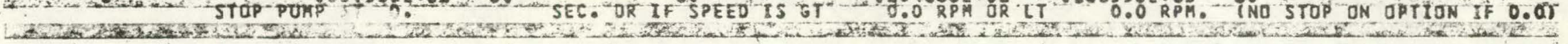


- PUTP HEXO HULTIPTIER CURVE

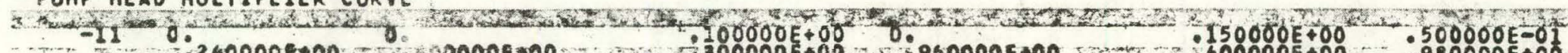

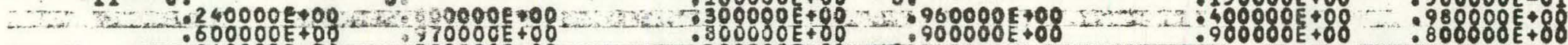
G.

2. RUAP IORQUE MULIIPLIAR CURVE

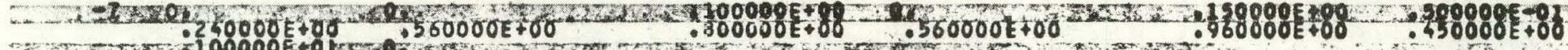
F 
PUAP CURVE SET TUMBER I HAS 16 CURVES TO BE REAO.

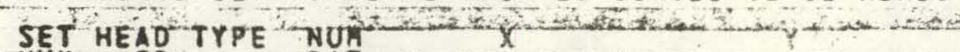

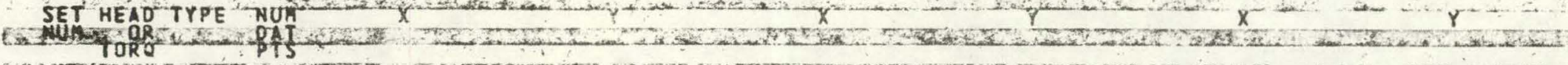

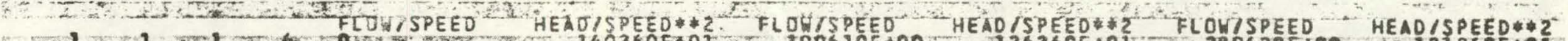

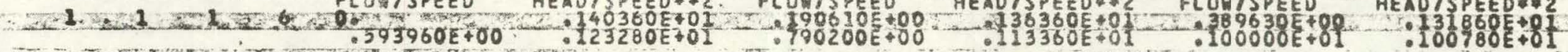

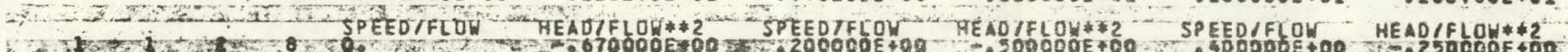

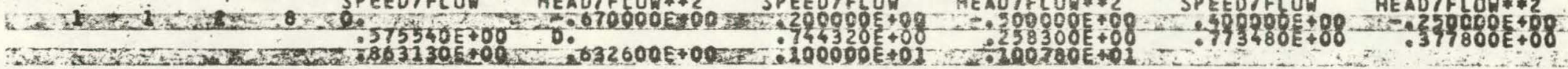
LXED SWXY

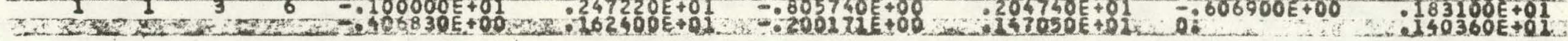
ELI I 1 W LDSDE -

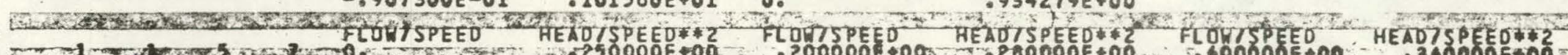

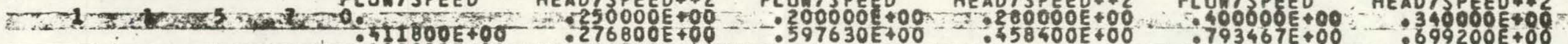

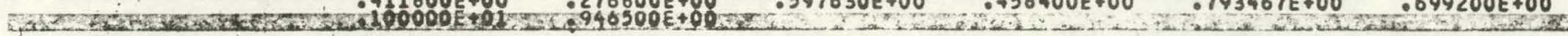
ZED ESTER

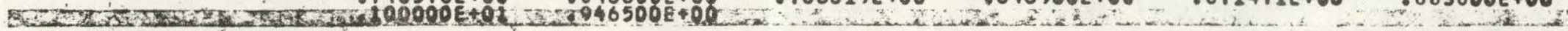

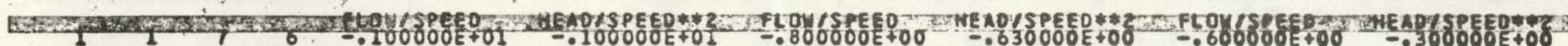

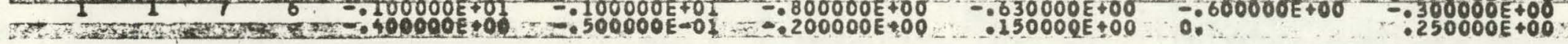
LEFEY 1 P आEल

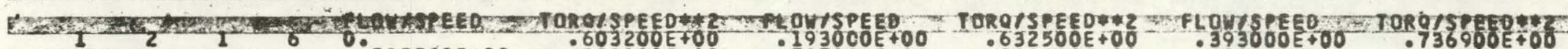

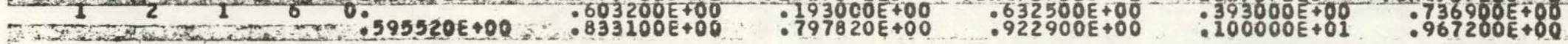

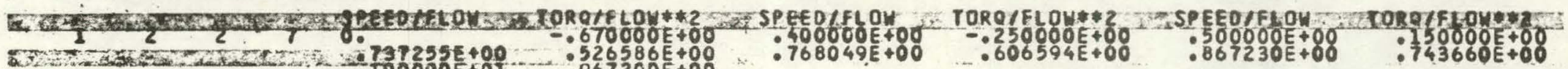
S.

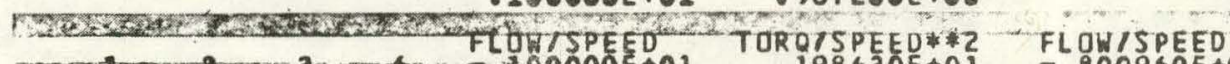

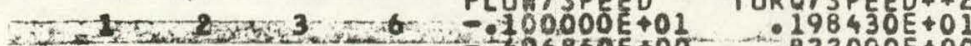
P.

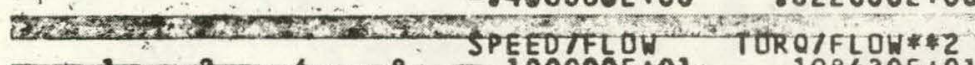

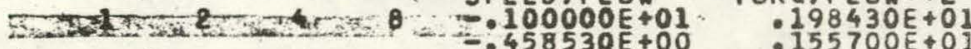
a

-.800960E TOO TOROTSPEEDF*2 $-: 199280 E+00 \quad: 664800 \mathrm{O}+00$ SPEED/FLOW $=: 822340 \mathrm{E}+00$ TORO/FLOW**2 $183080 E+01$
$: 1436200 \mathrm{E}+01$ $.123361 \mathrm{E}+01$ FLOWISPEED TOROTSPEED+FL $\overline{0}_{0}: 606388 E+00 \quad: 1863200 \mathrm{E}+010$ SPEED/FLOH TOROTFLOW\# कL $=: 633710 \mathrm{E}+00 \quad: 168240 \mathrm{E}+01$ 


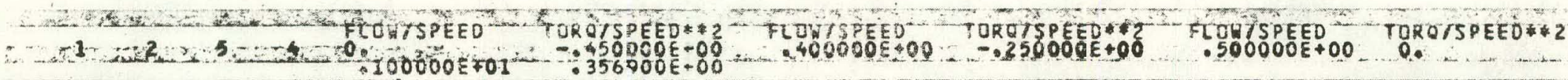

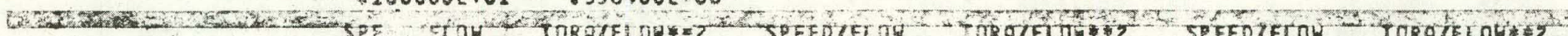

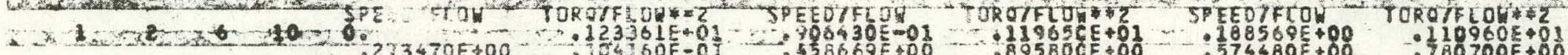

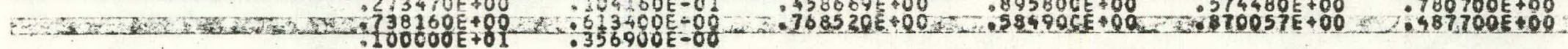

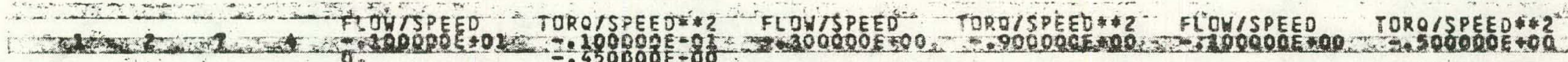

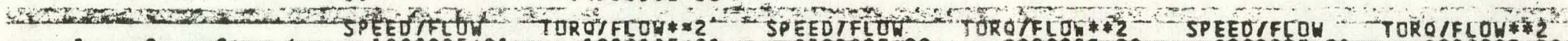

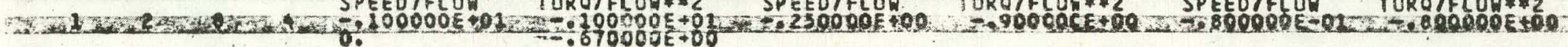
1. 


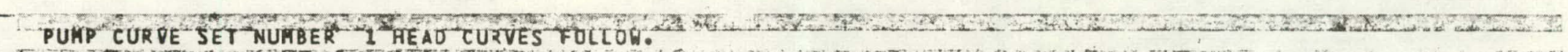

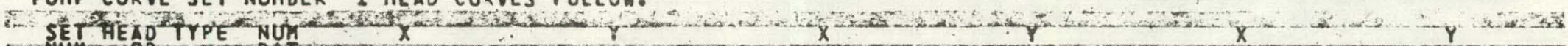

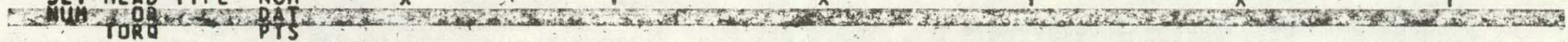

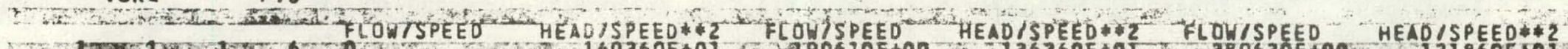

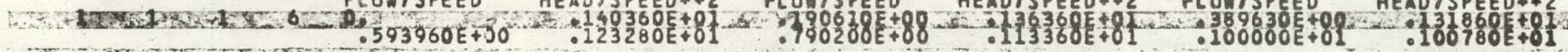

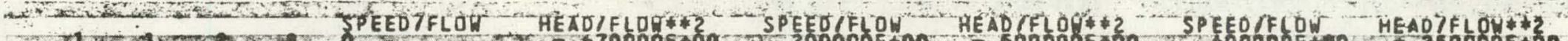
Z1. Z1. - $\therefore$.

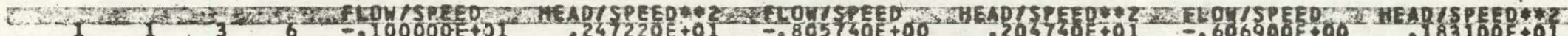

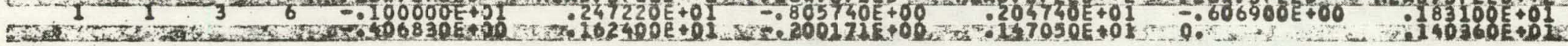

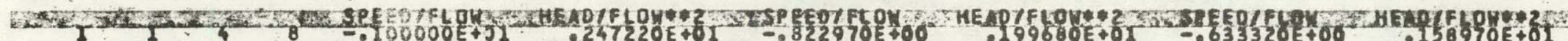

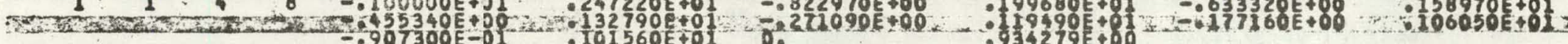

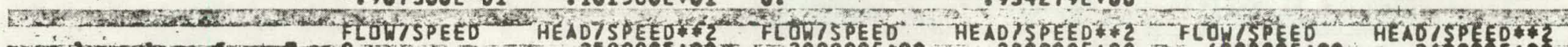

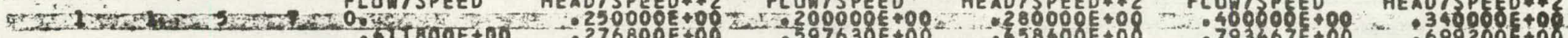

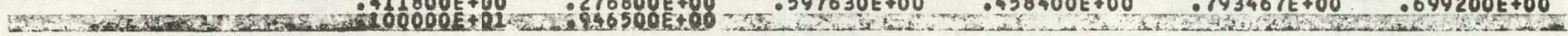
TCESTH I

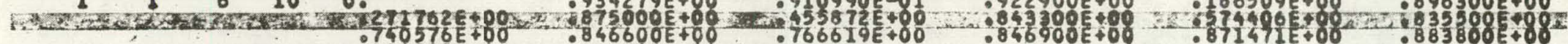

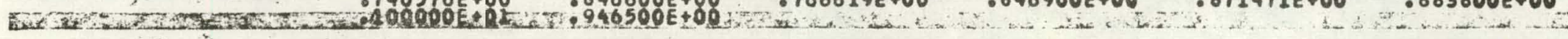

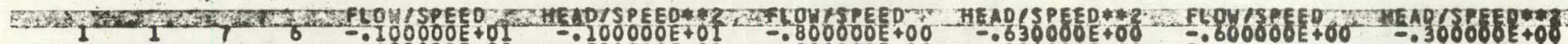

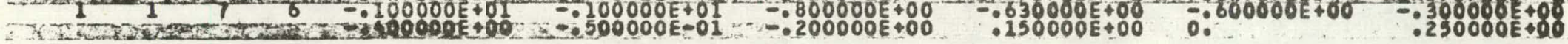

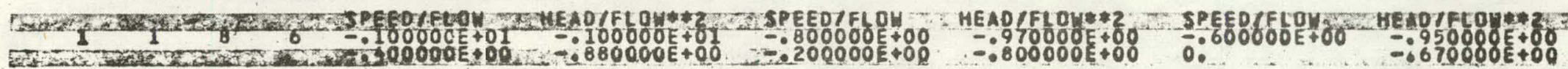


PUAP CURVE SET NUHBER I TORGUE CURVES FOLLOW. SET HEA TYP

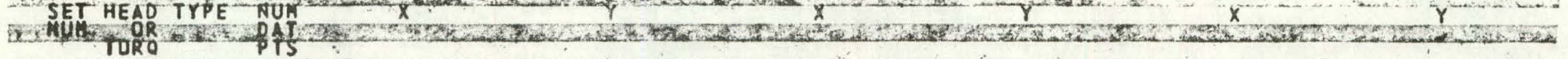

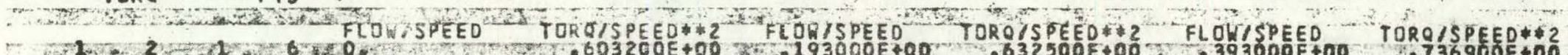

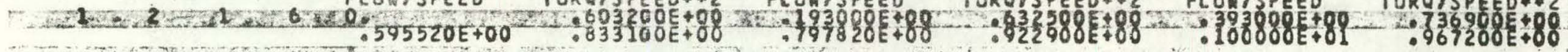

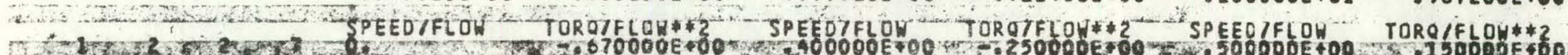

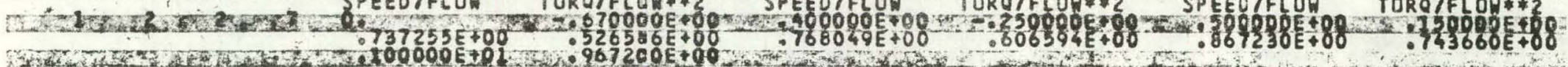

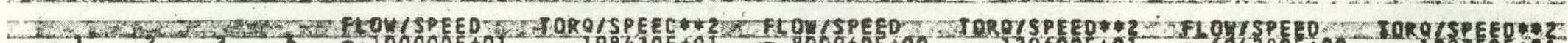
ENS

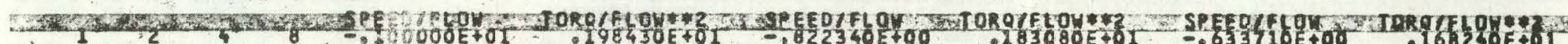

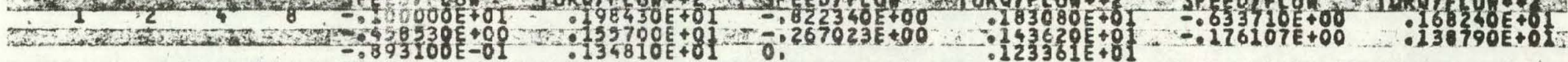
FH2.

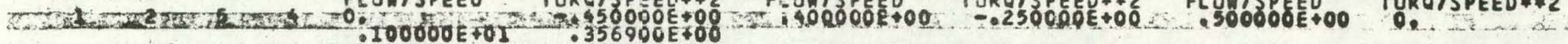

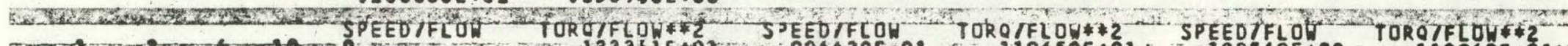

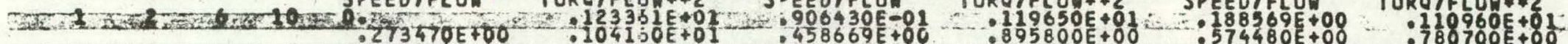

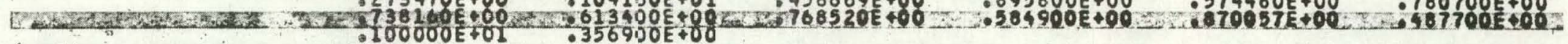

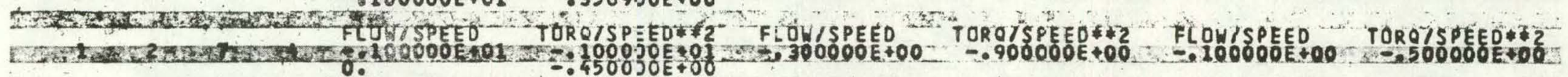

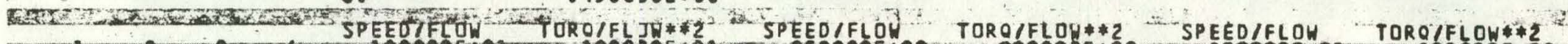

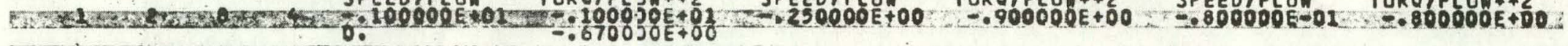

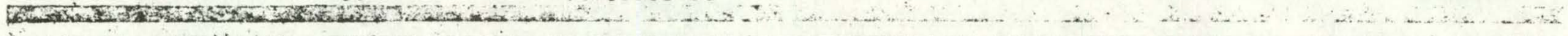

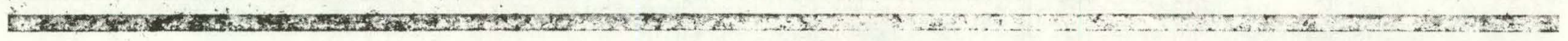




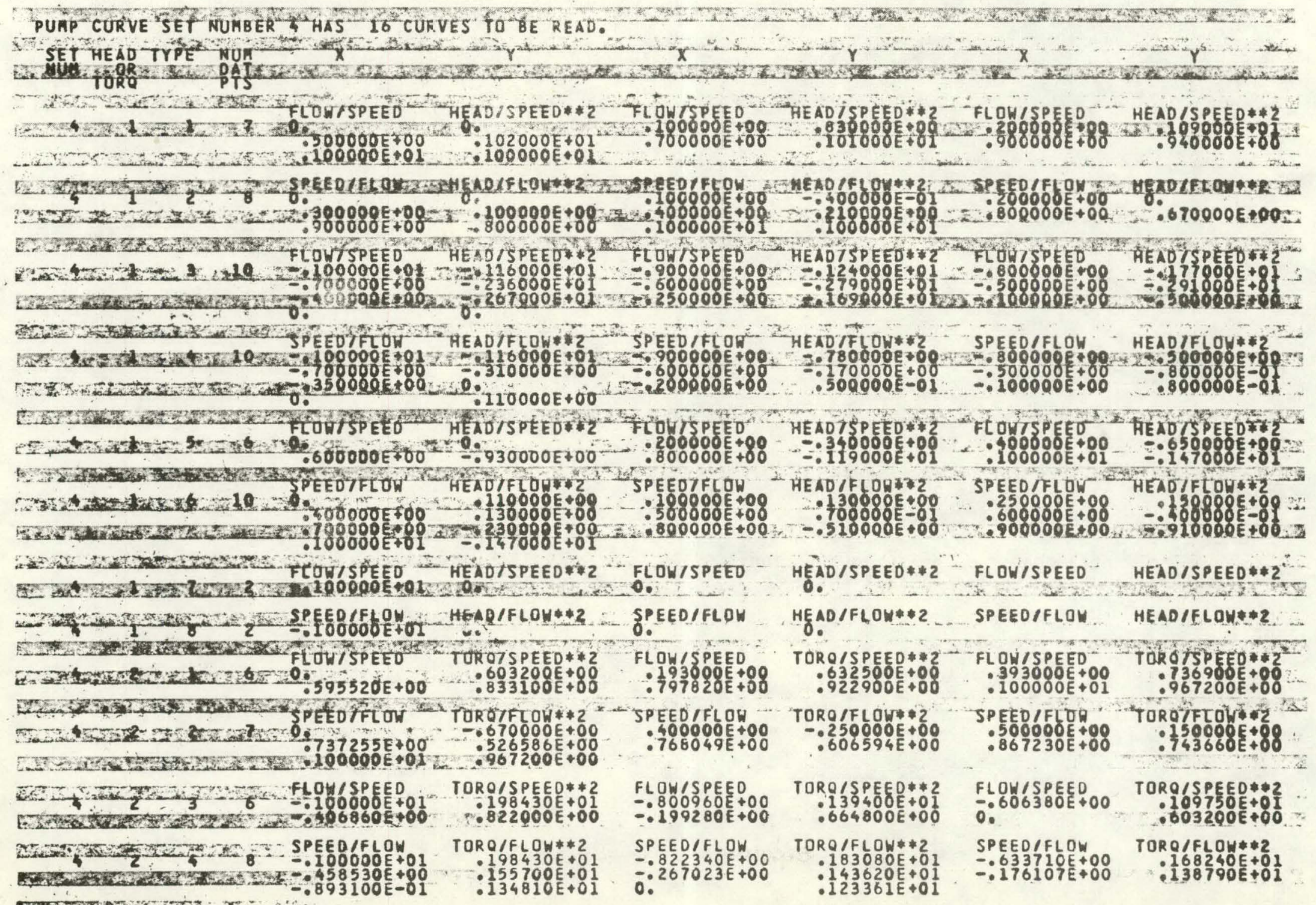




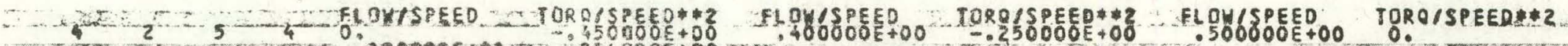

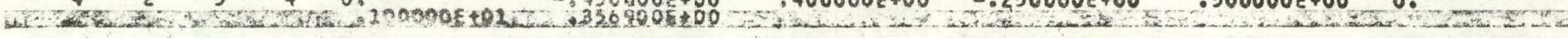

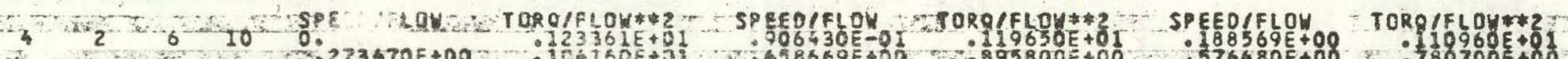

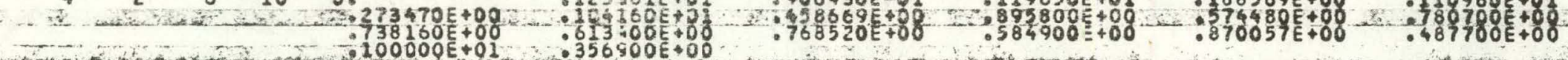
W TWE JEXE Y

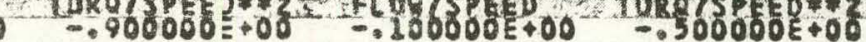

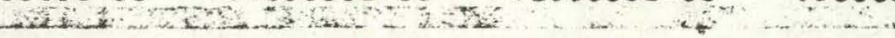

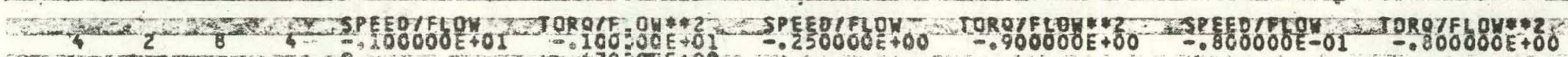

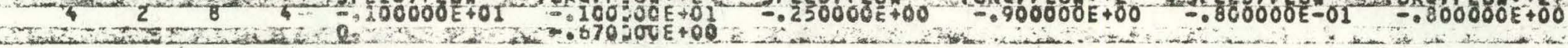




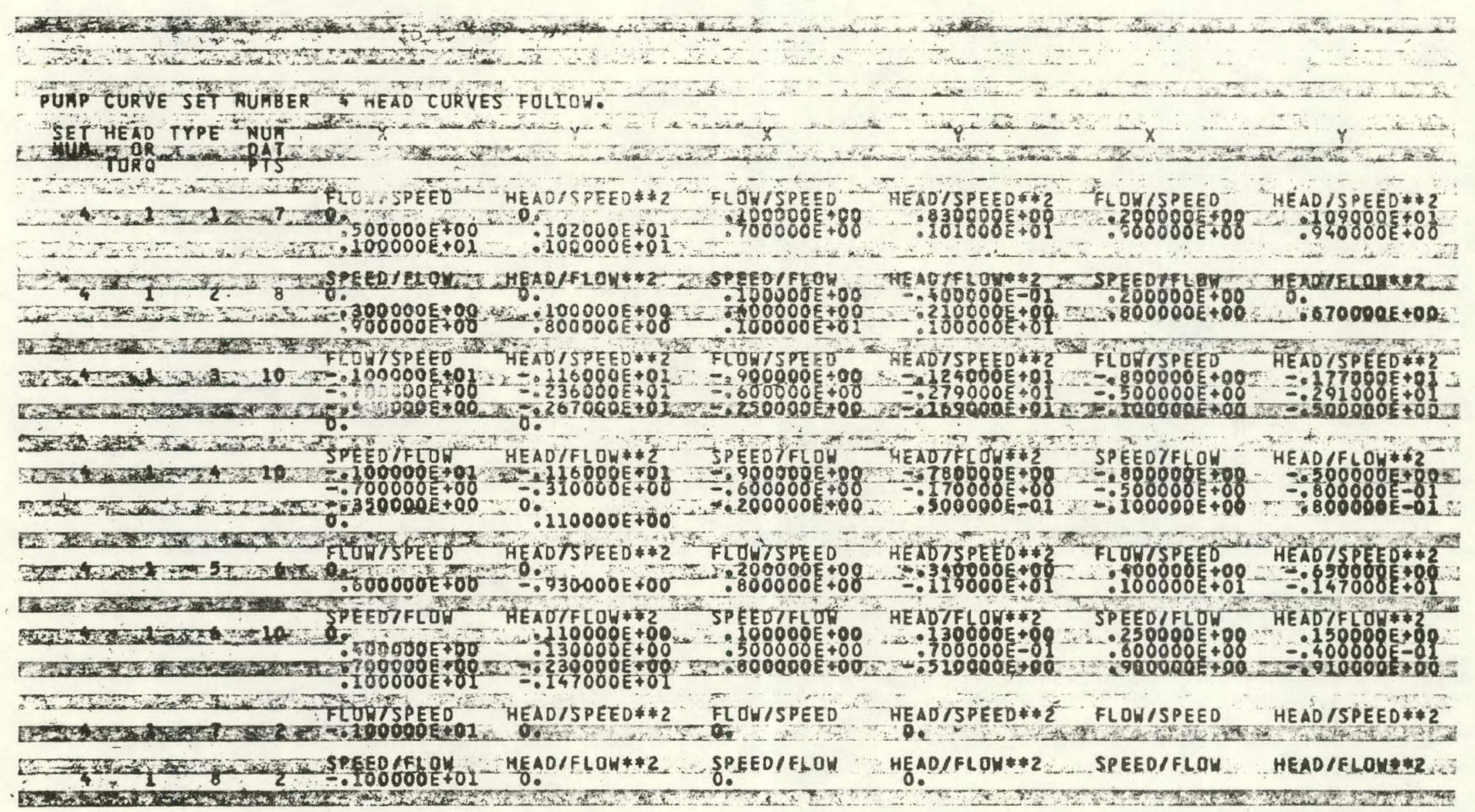


- PUMP CURVE SET NUABER 4 TURQUE CURVES FULLOW.

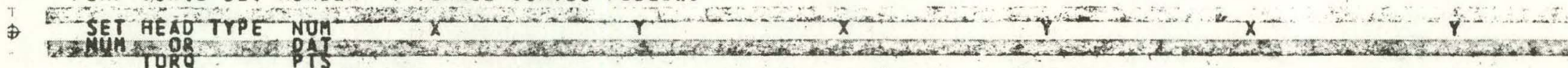

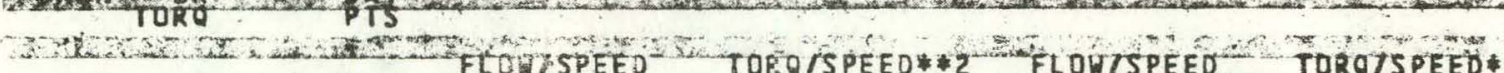

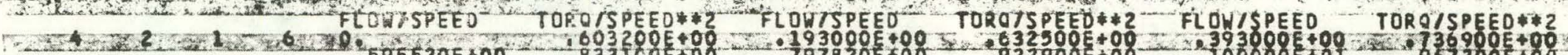

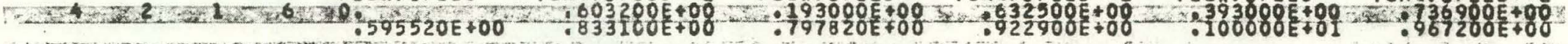

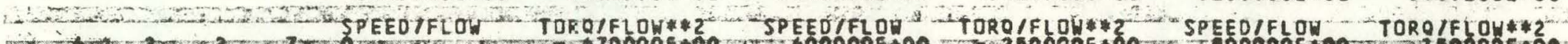

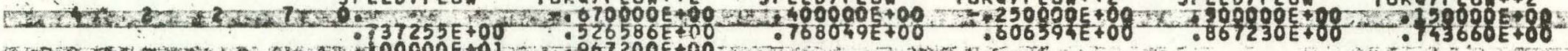

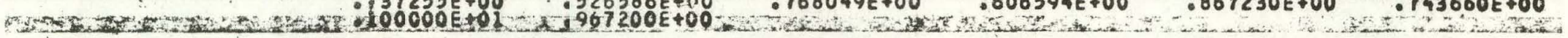

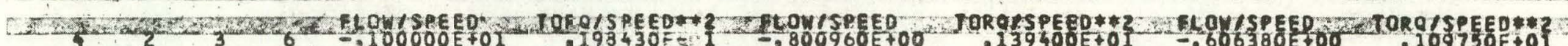
ar ENAE

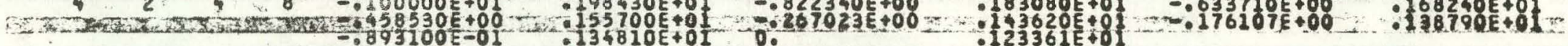

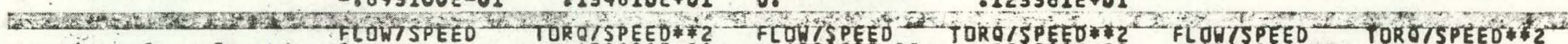

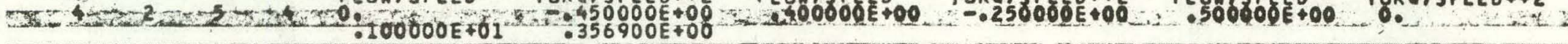

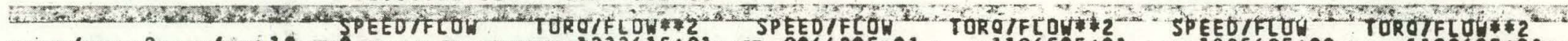

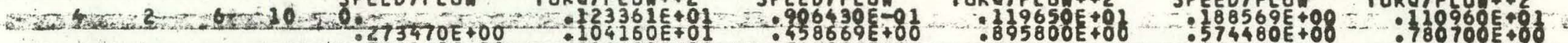

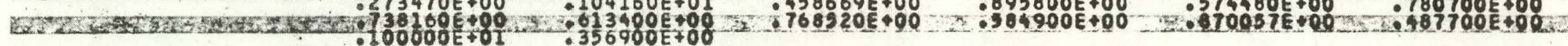

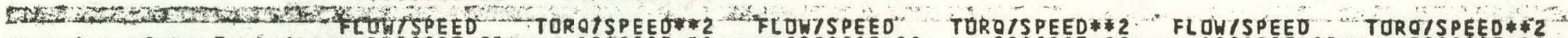

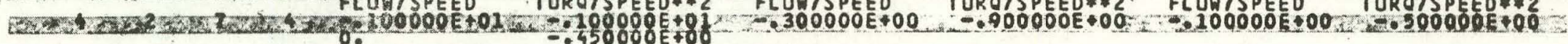

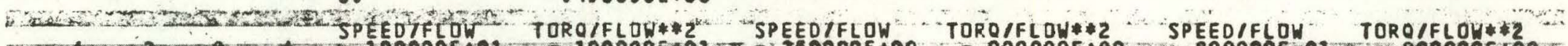

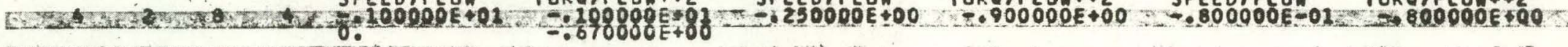
Fr. 


\footnotetext{
PARAKETERS FOR I CHECKVACVES. VALV TRIP AREA LATCH BACR PRESSURE FORWARO DPEN REVERSE CLOSES REVERSE

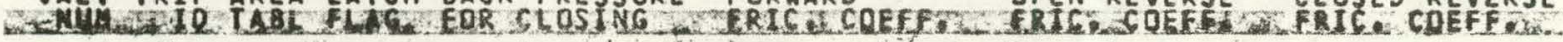

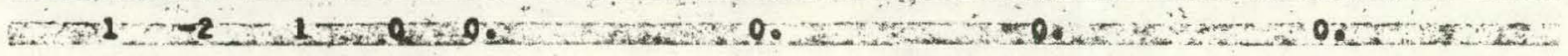


PARAMETERS FOR TLEAKS.

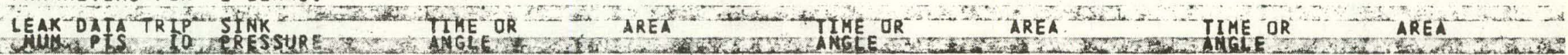

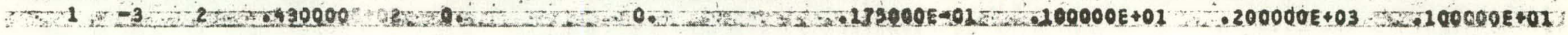


DATA FOR 3 FILL SYSTEMS WEL A

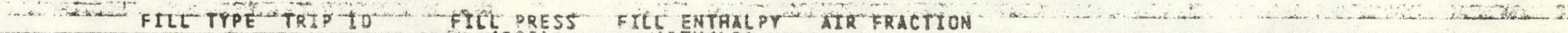

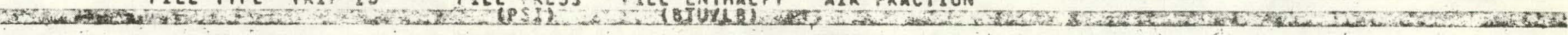

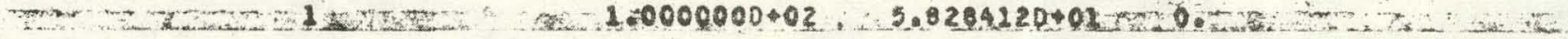

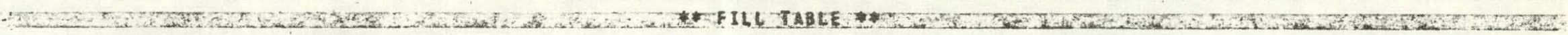

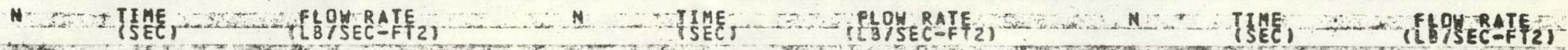

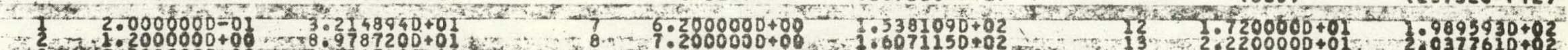

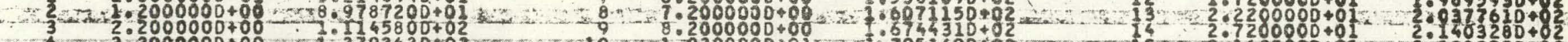

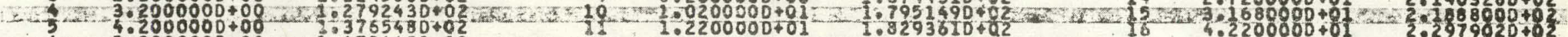

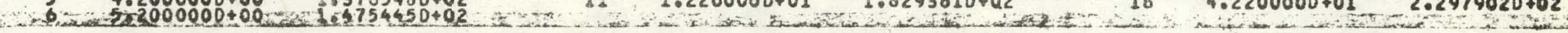

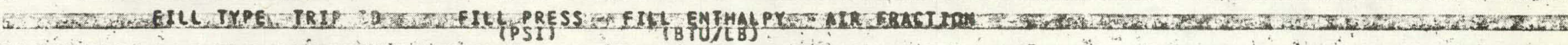

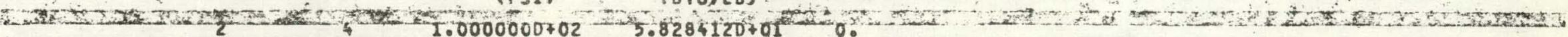

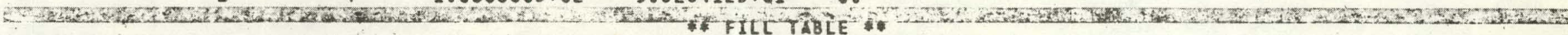

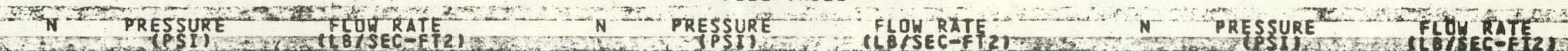

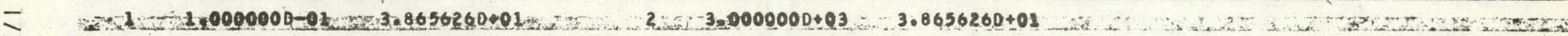

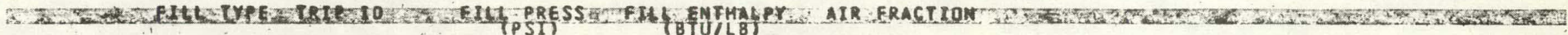

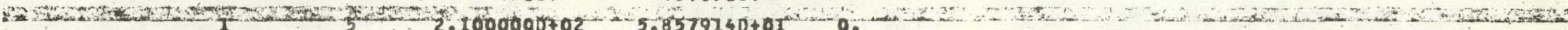

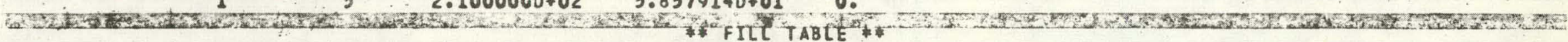

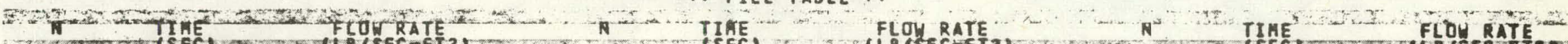

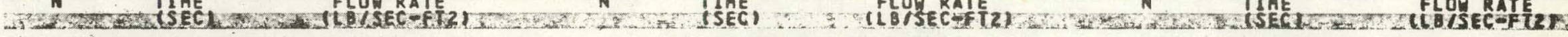

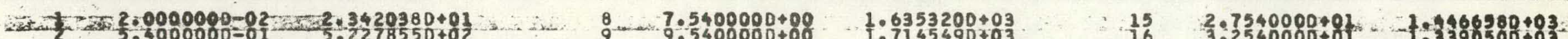

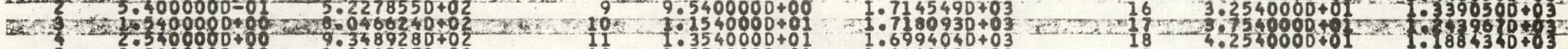

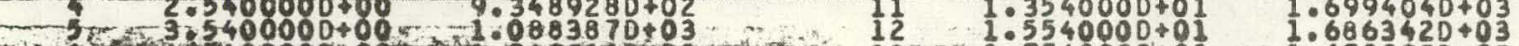

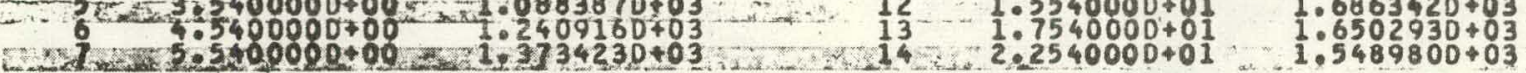

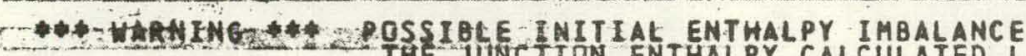

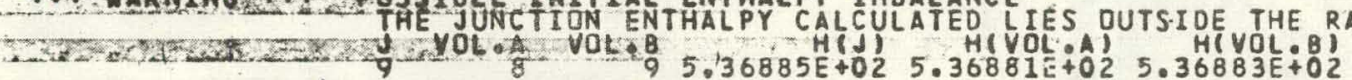

WARAING OF* POSSIELE TNITIAL ENTHALPY IMBALANCE

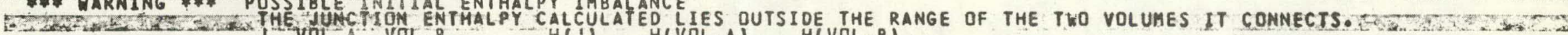

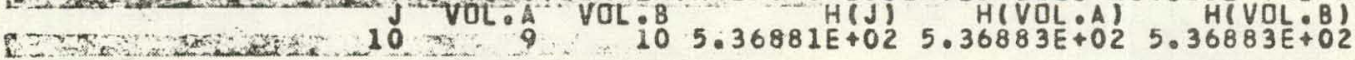

A + HARHLHG * POSSIBLE INITIAL ENTHALPY IMBALAMCE

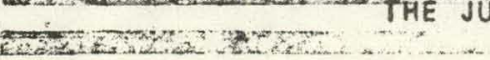




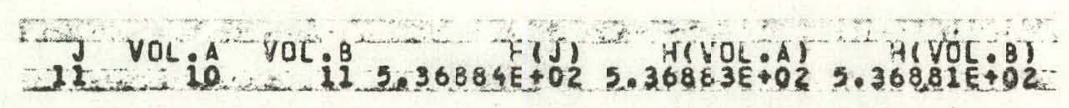

$\vec{\nabla}$ 


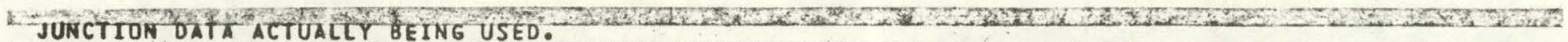

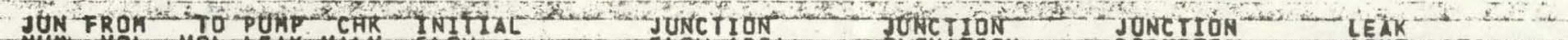

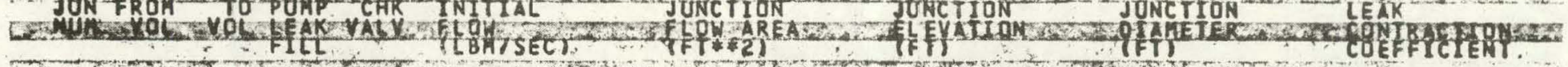

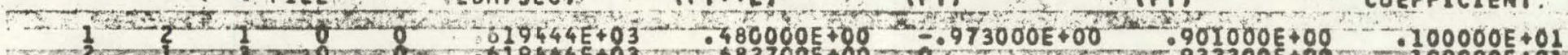

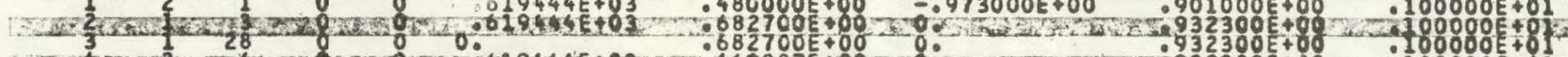

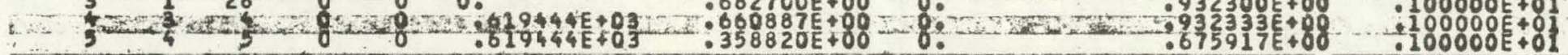

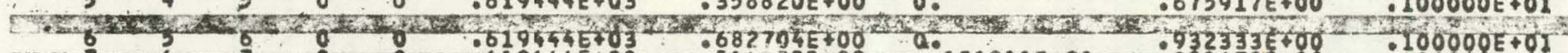

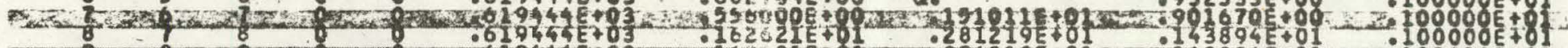

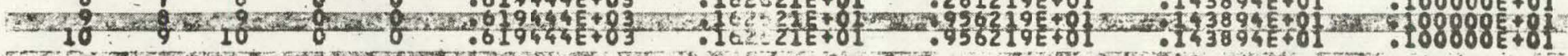

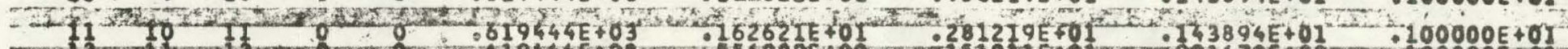

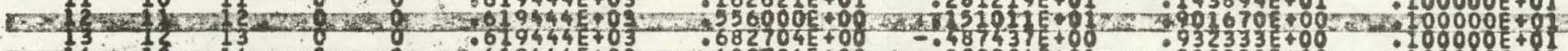

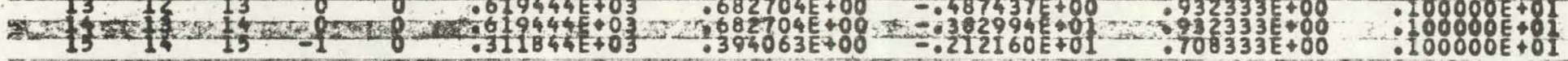

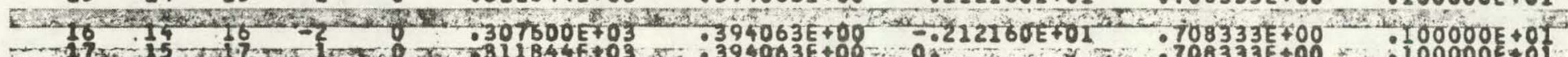

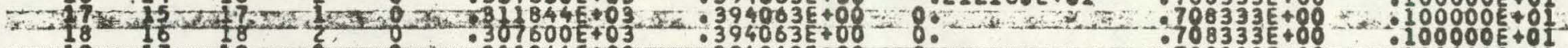

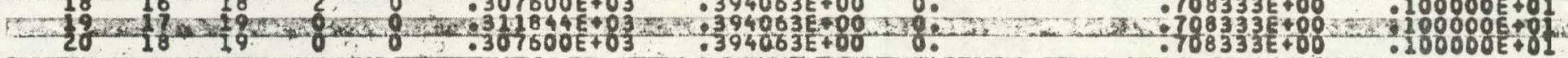

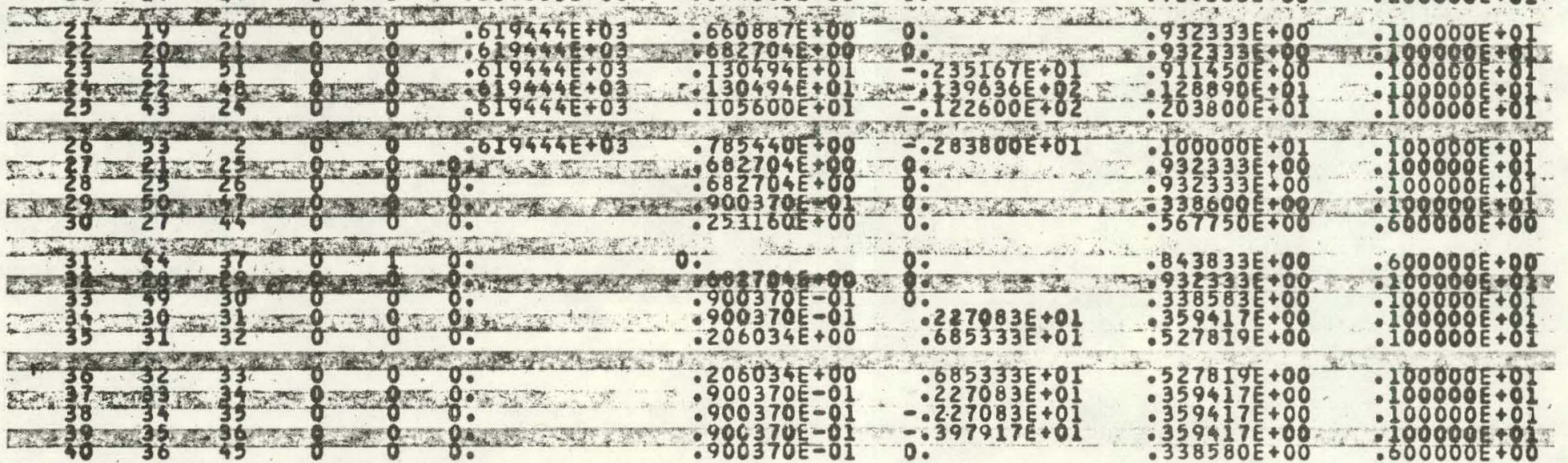

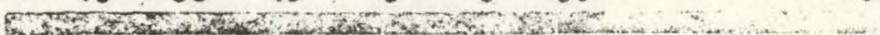




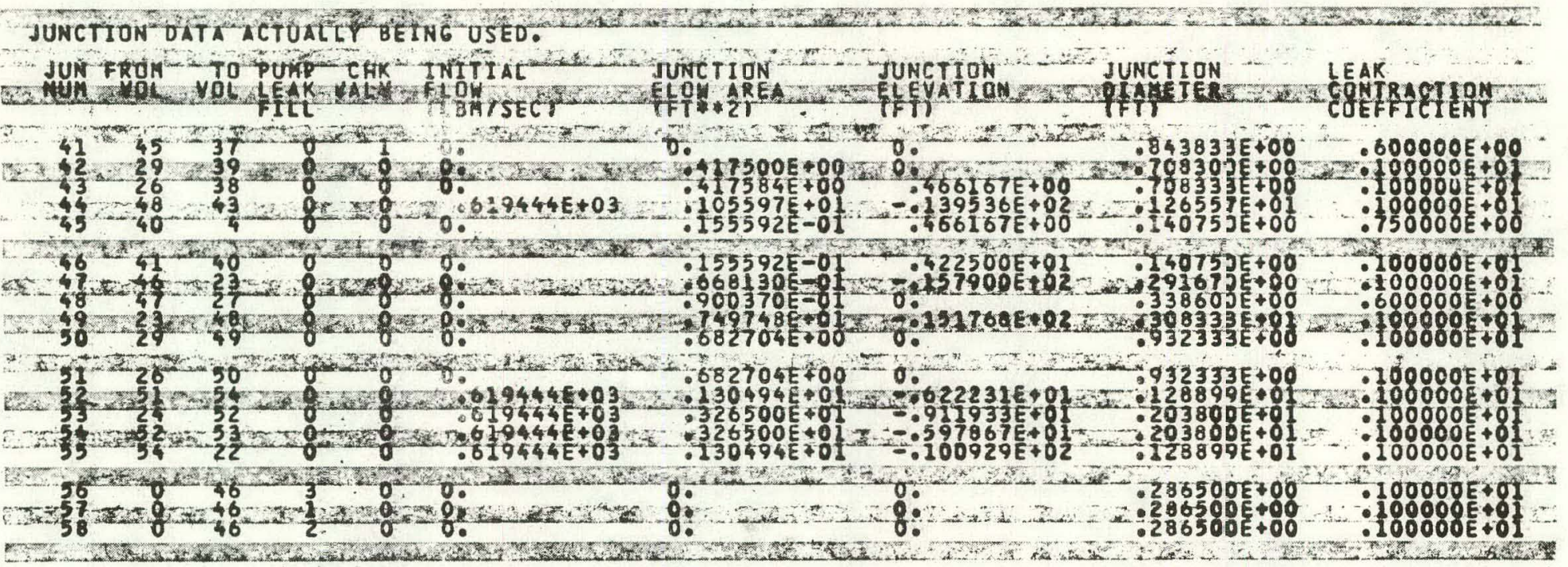


JUNCT TON DATA ACTUACCY BEING USEO.

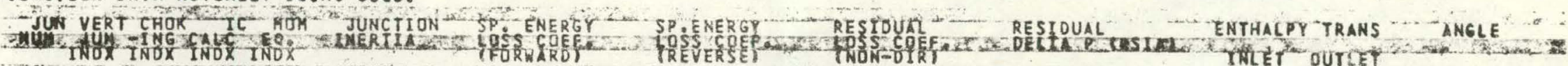

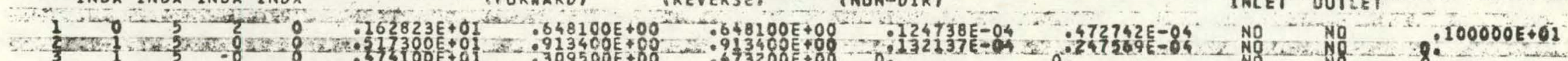

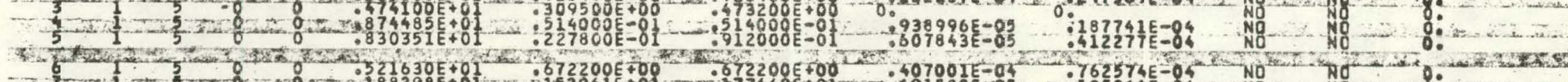

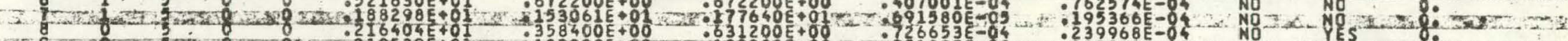

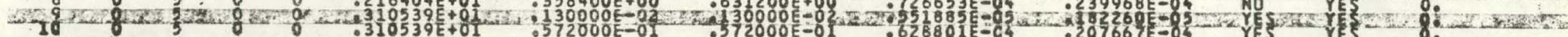

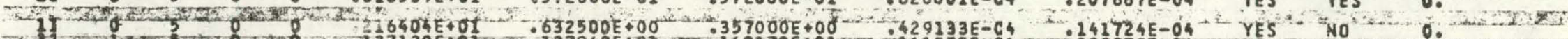

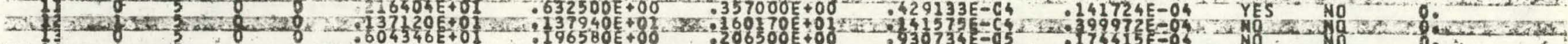

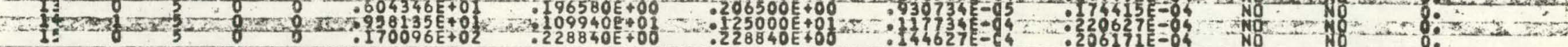

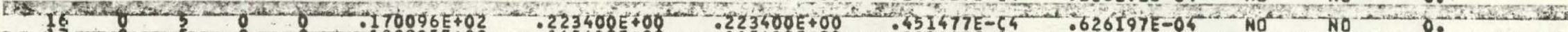

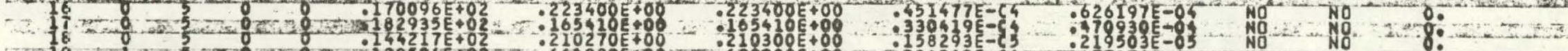

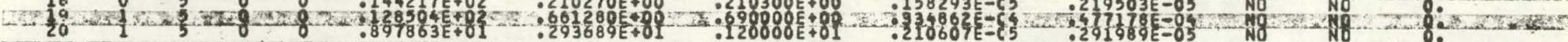

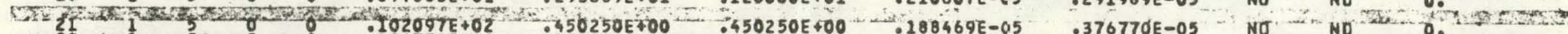

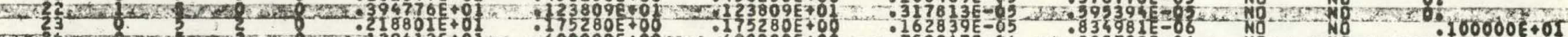

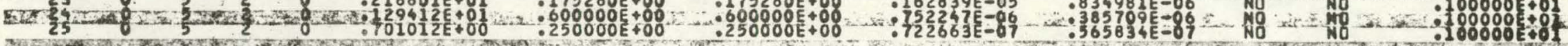

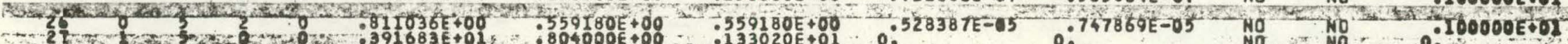

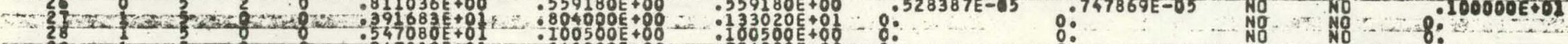

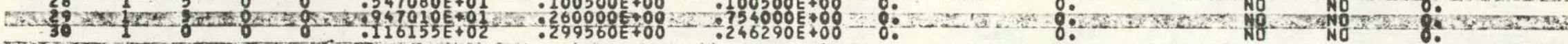

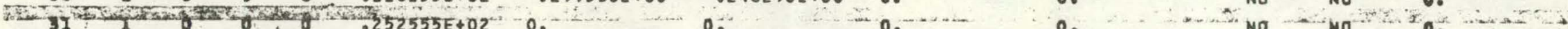

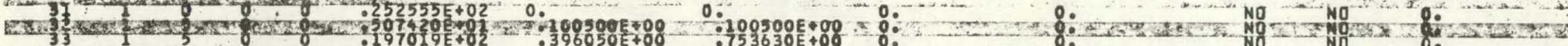

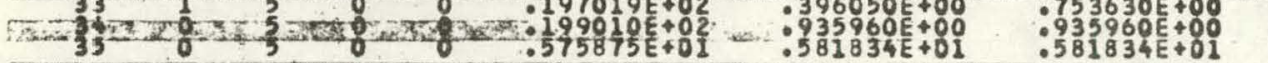

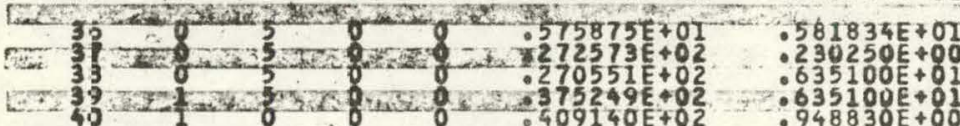

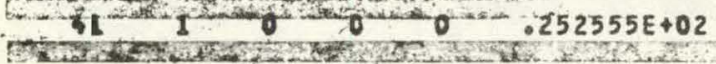
0. .58
$: 23025$
$: 635100+0$ $6355100 E+01$
$.438348 \mathrm{E}+00$ 0 .

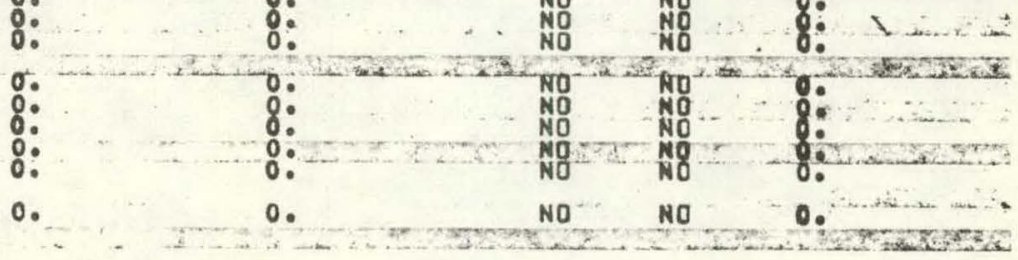




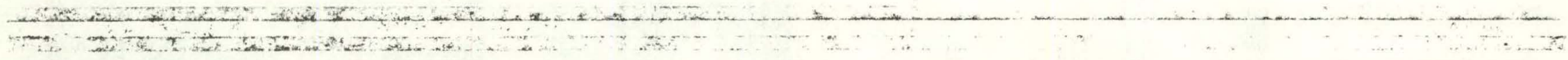
JUNCTION DATA ACTUALLY BE USED. U

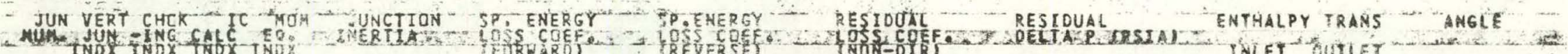

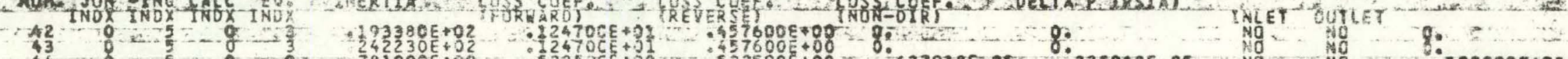

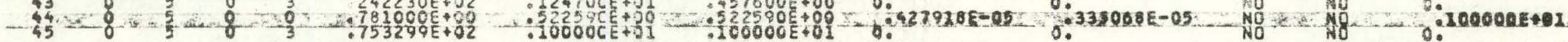

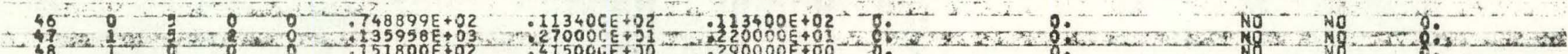

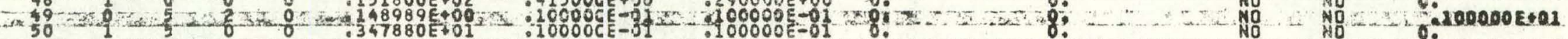

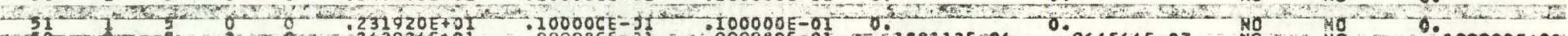

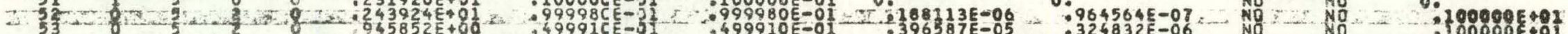

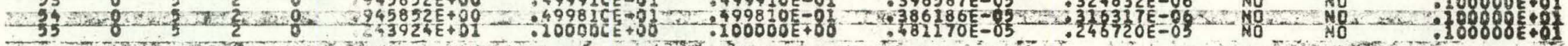

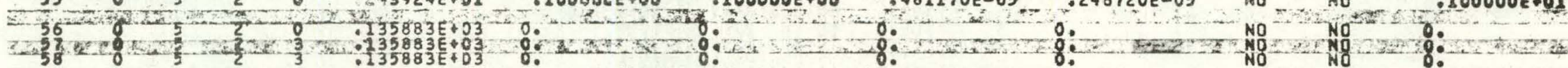

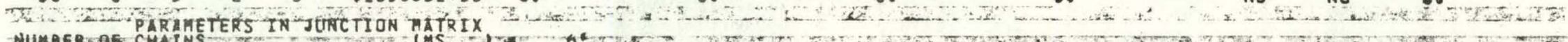

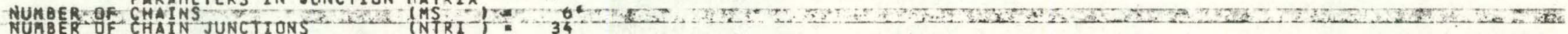

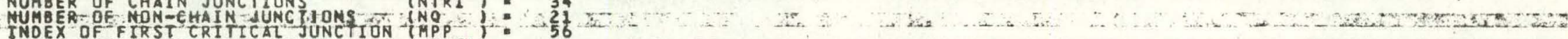

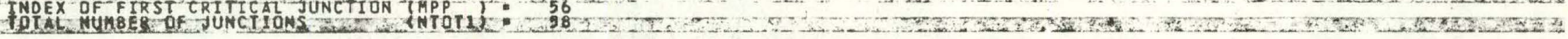


DATA FOR 30 HEAT CONOUCTING SLABS.

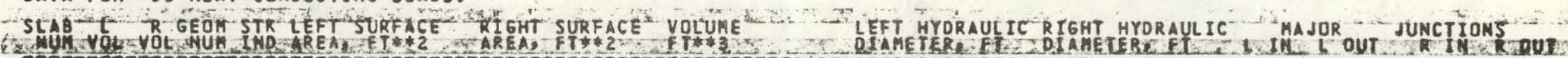

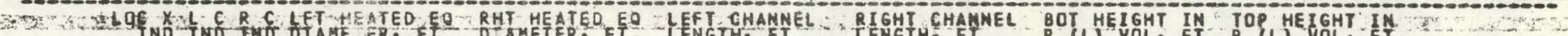

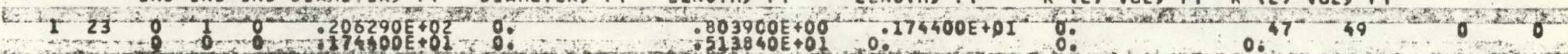

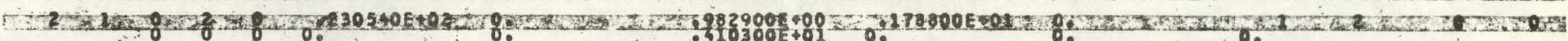

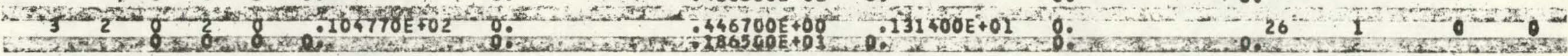

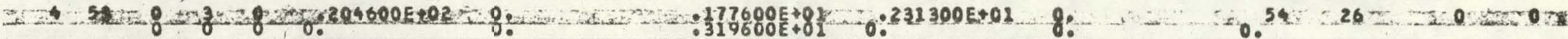

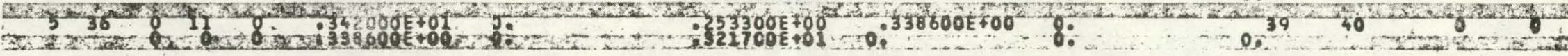

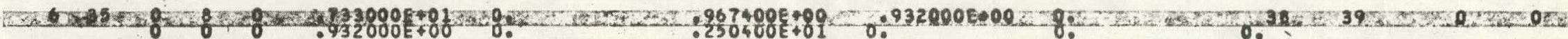

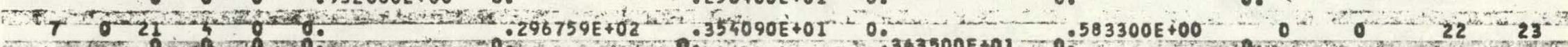

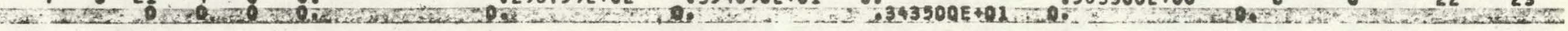

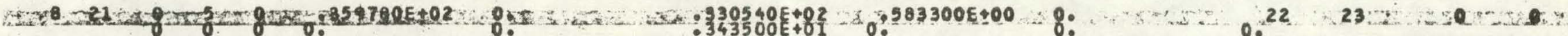

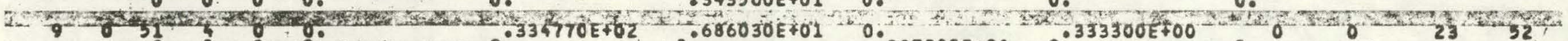

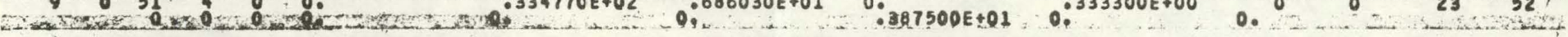
5. 19.

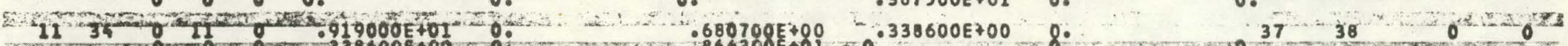
EF

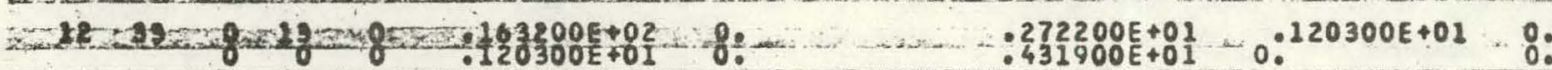

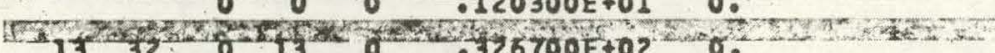
(13) 32 O $326700 \mathrm{E}$ $864300 E+61 \quad 00^{.120300 E+01} 8:$ 36 $\quad 37 \quad 0 \quad 0$

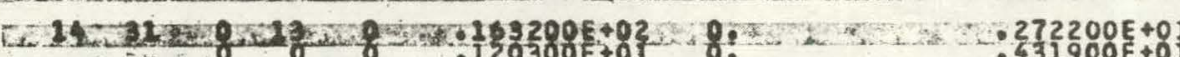

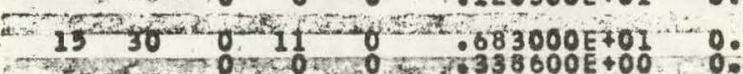

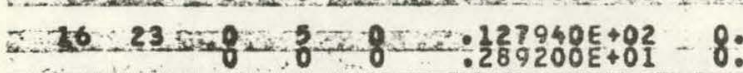

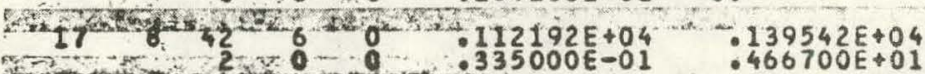
$.506100 \mathrm{E}+00$ $0 \div 120300 E+01$ 8: $: 1125258 E+82 \quad 0: 289200 E+01 \quad 8:$

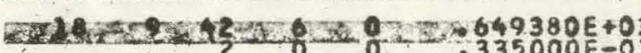
$.807680 \mathrm{E}+03$ $\begin{array}{rl}5139 C 0 E+01 & 335080 E-01 \\ 5790 C 0 E+01 & : 579000 E+01\end{array}$ $297500 E+01$
$.3350 C 0 E+01 \quad: 335000 E-01$

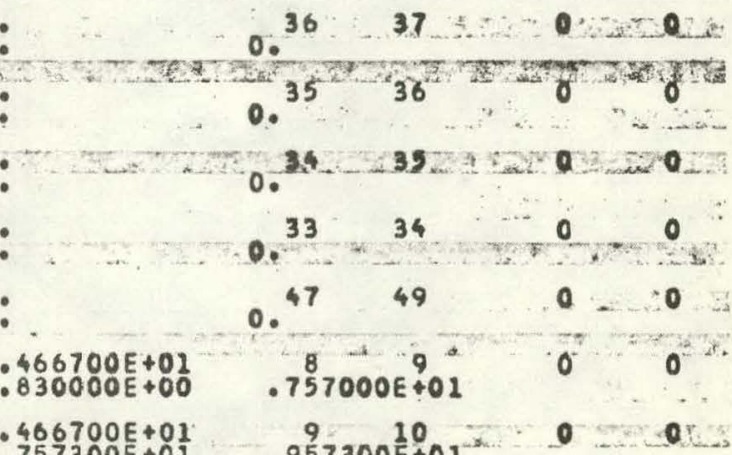
ard 


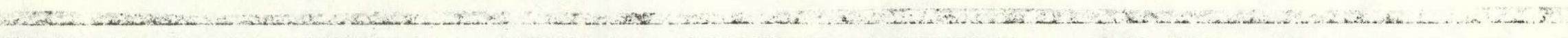

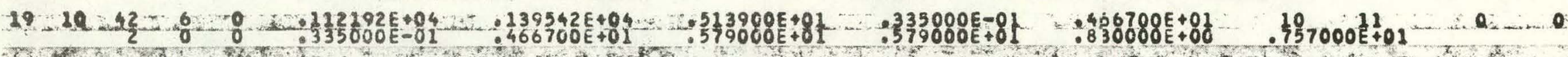

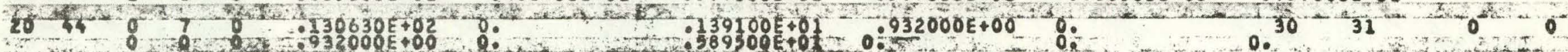

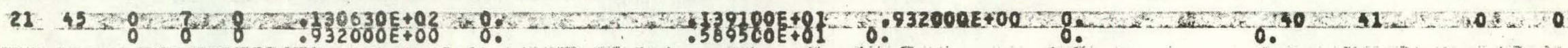

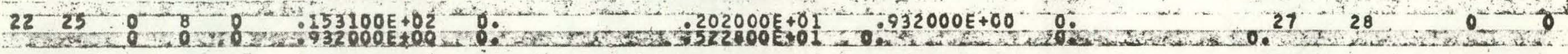

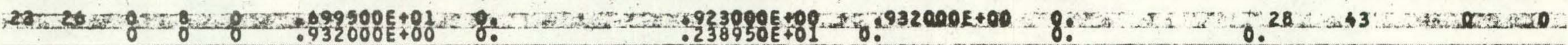

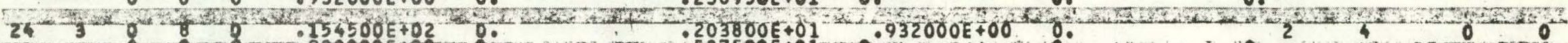

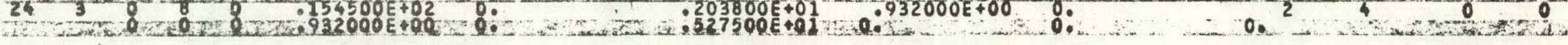

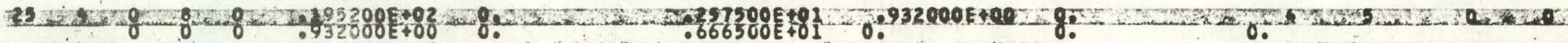

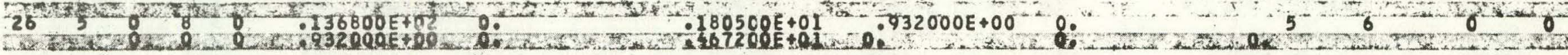

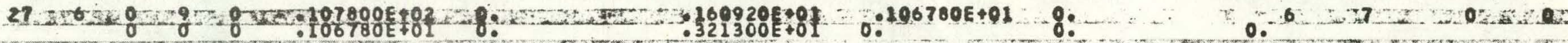

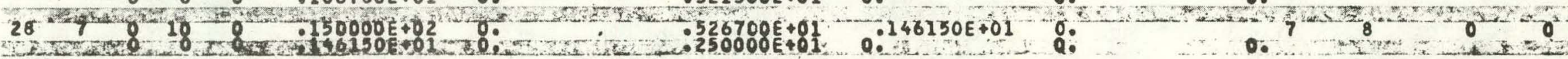

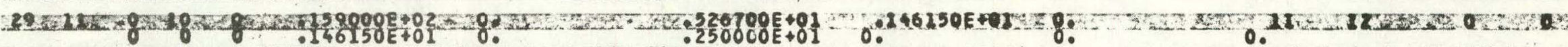

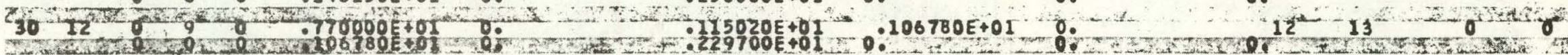

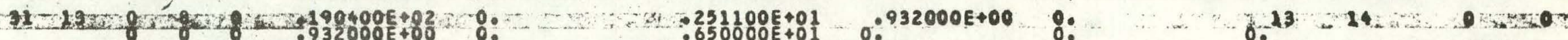

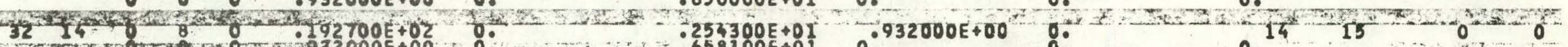

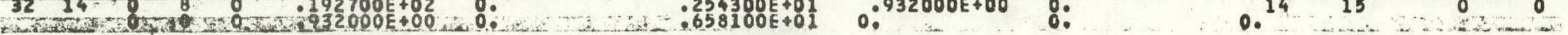

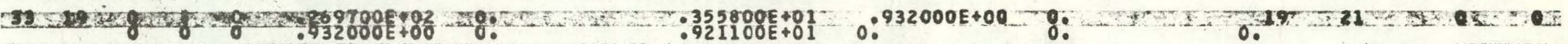

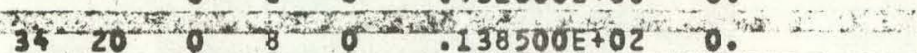

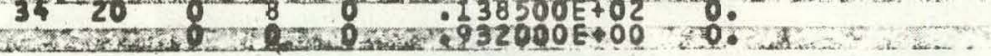

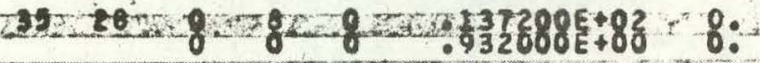

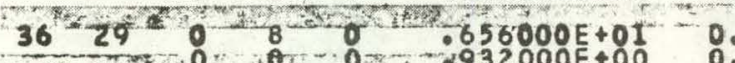

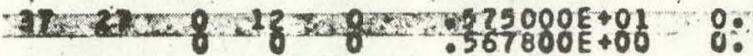

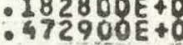
0 $0932000 E+0$ $181100 E+01$
$.4686 C O E+01$ $.8660 C Q E+00$ -224100E+01 $-492700 E+00$
$322900 E+01$ $\begin{array}{lll}38^{7} 46 & 15 & 475400 E+02\end{array}$ $8690 \mathrm{COE}+01$
$: 1816 \mathrm{COE}+02$ $.932000 E+00$ 0.

$.932000 E+00$ $0.567800 E+00 \quad 0$ :

$833330 E+00 \quad 8$
$: 181600 \mathrm{E}+02$ $a^{21} 22$ म 000

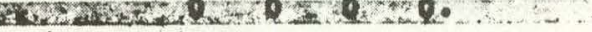

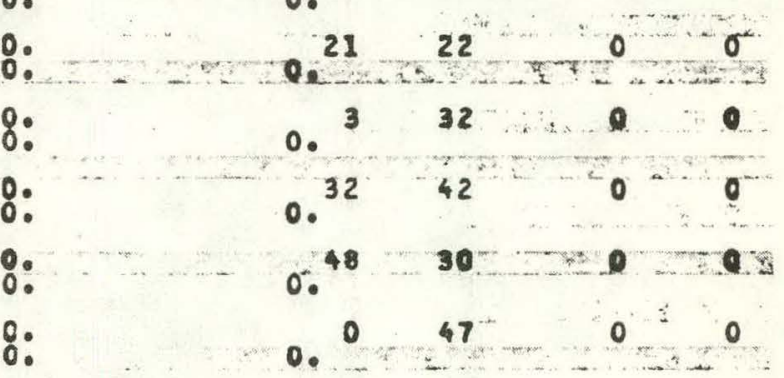




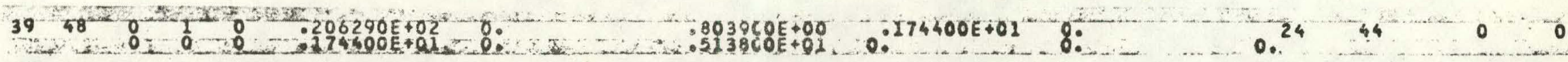

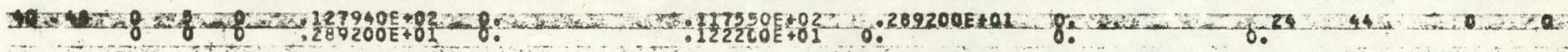

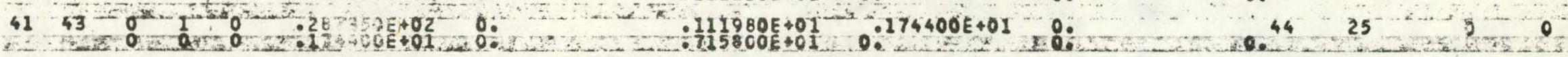

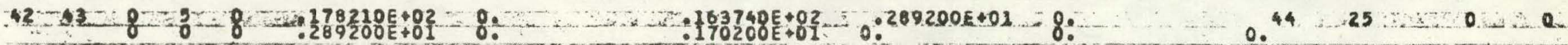

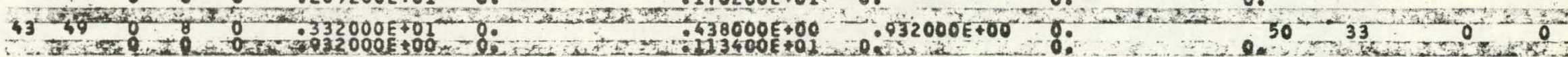

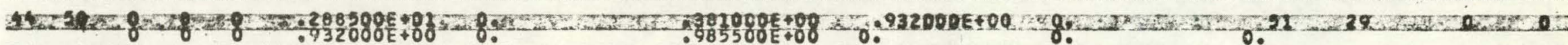

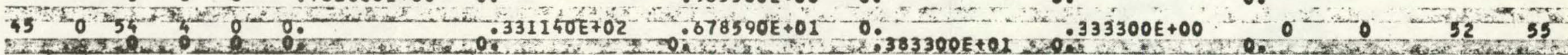

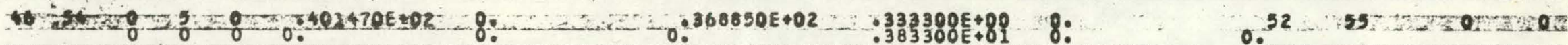

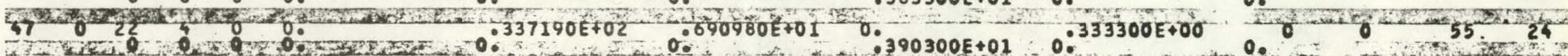

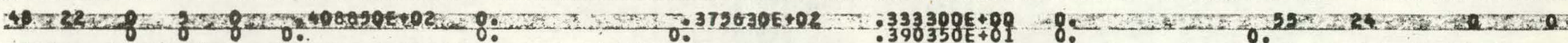

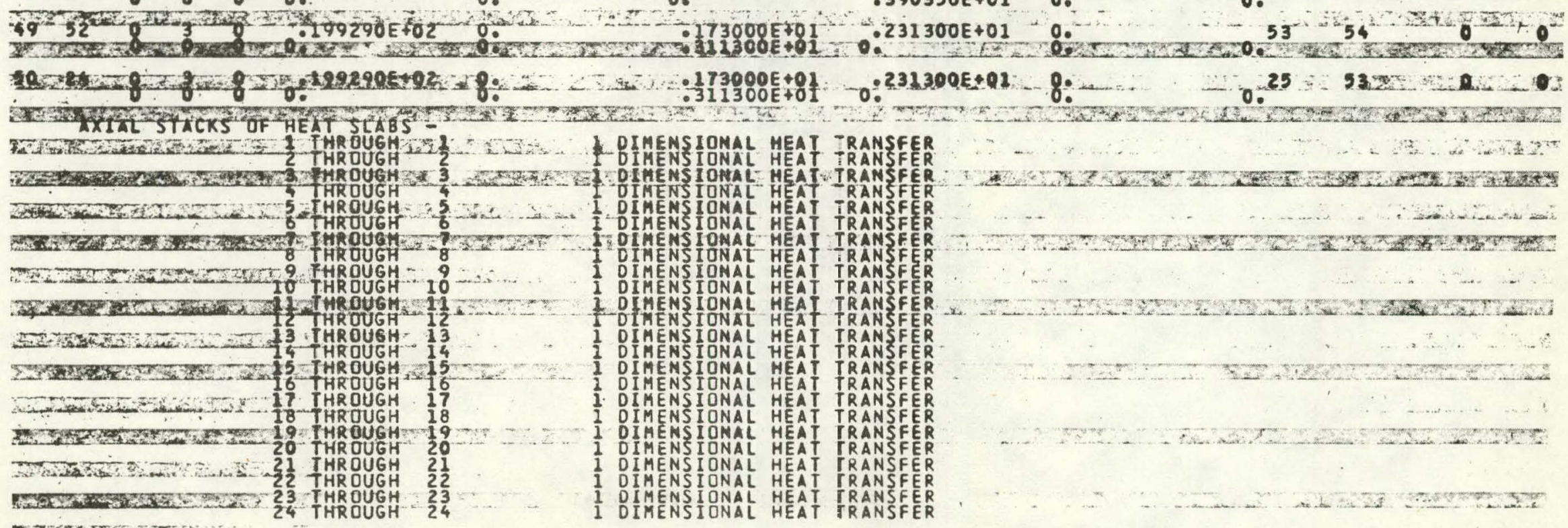

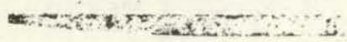




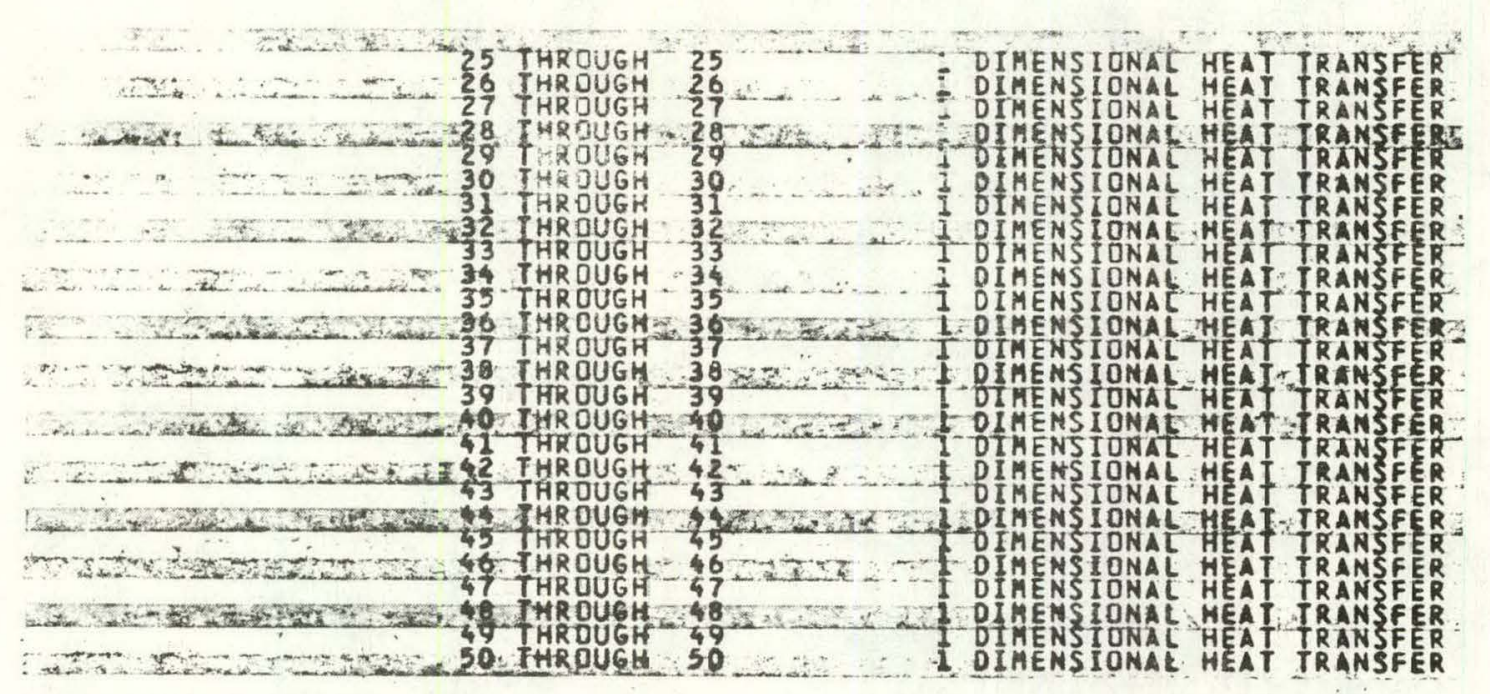




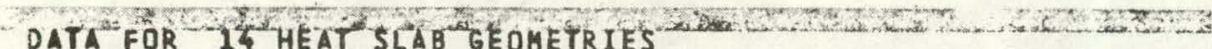
*

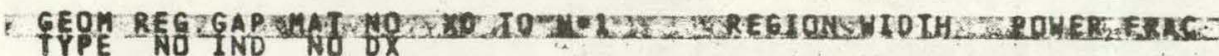

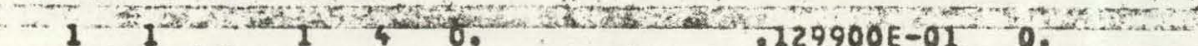

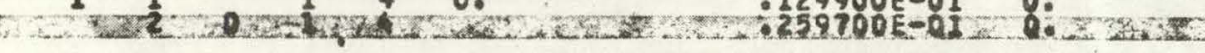

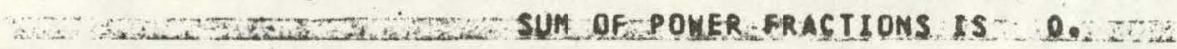

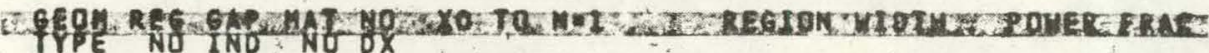

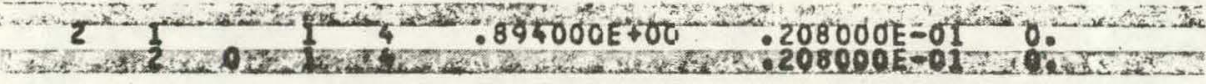

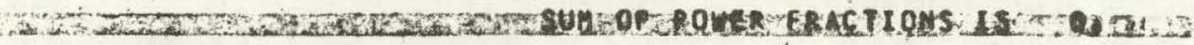

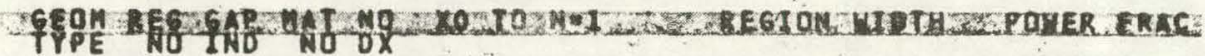

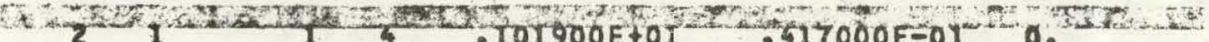

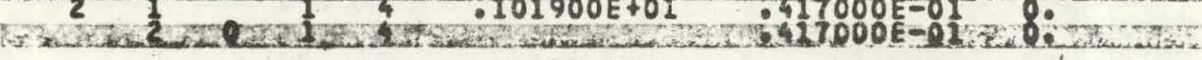

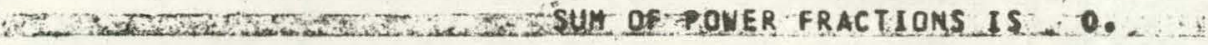

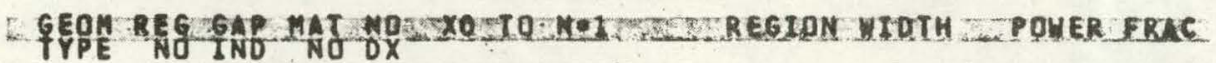

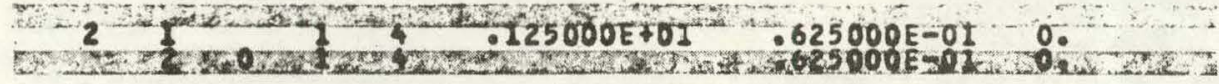

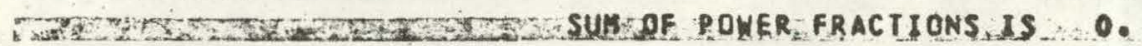

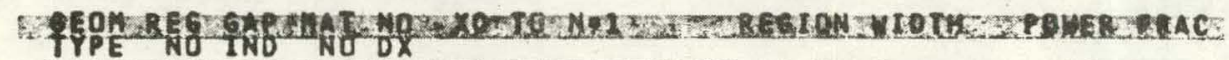

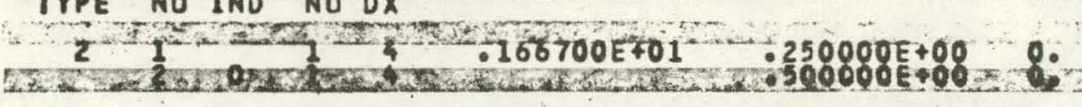

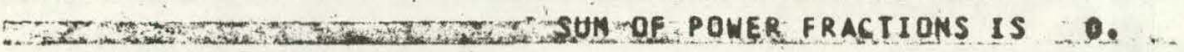

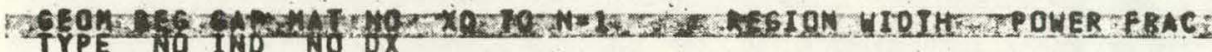

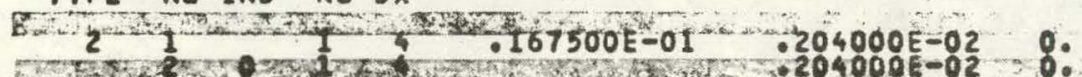

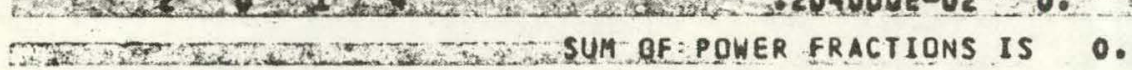

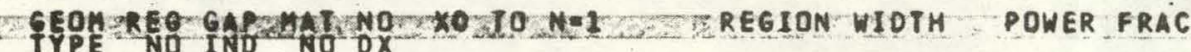

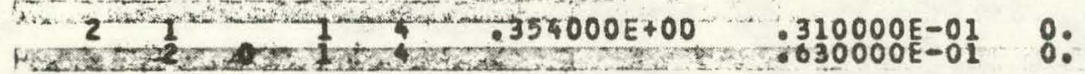

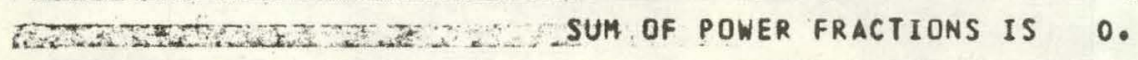
EGEPESG GAPIHANO XOTO N=1. REGION WIDTH POWER FRAC $\rightarrow$ T 


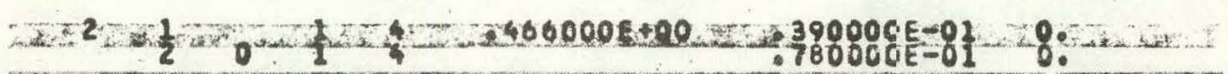

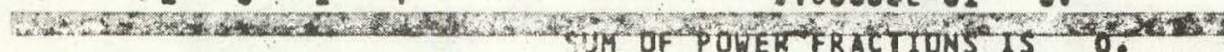
GEDH REG GAP THT NO XO TU NaI IND REGION WIOTH POWER FRAC

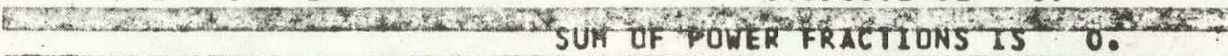

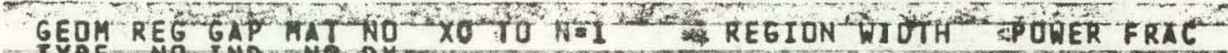
EYPE-NA INO HO OXP.

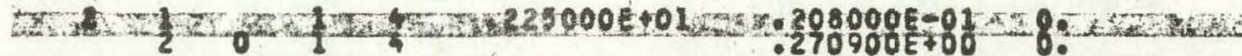

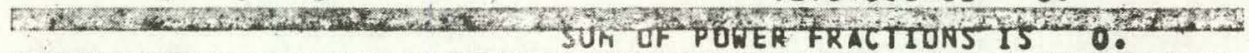

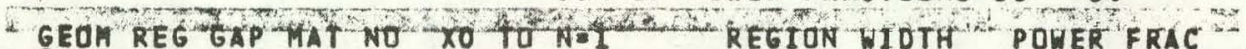

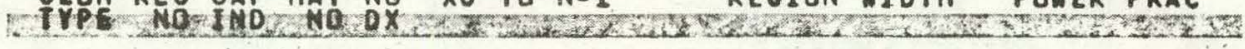
3 32 2 FW

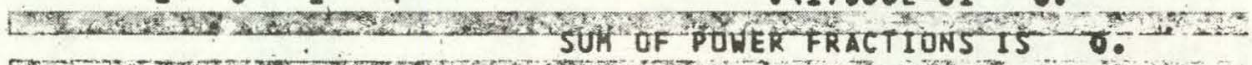

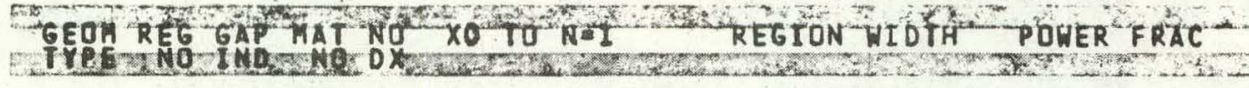
z.5 2 Rin GEOH REG GA AAT WO $X O^{\circ} T O^{-1}=I$ REGION WIOTH POWER FRAC

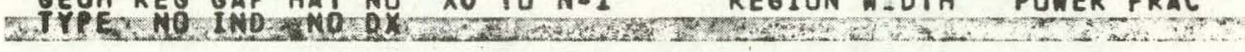

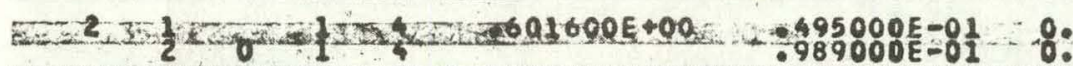

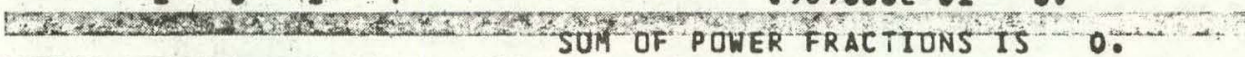
GEOH KEEGGP NAT NO XO TO WB W REGION WIDTH POWER FRAC

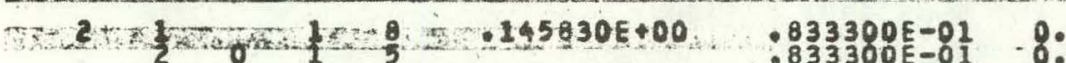

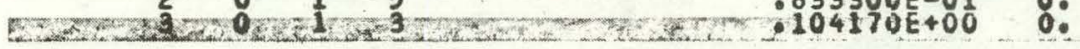

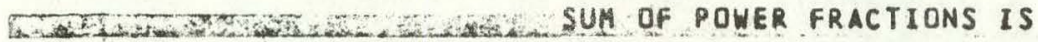


PROUPERTIES FOR HEAT CONDUCTING MATERIAL NUHBER I

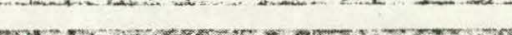

PRD

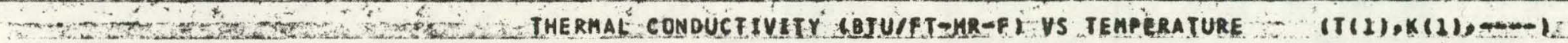

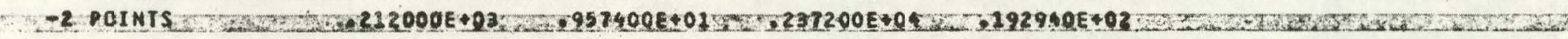

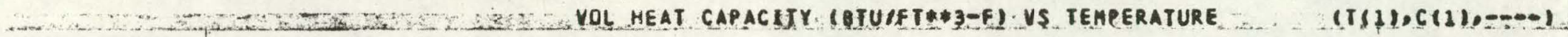

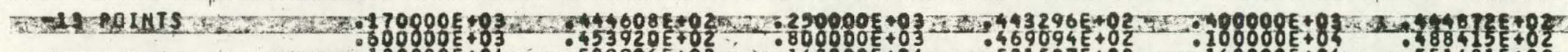

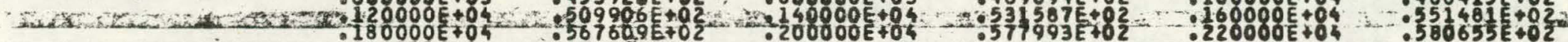

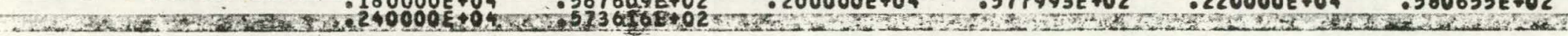


EXPJP4/CE

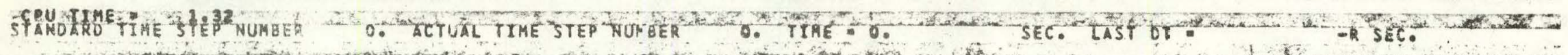

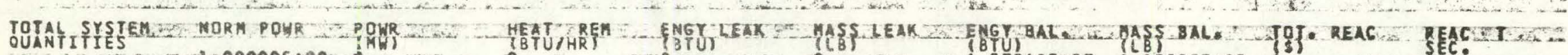

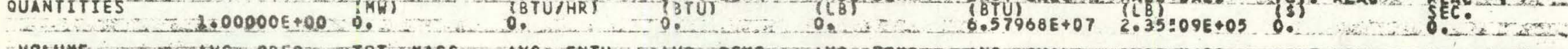

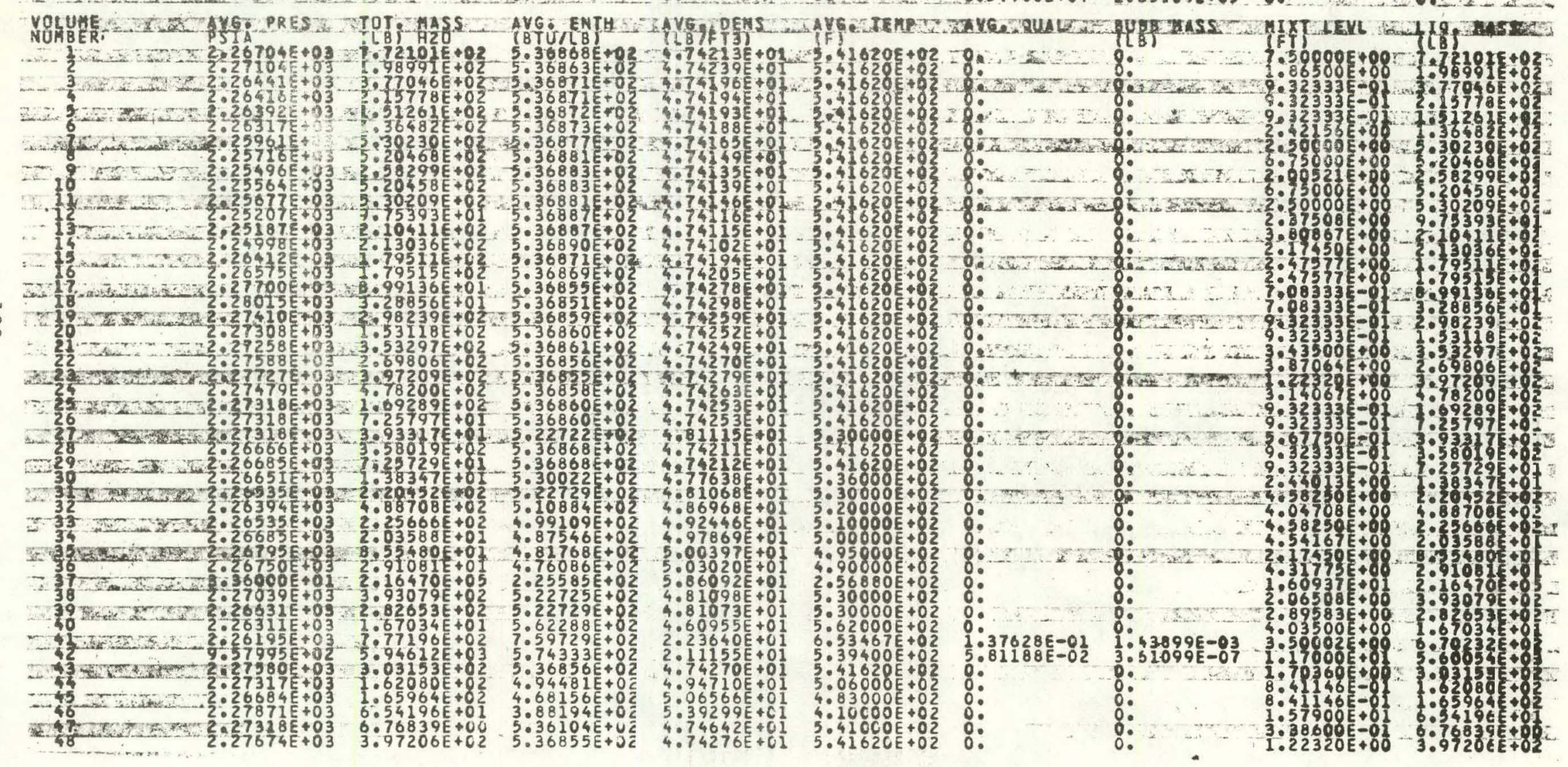




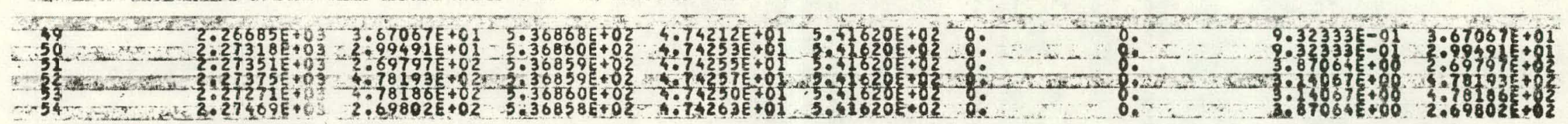

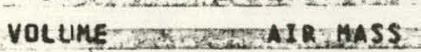

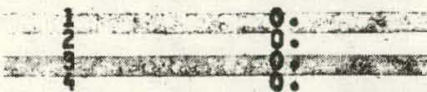

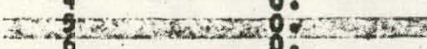

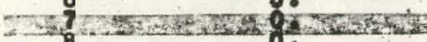

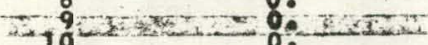

Il

ए 13 as

515 a

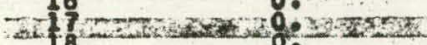

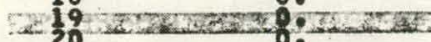

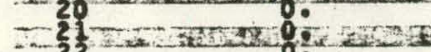

$\overrightarrow{0}$

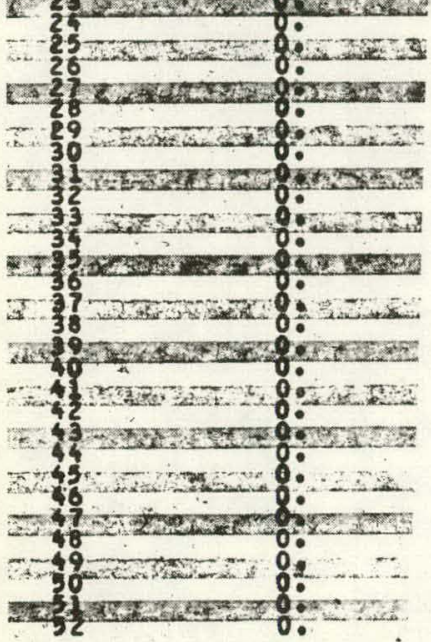




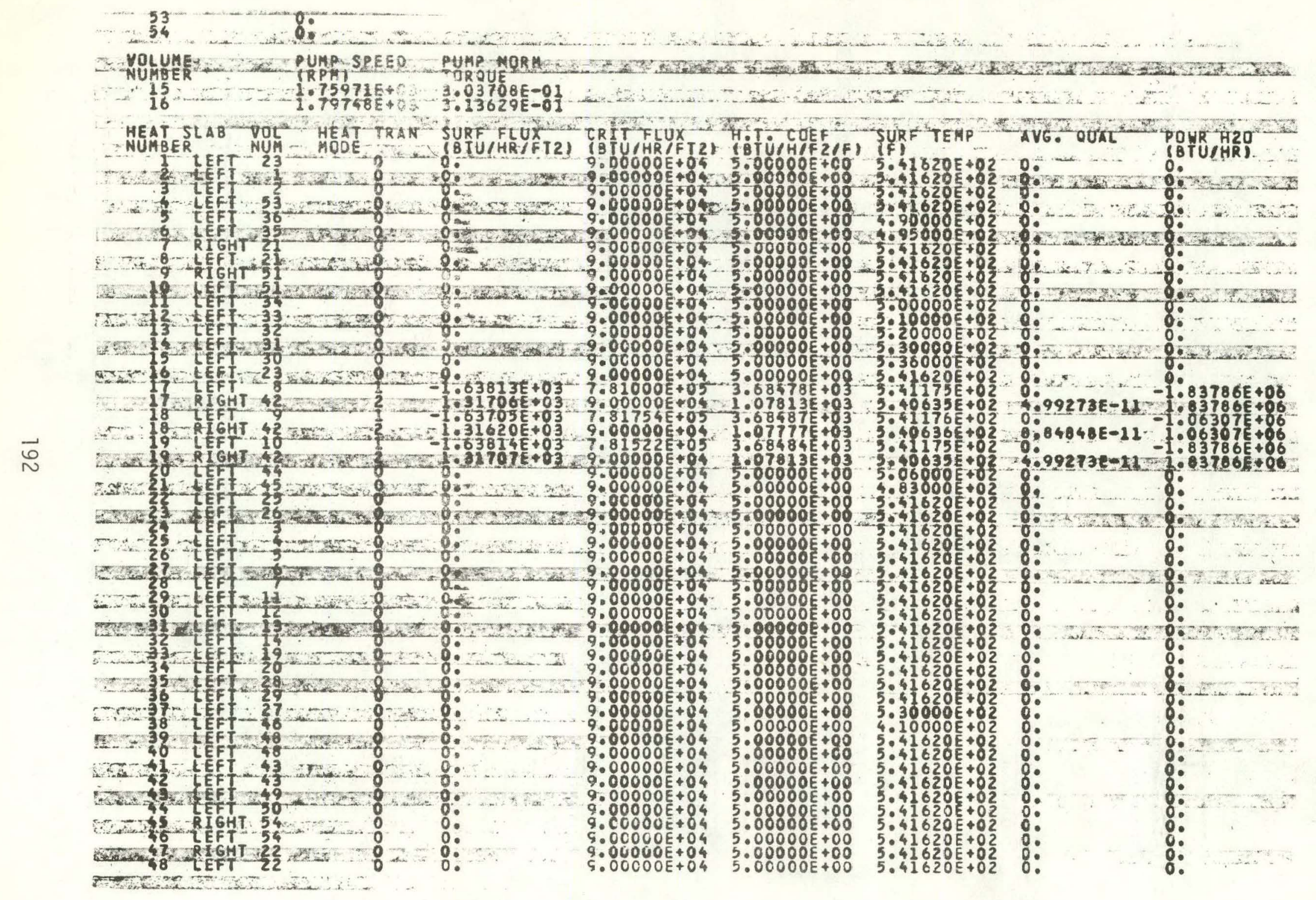




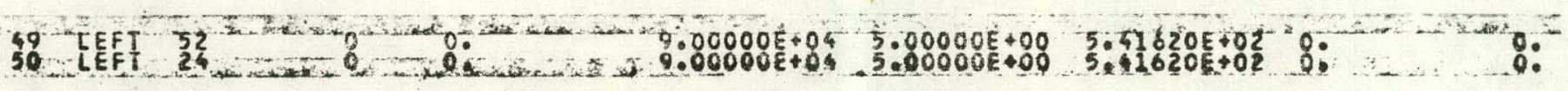


EXPJPGIC E

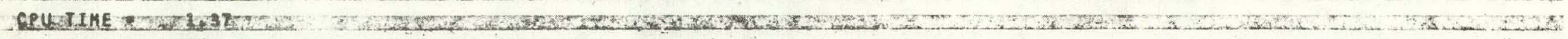

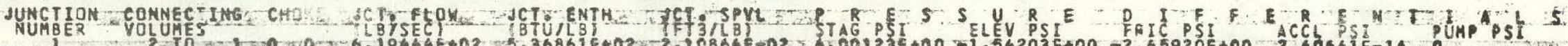

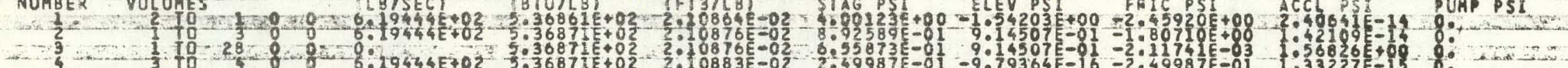
$\begin{array}{lll}4 & \end{array}$

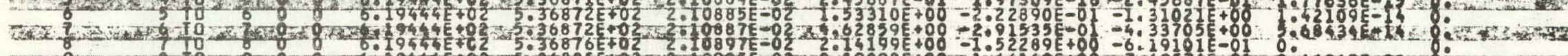
EN 10 N-

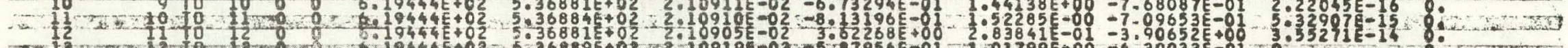

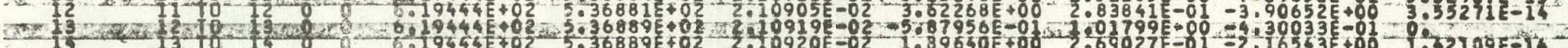

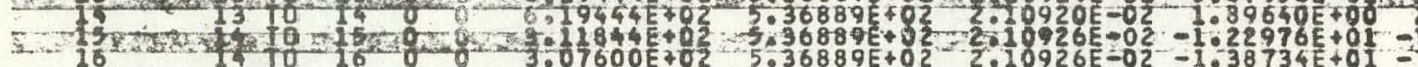

$\begin{array}{rl}16 & 10 \\ 17 & 16\end{array}$

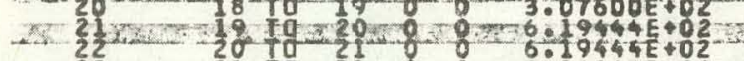

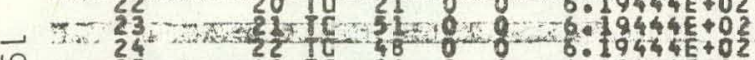

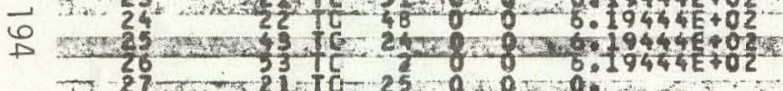
2.28
-30

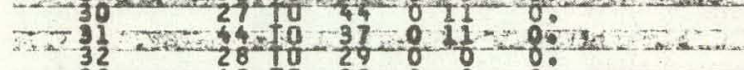

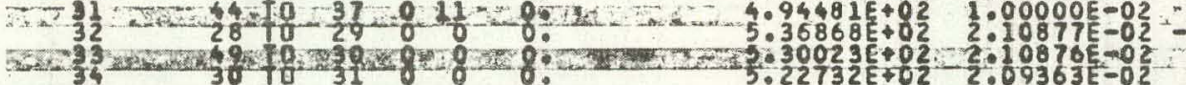

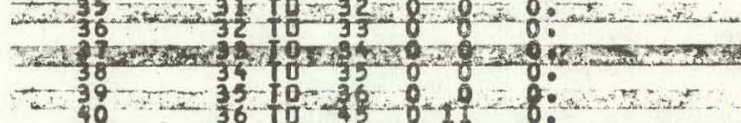

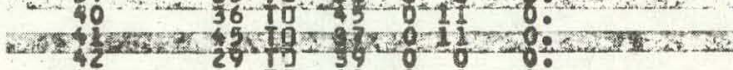

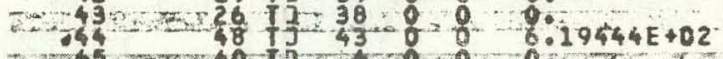
44
45
46

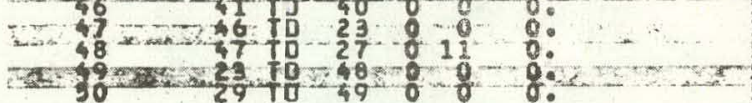

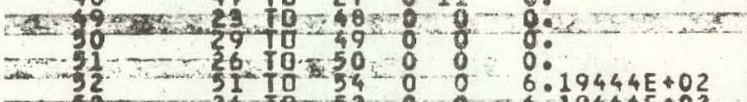
O $0.19444 E+02 \quad 5: 36862 E+0$ ER.

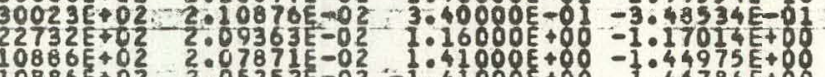
$4.99112 \mathrm{KE}+02-2.03068 \mathrm{E}-02=$ $.76089 \mathrm{E}+02$
$.68156 \mathrm{E}+02$

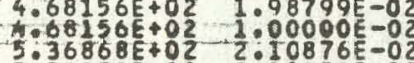
$36859 \mathrm{E}+02$ $36871 E+02 \quad 2010848 \mathrm{E}-02$ $-1.05570 \mathrm{E}+00 \quad 7.99327 \mathrm{E}=01,-5035788 \mathrm{E}-02$ $1.43810 E+00 \quad 2: 95625 \mathrm{E}+00 \quad$

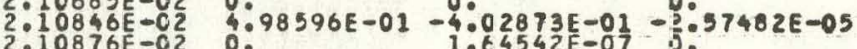
2.10876E-02 8: $1.645426=07$

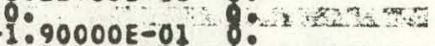
$-1.01355 \mathrm{E}-02-80$ $5.78581 \mathrm{E}-82$

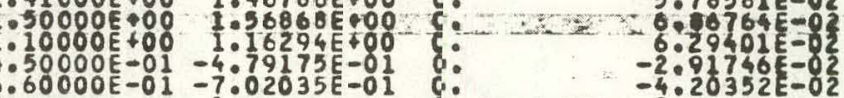
1:70081E-g $-1.05490 E-01$
$-1.39435 E+00$ 9:56974E-02 1.66553
1.66568
1 $4.44089 E-168$

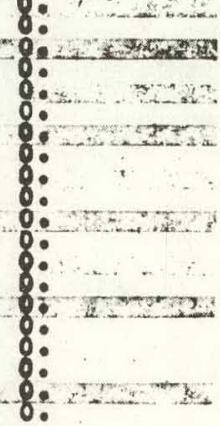




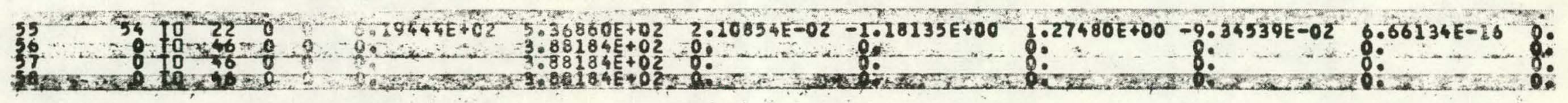


EXPJP4GCE

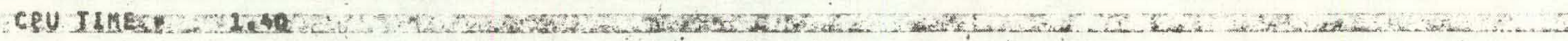

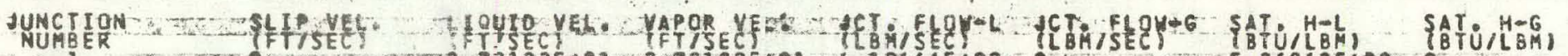

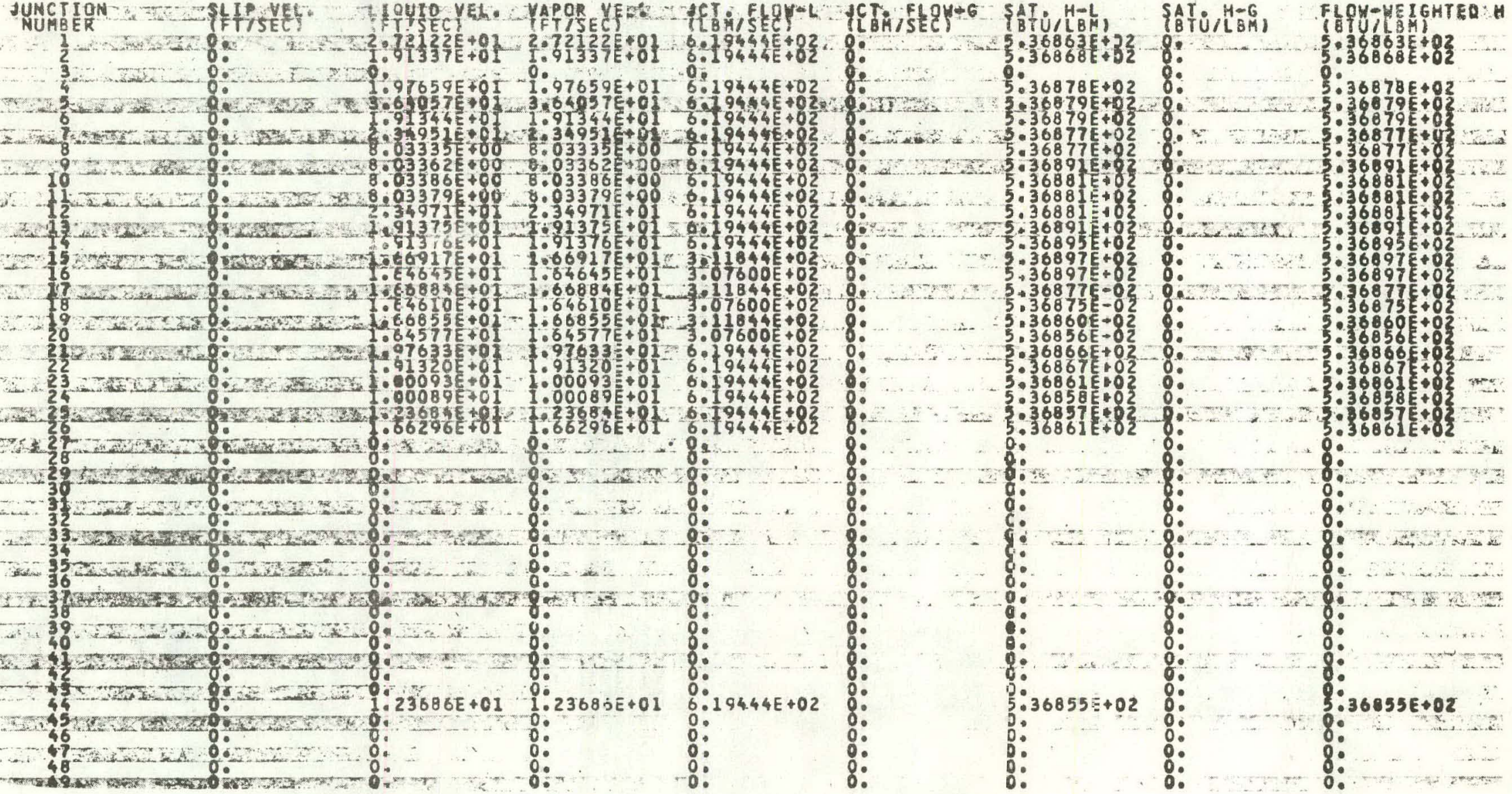




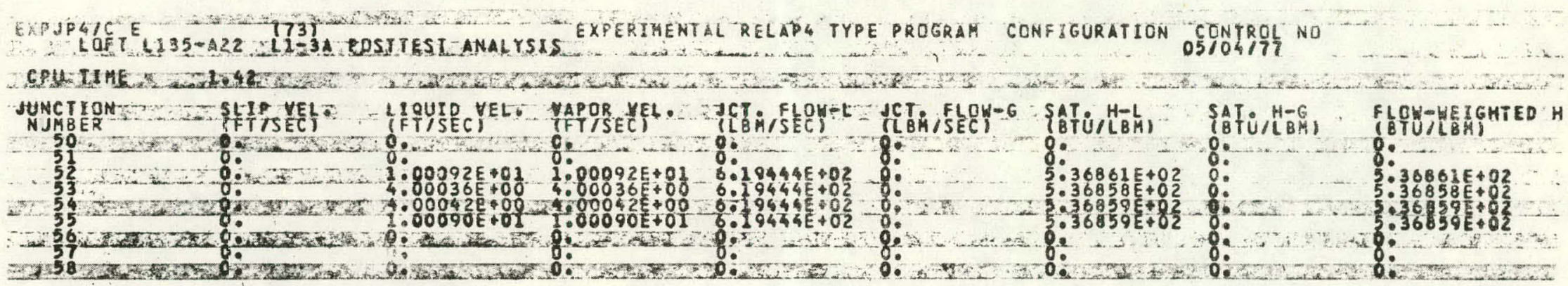




\section{DISTRIBUTION RECORD FOR TREE-NUREG 1131}

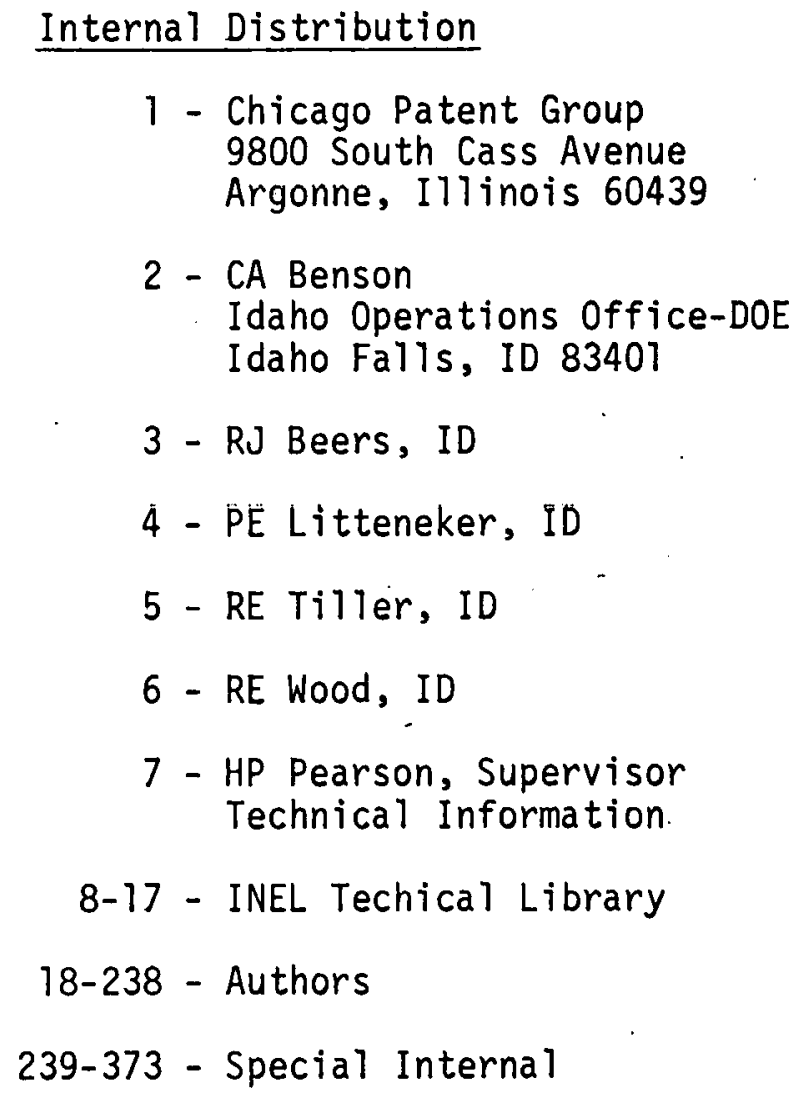

